\title{
Use and Organizational Effects of Measurement and Analysis in High Maturity Organizations: Results from the 2008 SEI State of Measurement and Analysis Practice Surveys
}

Dennis R. Goldenson James McCurley

Robert W. Stoddard II

February 2009

TECHNICAL REPORT

CMU/SEI-2008-TR-024

ESC-TR-2008-024

Software Engineering Process Management

Unlimited distribution subject to the copyright.

http://www.sei.cmu.edu 
This report was prepared for the

SEI Administrative Agent

ESC/XPK

5 Eglin Street

Hanscom AFB, MA 01731-2100

The ideas and findings in this report should not be construed as an official DoD position. It is published in the interest of scientific and technical information exchange.

This work is sponsored by the U.S. Department of Defense. The Software Engineering Institute is a federally funded research and development center sponsored by the U.S. Department of Defense.

Copyright 2008 Carnegie Mellon University.

\section{NO WARRANTY}

THIS CARNEGIE MELLON UNIVERSITY AND SOFTWARE ENGINEERING INSTITUTE MATERIAL IS FURNISHED ON AN “AS-IS” BASIS. CARNEGIE MELLON UNIVERSITY MAKES NO WARRANTIES OF ANY KIND, EITHER EXPRESSED OR IMPLIED, AS TO ANY MATTER INCLUDING, BUT NOT LIMITED TO, WARRANTY OF FITNESS FOR PURPOSE OR MERCHANTABILITY, EXCLUSIVITY, OR RESULTS OBTAINED FROM USE OF THE MATERIAL. CARNEGIE MELLON UNIVERSITY DOES NOT MAKE ANY WARRANTY OF ANY KIND WITH RESPECT TO FREEDOM FROM PATENT, TRADEMARK, OR COPYRIGHT INFRINGEMENT.

Use of any trademarks in this report is not intended in any way to infringe on the rights of the trademark holder.

Internal use. Permission to reproduce this document and to prepare derivative works from this document for internal use is granted, provided the copyright and "No Warranty" statements are included with all reproductions and derivative works.

External use. This document may be reproduced in its entirety, without modification, and freely distributed in written or electronic form without requesting formal permission. Permission is required for any other external and/or commercial use. Requests for permission should be directed to the Software Engineering Institute at permission@sei.cmu.edu.

This work was created in the performance of Federal Government Contract Number FA8721-05-C-0003 with Carnegie Mellon University for the operation of the Software Engineering Institute, a federally funded research and development center. The Government of the United States has a royalty-free government-purpose license to use, duplicate, or disclose the work, in whole or in part and in any manner, and to have or permit others to do so, for government purposes pursuant to the copyright license under the clause at 252.227-7013.

For information about SEI reports, please visit the publications section of our website (http://www.sei.cmu.edu/publications). 


\section{Table of Contents}

Acknowledgments $\quad$ vii

Abstract $\quad$ ix

1 Introduction 1

2 The Respondents and Their Organizations 3

$3 \quad$ Baselining Variability in Process Outcomes: Value Added by Process

Performance Modeling

$4 \quad$ Baselining Variability in Process Implementation 11

4.1 Stakeholder Involvement in Setting Measurement and Analysis Goals and Objectives 11

4.2 Measurement-Related Training 12

4.3 Process Performance Modeling 14

$\begin{array}{ll}4.4 & \text { Analytic Methods } \\ \end{array}$

$5 \quad$ Baselining High Maturity Organizational Context 27

5.1 Management Support, Staffing, and Resources 27

5.2 Technical Challenge 31

5.3 Barriers and Facilitators 32

$6 \quad$ Explaining Variability in Organizational Effects of Process Performance Modeling 35

6.1 Analysis Methods Used in this Report 35

6.2 Process Performance Modeling and Analytic Methods 38

$\begin{array}{lll}6.3 & \text { Management Support } & 45\end{array}$

6.4 Stakeholder Involvement in Setting Measurement and Analysis Goals and Objectives 48

6.5 Measurement-Related Training 51

$\begin{array}{lll}6.6 & \text { Technical Challenge } & 56\end{array}$

$\begin{array}{ll}6.7 & \text { In Summary: A Multivariable Model } \\ \end{array}$

$7 \quad$ Performance Outcomes of Measurement and Analysis Across Maturity Levels 63

$8 \quad$ Summary and Conclusions $\quad 69$

Appendix A: Questionnaire for the Survey of High Maturity Organizations $\quad 71$

Appendix B: Questionnaire for the General Population Survey 116

Appendix C: Open-Ended Replies: Qualitative Perspectives on the Quantitative Results 137

$\begin{array}{ll}\text { References } & 169\end{array}$ 
ii | CMU/SEI-2008-TR-024 


\section{List of Figures}

Figure 1: Respondents' organizational roles 3

Figure 2: Measurement and analysis roles of survey respondents 4

Figure 3: CMMI maturity levels of responding organizations 5

Figure 4: Sectors represented in responding organizations 6

Figure 5: Product and service focus of responding organizations 6

Figure 6: Mix of engineering activities in responding organizations $\quad 7$

Figure 7: Number of full-time engineering employees in responding organizations $\quad 7$

Figure 8: Primary location of responding organizations 8

Figure 9: Effects attributed to using process performance modeling 9

Figure 10: Overall effect attributed to process performance modeling 10

Figure 11: Stakeholder involvement in responding organizations 12

Figure 12: Measurement related training required for employees of responding organizations 13

Figure 13: Specialized training on process performance modeling in responding organizations 13

Figure 14: Sources of process performance model expertise in responding organizations $\quad 14$

Figure 15: Emphasis on healthy process performance model ingredients $\quad 15$

Figure 16: Use of healthy process performance model ingredients 16

Figure 17: Operational purposes of process performance modeling 17

Figure 18: Other management uses of process performance modeling 18

Figure 19: Diversity of process performance models: product quality and project performance 19

Figure 20: Diversity of process performance models: process performance 19

Figure 21: Routinely modeled processes and activities 20

Figure 22: Use of process performance model predictions in reviews 21

Figure 23: Use of diverse statistical methods

Figure 24: Use of optimization techniques 23

Figure 25: Use of decision techniques 24

Figure 26: Use of visual display techniques 24

Figure 27: Use of automated support for measurement and analysis activities 25

Figure 28: Use of methods to ensure data quality and integrity 26

Figure 29: Level of understanding of process performance model results attributed to managers 28

Figure 30: Availability of qualified process performance modeling personnel 28

Figure 31: Staffing of measurement and analysis in responding organizations 29

Figure 32: Level of understanding of CMMI intent attributed to modelers 30

Figure 33: Promotional incentives for measurement and analysis in responding organizations 31 
Figure 34: Project technical challenge in responding organizations

Figure 35: Management \& analytic barriers to effective measurement and analysis

Figure 36: Management \& analytic facilitators of effective measurement and analysis

Figure 37: Major obstacles to achieving high maturity

Figure 38: Example: relationship between maturity level and frequency of use of measurement and analysis, from 2007 state of the practice survey

Figure 39: Relationship between emphasis on healthy process performance model ingredients and overall value attributed to process performance models

Figure 40: Relationship between use of healthy process performance model ingredients and overall value attributed to process performance models

Figure 41: Relationship between diversity of models used (for predicting product quality and project performance) and overall value attributed to process performance models

Figure 42: Relationship between use of exemplary modeling approaches and overall value attributed to process performance models

Figure 43: Relationship between use of statistical methods and overall value attributed to process performance models

Figure 44: Relationship between use of optimization methods and overall value attributed to process performance models

Figure 45: Relationship between automated support for measurement and analysis and overall value attributed to process performance models

Figure 46: Relationship between data quality and integrity checks and overall value attributed to process performance models

Figure 47: Relationship between use of process performance model predictions in status and milestone reviews and overall value attributed to process performance models

Figure 48: Relationship between managers' understanding of model results and overall value attributed to process performance models

Figure 49: Relationship between management support for modeling and overall value attributed to process performance models

Figure 50: Relationship between process performance model staff availability and overall value attributed to process performance models

Figure 51: Relationship between stakeholder involvement and overall value attributed to process performance models

Figure 52: Relationship between stakeholder involvement and use of process performance model predictions in status and milestone reviews

Figure 53: Relationship between stakeholder involvement and emphasis on healthy process performance model ingredients

Figure 54: Relationship between stakeholder involvement and use of healthy process performance model ingredients

Figure 55: Relationship between management training and overall value attributed to process performance models

Figure 56: Relationship between management training and use of process performance model predictions in reviews

Figure 57: Relationship between management training and level of understanding of process performance model results attributed to managers

Figure 58: Relationship between management training and stakeholder involvement in responding organizations 
Figure 59: Relationship between management training and emphasis on healthy process performance model ingredients

Figure 60: Relationship between management training and use of diverse statistical methods

Figure 61: Relationship between modeler training and overall effect attributed to process performance modeling

Figure 62: Relationship between project technical challenge and overall organizational effect attributed to process performance modeling

Figure 63: Relationship between use of process performance model predictions in reviews and overall effect attributed to process performance modeling, with lower project technical challenge

Figure 64: Relationship between use of process performance model predictions in reviews and overall effect attributed to process performance modeling, with higher project technical challenge

Figure 65: Relationship between emphasis on healthy process performance model ingredients and overall effect attributed to process performance modeling, with lower project technical challenge

Figure 66: Relationship between emphasis on healthy process performance model ingredients and overall effect attributed to process performance modeling, with higher project technical challenge

Figure 67: Relationship between maturity level and overall value attributed to measurement and analysis

Figure 68: Relationship between use of product and quality measurement results and overall value attributed to measurement and analysis

Figure 69: Relationship between use of project and organizational measurement results and overall value attributed to measurement and analysis

Figure 70: $\quad$ ML 5 only - Relationship between use of project /organizational measurement results and overall value attributed to measurement and analysis

Figure 71: ML1/DK only - Relationship between use of project /organizational measurement results and overall value attributed to measurement and analysis 
vi | CMU/SEI-2008-TR-024 


\section{Acknowledgments}

Thanks are due to the many individuals who took time from their busy schedules to complete our questionnaires. We obviously could not do work of this kind without their willingness to share their experiences in an open and candid manner. The high maturity survey could not have been accomplished without the timely efforts of Joanne O'Leary and Helen Liu. We particularly appreciate their extremely competent construction and management of the CMMI Appraisal database. Deen Blash has continued to provide timely access to the SEI Customer Relations database from which the general population survey sample was derived. Mike Zuccher and Laura Malone provided indispensable help in organizing, automating, and managing the sample when the surveys were fielded. Erin Harper furnished her usual exceptional skills in producing this report. We greatly appreciate her domain knowledge as well as her editorial expertise. Thanks go to Bob Ferguson, Wolf Goethert, Mark Kasunic, Mike Konrad, Bill Peterson, Mike Phillips, Kevin Schaaff, Alex Stall, Rusty Young, and Dave Zubrow for their review and critique of the survey instruments. Special thanks also go to Mike Konrad, Bill Peterson, Mike Phillips, and Dave Zubrow for their timely and helpful reviews of this report. 
viii | CMU/SEI-2008-TR-024 


\section{Abstract}

There has been a great deal of discussion of late about what it takes for organizations to attain high maturity status and what they can reasonably expect to gain by doing so. Clarification is needed along with good examples of what has worked well and what has not. This may be particularly so with respect to measurement and analysis. This report contains results from a survey of high maturity organizations conducted by the Software Engineering Institute (SEI) in 2008. The questions center on the use of process performance modeling in those organizations and the value added by that use. The results show considerable understanding and use of process performance models among the organizations surveyed; however there is also wide variation in the respondents' answers. The same is true for the survey respondents' judgments about how useful process performance models have been for their organizations. As is true for less mature organizations, there is room for continuous improvement among high maturity organizations. Nevertheless, the respondents' judgments about the value added by doing process performance modeling also vary predictably as a function of the understanding and use of the models in their respective organizations. More widespread adoption and improved understanding of what constitutes a suitable process performance model holds promise to improve CMMI-based performance outcomes considerably. 
x | CMU/SEI-2008-TR-024 


\section{Introduction}

There has been a great deal of discussion of late about just what it takes for organizations to attain high maturity status and what they can reasonably expect to gain by doing so. Clarification is needed along with good examples of what has worked well and what has not. This may be particularly so with respect to measurement and analysis and the use of process performance modeling. By process performance modeling, we refer to the use of analytic methods to construct process performance models and establish baselines.

Such discussion needs to be conducted in a spirit of continuous improvement. Just as CMMI models have matured since the CMM for Software first appeared, more and more organizations have achieved higher levels of capability and maturity in recent years [Paulk 1993, SEI 2002, SEI 2008b]. Yet there is room for further process improvement and for better understanding of how high maturity practices can lead to better project performance and quality outcomes [Stoddard 2008].

This report contains results from a survey of high maturity organizations conducted by the Software Engineering Institute (SEI) in 2008. The questions center on the use of process performance modeling in those organizations and the value added by that use. There is evidence of considerable understanding and use of process performance models among the organizations surveyed; however there also is variation in responses among the organizations surveyed. The same is true for the survey respondents' judgments about how useful process performance models have been for their organizations. As is true for less mature organizations, room remains for continuous improvement among high maturity organizations. Nevertheless, the respondents' judgments about the value added by doing process performance modeling also vary predictably as a function of the understanding and use of the models in their respective organizations. More widespread adoption and improved understanding of what constitutes a suitable process performance model holds promise to improve CMMI-based performance outcomes considerably.

Similar results have been found in two other surveys in the SEI state of measurement and analysis practice survey series [Goldenson 2008a, Goldenson 2008b]. ${ }^{1}$ Based on organizations across the full spectrum of CMMI-based maturity in 2007 and 2008, both studies provide evidence about the circumstances under which measurement and analysis capabilities and performance outcomes are likely to vary as a consequence of achieving higher CMMI maturity levels. Most of the differences reported are consistent with expectations based on CMMI guidance, which provides confidence in the validity of the model structure and content. Instances exist where considerable room for organizational improvement remains, even at maturity levels 4 and 5. However, the results typically show characteristic, and often quite substantial, differences associated with CMMI maturity level. Although the distributions vary somewhat across the questions, there is a common stair-step pattern of improved measurement and analysis capabilities that rises along with reported performance outcomes as the survey respondents' organizations move up in maturity level.

The SEI state of measurement and analysis survey series began in 2006 [Kasunic 2006]. The focus in the first two years was on the use of measurement and analysis in the wider software and systems engineering community. A comparable survey was fielded in 2008. This is the first year the study also focused on measurement and analysis practices in high maturity organizations. 
The survey described in this report is organized around several important issues faced in the adoption and use of measurement and analysis in high maturity organizations. Confusion still exists in some quarters about the intent of CMMI with respect to the practice of measurement and analysis. Hence questions have been asked to identify the extent to which such practices do or do not meet that intent. Questions focus particularly on what constitutes a suitable process performance model in a CMMI context. Related questions ask about the breadth of statistical, experimental, and simulation methods used; attention paid to data quality and integrity; staffing and resources devoted to the work; pertinent training and coaching; and the alignment of the models with business and technical objectives. Equally importantly, the survey respondents were queried about technical challenges and other barriers to and facilitators of successful adoption and use of process performance models in their organizations.

The remainder of this document is broken up into eight sections and three appendices, followed by the references. A description of the survey respondents and their organizations is contained in Section 2. Basic descriptions of variability in reported process performance and its outcomes can be found in Section 3. Section 4 contains similar descriptions of process performance models and related processes. Differences in organizational sponsorship for and technical challenges facing process improvement in this area are summarized in Section 5. The results in Sections 3 to 5 will be used over time to identify changes and trends in how measurement and analysis is performed in high maturity organizations.

The extent to which variability in process outcomes can be explained by concurrent differences in process and organizational context is examined in Section 6. Selected results from the 2008 companion survey based on organizations from across the full spectrum of CMMI-based maturity levels are found in Section 7. These results highlight the potential payoff of measurement and analysis in lower maturity organizations. The report summary and conclusions are in Section 8. The questionnaires and invitations to participate in the surveys are reproduced in Appendix A and Appendix B. Appendix C contains free form textual replies from the respondents to the high maturity survey, which we hope will provide a better qualitative sense of the meaning that can be attributed to the quantitative results.

This survey is the most comprehensive of its kind yet done. We expect it to be of considerable value to organizations wishing to continue improving their measurement and analysis practices. We hope that the results will allow you to make useful comparisons with similar organizations and provide practical guidance for continuing improvement in your own organization. 


\section{The Respondents and Their Organizations}

Invitations to participate in the survey were sent to the sponsors of all organizations recorded by the SEI as having been appraised for their compliance with CMMI maturity levels four or five over the five-year period ending in March 2008. Personalized announcements about the survey, invitations, and up to three reminders to participate were sent in May and June. A total of 156 questionnaires were returned for a 46 percent completion rate. ${ }^{2}$

Most or all of the survey respondents were in a position to be conversant with the use of process performance baselines and models in their respective organizations. Including most of those who chose the "other" category in Figure 1, the majority of the survey respondents filled management roles in their organizations. As can be inferred by some of the less populated categories, some of the sponsors delegated completion of their questionnaires to others. We also know from email and voice exchanges that some sponsors completed them jointly with knowledgeable staff members, including process and quality engineers. While almost a third of the respondents characterized themselves largely as users of measurement-based information, closer to two-thirds of them said that they were both providers and users of such information (see Figure 2).

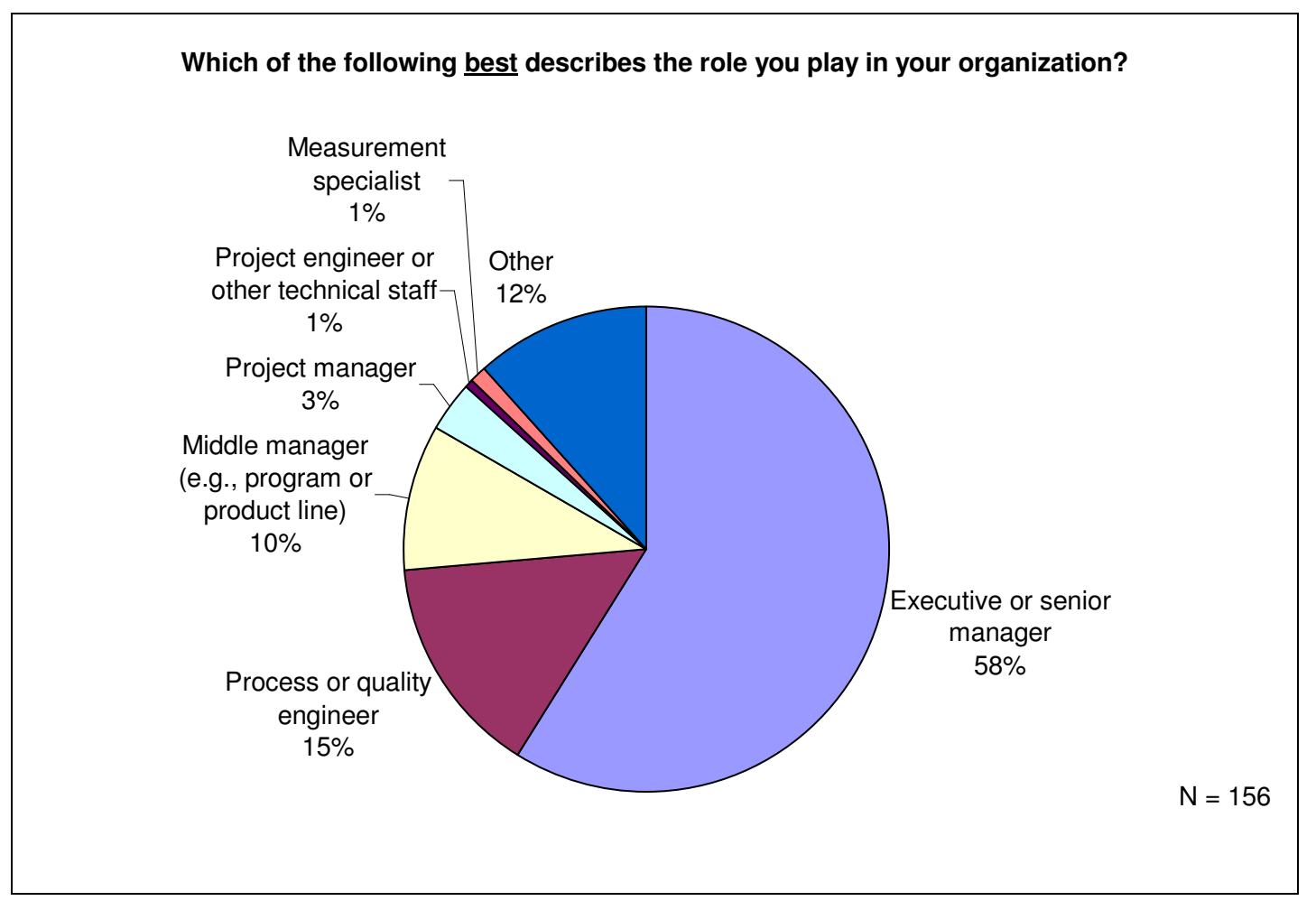

Figure 1: Respondents' organizational roles

2 As can be seen throughout the remainder of this report, over 90 percent of the respondents answered most or all of the survey questions. 


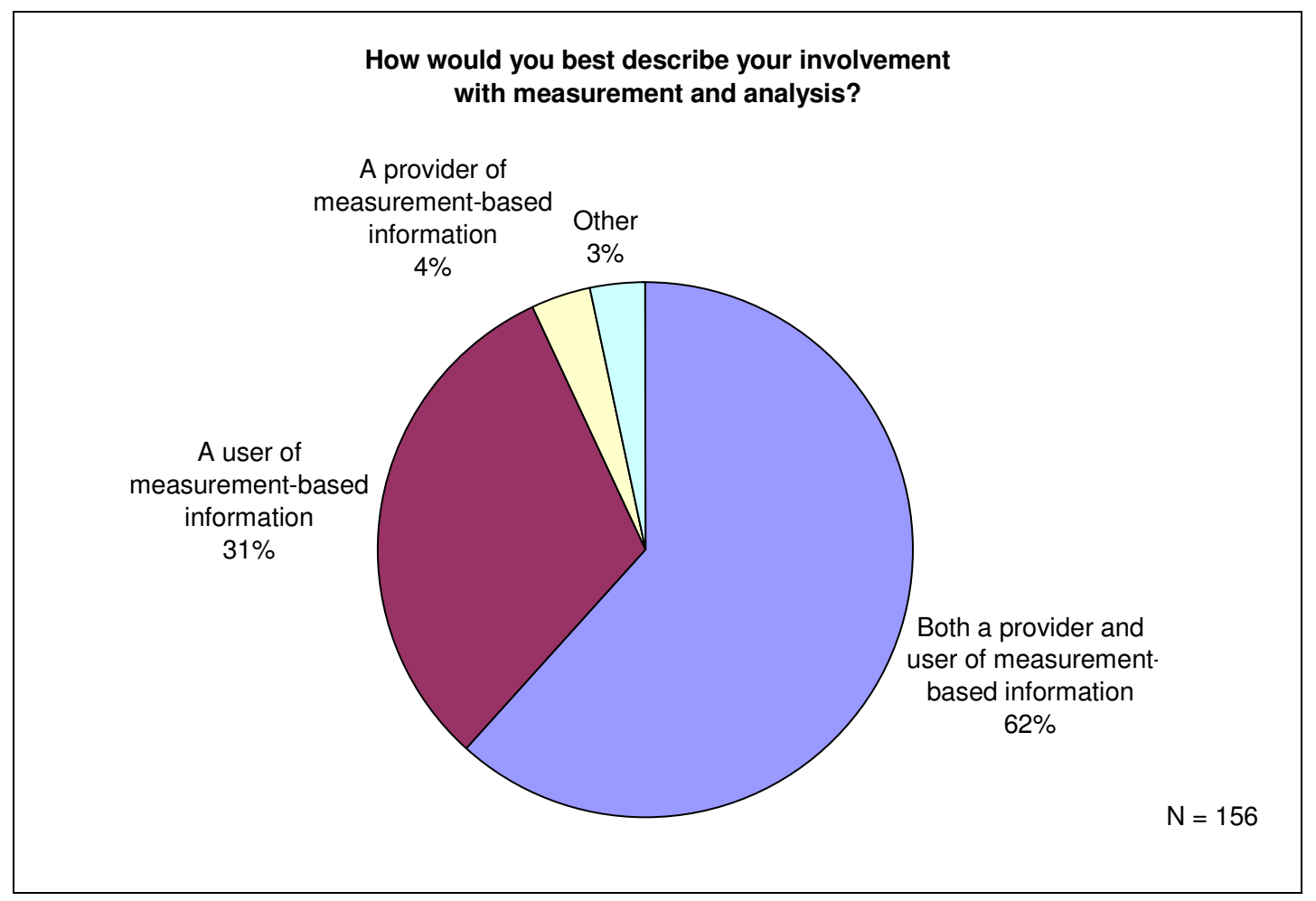

Figure 2: Measurement and analysis roles of survey respondents

Notice in Figure 3 that three quarters of the respondents from the high maturity organizations reported that they were from CMMI maturity level five organizations. That is consistent with the proportions for maturity levels four and five as reported in the most recent Process Maturity Profile [SEI 2008a].

A comparison of their reported and appraised maturity levels also suggests that the respondents were being candid in their replies. The current maturity levels reported by 90 percent of the respondents do in fact match the levels at which their respective organizations were most recently appraised. Of the remaining ten percent, four respondents reported higher maturity levels, one moving from level three to level five and three moving from level four to level five. Of course, it is quite reasonable to expect some post-appraisal improvement. 


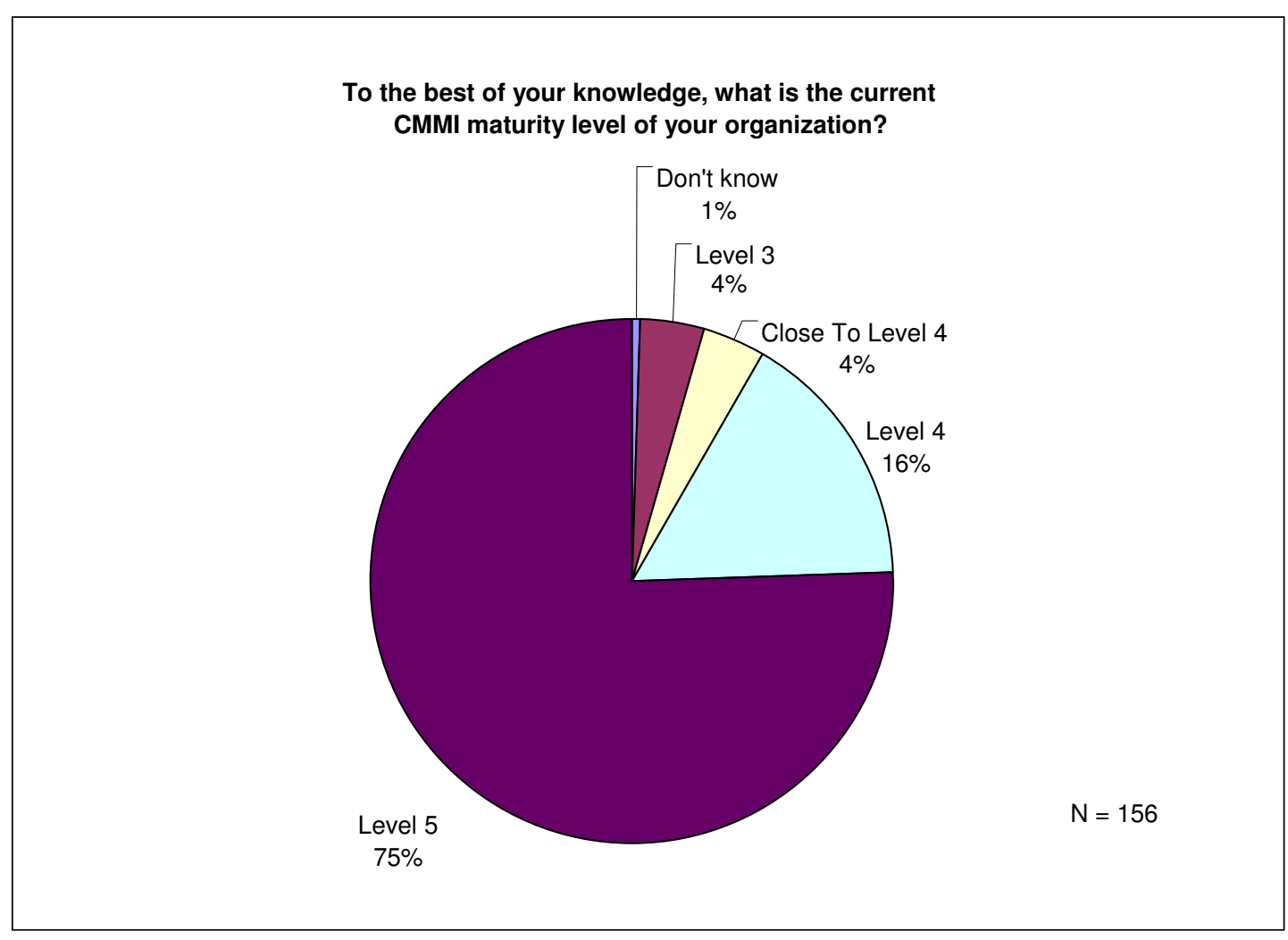

Figure 3: CMMI maturity levels of responding organizations

More interestingly however, twelve respondents reported maturity levels that were lower than their appraised maturity levels. One of the 28 whose organizations were appraised at maturity level four reported being at level three, and eleven of the 124 appraised at maturity level five reported no longer being at that level. One of them reported currently being at maturity level four, another person answered "don't know" and nine reported that they were now at maturity level three. These individuals apparently were reporting about perceived changes in their organizational units or perhaps perceived changes in appraisal criteria that led to a lower process maturity level in their view.

The remaining charts in this section characterize the mix of organizational units that participated in the survey. As noted earlier, we intend to track these or similar factors over time, along with changes in the use and reported value of measurement and analysis in CMMI-based process improvement.

More than a quarter of the organizational units are government contractors or government organizations (see Figure 4). ${ }^{3}$ About two-thirds of them focus their work on product or system development (see Figure 5). Almost all of them focus their work on software engineering, although large proportions also report working in other engineering disciplines (see Figure 6). The numbers of their full-time employees who work predominately in software, hardware, or systems engineering are distributed fairly evenly from 200 or fewer through more than 2000 (see Figure 7). Over half of the participating organizations are primarily located in the United States or India; no other country exceeds four percent of the responding organizations, with the exception of China which accounts for 15 percent (see Figure 8).

3 The "other" category contains various combinations of the rest of the categories, including defense but also IT, maintenance, system integration and service provision. 
How is your organization best described?

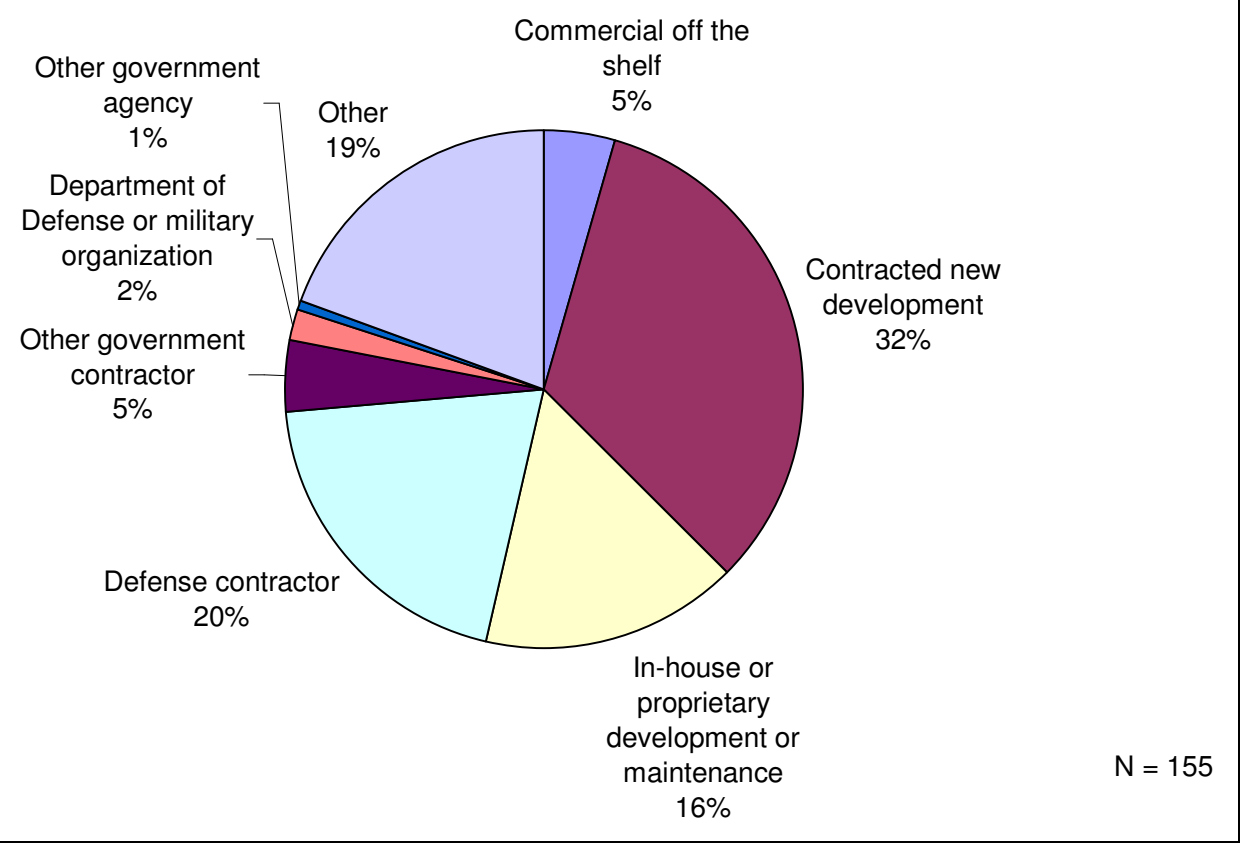

Figure 4: Sectors represented in responding organizations

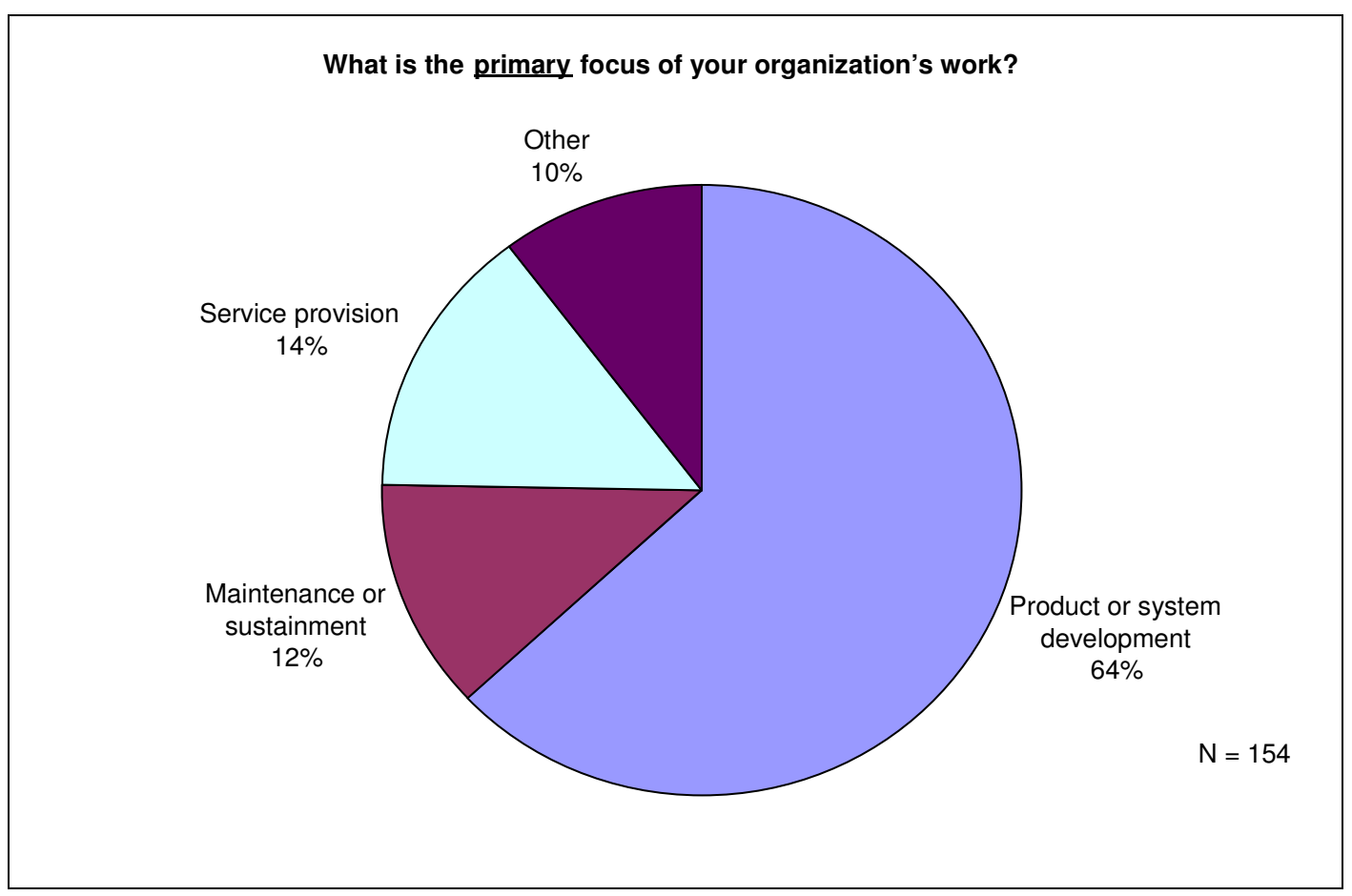

Figure 5: Product and service focus of responding organizations 


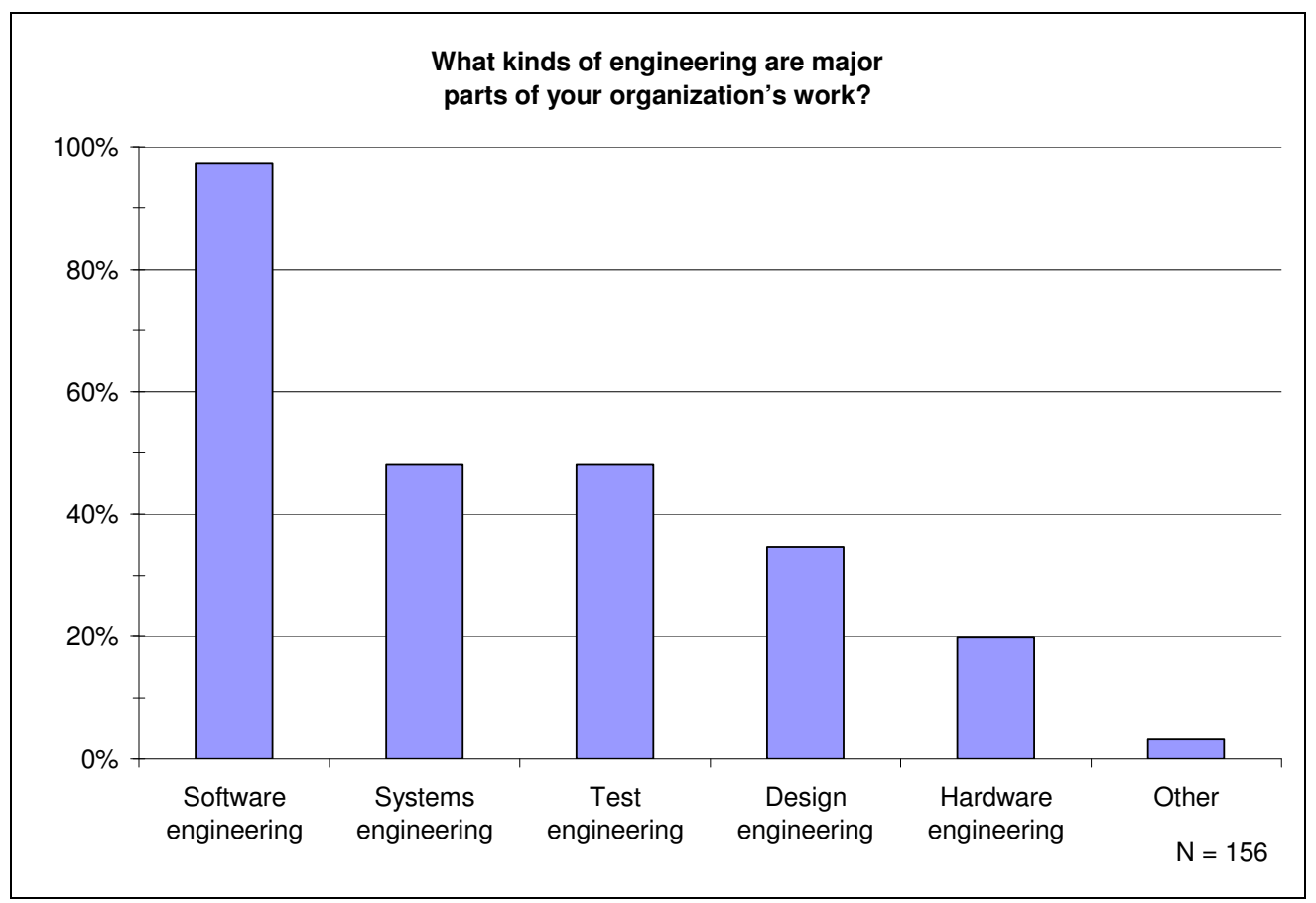

Figure 6: Mix of engineering activities in responding organizations

Approximately how many full-time employees in your organization work predominantly in software, hardware or systems engineering?

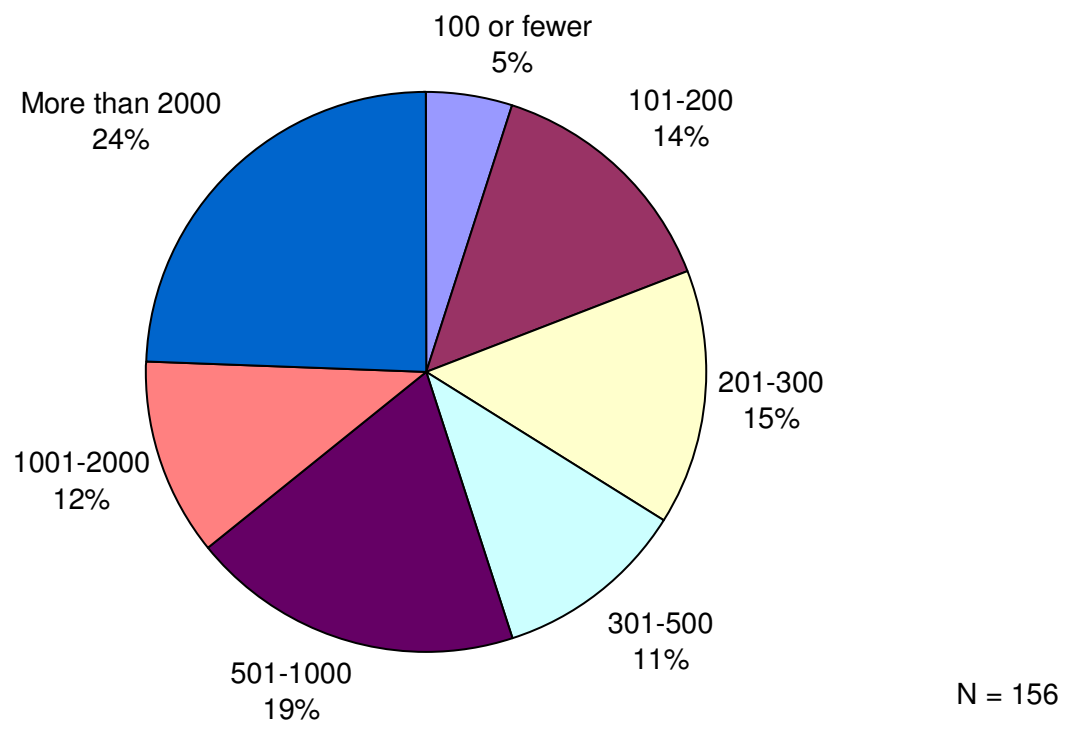

Figure 7: Number of full-time engineering employees in responding organizations 
In what country is your organization primarily located?

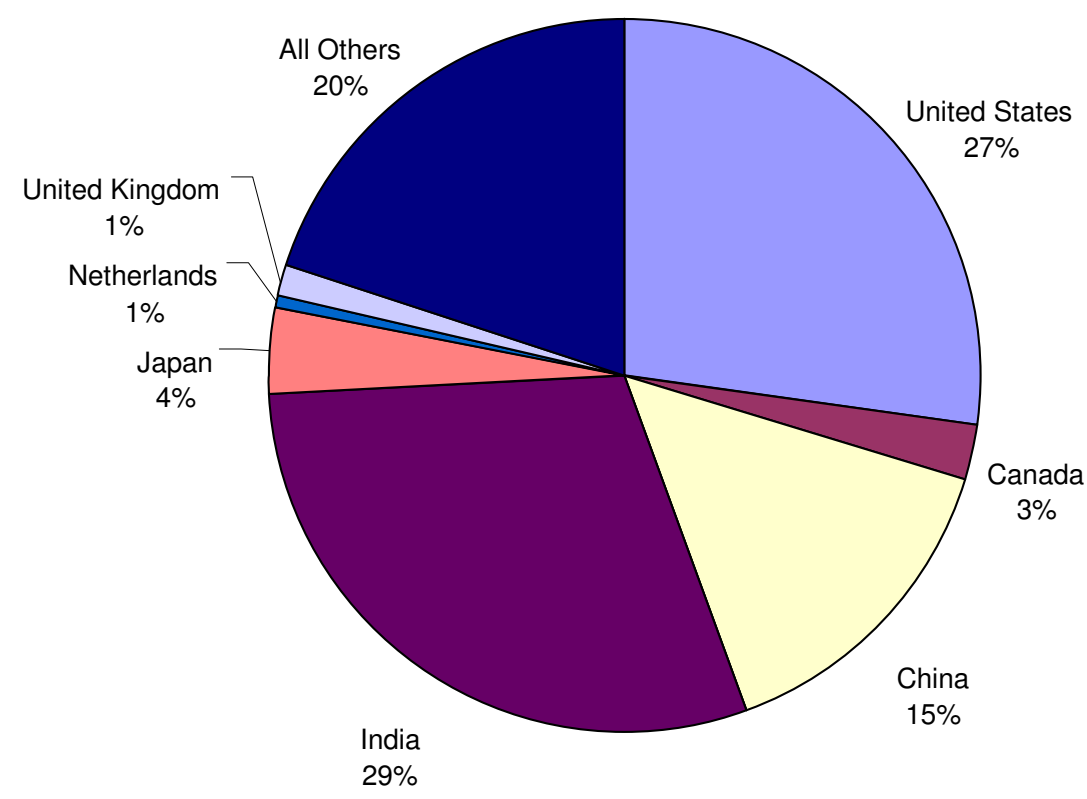

$N=155$

Figure 8: Primary location of responding organizations 


\section{Baselining Variability in Process Outcomes: Value Added by Process Performance Modeling}

There currently is considerable interest in process performance models among organizations that have achieved or aspire to CMMI high maturity status. The development of such models is discussed in the Organizational Process Performance (OPP) process area, and the varied uses of process performance models is covered in the Quantitative Project Management (QPM), Causal Analysis and Resolution (CAR), and Organizational Innovation and Deployment (OID) process areas. However, further clarification is needed along with good examples of what has worked well and what has not. Questions about process performance models form a predominant theme in the survey to address this situation.

The survey respondents' reports about the effects of their process performance modeling efforts are described in this section. They were first asked a series of questions describing several specific effects that have been experienced in a number of high maturity organizations [Goldenson 2007a, Gibson 2006, Goldenson 2003b, Stoddard 2008]. As shown in Figure 9, over three-quarters of them reported experiencing better project performance or product quality frequently or almost always. A similar incidence of fewer project failures was reported by over 60 percent of the respondents. Almost as many respondents reported a similar incidence of better tactical decision making, and over 40 percent said that they had experienced comparable improvements in strategic decision making as a result of their process performance modeling activities.

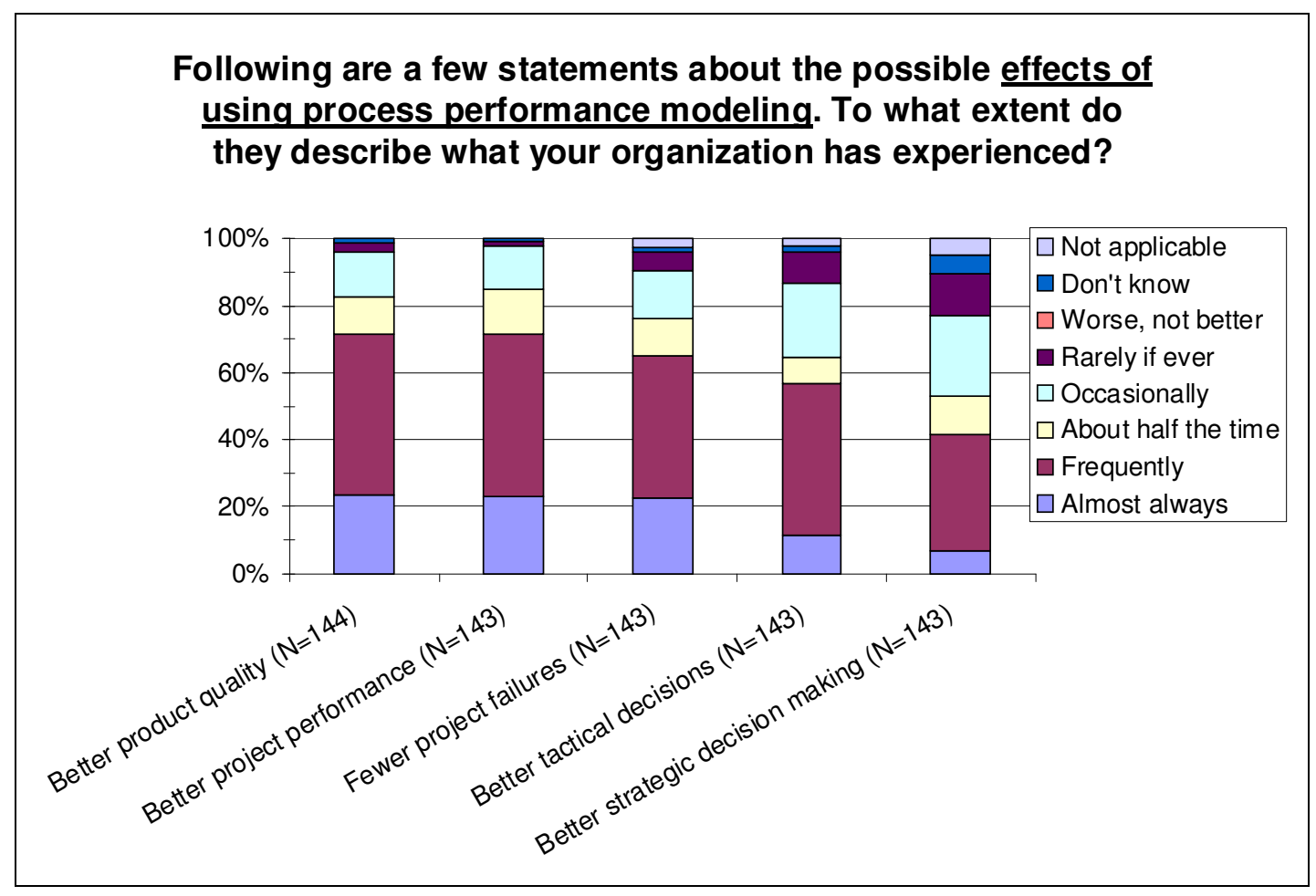

Figure 9: Effects attributed to using process performance modeling

These results add insight about the benefits of process performance models; however the question series also served to get the respondents thinking about how they could best characterize the over- 
all value of process performance modeling for their organizations. The respondents' answers to a single question about such an effect are shown in Figure 10. As the figure shows, over half of the respondents said that they have obtained much useful information from their process performance models, which proved to be very valuable to their organizations. Another eight percent said that the models have been extremely valuable and that they could not do their work properly without them. While almost 40 percent said that their process performance efforts have yielded only mixed value, only a handful reported gaining little or no value from their models, and none of the survey respondents chose the option that their modeling efforts had been harmful overall.

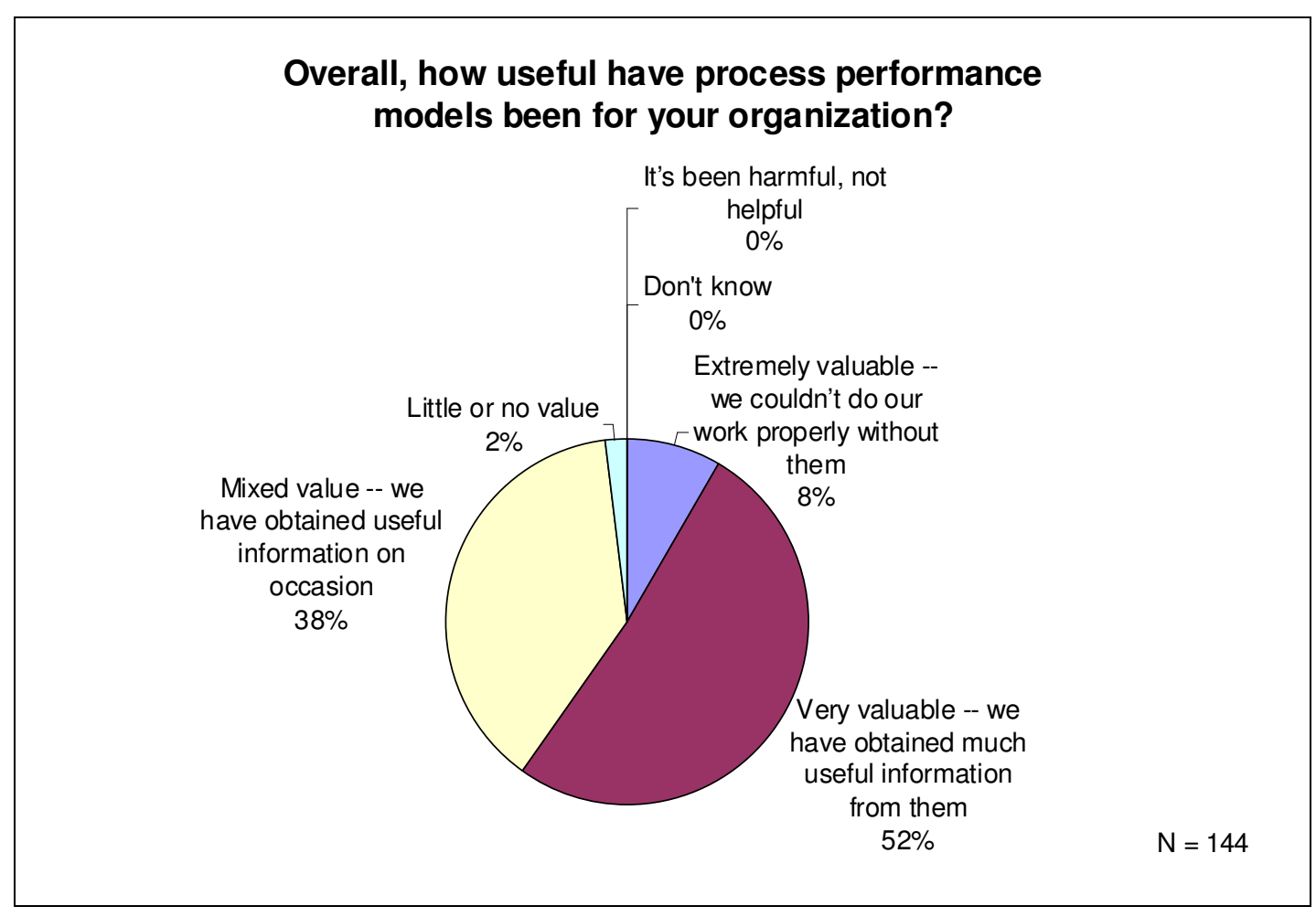

Figure 10: Overall effect attributed to process performance modeling

As noted in Section 1, the responses to the questions on specific and overall benefits of process performance models are intended to serve as barometers of community adoption to be tracked over the next several years. They also are crucial for explaining variability in outcomes of process performance modeling. We have relied in Section 6 on the question about the overall effect attributed by the survey respondents to their organizations' modeling efforts. The questions about specific effects of the modeling are not necessarily equally pertinent to all of the surveyed organizations; however, similar results to those based on the overall question also exist using a composite measure of the specific effects. ${ }^{4}$

\footnotetext{
$4 \quad$ Note that some of the questions described in Sections 4 and 5 that are used as $x$ variables in Section 6 also have been modeled or discussed there as interim y variables.
} 


\section{Baselining Variability in Process Implementation}

The survey respondents' reports about the extent to which their process activities differed are described here. These include the respondents' reports about stakeholder involvement in setting measurement and analysis goals and objectives; measurement-related training; their understanding and use of process performance models; and their use of various data analytic methods. As described in more detail in Section 6, several composite variables based on related groups of these questions and individual questions described here vary predictably with the effects attributed by the survey respondents to their organizations' modeling efforts.

\subsection{Stakeholder Involvement in Setting Measurement and Analysis Goals and Objectives}

The importance of stakeholder involvement for process improvement in general and measurement and analysis in particular is widely acknowledged. This can be seen in CMMI generic practice 2.7 which emphasizes the importance of identifying and involving relevant stakeholders during process execution. Such notions are basic to goal-driven measurement [Park 1996, van Solingen 1999]. It also is crucial for the CMMI Measurement and Analysis process area, particularly in specific goal 1 and specific practice 1.1, which are meant to ensure that measurement objectives and activities are aligned with the organizational unit's information needs and objectives, and specific practice 2.4 , which emphasizes the importance of reporting the results to all relevant stakeholders. Empirical evidence indicates that the existence of such support increases the likelihood of the success of measurement programs in general [Goldenson 1999, Goldenson 2000, Gopal 2002].

Experience with several leading high maturity clients has shown that insufficient stakeholder involvement in the creation of process performance baselines and models can seriously jeopardize the likelihood of using them productively. Stakeholders must actively participate not only in what outcomes are worthy of being predicted with the models, but also in identifying the controllable $\mathrm{x}$ factors that have the greatest potential to assist in predicting those outcomes. Many organizations pursuing baselines and models make the mistake of identifying the outcomes and controllable factors from the limited perspective of the quality and process improvement teams.

We asked a series of questions seeking feedback on the involvement of eight different categories of potential stakeholders. As shown in Figure 11, these groups are commonly present in most organizational and project environments. The groups are listed in Pareto order by the proportions of respondents who reported that those stakeholder groups were either substantially or extensively involved in deciding on plans of action for measurement and analysis in their organizations. Notice that process/quality engineers and measurement specialists are more likely to have the most involvement, while project engineers and customers have the least.

Observations by SEI technical staff and others suggest that successful high maturity organizations involve stakeholders from a variety of disciplines in addition to those summarized in Figure 11, such as marketing, systems engineering, architecture, design, programming, test, and supply chain. This question will also be profiled across time to gauge the impact of richer involvement of other stakeholder groups. 


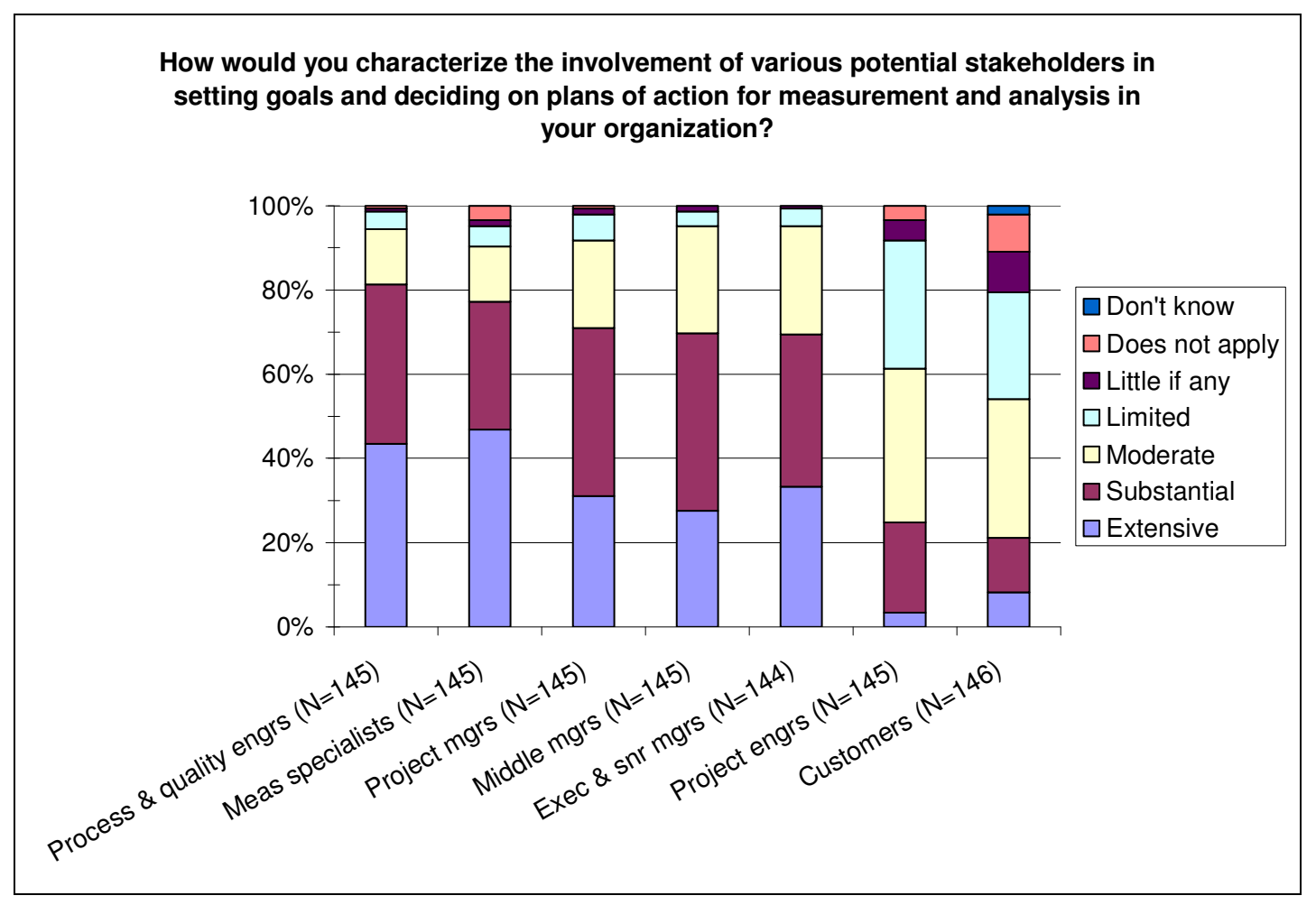

Figure 11: Stakeholder involvement in responding organizations

\subsection{Measurement-Related Training}

The questions in this section aim to provide insight into the type and volume of training done by the surveyed organizations for the key job roles related to the practice and use of process performance modeling. A series of questions also asks about the sources of training and training materials used by these organizations. ${ }^{5}$

Notice in Figure 12 that the bulk of training-related activity for executive and senior managers was limited to briefings, although about 15 percent of them have completed in-service training courses. Middle and project-level managers were much more likely to take one- or two-day courses, and almost twenty percent of the project managers typically took one- to four-week courses. The process and quality engineers were most likely to have taken the most required course work. Of course, some of these same people build and maintain the organizations' process performance models. Similar results can be seen in Figure 13 for those who build, maintain, and use the organizations' process performance models. Figure 14 summarizes the sources by which the surveyed organizations ensured that their process performance model builders and maintainers were properly trained. Almost 90 percent relied on training developed and delivered within their own organizations. However, over 60 percent contracted external training services, and almost 30 percent purchased training materials developed elsewhere to use in their own courses. About a third of them emphasized that they hire people based on their existing expertise.

5 SEl experience regarding the nature and degree of training and their associated outcomes of process performance modeling suggest that 5 to 10 percent of an organization's headcount must be trained in measurement practices and process performance modeling techniques to have a serious beneficial impact on the business. 


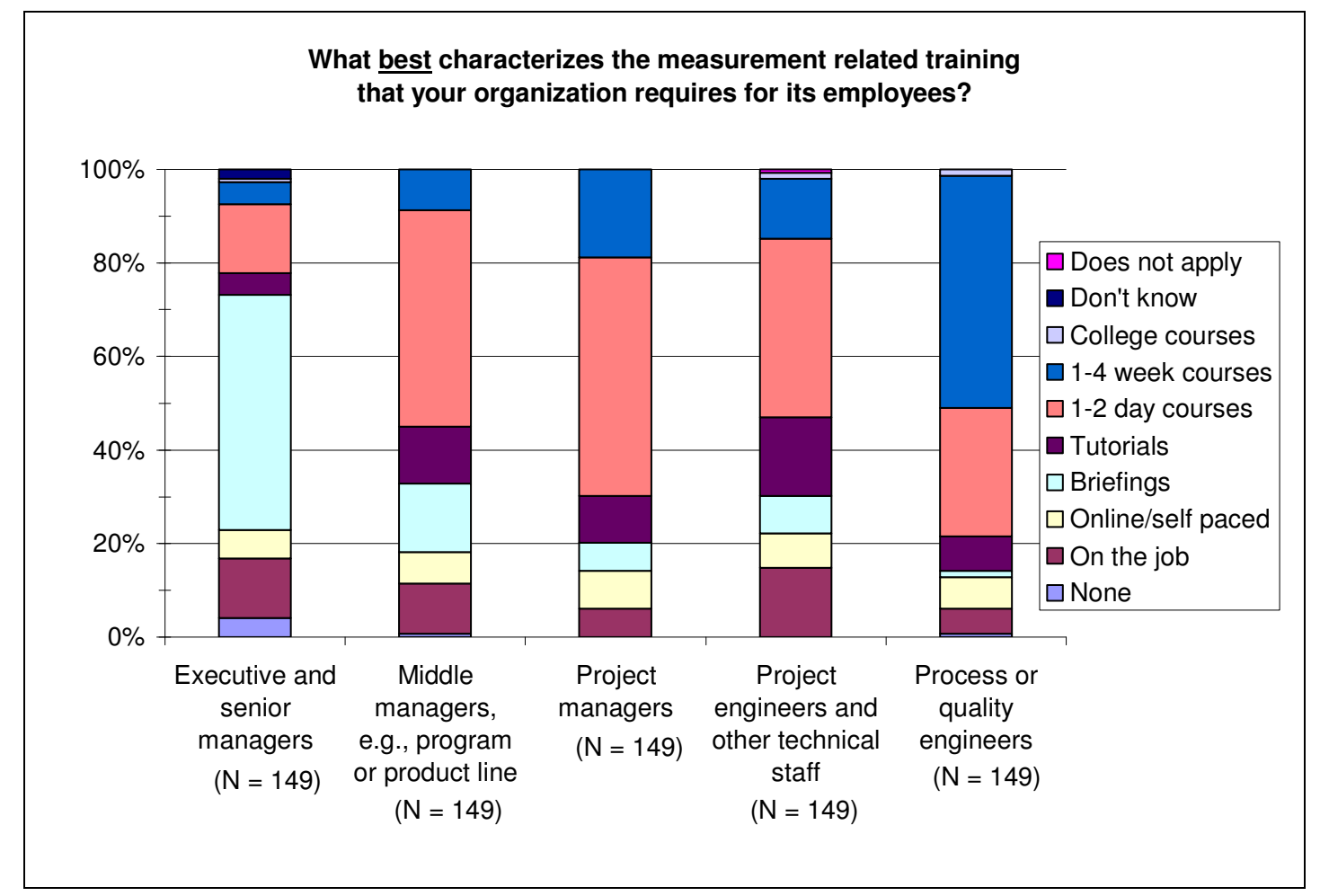

Figure 12: Measurement related training required for employees of responding organizations

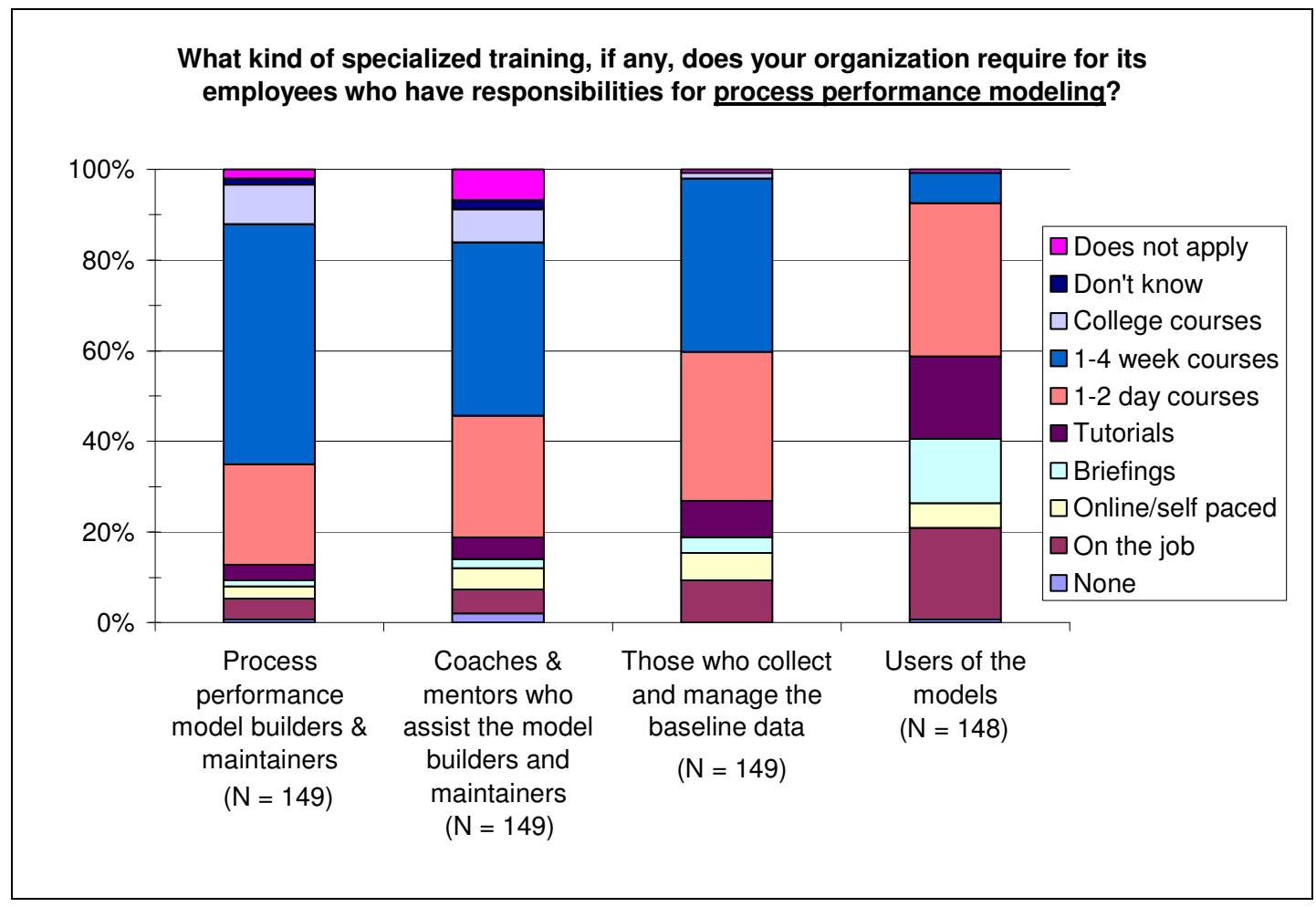

Figure 13: Specialized training on process performance modeling in responding organizations 


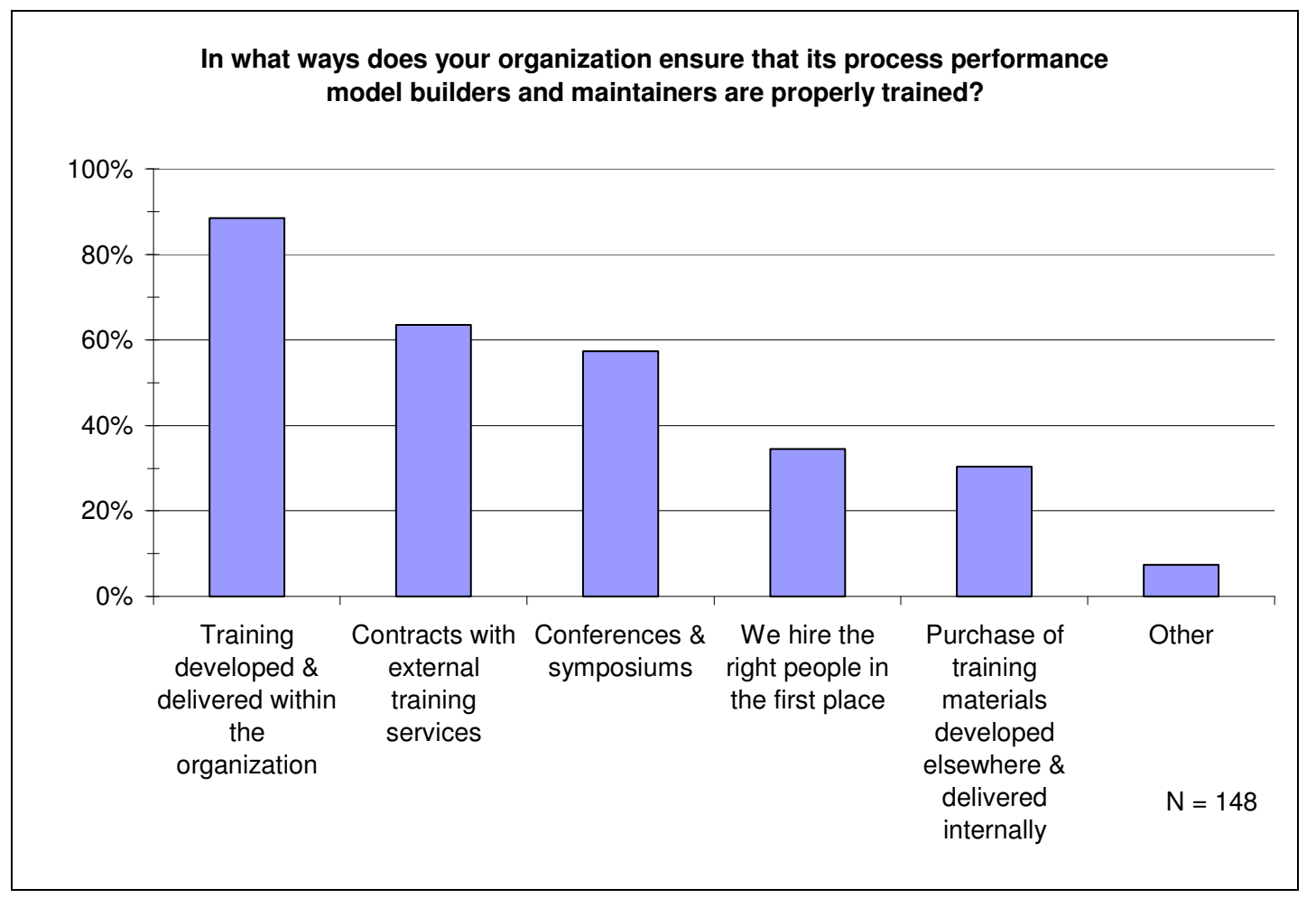

Figure 14: Sources of process performance model expertise in responding organizations

Earlier observations by SEI technical staff and others underscore the importance of measurement training and coaching for management in addition to the training for measurement analysts and model builders. Several of the questions used in this survey and other related questions will be profiled over time to help gauge the state of the practice in training on measurement and analysis. The results will be used to help guide future training and services offered by the SEI. Training remains one of the most important and problematic measurement deployment issues within many organizations. Many organizations believe they have fully deployed Six Sigma when in fact their staff members are not armed with a balanced and complete statistical toolkit for conducting regression analysis, probabilistic modeling, or various types of simulation modeling.

\subsection{Process Performance Modeling}

Over the past two years, SEI technical staff and others have worked to clarify what have been called the "healthy ingredients" of process performance models [Young 2008a, Young 2008b]. The healthy ingredients include

- modeling uncertainty in the model's predictive factors

- $\quad$ ensuring that the model has controllable factors in addition to possible uncontrollable factors

- $\quad$ identifying factors to construct models that are directly associated with sub-processes

- $\quad$ predicting final and interim project outcomes

- using confidence intervals to provide a range of expected outcome behaviors enabling "what-if" analysis using the model

- $\quad$ enabling projects to identify and implement mid-course corrections to help ensure project success 
Two series of questions focused on the detailed aspects of these ingredients. Composite measures based on answers to both questions showed a strong association with respondents' reports about the value of using process performance models.

The first set of questions focused on the emphasis the responding organizations placed on the various healthy ingredients in their modeling efforts. The results in Figure 15 show that the organizations varied considerably in their emphasis on these factors. While many of the organizations addressed these factors quite extensively, room for improvement exists among some of the organizations, particularly on the right side of the Pareto ordering. The same is so for the question set that focused on the purposes for which the organizations used their models. As seen in Figure 16, there is considerable room for improvement in modeling variation in process outcomes and in enabling "what-if" analyses.

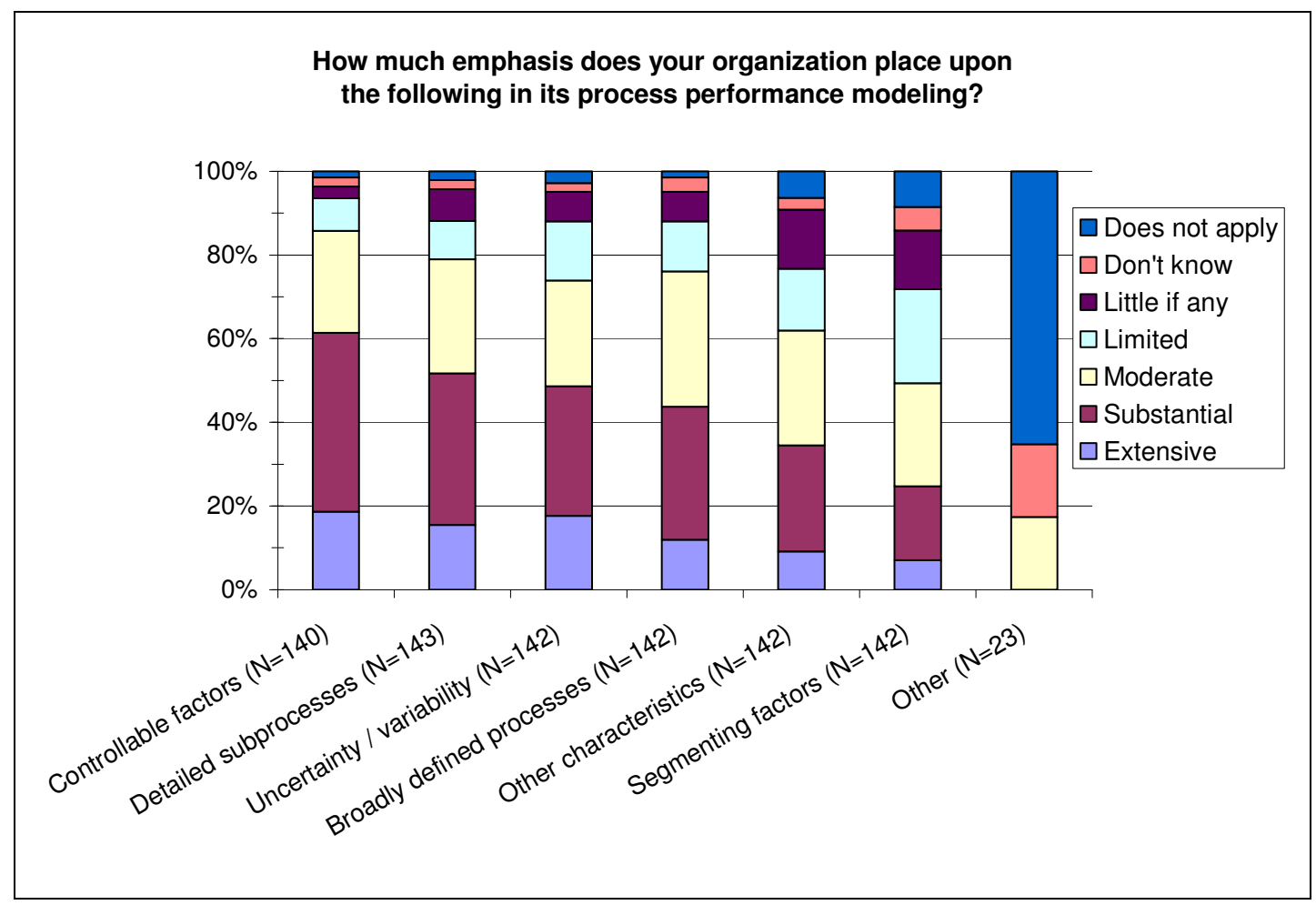

Figure 15: Emphasis on healthy process performance model ingredients 


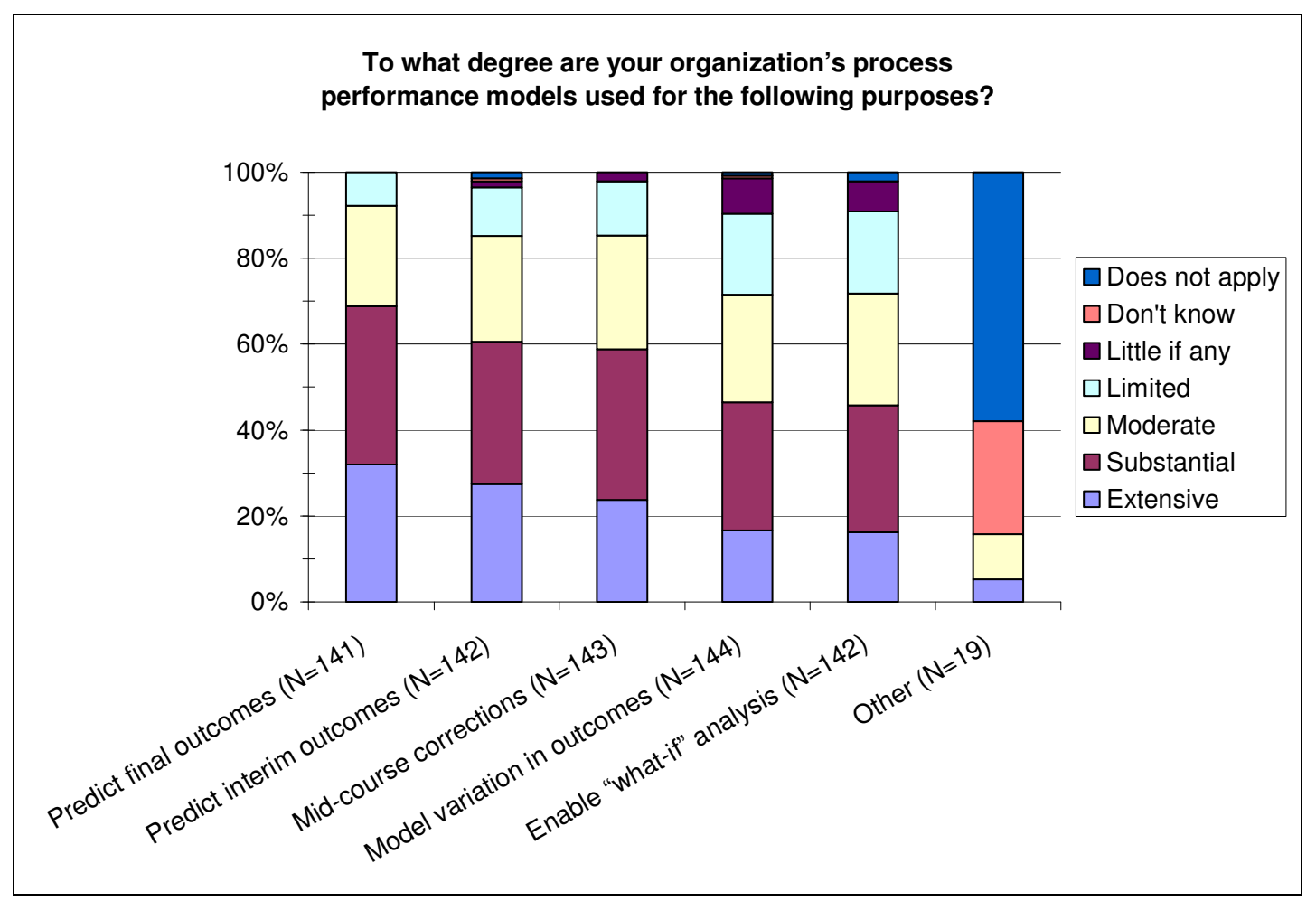

Figure 16: Use of healthy process performance model ingredients

As just shown, many CMMI high maturity organizations do recognize and implement these ingredients to maximize the business value of their process performance modeling. However, better understanding and implementation of these healthy ingredients remains a need in the wider community. These questions will be profiled in successive surveys for the next several years.

SEI technical staff and others have observed a disparity of application and use of process performance models and baselines among various clients. Far greater business value appears to accrue in organizations where the use of models and baselines includes the complete business and its functions rather than isolated quality or process improvement teams. We asked a series of questions to provide insight into the scope of use of the process performance models and baselines implemented in the respondents' organizations. These include:

- $\quad$ operational purposes for which the models and baselines are used

- functional areas where process performance models and baselines are actively used

- $\quad$ quality, project, and process performance outcomes to be predicted

- $\quad$ processes and activities that are routinely modeled

As shown in Figure 17, project monitoring, identifying opportunities for corrective action, project planning, and identifying improvement opportunities were the most common operational uses noted by the survey respondents. All of these operational uses were identified by over half of the respondents. 


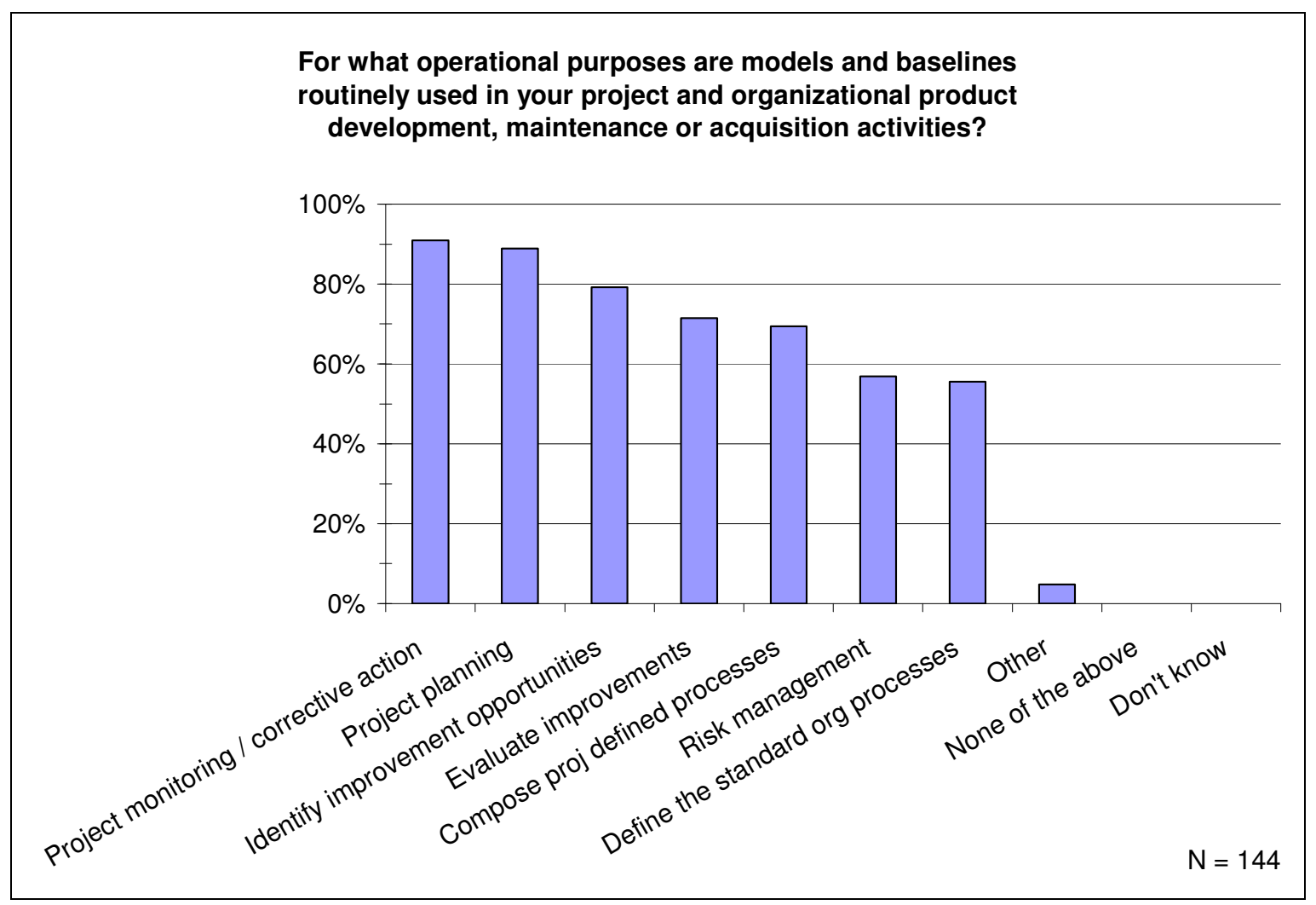

Figure 17: Operational purposes of process performance modeling

However, the same cannot be said for the functional areas of the organizations' businesses that are not directly related to software and software intensive systems per se. As shown in Figure 18, only one of these functional areas was routinely modeled by more than 50 percent of the responding organizations.

Like all of the other questions, the questions about operational uses and other business functional areas will be profiled across time to enable an empirical link to overall business benefit and to observe the changing profile within the community as adoption accelerates. However, these questions have not been used in our statistical modeling exercises presented in Section 6. It does not make sense to use every question to model the effects of process performance modeling. There is no theoretical reason to expect association for some of the questions. Others, such as these two question sets, are not well distributed empirically to serve as useful predictors. 


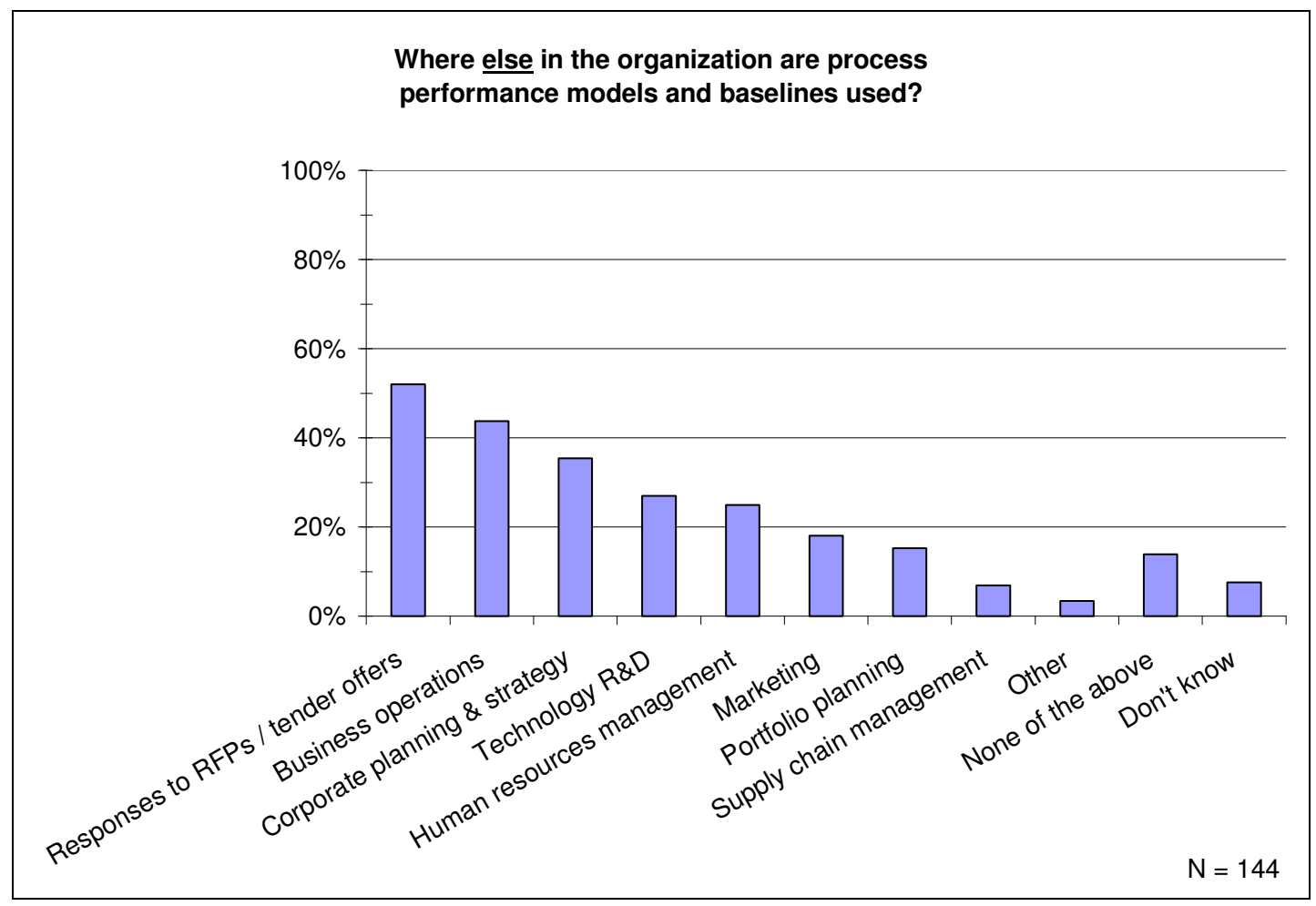

Figure 18: Other management uses of process performance modeling

The diversity of process performance models used to predict quality, project, and process performance outcomes are another matter entirely. As can be seen in Figure 19 and Figure 20, there is considerably more variation in the extent to which various outcomes and interim outcomes are predicted by the process performance models used in the organizations that participated in this survey. Delivered defects, cost, and schedule duration were commonly modeled by over 80 percent of the organizations. Accuracy of estimates was modeled by close to three-quarters of them. Estimates at completion and escaped defects were modeled by over 60 percent of the respondents' organizations. However, the other outcomes were predicted less commonly.

As shown in Section 6, a composite variable based on the diversity of models used to predict product quality and project performance outcomes is quite strongly related to the differences in overall value that the survey respondents attribute to their organizations' process performance modeling activities. A composite variable based on the diversity of models used to predict interim performance outcomes also is related to the reported value of their respective modeling efforts, although less strongly. 


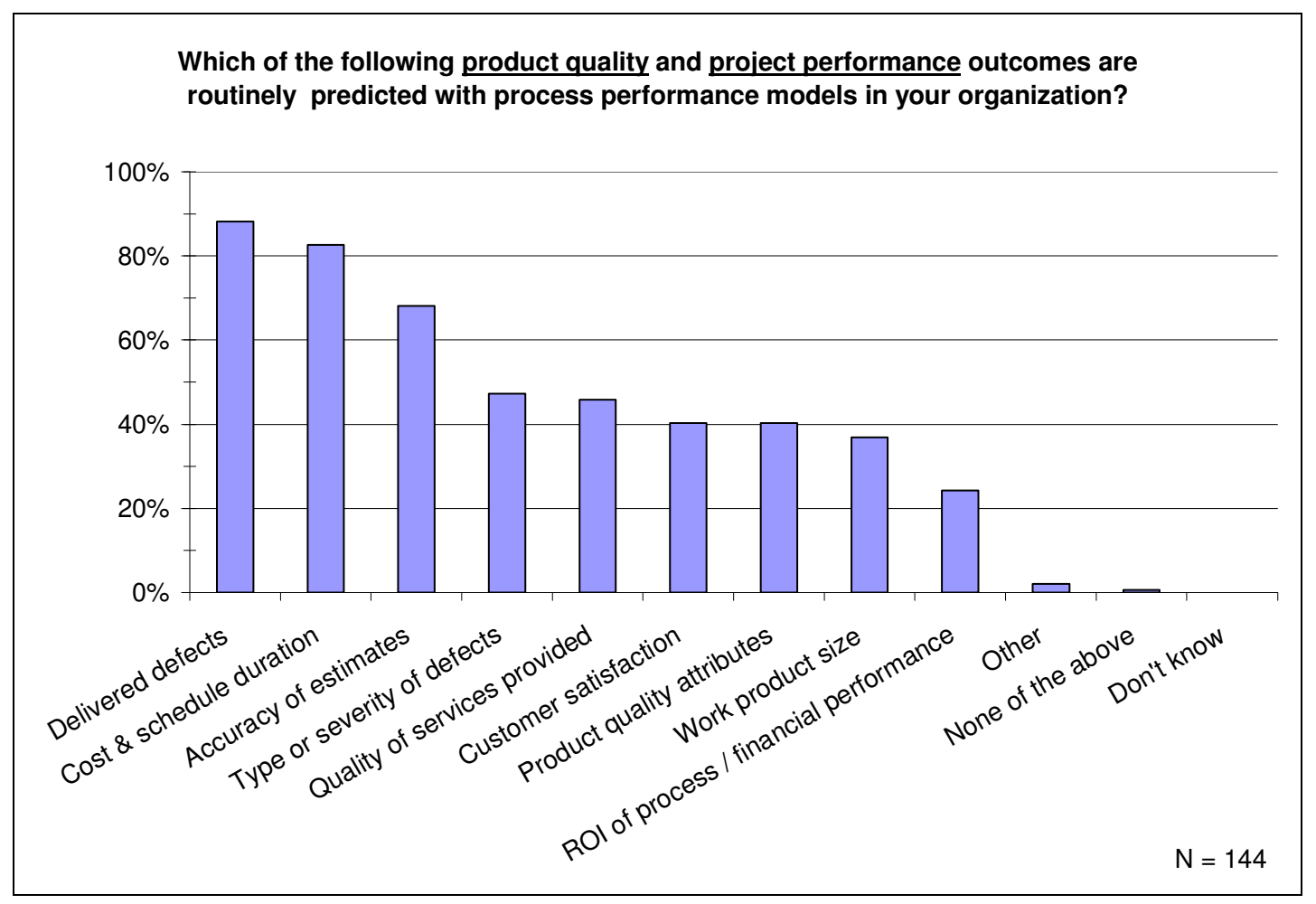

Figure 19: Diversity of process performance models: product quality and project performance

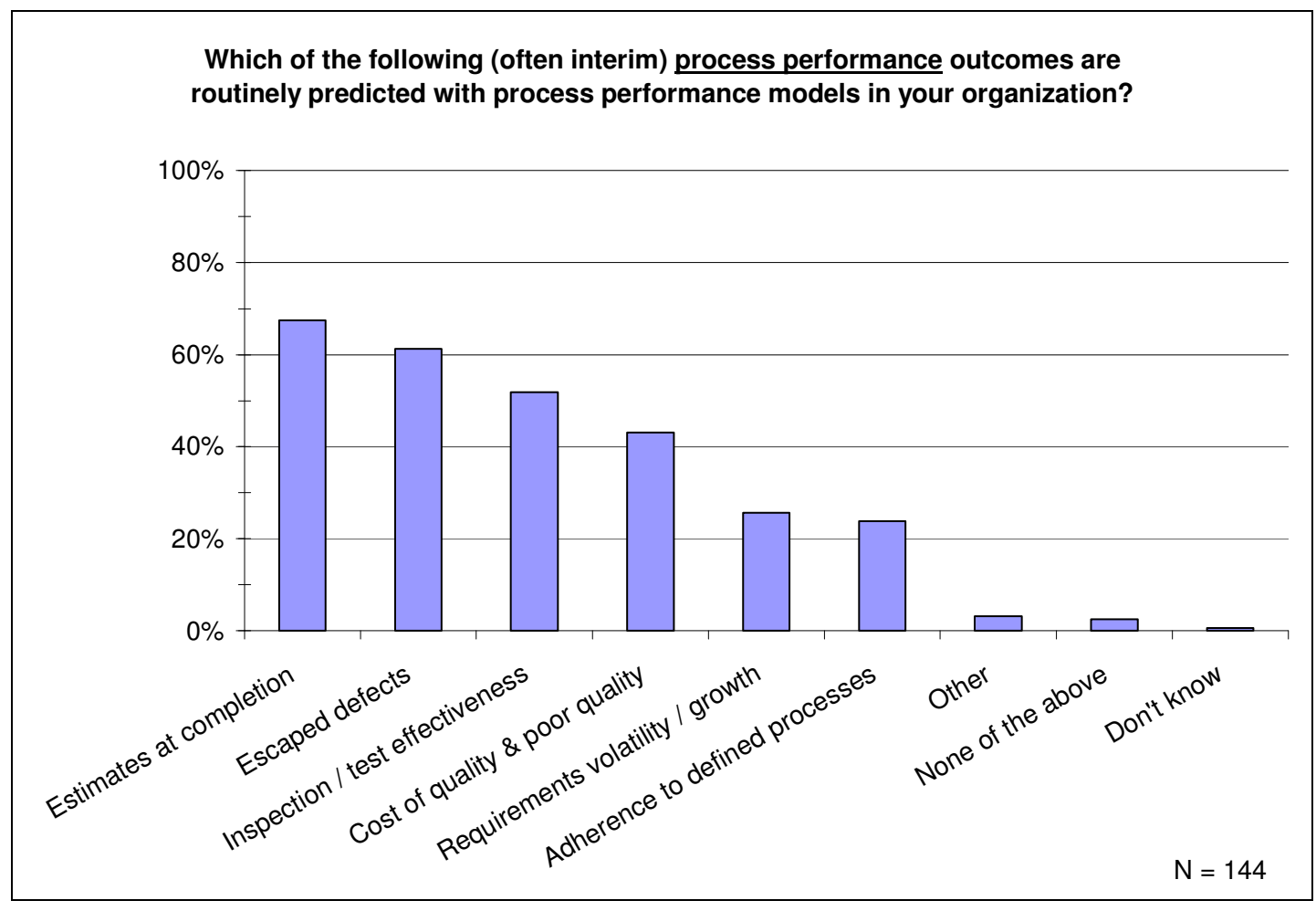

Figure 20: Diversity of process performance models: process performance

The processes and related activities routinely modeled are summarized in Figure 21. Not surprisingly, project planning, estimation, quality control, software design, and coding were modeled most com- 
monly. Modeling of requirements engineering activities was reported by almost half of the responding organizations; however, there is considerable room for improvement elsewhere.

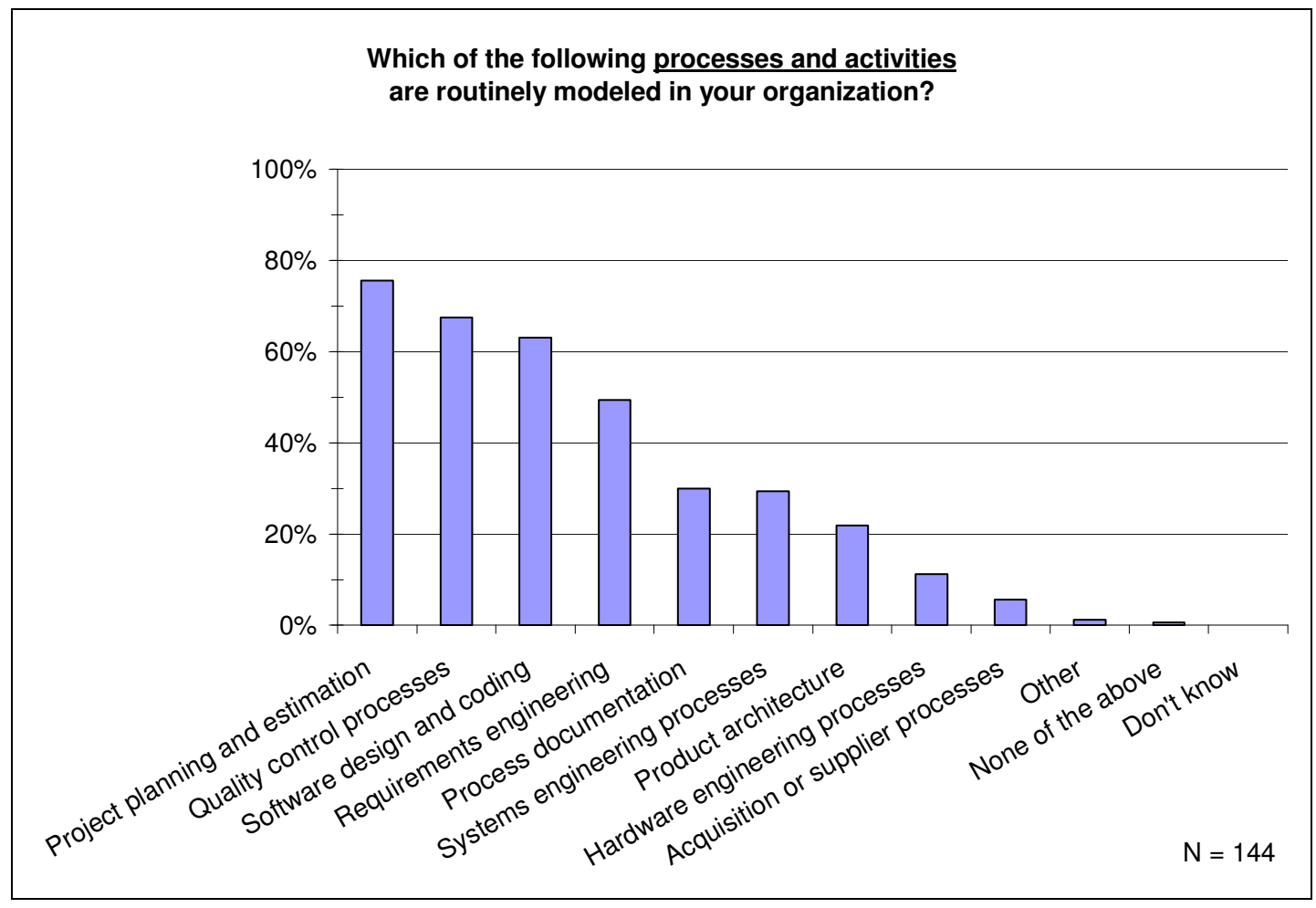

Figure 21: Routinely modeled processes and activities

Finally, notice in Figure 22 that almost 60 percent of the survey respondents reported that process performance model predictions were used at least frequently in their organizations' status and milestone reviews. Another large group (close to 20 percent) reported that they use such information about half the time in their reviews, while 21 percent say they do so only occasionally at best.

In fact, this question turns out to be more closely related statistically to the performance outcomes of doing process performance modeling of all the $\mathrm{x}$ variables examined in Section $6 .{ }^{6}$ Some organizations develop process performance models that end up on a shelf unused, because either the models are predicting irrelevant or insignificant outcomes or they lack controllable $\mathrm{x}$ factors that provide management direct insight on the action to take when predicted outcomes are undesirable. To have an institutional effect, process performance models must provide breadth and depth so that they can play a role in the various management reviews within an organization and its projects.

6 This question also is of interest in its own right as a measure of the value added by doing process performance modeling. Much like the respondents' direct reports in Section 3 about the outcomes of doing process performance modeling, frequency of use of the model predictions for decision making does vary as a function of the way in which the models are built and used, as well as the respondents' answers to other questions described elsewhere in Sections 3 and 4 about differences in other process activities and organizational context. 


\section{How often are process performance model predictions used to inform decision making in your organization's status and milestone reviews?}

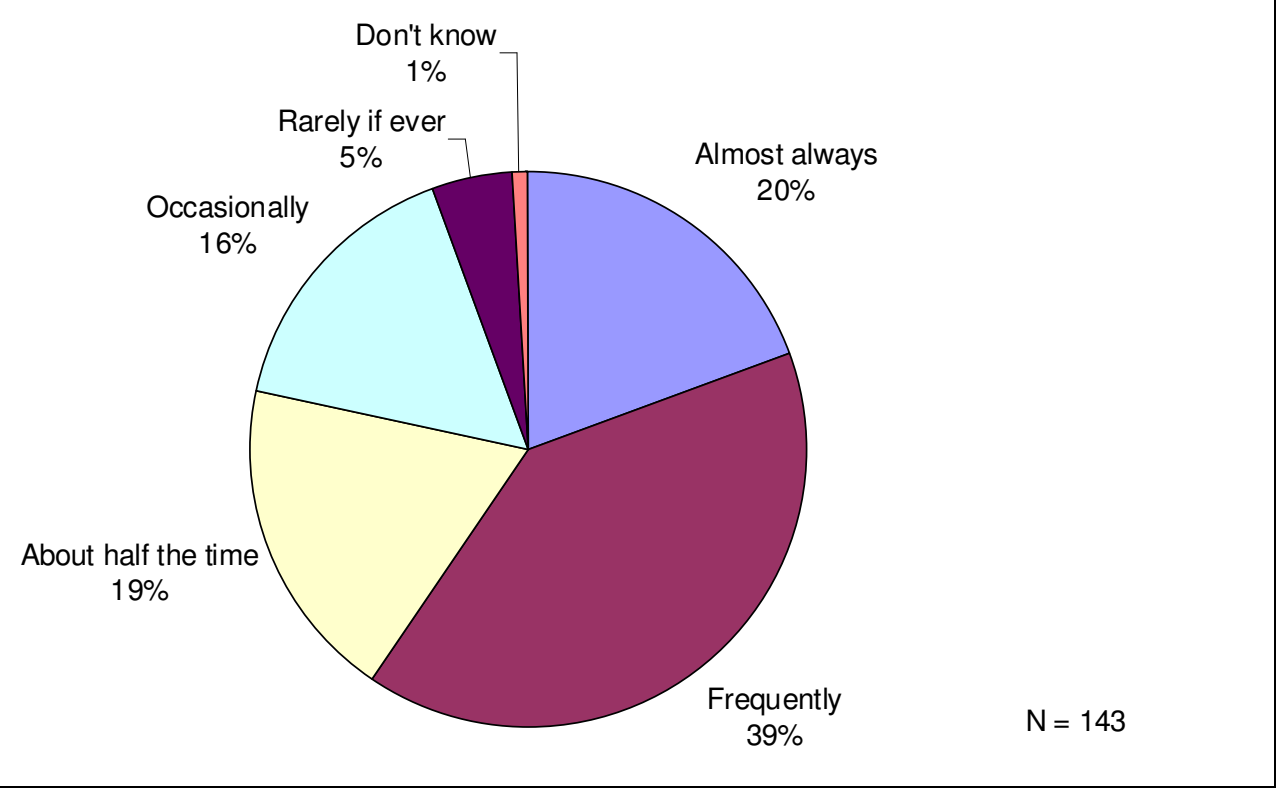

Figure 22: Use of process performance model predictions in reviews

\subsection{Analytic Methods}

This set of questions solicited detailed feedback on the extent to which the responding organizations used a series of statistical, probabilistic, and simulation techniques. Along with broad stakeholder involvement and management support, the use of a rich variety of analytic methods has been shown to be closely related to the likelihood of the success of measurement programs in general [Goldenson 1999, Goldenson 2000, Gopal 2002]. The questions also closely mirror the analytic methods taught in SEI courses as part of a toolkit focusing on CMMI high maturity and process performance modeling. ${ }^{7}$

These questions serve a two-fold purpose, namely to track the profile of technique adoption by the community across time and to correlate business impact to the degree of sophistication of the analytical toolkits employed. Additionally, the questions themselves were intended to introduce the survey respondents who were not yet familiar with them to a full range of techniques that might be used profitably in their own process performance modeling.

Note in Figure 23 that there is a wide range in the extent to which the organizations use these methods. Various statistical process control (SPC) methods are used most often. Least squares (continuous) regression and even analysis of variance methods are used relatively extensively. However, categorical (e.g., logistic or loglinear) regression and especially designed experiments are used much less

$7 \quad$ More information about these courses, Improving Process Performance Using Six Sigma and Designing Products and Processes Using Six Sigma, can be found at http://www.sei.cmu.edu/products/courses/p49b.html and http://www.sei.cmu.edu/products/courses/p56b.html. 
extensively. ${ }^{8}$ Such methods can be very appropriate for categorical and ordered data, which are quite common in management environments and software and systems engineering environments.

As seen in Section 6, the extent of use of these methods is strongly related statistically to the value attributed by the survey respondents to their process performance modeling efforts. The same is so for the use of a variety of modeling and optimization techniques. However, as shown in Figure 24, the lead-in question asked simply whether or not the methods were used at all, and the use of the techniques was much less common than are the statistical techniques summarized in Figure 23. In fact, over 20 percent of the respondents use none of these techniques.

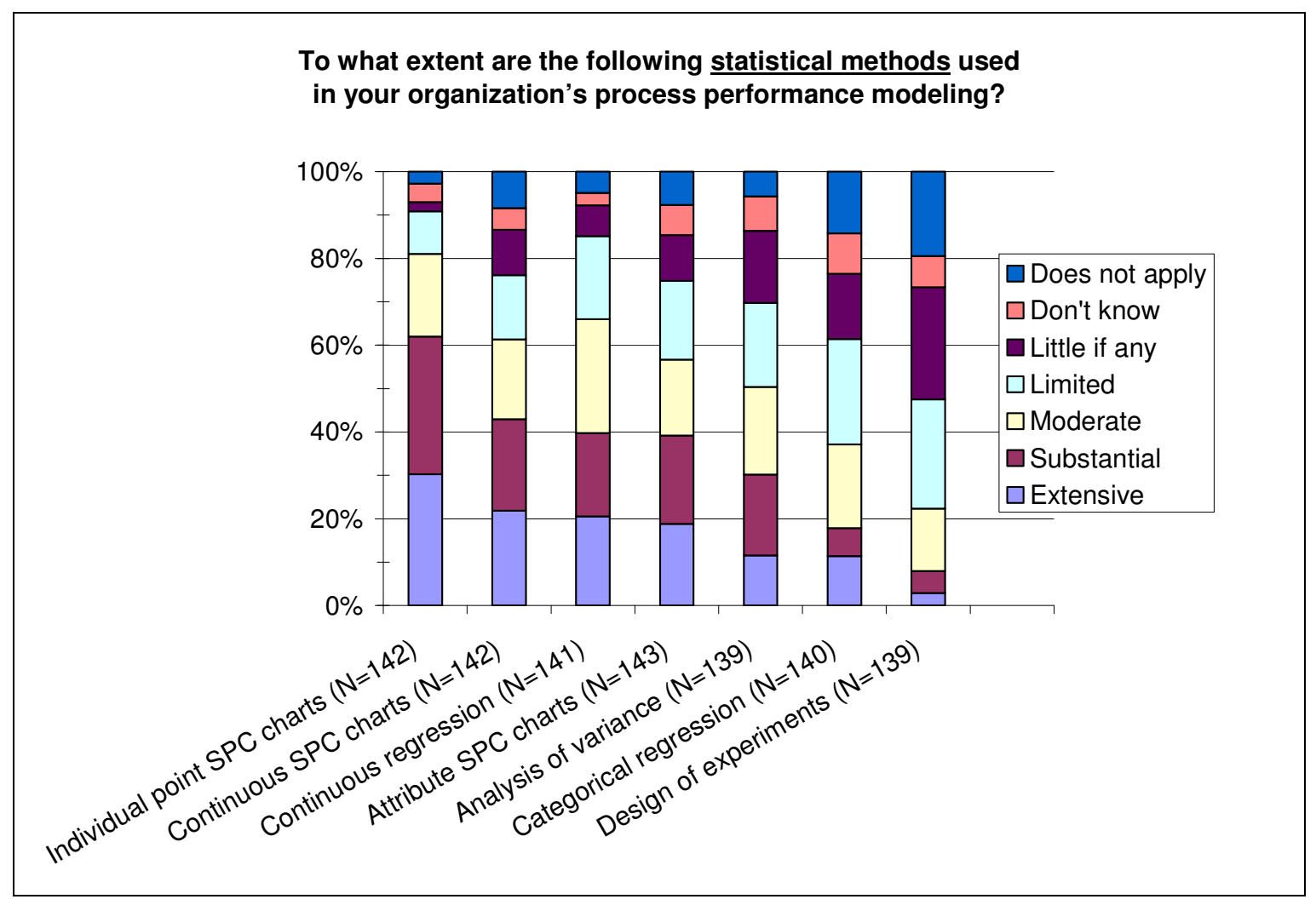

Figure 23: Use of diverse statistical methods

8 For comparison with an earlier survey of high maturity organizations, see Crosstalk [Goldenson 2003a]. 


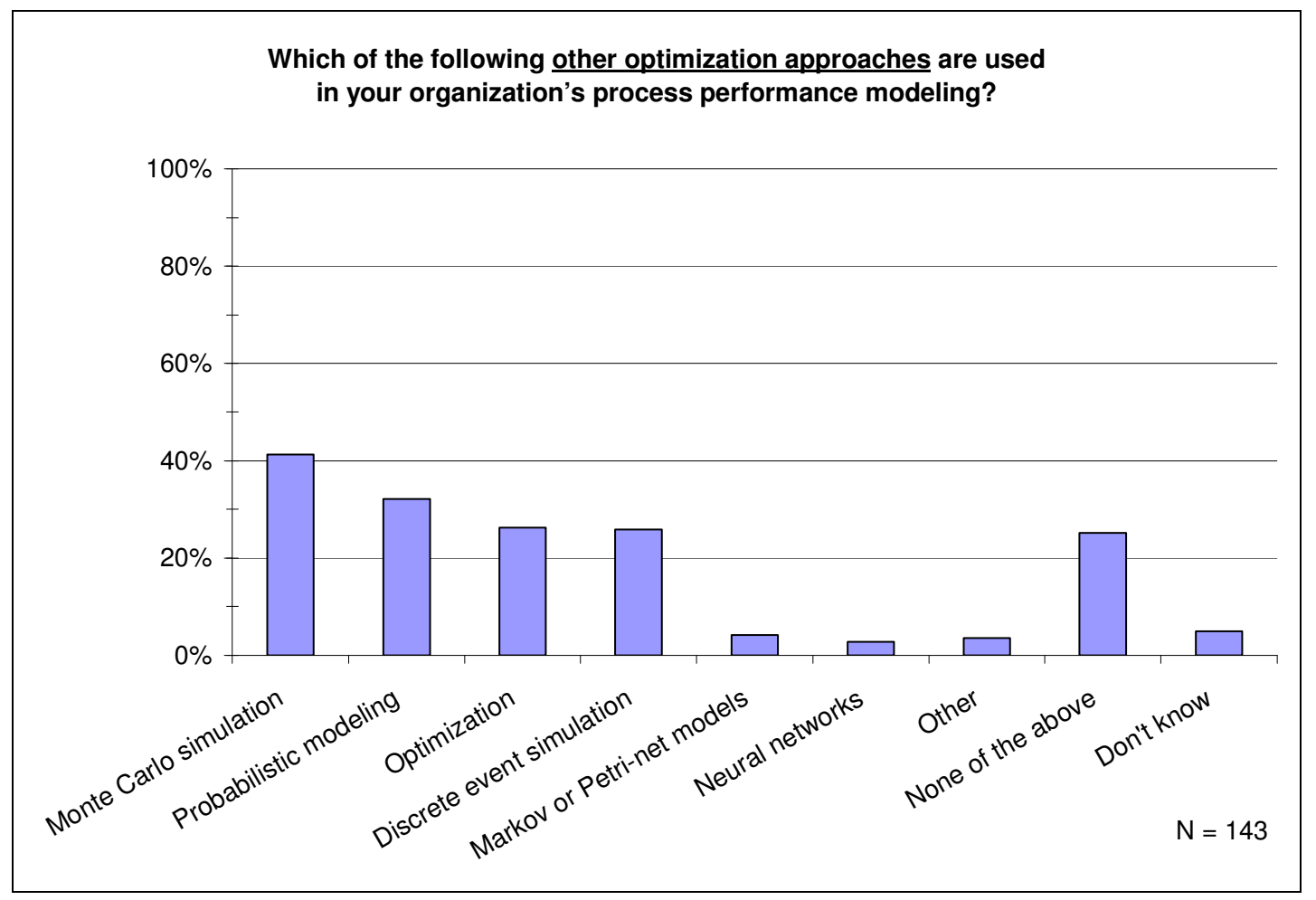

Figure 24: Use of optimization techniques

The questionnaire also queried the respondents about the use in their organizations of a variety of decision and display techniques. These questions were included largely to track the adoption profile by the community across time and to introduce the survey respondents who were not yet familiar with them to a full range of techniques that might be used profitably in their own organizations. As shown in Figure 25 , relatively large numbers of the responding organizations report using decision trees, weighted multi criteria methods, and wide band Delphi; however the other techniques are not widely used. In contrast, the results in Figure 26 show that much larger numbers of these organizations use a series of common visual display techniques. It is somewhat surprising that over half report using box plots. Note however that the exception is categorical mosaic charts, such as those used in Section 6 of this report. Such visual displays are appropriate for categorical and ordered data, which also are quite common in management environments and software and systems engineering. 


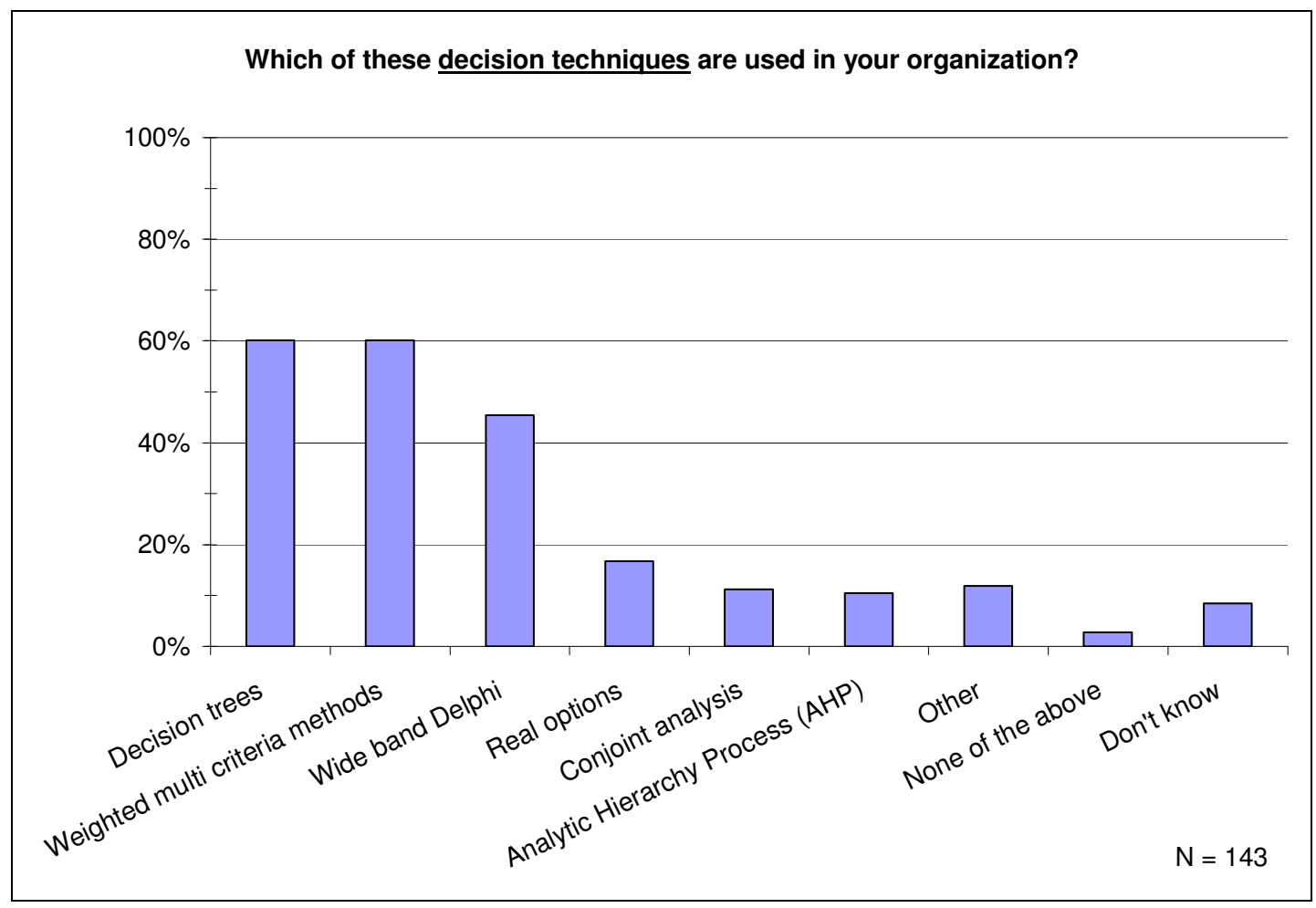

Figure 25: Use of decision techniques

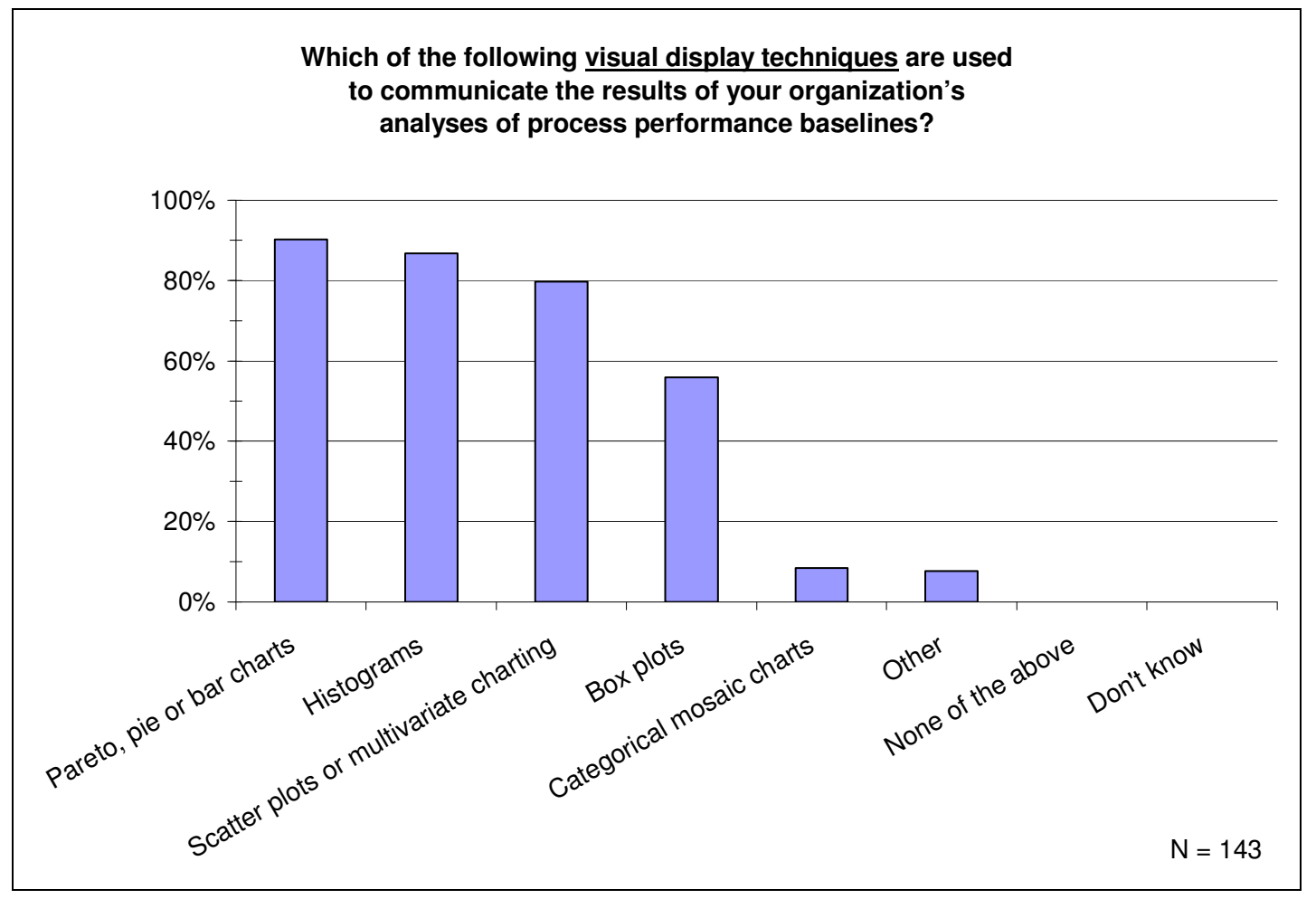

Figure 26: Use of visual display techniques

Two other sets of analytic questions were included in the survey questionnaire. The rationale for both is consistent with observations by SEI technical staff and others as well as best practice in measurement 
and analysis. Organizations in our experience have reported difficulties with the manual collection of data, often including significant challenges to maintaining the quality and integrity of the data that are collected. The automation questions refer to a growing list of different types of automation, ranging from workflow automation to statistical analysis packages. The results are summarized in Figure 27. Reliance on spreadsheets, automated data collection, and management software was relatively extensive; however, the same is not yet so for statistical packages, workflow automation, or report preparation software.

The reported use of methods to ensure data quality and integrity that are summarized in Figure 28 suggest that these high maturity organizations pay reasonably close attention to these important matters. Still, the proportions of frequent use drop off considerably to the right side of the Pareto distribution. There is room for continuous improvement here as well.

Moreover, as shown in Section 6, both of these question sets are moderately strongly related statistically with the respondents' reports of the value added by their organizations' process performance modeling. The results will be used to help guide future SEI training and coaching. Other current work at the SEI focuses on these issues as well [Kasunic 2008], and we may focus on the topic in more detail in future state of the practice surveys.

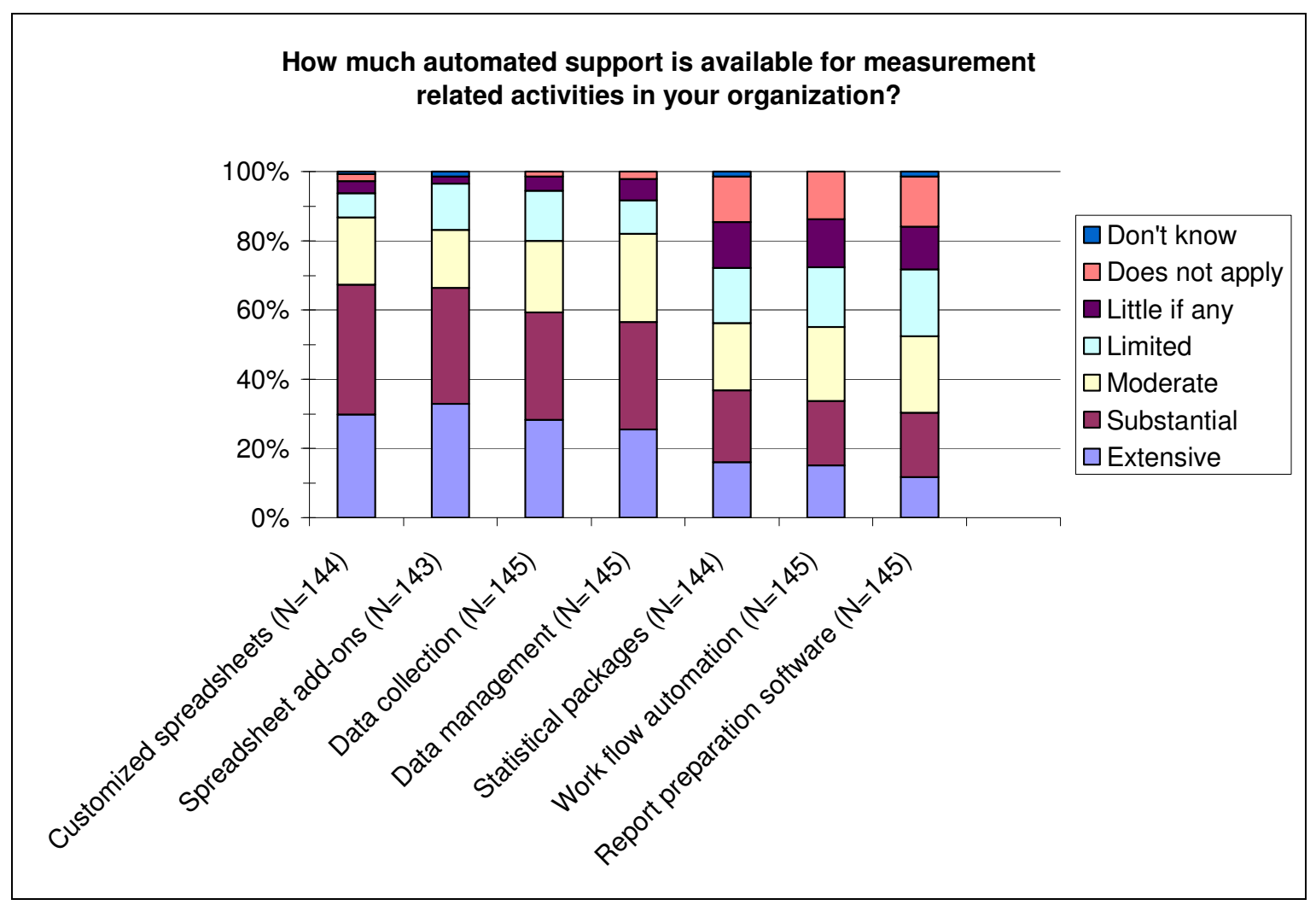

Figure 27: Use of automated support for measurement and analysis activities 


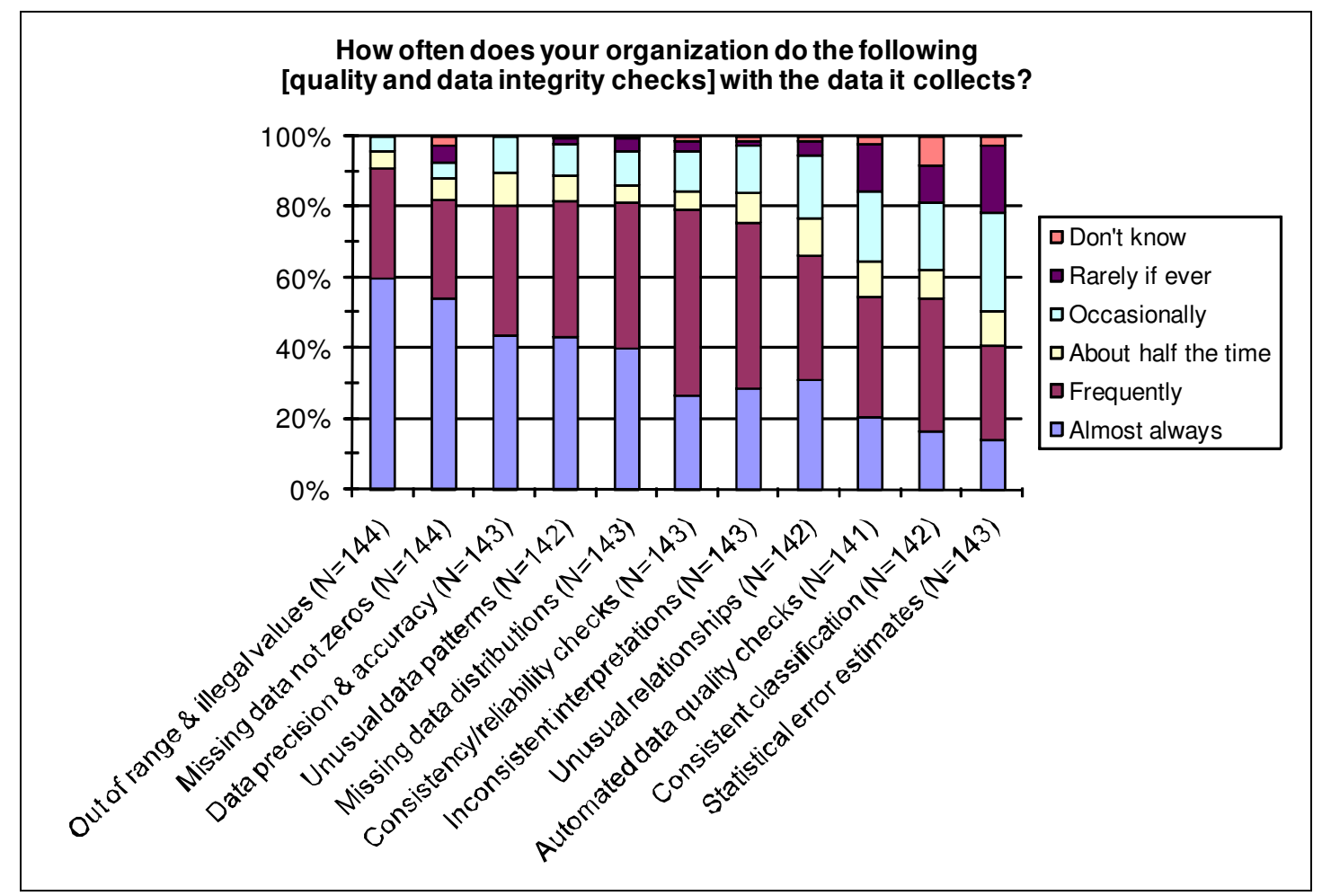

Figure 28: Use of methods to ensure data quality and integrity 


\section{Baselining High Maturity Organizational Context}

The survey respondents' reports about the extent to which their organizational contexts differed are described here. These include management support, staffing, and resources; differences in the technical challenges faced by their projects; and other barriers and facilitators to successful use of process performance modeling.

\subsection{Management Support, Staffing, and Resources}

The importance of management support for process improvement is widely acknowledged. There is empirical evidence that the existence of such support can increase the likelihood of the success of measurement and analysis programs in general [Goldenson 1999, Goldenson 2000, Gopal 2002].

In order for management to provide truly informed support for the creation and use of process performance baselines and models, they must understand the results presented. The answers to such a question are summarized in Figure 29. As shown in the figure, the modal category (46 percent) is "moderately well." That and the fact that over 10 percent more of the respondents reported less understanding by management users of their model results provides confidence on face validity grounds that these respondents are replying candidly.

However, note that over 40 percent of the respondents reported that managers in their organizations understood the model results very well or even extremely well. As described in Section 6, answers to this question varied consistently with the respondents' independently recorded answers about the effects of using their organizations' process performance models. Answers to this and similar questions will be profiled across time to evaluate the growth in confidence that management users have in understanding the results of process performance baselines and models.

The availability of qualified and well-prepared individuals to do process performance modeling is another important measure of management support. As shown in Figure 30, most of the respondents said that such individuals are available when needed on at least a frequent basis; however, over thirty percent experience difficulty in obtaining such expertise. 


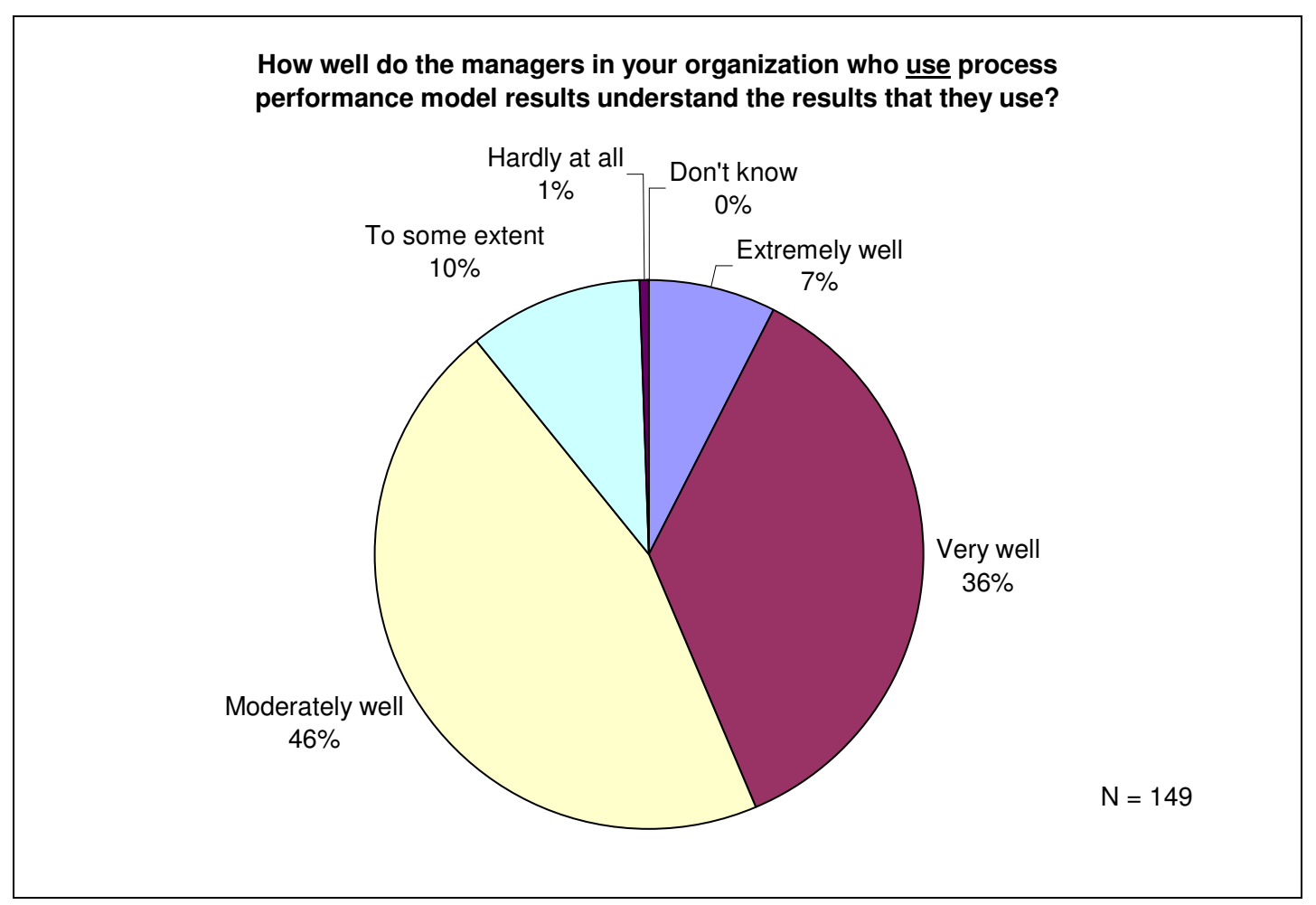

Figure 29: Level of understanding of process performance model results attributed to managers

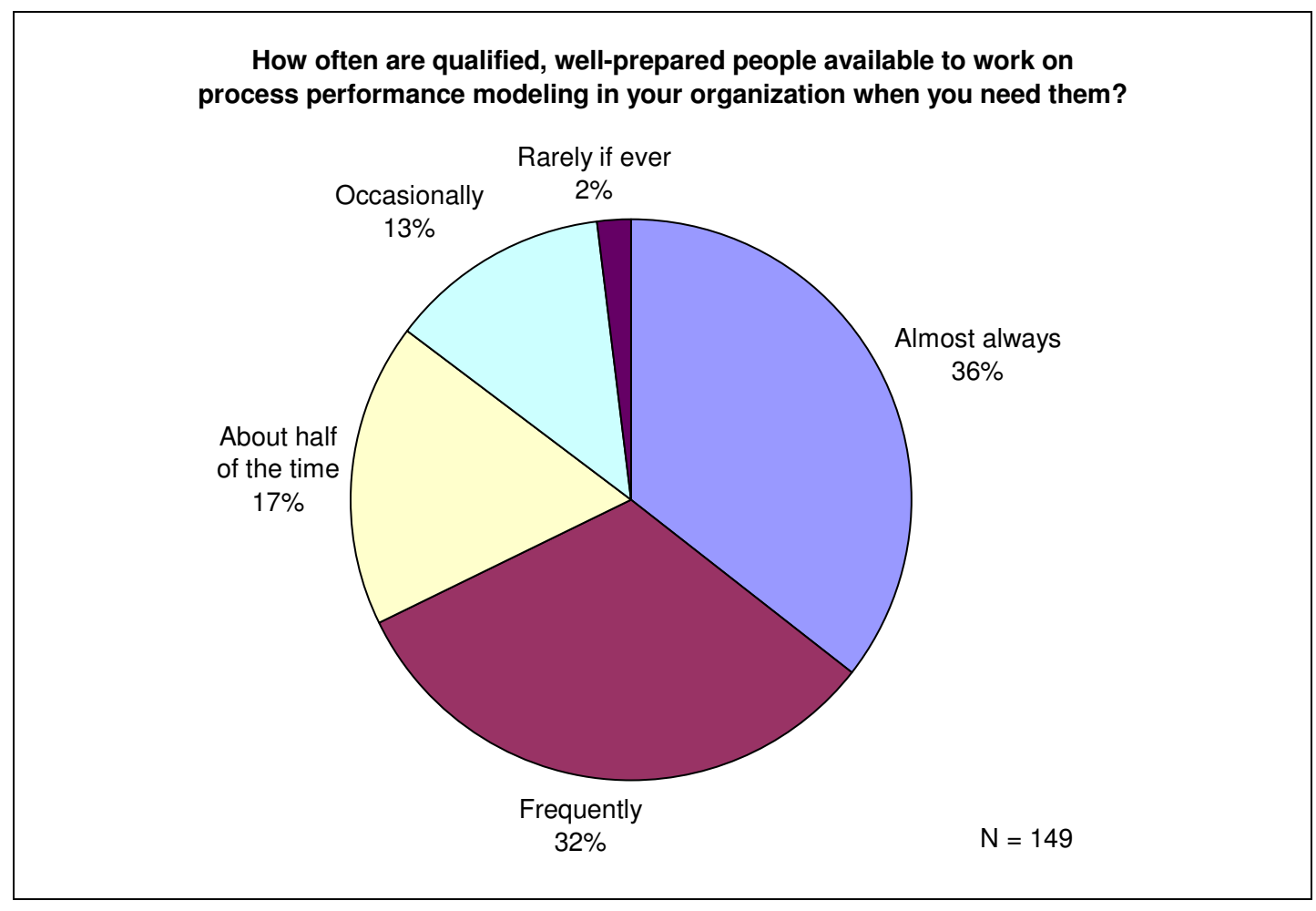

Figure 30: Availability of qualified process performance modeling personnel

We also asked a question in this context about how measurement and analysis is staffed in the survey respondents' organizations. The results are summarized in Figure 31. The bulk of these respondents 
said that their organizations relied on organization-wide groups or corporate support groups such as engineering process, quality assurance, or measurement groups. However, there are discrepancies between these results and those from other SEI surveys. Results from the SEI's 2007 general population state of the measurement and analysis practice survey found that higher maturity organizations were more likely to rely on staff from projects and similar organizational units throughout their organizations [Goldenson 2007b]. Such a result is consistent with the existence of widespread measurement expertise throughout such organizations.

It is possible that the respondents in the current survey answered the question from a different perspective since they knew that they were chosen because of their high maturity status. However, unpublished results from the 2008 SEI general population survey are similar to the high maturity results shown here. Sampling bias may be a factor, but the question wording itself also needs to be made clearer in future series. Since there is some question about the generalizability of these results, relationships with the respondents' reports about the overall value of their process performance modeling efforts are not shown in this report.

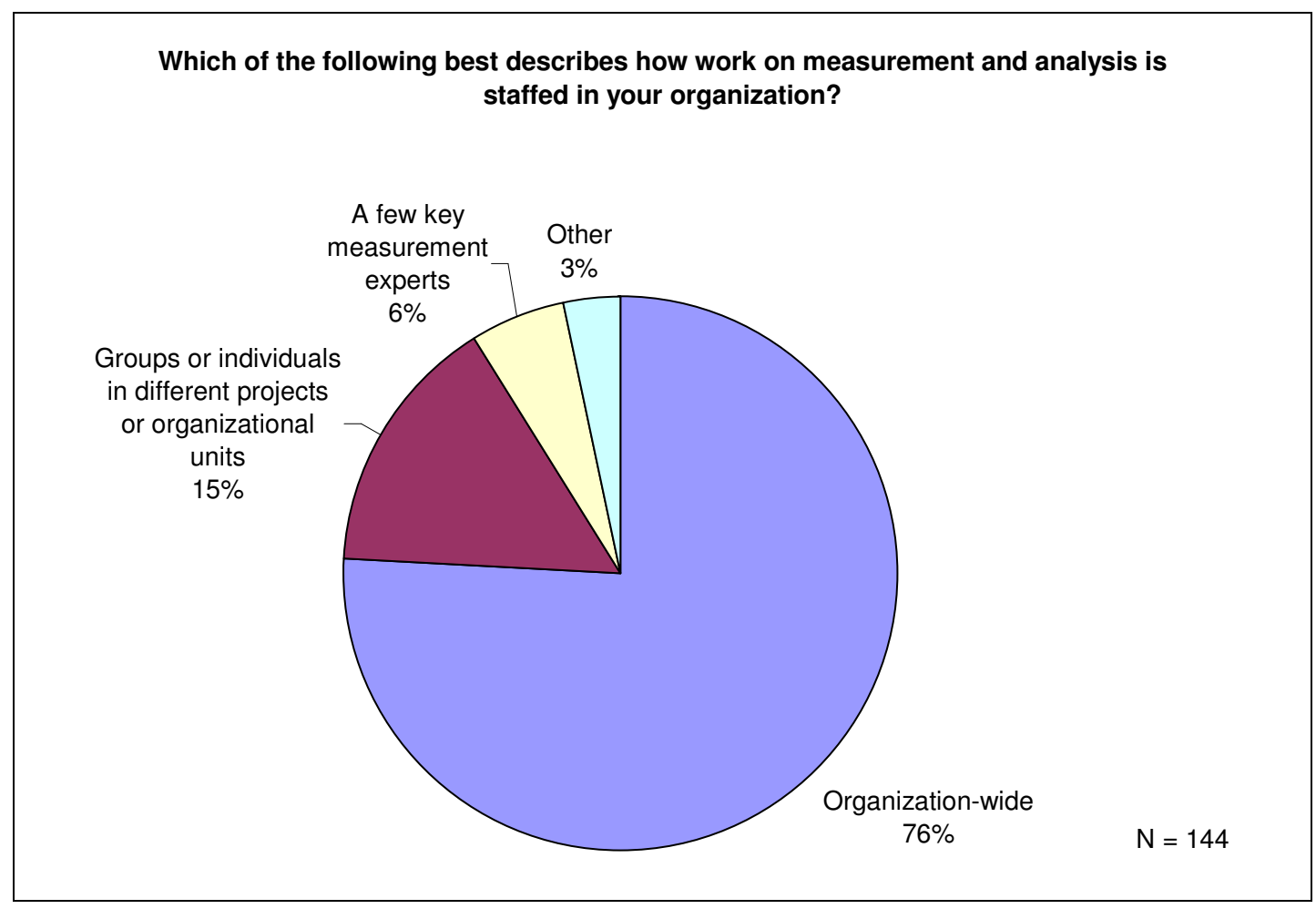

Figure 31: Staffing of measurement and analysis in responding organizations

We also asked the survey respondents a short series of questions about how well the builders and maintainers of their process performance models understand the CMMI definitions and concepts surrounding process performance baselines and models. Notice in Figure 32 that over 80 percent of the respondents said that their model builders and maintainers understood the CMMI definitions of process performance baselines and models very well or better. However, their perceptions of the modelers' understanding of the circumstances under which such baselines and models were likely to be useful are somewhat lower. 
Knowing that a number of misconceptions about baselines and models exist in the community, these questions serve to evaluate the current self-perception of a knowledge or training gap. Admittedly, this question series convolutes the recognition of knowledge with the unrecognized lack of knowledge. Hopefully profiling the answers to this question across time will reflect a growing confidence by the community in its understanding of process performance baselines and models.

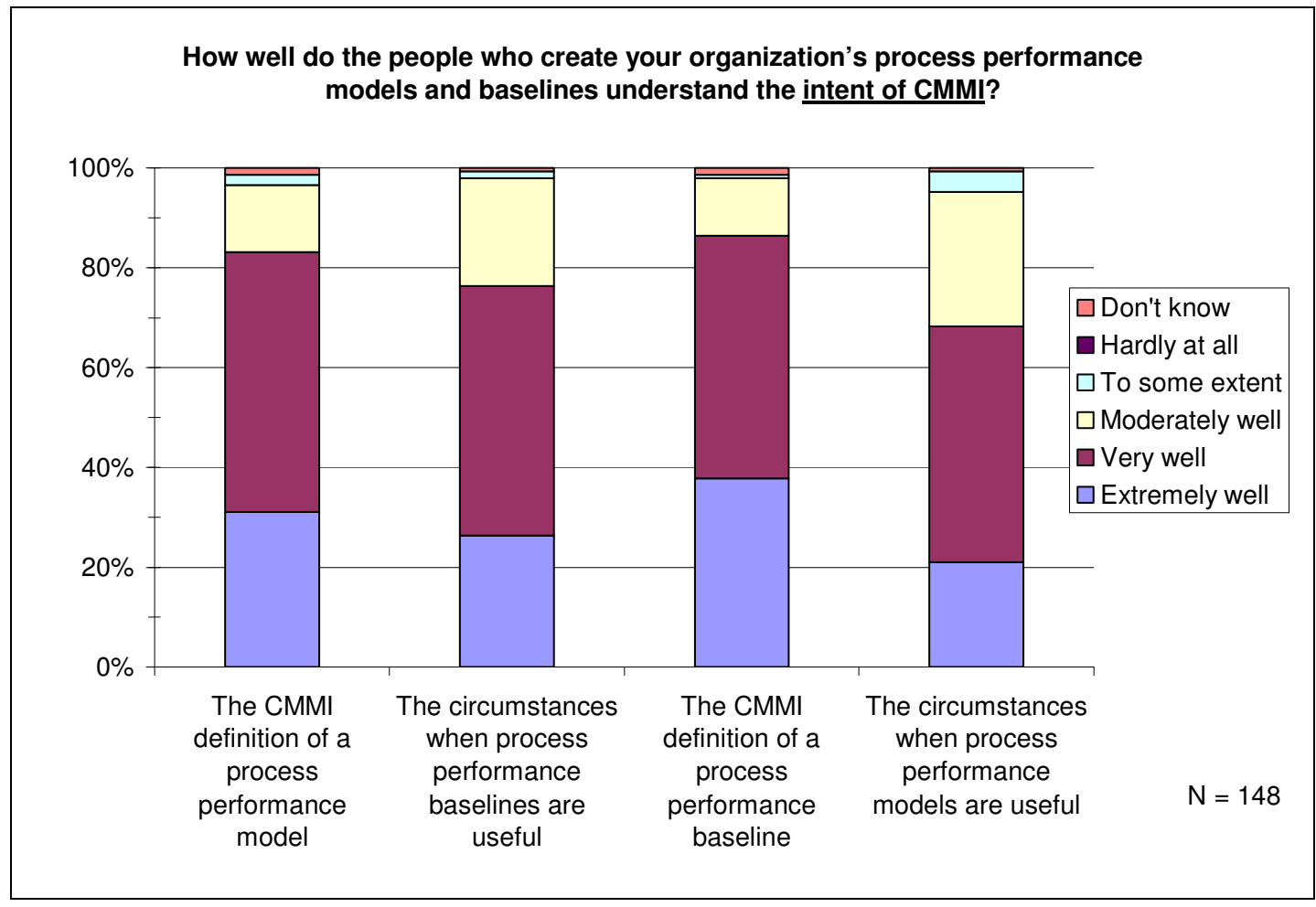

Figure 32: Level of understanding of CMMI intent attributed to modelers

To what extent does the mixed use of incentives matter for the outcomes of quality, performance, or process improvements? While differences in accepted labor practices by domain and industry will affect the results, can significant incentives and rewards play a vital role in the adoption and use of measurement and modeling that dramatically improve business results? To address such issues, we asked a series of questions meant to provide insight into the promotional or financial incentives that are tied to the deployment and adoption of measurement and analysis in the respondents' organizations. The results are summarized in Figure 33. As shown in the figure, almost half of the survey respondents reported that no such incentives exist in their organizations; however, the others did report the use of such incentives for one or more of their employee groups. Given the loose coupling of this question series to process performance modeling per se, we have not addressed this topic further in this report. However, we do intend to track such questions over time and in more detail elsewhere. 


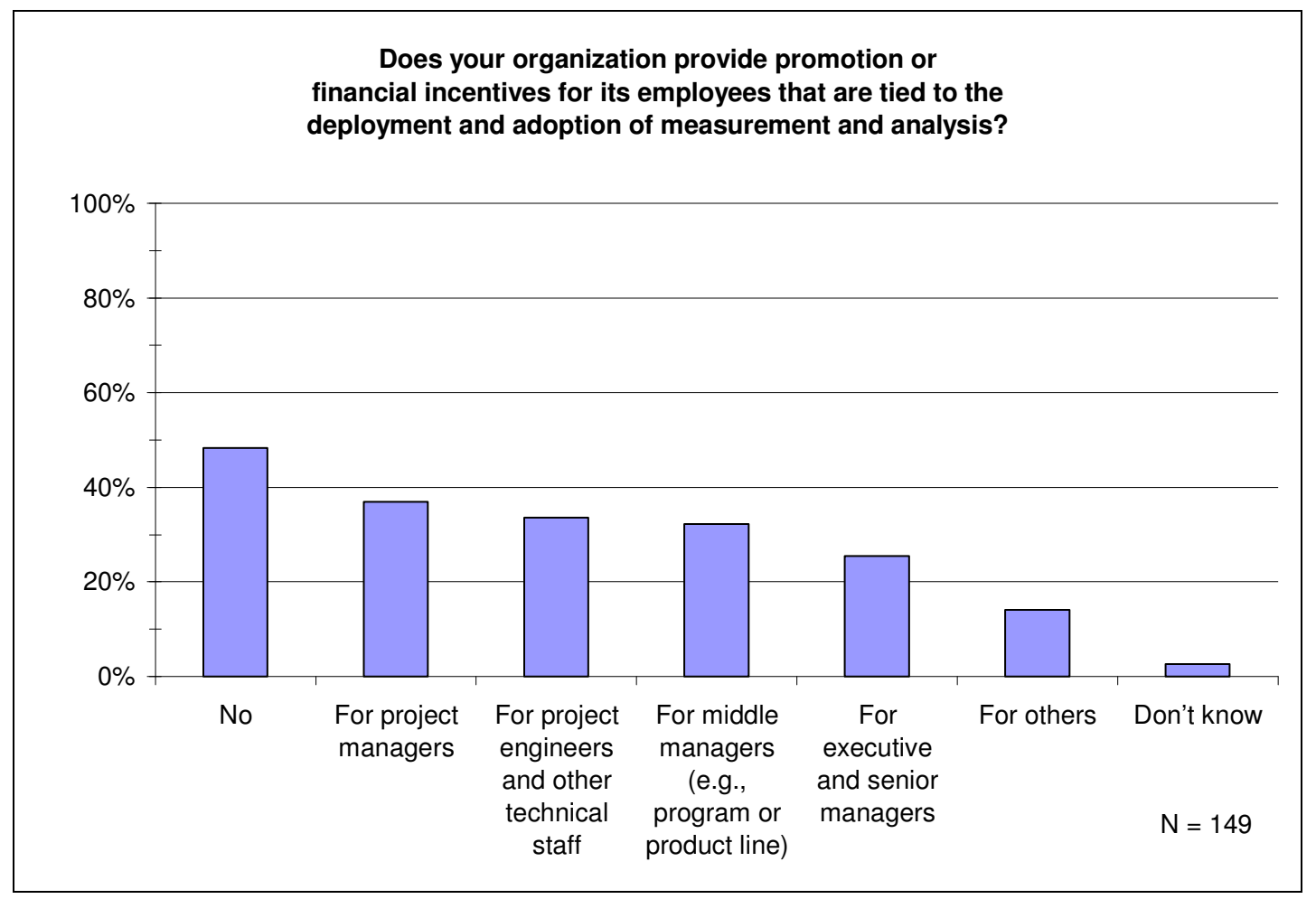

Figure 33: Promotional incentives for measurement and analysis in responding organizations

\subsection{Technical Challenge}

This set of questions asked the respondents about a series of technical challenges that may have been faced by the projects and product teams in their organizations. The individual questions focused most heavily on product characteristics, although some relate more directly to organizational context. The concern is that different degrees of technical challenge can warrant different degrees of sophistication in measurement, analytic methods, and predictive modeling. Previous work has suggested that such challenges can directly affect the chances of project success independently of project capability [Elm 2008, Ferguson 2007].

As shown in Figure 34, issues with respect to extensive interoperability, large amounts of development effort, and quality constraints presented the greatest difficulty from the respondents' perspectives. However, as will be shown in Section 6, the overall level of technical challenge reported by these respondents remained relatively low. 


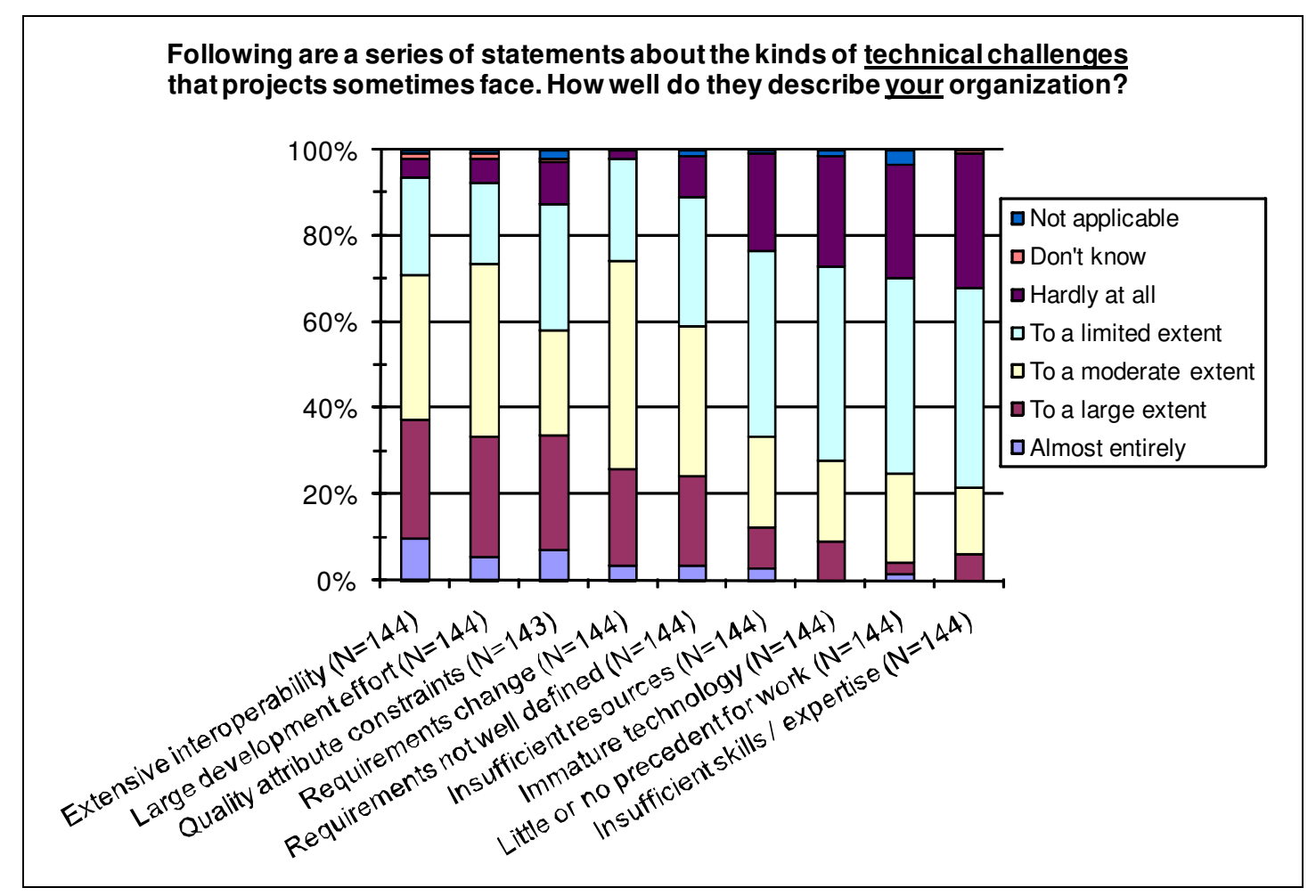

Figure 34: Project technical challenge in responding organizations

\subsection{Barriers and Facilitators}

The survey questionnaire included a battery of questions about the extent to which responding organizations experienced several common situations in doing their process performance modeling. Some of the questions were stated negatively as management and analytic barriers or obstacles to doing such work. Others were stated positively as management and analytic facilitators or enablers of successful baselining and modeling efforts. The results may serve to forewarn organizations as well as help guide and prioritize the process performance coaching provided by the SEI and others. Composite variables based on these same questions were used in Section 6 to help explain the variation in the degree of business benefit attributed to the use of the participating organizations' process performance models. ${ }^{9}$

Notice in Figure 35 that almost 50 percent of the survey respondents reported that their organizations have experienced difficulty to at least a moderate extent in doing process performance modeling because of the time that it takes to accumulate enough historical data. ${ }^{10}$ A comparable number of the respondents reported that their organizations experienced difficulty because their managers were less willing to fund new work when the outcome was uncertain.

$9 \quad$ In addition to the distinction shown here between barriers and facilitators, the individual items also were grouped separately as aspects of management support and use of exemplary modeling approaches for the analyses in Section 6.

10 While this can present considerable difficulty, modeling and simulation can provide useful solutions in the absence of such information. 


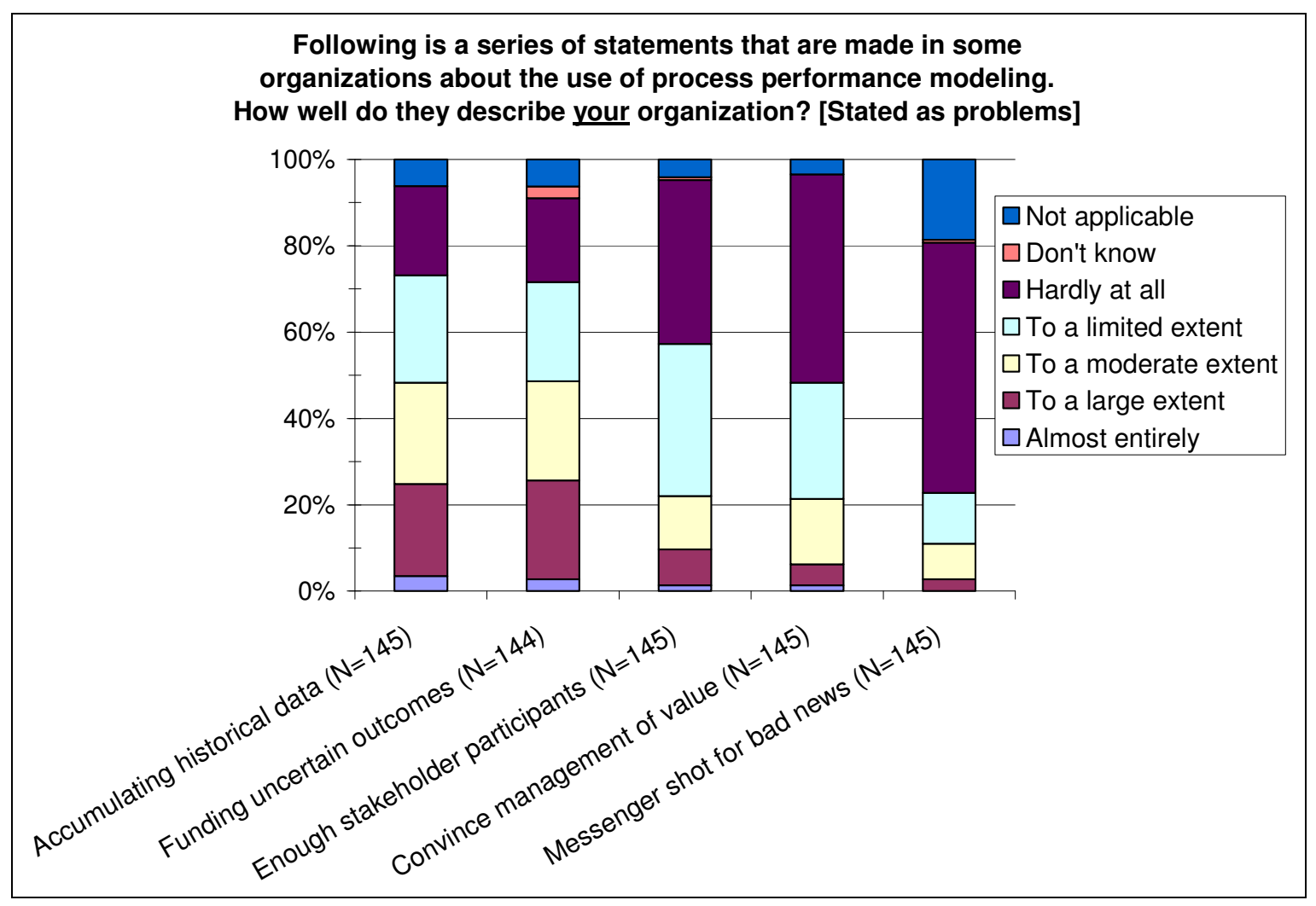

Figure 35: Management \& analytic barriers to effective measurement and analysis

Figure 36 shows comparable results for facilitators of successful process performance modeling. On the positive side, over 70 percent of the respondents reported that their organizations have been made better because their managers wanted to know when things were off track. However, none of the other situations were widely identified by the respondents as management and analytic facilitators or enablers of successful baselining and modeling efforts in their organizations.

A second battery of questions asked about major obstacles that may have inhibited progress during the respondents' organizations' journeys to high maturity. As shown in Figure 37, several of these potential difficulties were experienced by 20 percent or more of the organizations, and barely 20 percent reported not having experienced any of them. Many of the questions in this series overlap with others in the survey, and others are only loosely coupled to process performance modeling per se. Hence we have not included them in the analysis in Section 6. However they may prove to be worth clarifying and tracking over time. 


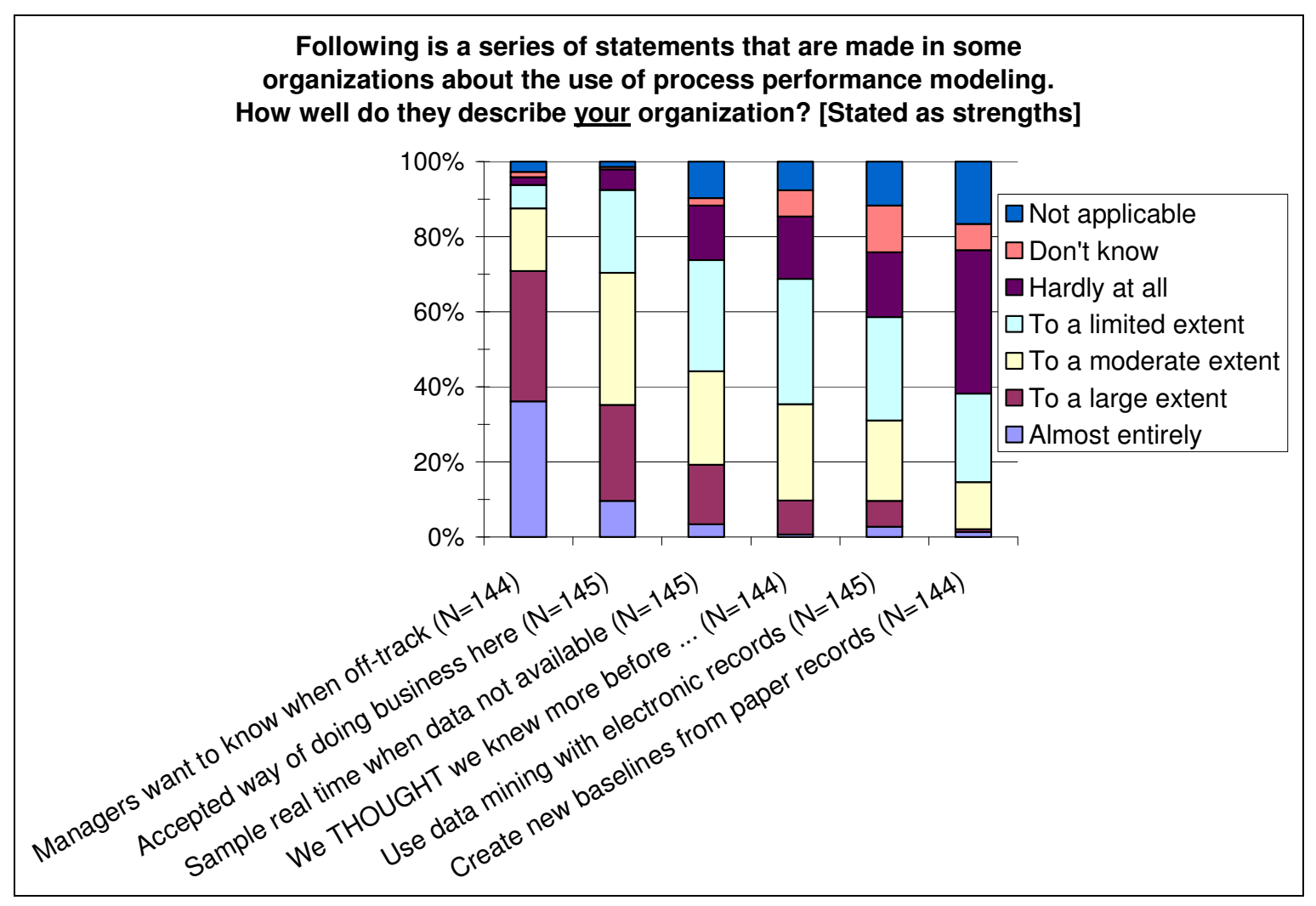

Figure 36: Management \& analytic facilitators of effective measurement and analysis

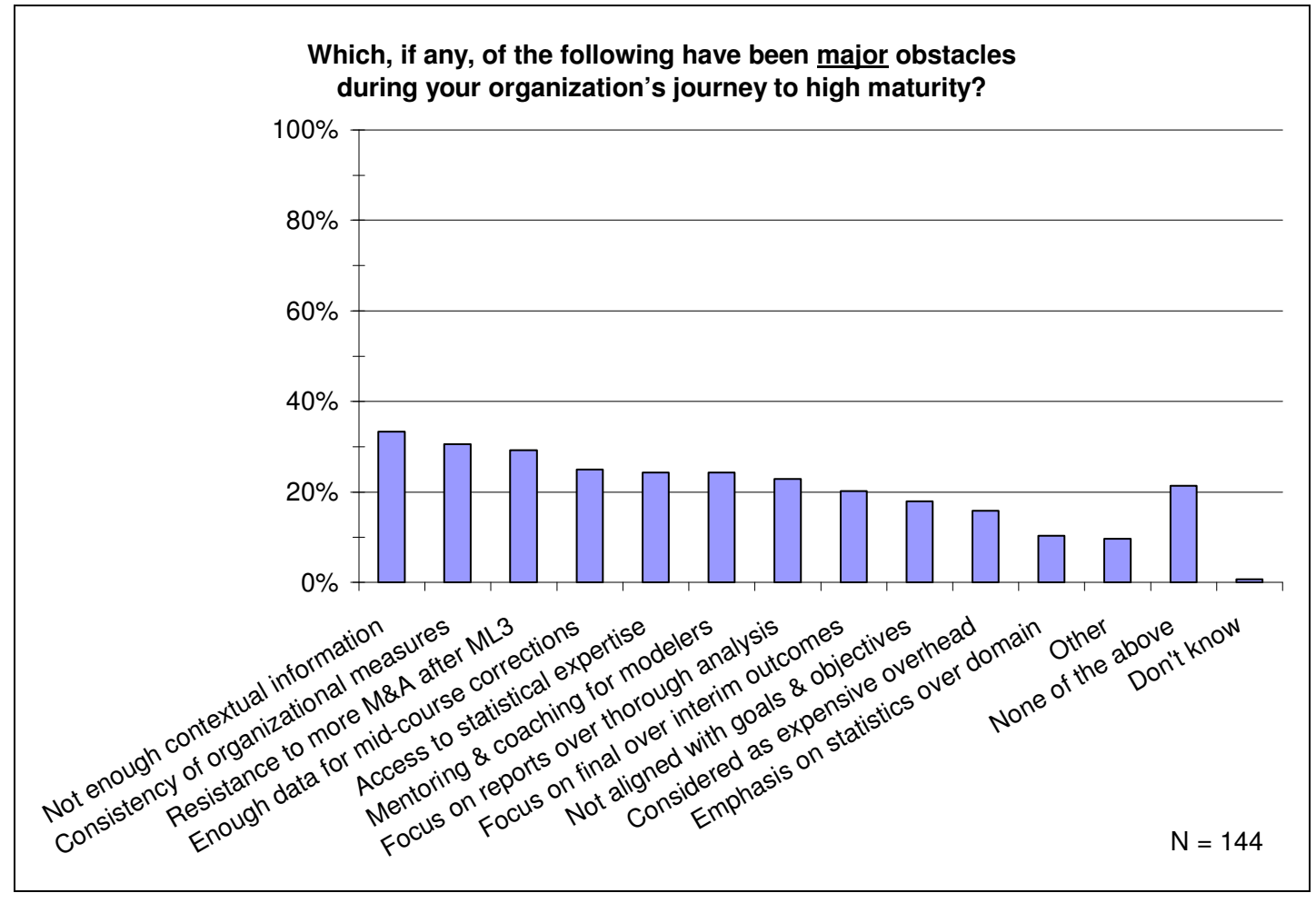

Figure 37: Major obstacles to achieving high maturity 


\section{Explaining Variability in Organizational Effects of Process Performance Modeling}

Results describing the degree to which the respondents' reports about the value of process performance modeling to their organizations varied as a function of their answers to the survey questions about the various process and organizational contextual factors discussed earlier in this report. Those results are described in this section. As noted in Section 3, we use the question about the overall effect attributed by the respondents to their organizations' modeling efforts as the "big Y" factor here. The questions about specific effects of the modeling are not all necessarily equally pertinent to all of the surveyed organizations; however, similar results to those based on the overall question also exist using a composite measure of the specific effects. Some of the other questions that are used as $\mathrm{x}$ variables also are used or discussed here as interim y variables.

\subsection{Analysis Methods Used in this Report}

\section{Summarizing the results}

Most of the results described in this section summarize relationships between two variables. ${ }^{11}$ They are described using a graphical mosaic representation that shows in an intuitive visual manner the extent to which the survey respondents' answers vary in a consistent manner. An example can be seen in Figure 38. The data for this example come from the 2007 SEI state of measurement and analysis survey [Goldenson 2008b].

Notice that the maturity level values are displayed along the horizontal $\mathrm{x}$ axis of the mosaic and the variable name is displayed below it. Labels for the respondents' answer to a question about how frequently measurement and analysis activities took place in their organizations are displayed to the right of the mosaic on the vertical y axis; the variable name used in the statistical software is shown on the left side of the mosaic. The proportions of responses about frequency of measurement use for the organizations at each maturity level are shown in separate columns of the mosaic, where each value of the y-variable is represented in a separate mosaic tile. The percentages represented by - 0 to 1 also appear to the left of the full mosaic and correspond to the heights of the tiles. A separate, single column mosaic to the right shows the total of all the responses about frequency of use, regardless of maturity level. It also serves as a legend that visually identifies each value of the ordinal $y$ variable in the corresponding $x$ variable columns. Note that the value labels for the $y$-variable are aligned with the total distribution in the single column mosaic that serves as a legend for the comparison with the $\mathrm{x}$-variable in the full mosaic.

As shown in the figure, the organizations at maturity level one were much less likely to report using measurement and analysis on a routine basis, although over a quarter of them do claimed to do so. Not surprisingly, the proportions of organizations that reported being routine measurement users increase in a stair-step pattern along with increasing maturity level, with the biggest difference between level one and two. Notice also that the width of each column varies in proportion to the number of responding organizations at each maturity level. This can provide a quick sense of how evenly or unevenly the survey responses are distributed. In this instance there are quite a few more organizations at maturity level one. (Maturity levels four and five are combined since almost all of these organizations say they are at level 5.) 


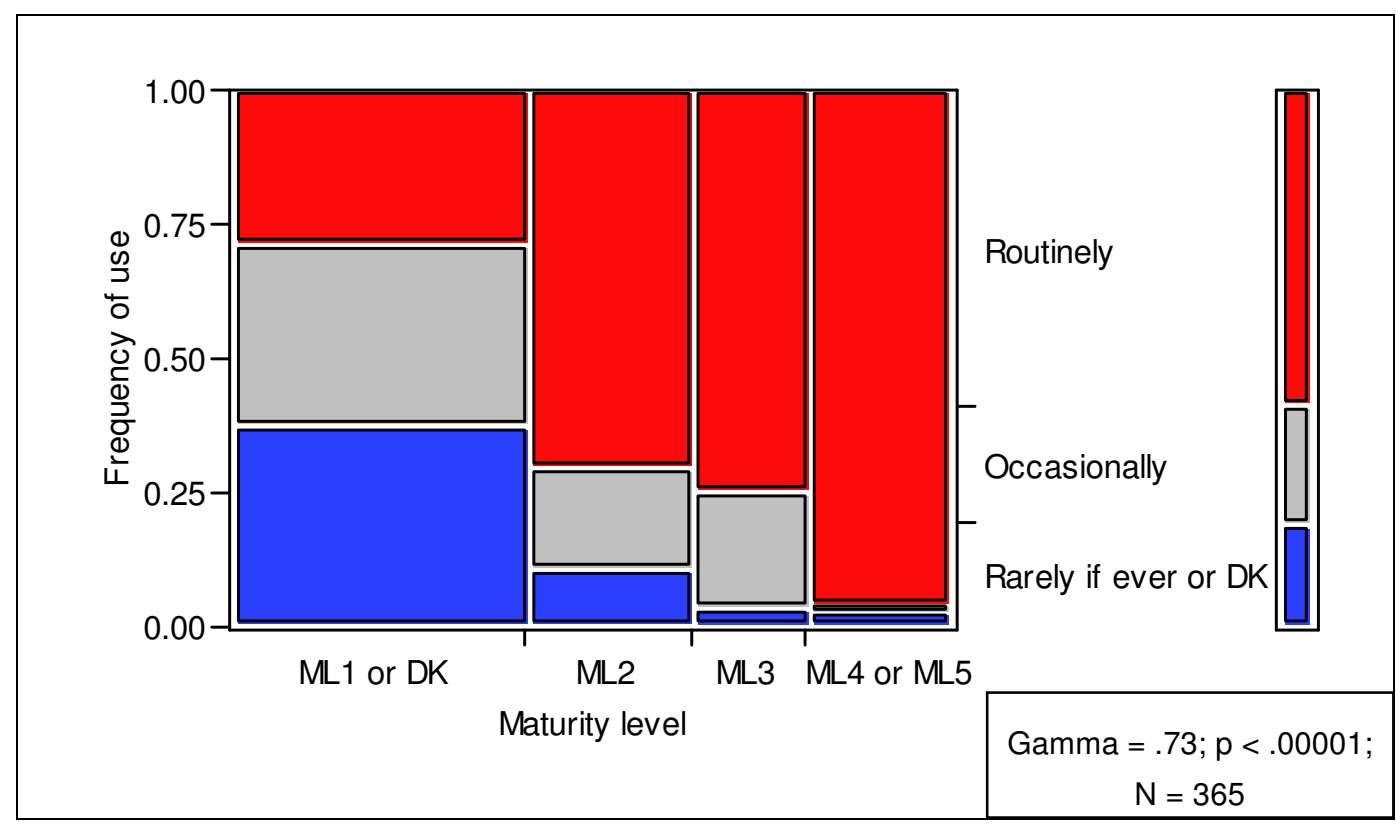

Figure 38: Example: relationship between maturity level and frequency of use of measurement and analysis, from 2007 state of the practice survey

The overall strength of the relationship between the two variables can be described by the value of the gamma statistic. Goodman and Kruskal's gamma is an ordinal measure of association that is appropriate for ordered categorical measures such as those that are used in this report. ${ }^{12}$ It is symmetric, which means that its value will be the same regardless of which variable is considered to be an $\mathrm{x}$ factor or a $\mathrm{y}$ factor. The value of gamma represents the difference between concordant and discordant pairs of values on two variables. It is computed as the excess of concordant pairs as a percentage of all pairs, ignoring ties. The notion of concordance for any pair of values means that as the $\mathrm{x}$ value increases its corresponding y value also must increase (or decrease for negative relationships). Gamma is based on weak monotonicity (i.e., ignoring ties means that the y value can remain the same rather than increase).

Similar to many other correlation coefficients and measures of association, gamma varies from -1 to 1 . Values of 0 indicate statistical independence (no relationship) and values of 1 indicate perfect relationships (-1 is a perfect negative relationship, where values on one variable decrease while the other increases). Gamma is a proportional reduction in error (PRE) statistic with an intuitive interpretation. Conceptually similar to Pearson's $r^{2}$ for interval or ratio data, the value of gamma is simply the proportion of paired comparisons where knowing the rank order of one variable allows one to predict accurately the rank order of the other variable.

The $\mathrm{p}$ value in the figure is the result of a statistical test of the likelihood that a concordant relationship of gamma's magnitude could have occurred by chance alone. In this instance the chances that a gamma of .73 would occur simply by random chance is less than one in 100,000. The relationship is based on the number $(\mathrm{N})$ of survey respondents (365) who answered both questions. By convention, $\mathrm{p}$ values less than or equal to .05 are considered statistically significant.

12 A clear description may be found in Linton Freeman's now classic basic text [Freeman 1965]. 


\section{Composite measures}

Many of the relationships described in this report use composite measures that are based on combinations of several related component questions. The measure of emphasis on "healthy process performance model ingredients" shown in Figure 39 on page 38 is one such composite. It is based on a combination of the respondents' answers to the group of related questions described in Figure 15 on page 15 that asked about the extent to which their organizations' process performance models were used for various purposes. The possible answers to those questions include "extensive," "substantial," "moderate," "limited" and "little if any."13

Like most of the other composite measures used in this report, this one is a weighted, summed index of the respondents' answers to each of those questions. ${ }^{14}$ Much like a grade-point average, the answers are assigned, ordered numeric values that are simply added and then divided by the number of valid answers to the series of questions for each respondent. ${ }^{15}$ For example in Figure 39, "extensive" answers are scored as the value 5, "substantial" as 4, down to "little if any" as 1 . The index scores are then separated into the categories shown on the figures' $\mathrm{x}$ or $\mathrm{y}$ axes based on the distribution of response values.

The category cutting points are set based on the closeness to the component questions' response categories and ensuring that there are enough cases in each category for meaningful analysis. In Figure 39, the lowest category ("< Moderate") includes the composite scores with values less than 3 . The second category ("Moderate to < midway toward substantial") includes values that range from 3 to less than 3.5. The third category ("Toward but $<$ substantial") ranges from 3.5 to less than 4 . The highest category ("Substantial or better") includes composite scores that are equal to or greater than 4 .

There are several reasons to combine the component questions into single composite indices. Of course, reducing the number simplifies the analysis. While it may seem counterintuitive, combining the components also follows a basic reliability principle. There always is noise in survey data (actually in measured data of any kind). Respondents can be uncertain about their answers concerning the details of a specific question, or the lack of clarity in the wording of a specific question may cause different respondents to attribute different meanings to the same question. Other things being equal, the unreliability can be averaged out such that the composite index is more reliable than many or all of its individual components [Hill 2006, Coleman 1964, Guilford 1954].

\section{Interpretation}

Survey data such as these do not speak for themselves. Interpretation is necessary for all statistical analyses, including those based on controlled experiments. Perceptions and expectations often differ among survey respondents and maturity levels. Moreover, survey data such as these often are collected at a single point in time. It is difficult to separate cause and effect, which often are reciprocal over time. Proportions and strength of association sometimes vary in subtle ways. Still, the differences described

13 The very few answers of "don't know" and "does not apply" were excluded from the calculations. Answers to the "other" categories that sometimes exist in related question sets also were included in the composite indices.

14 In other instances, the composite variables were simply counts of the numbers of check boxes the respondents selected.

15 The weighting and summing are mathematically equivalent to an arithmetic mean; however, also much like a grade point average, the results simply are rank orders. Such indices are not interval- or ratio-level measures that can be added or multiplied meaningfully. 
in this report are consistent with what we think we know about process maturity and measurement practice.

\subsection{Process Performance Modeling and Analytic Methods}

As shown in Figure 39, there is a very strong empirical relationship between the value the respondents attribute to their organizations' process performance modeling efforts and the degree to which that modeling is consistent with the emphases on the healthy ingredients of such models. Those whose organizations placed greater emphasis on controllable and uncontrollable factors, detailed subprocesses and more broadly defined processes, modeling uncertainty and variability-along with important segmenting factors-were considerably more likely to attribute more value to their modeling efforts. Note also by the width of the columns that there was considerable room for improving such emphasis, which may add considerable business value.

A similar result is shown in Figure 40, which is based on the respondents' reports about the uses to which process performance models were put in their organizations. This relationship is somewhat stronger than the first one. Equally noteworthy, more organizations appear to have implemented their models consistently with the healthy ingredients, as seen by the column widths in the figure. They were considerably more likely to use their models to predict both interim and final process outcomes, identify the need for mid-course corrections, model expected variability of outcomes, and enable what-if analyses.

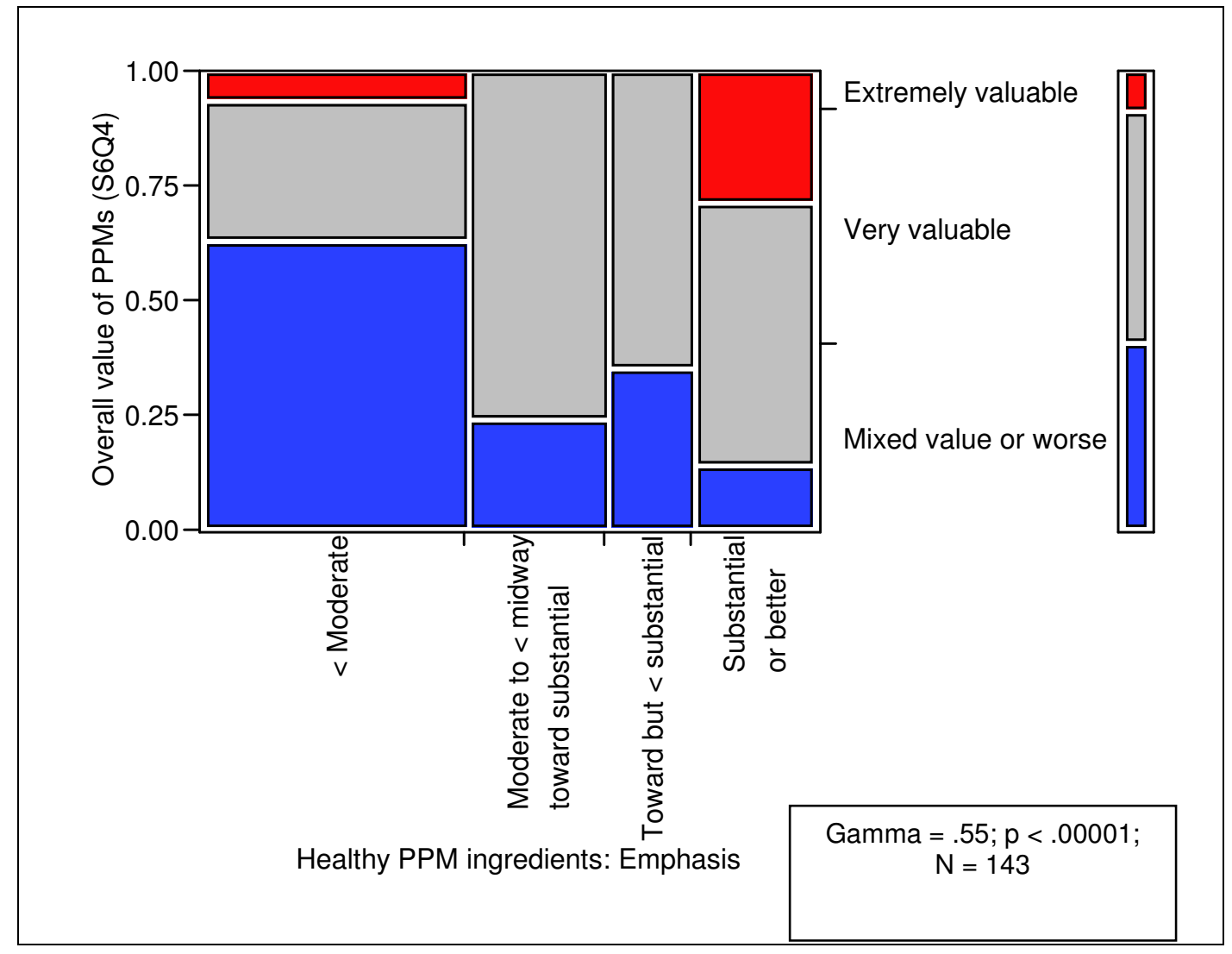

Figure 39: Relationship between emphasis on healthy process performance model ingredients and overall value attributed to process performance models 


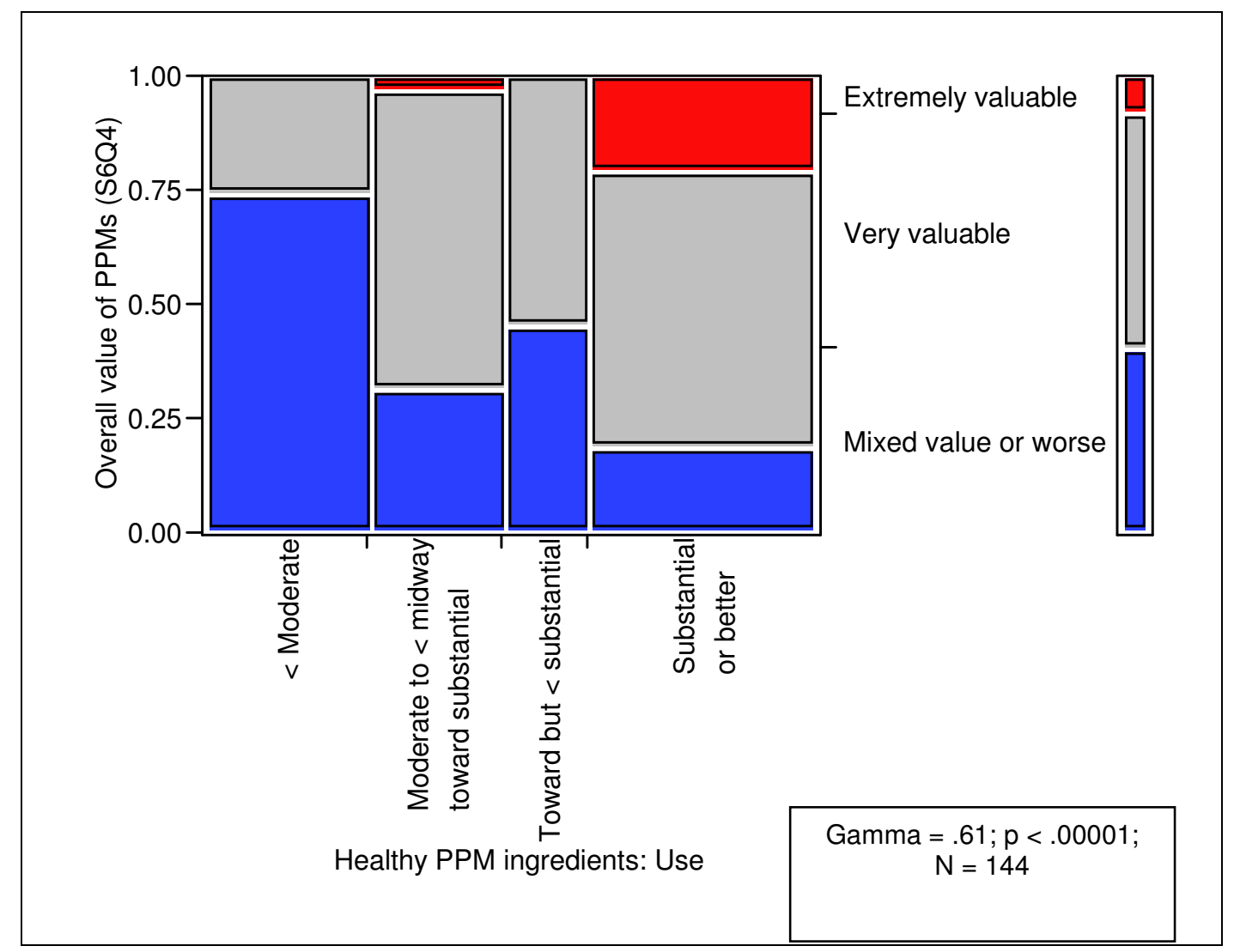

Figure 40: Relationship between use of healthy process performance model ingredients and overall value attributed to process performance models

A similarly strong relationship is shown in Figure 41. It shows the relationship between overall value attributed to process performance modeling and the diversity of models used to predict product quality and project performance. These include delivered defects, cost and schedule duration, accuracy of estimates, type and severity of defects, quality of services provided, customer satisfaction, product quality attributes, work product size, and measures of ROI or financial performance. As shown in the figure, organizations that maintained and used a richer and more varied suite of process performance models to predict product quality and project performance were much more likely to find value in their modeling than those that did not. ${ }^{16}$

16 A similar result exists for the diversity of models of interim performance outcomes (e.g., estimates at completion, escaped defects, and the other classes of measures described in Figure 20 on page 19); however, the relationship with diversity of models of interim performance outcomes as the $x$ factor is only moderately strong (gamma $=.36)$. These kinds of models appear to have less consistent value for the surveyed organizations. 


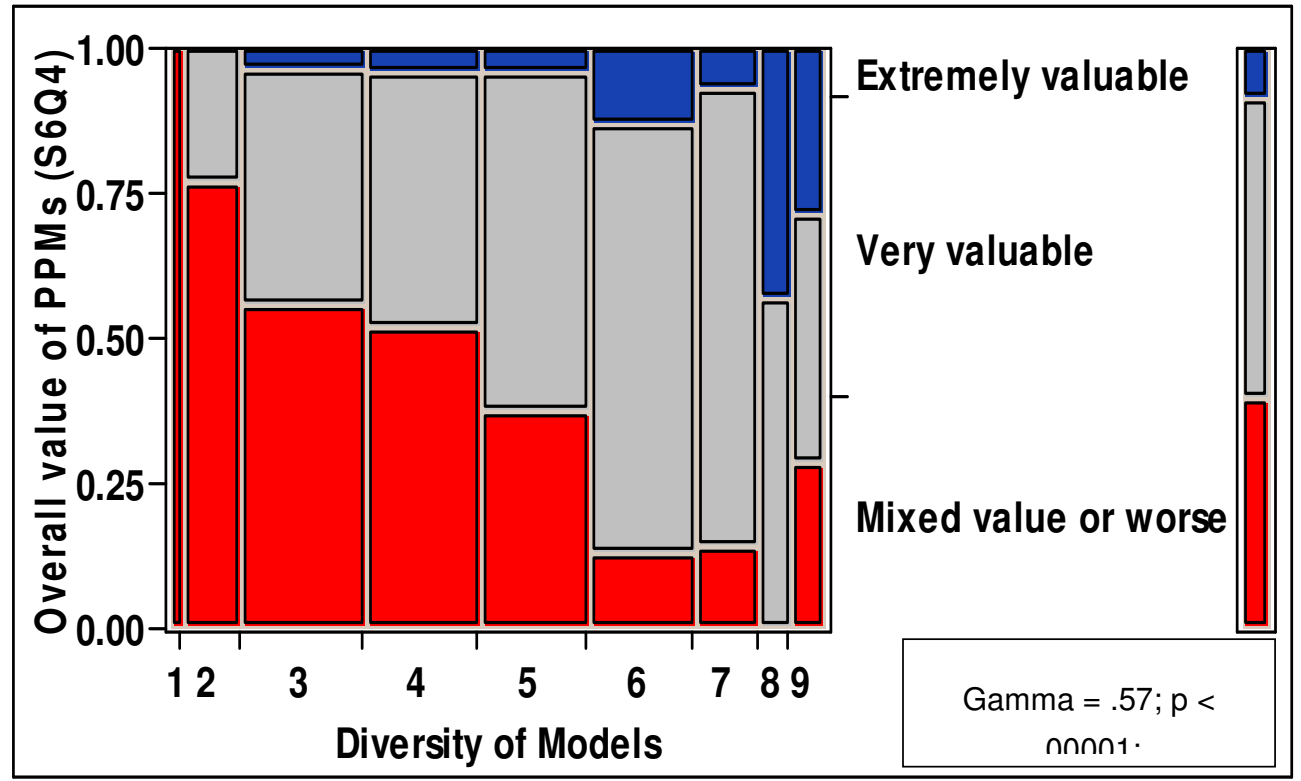

Figure 41: Relationship between diversity of models used (for predicting product quality and project performance) and overall value attributed to process performance models

As mentioned in Section 5.3, we grouped some of the questions about barriers and facilitators of process performance modeling into a composite measure of the use of exemplary modeling approaches. The following items were used to construct that measure:

- We have trouble doing process performance modeling because it takes too long to accumulate enough historical data. ${ }^{17}$

- We thought we knew what was driving process performance, but process performance modeling has taught us otherwise.

- We use data mining when similar but not identical electronic records exist.

- We do real time sampling of current processes when historical data are not available.

- We create our baselines from paper records for previously unmeasured attributes.

The relationship shown in Figure 42 is a strong one. Note that relatively few respondents said that such approaches described the situations in their organizations to even a moderate extent. We expect the relationship to become stronger as more organizations adopt such approaches over time and gain value from doing so.

17 This item was reverse scored for inclusion into the composite index since it is stated negatively as a barrier rather than a facilitator of process performance modeling. 


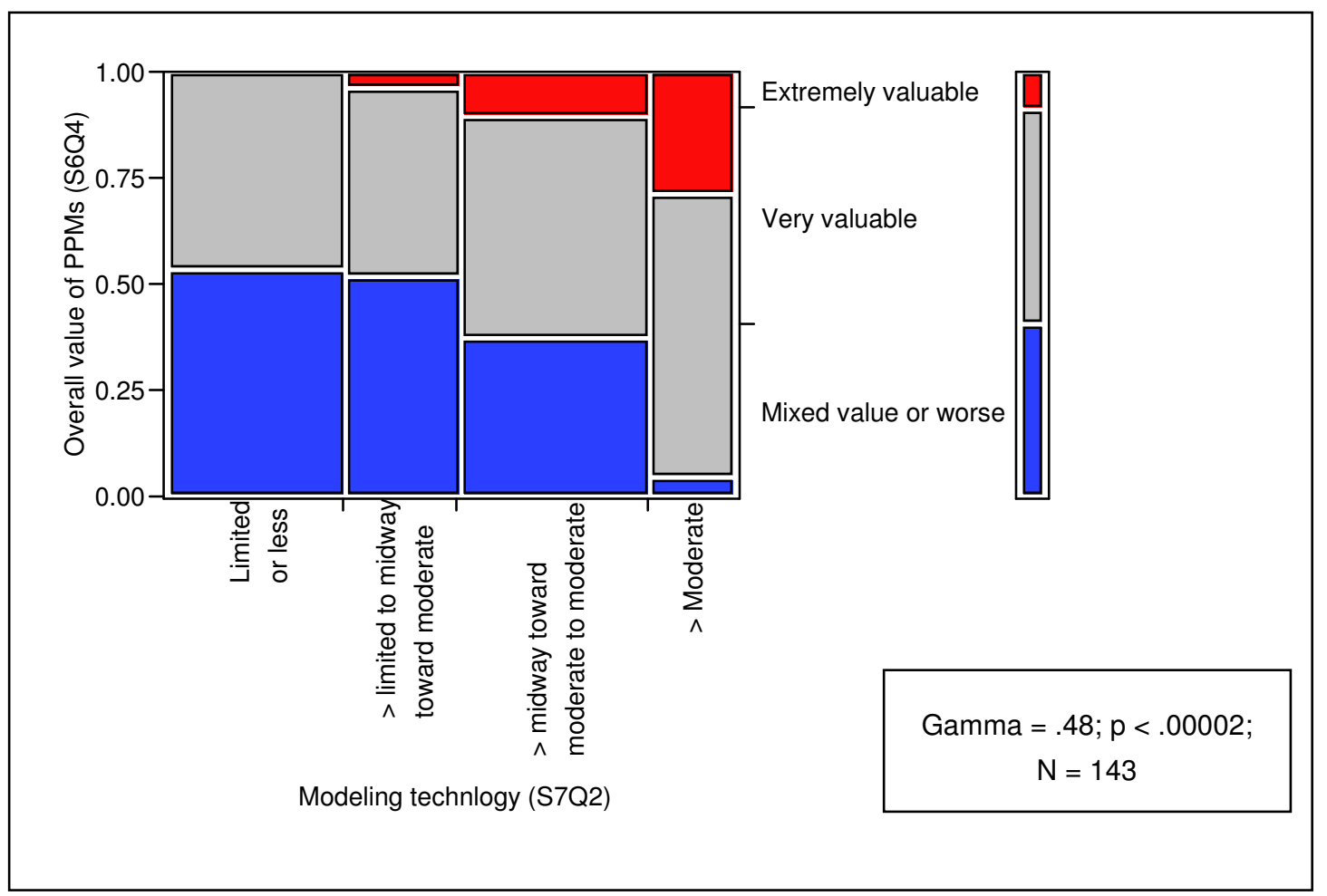

Figure 42: Relationship between use of exemplary modeling approaches and overall value attributed to process performance models

A richer set of analytic methods also appears to pay off for these organizations. Another quite strong relationship exists in Figure 43 between overall value attributed to process performance modeling and a composite measure based on the mix of different statistical methods used by these organizations. Recall that these include the following:

- regression analysis predicting continuous outcomes (e.g., bivariate or multivariate linear regression or non-linear regression)

- regression analysis predicting categorical outcomes (e.g., logistic regression or loglinear models)

- $\quad$ analysis of variance (e.g., ANOVA, ANCOVA, or MANOVA)

- $\quad$ attribute SPC charts (e.g., c, u, p, or np)

- $\quad$ individual point SPC charts (e.g., ImR or XmR)

- continuous SPC charts (e.g., XbarR or XbarS)

- design of experiments

Once again, the width of the leftmost column shows room for increasing the use of appropriate statistical methods. The greater likelihood of finding value as one moves to the right in the mosaic also suggests that improvement in an organization's statistical capabilities can be well worth the effort. ${ }^{18}$ 


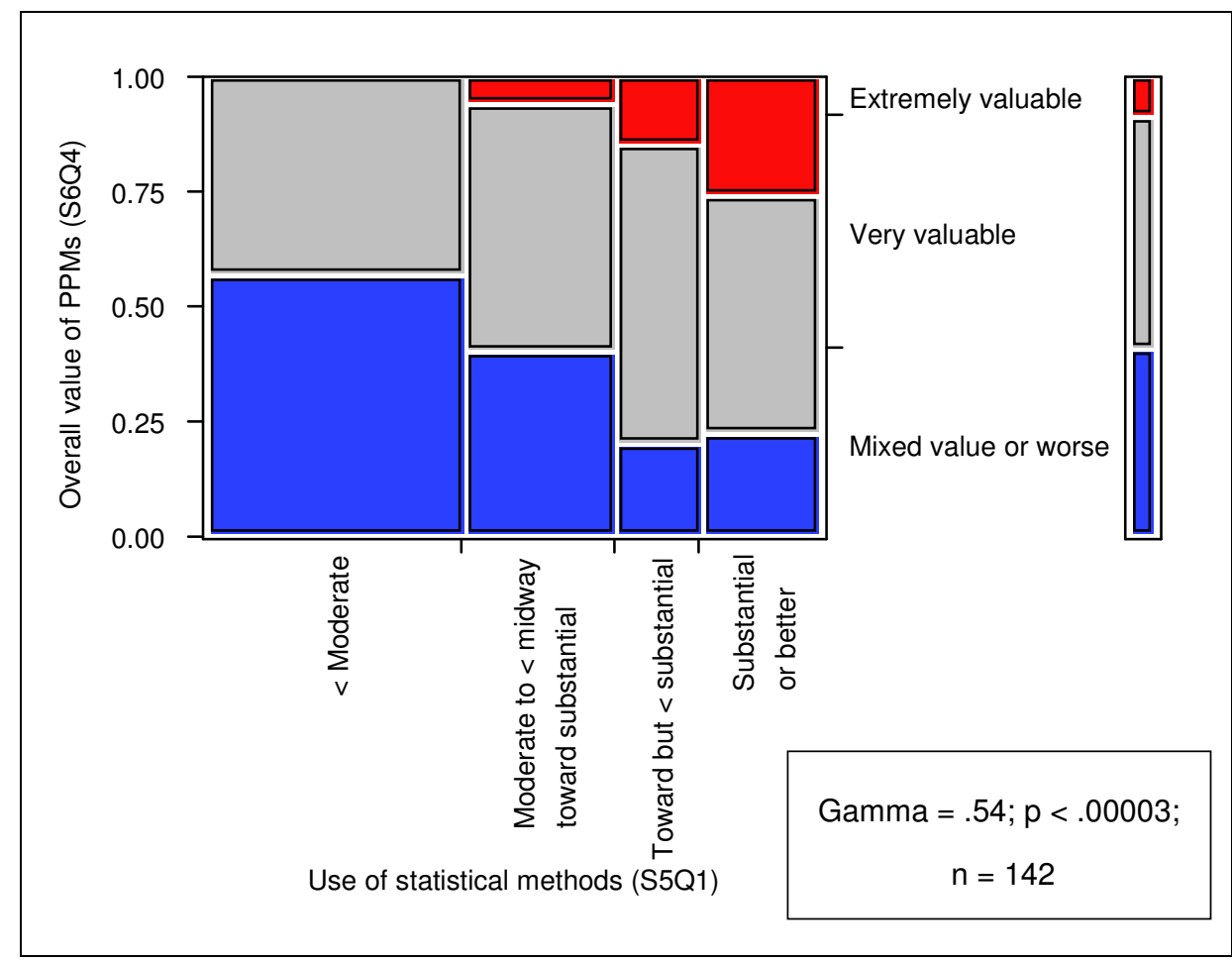

Figure 43: Relationship between use of statistical methods and overall value attributed to process performance models

There also is a moderately strong to strong relationship between use of optimization methods and value attributed to the organizations' process performance modeling. Recall that these include the following:

- Monte Carlo simulation

- discrete event simulation for process modeling

- Markov or Petri-net models

- $\quad$ probabilistic modeling

- neural networks

- optimization

As shown in Figure 44, the strength of the relationship may be attenuated because so few of the responding organizations used more than one of these methods. However, the result does suggest that more use of such analytic methods will prove to be worth the effort.

As shown in Figure 45 and Figure 46, comparably strong relationships also exist for the use of automated support for measurement and analysis and the use of data quality and integrity checks. As noted in Section 4.4 and can be seen in the width of the bars in Figure 45, there is considerable room for increasing automation in these organizations, but it is likely to pay off in better modeling outcomes. The $\mathrm{x}$ factor categories are much more evenly distributed in Figure 46, and all except those in the leftmost category are relatively likely to check their data for quality and integrity. Yet the overall pattern in the mosaic is quite consistent, with clear stair-step patterns of increases from left to right in the proportions who find their modeling efforts to be extremely valuable and decreases in those who report mixed value or worse. 


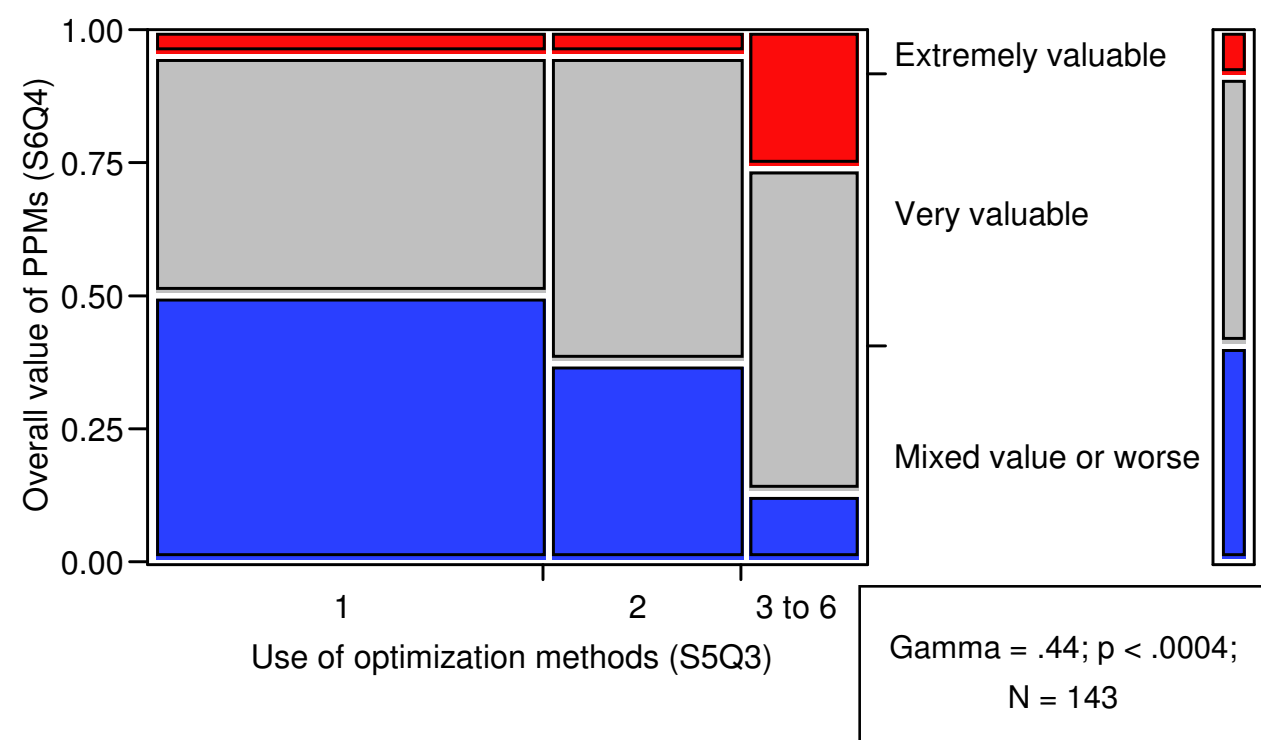

Figure 44: Relationship between use of optimization methods and overall value attributed to process performance models

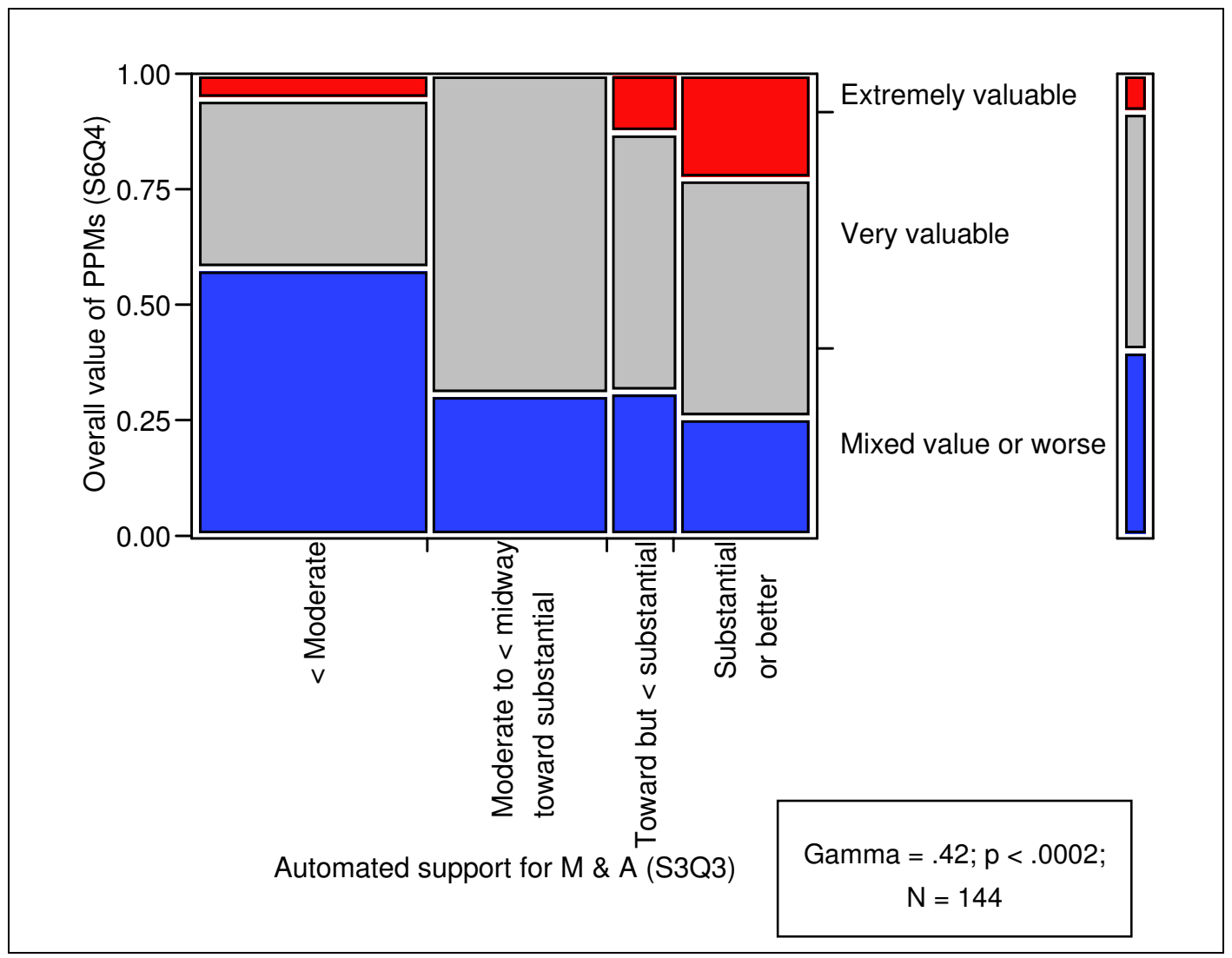

Figure 45: Relationship between automated support for measurement and analysis and overall value attributed to process performance models 


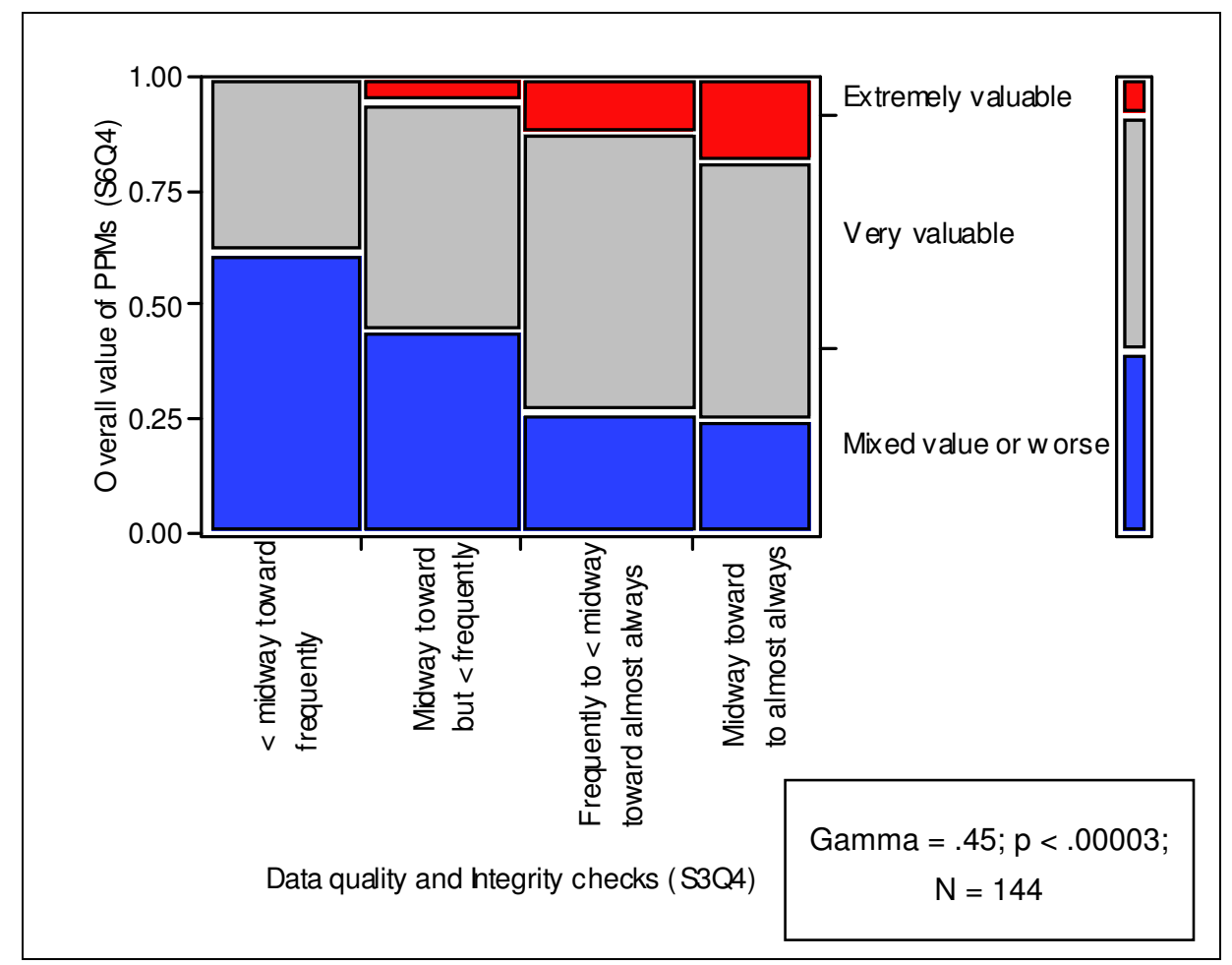

Figure 46: Relationship between data quality and integrity checks and overall value attributed to process performance models

Finally, notice the very strong relationship in Figure 47. The overall value attributed to process performance modeling varies quite predictably with the extent to which model results are used to inform decision making in status and milestone reviews. The extent to which the model results were used undoubtedly is a function of management support and the pertinence of the results as well as the quality of the models themselves and the analytic methods used to build them. Not surprisingly, this question turns out to be more closely related statistically to the performance outcomes of doing process performance modeling than any other $\mathrm{x}$ variable examined in this report. ${ }^{19}$ for other of our $x$ variables as well. Yet, as can be seen in Section 6.6, some of those who find relatively more overall value from their modeling activities also are consistently least likely to use them in their reviews. 


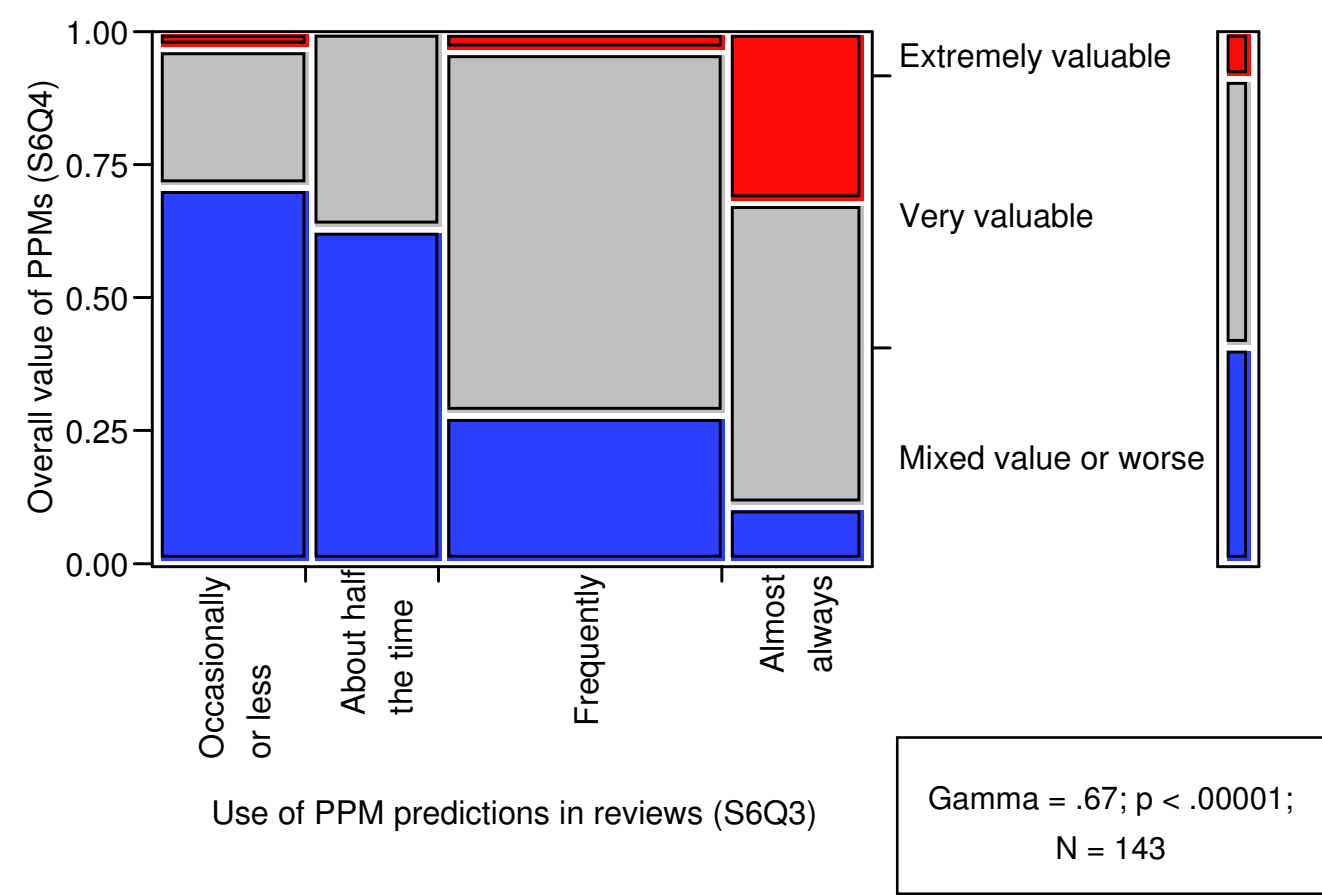

Figure 47: Relationship between use of process performance model predictions in status and milestone reviews and overall value attributed to process performance models

\subsection{Management Support}

As already discussed in Section 5, the importance of management support for process improvement is widely acknowledged in our field, and there is evidence that such support can increase the likelihood of the success of organizational measurement efforts [Goldenson 1999, Goldenson 2000, Gopal 2002].

We examine three aspects of such support in this section.

First of all, we asked the survey respondents how well the managers in their organizations who use process performance model results understood the results that they use. The relationship between their answers to the question and what they tell us elsewhere in the questionnaire about how useful process performance models have been for their organizations is shown in Figure 48. Their answers to the two questions co-vary quite consistently, and the relationship is a very strong one. 


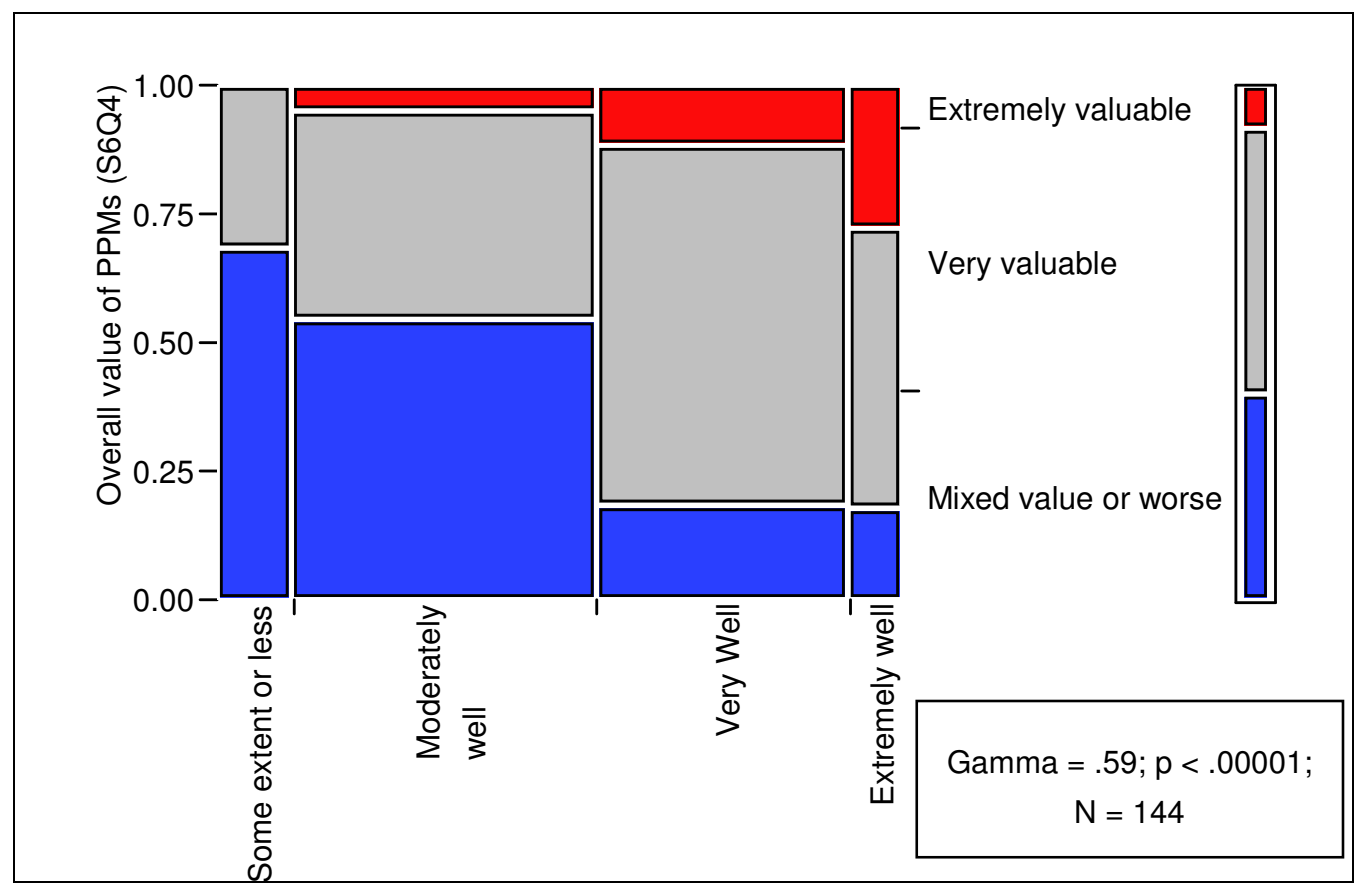

Figure 48: Relationship between managers' understanding of model results and overall value attributed to process performance models

Similar to the measure of exemplary modeling approaches shown in Figure 42, we also grouped some of the questions about barriers and facilitators of process performance modeling into a composite measure of management support for modeling. The following items were used to construct that measure: $^{20}$

- $\quad$ Doing process performance modeling has become an accepted way of doing business here.

- We make our decisions about the models we build without sufficient participation by management or other important stakeholders.

- We have trouble convincing management about value of doing process performance modeling.

- $\quad$ The messenger has been shot for delivering bad news based on process performance model predictions.

- Our managers want to know when things are off track.

- Our managers are less willing to fund new work when the outcome is uncertain.

As shown in Figure 49, this relationship also is a strong one. These results provide further evidence about the importance of management support for successful process performance modeling.

The availability of qualified and well-prepared individuals to do an organization's process performance modeling is another important measure of management support. The relationship in Figure 50 is only moderately strong. Recall however that most of these respondents are from organizations that already have achieved high maturity status. As can be seen by the relatively narrow columns on the left-hand

20 The negatively stated items were reverse scored for inclusion into the composite index since they are stated negatively as barriers rather than facilitators of process performance modeling. 
side of the mosaic, most of the survey respondents report that the necessary expertise most frequently is available when it is needed. ${ }^{21}$

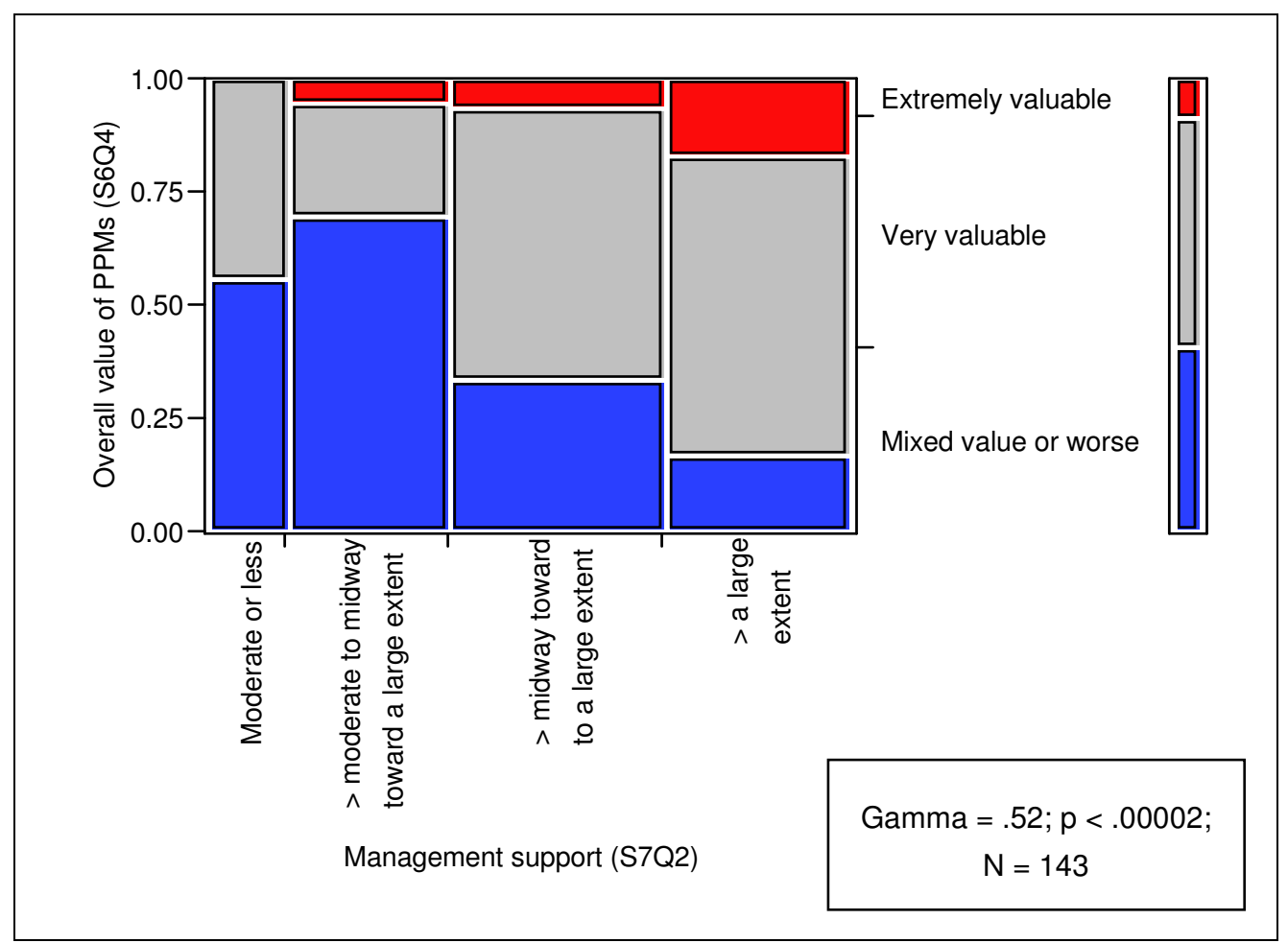

Figure 49: Relationship between management support for modeling and overall value attributed to process performance models

21 The gamma value is significant though attenuated because of the uneven distribution on the $x$ variable and the unexplained dip in the leftmost column of respondents who report that their organizations have achieved mixed value or less from in the outcomes of their process performance modeling activities. 


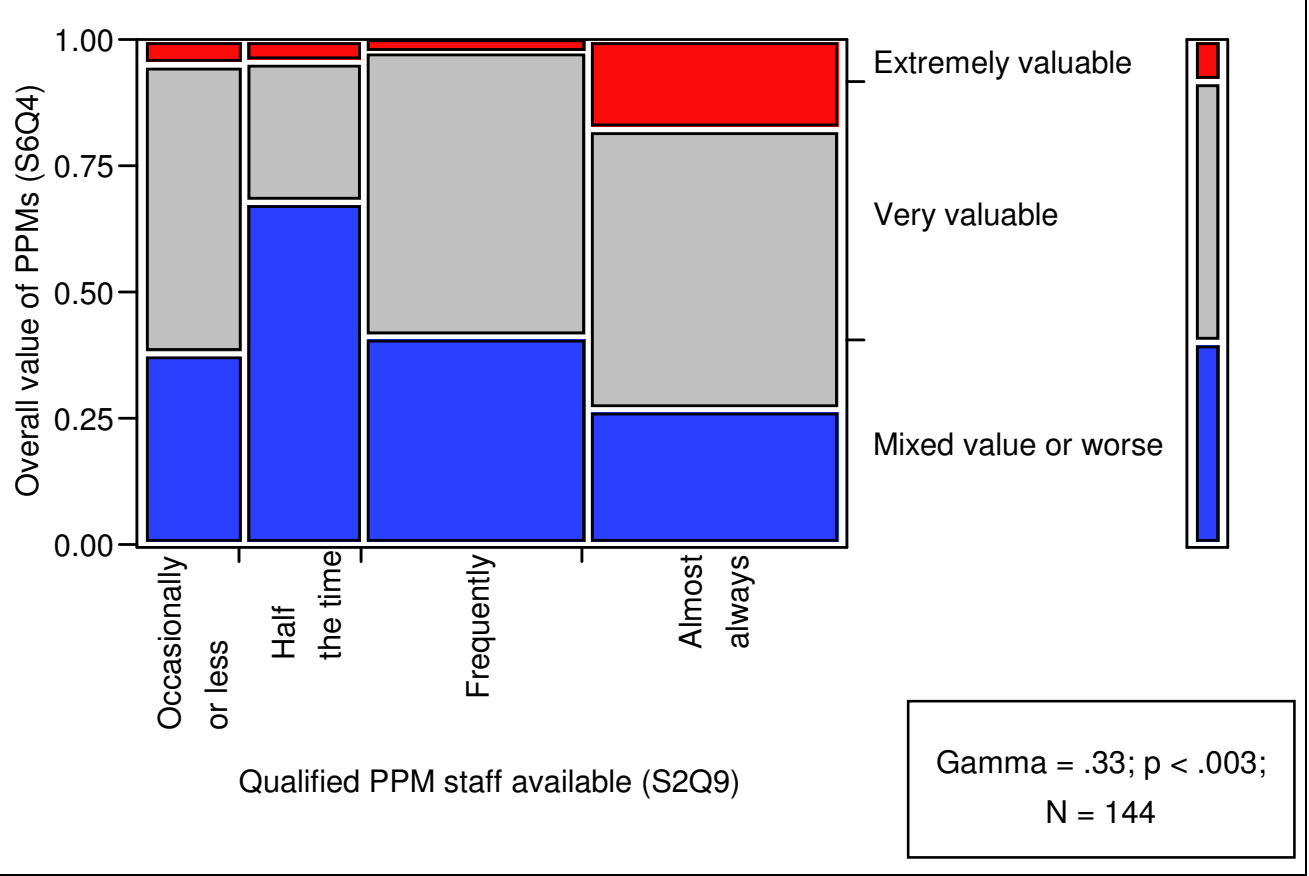

Figure 50: Relationship between process performance model staff availability and overall value attributed to process performance models

\subsection{Stakeholder Involvement in Setting Measurement and Analysis Goals and Objectives}

As mentioned in Section 4.1, the importance of stakeholder involvement is widely acknowledged by measurement experts. The inclusion of key stakeholders in deciding what to measure and why to do so is a basic notion of goal-driven measurement [Park 1996, van Solingen 1999]. It also is crucial for the CMMI Measurement and Analysis process area, particularly in specific goal 1 and specific practice 1.1 which are meant to ensure that measurement objectives and activities are aligned with the organizational unit's information needs and objectives, and in specific practice 2.4 which emphasizes the importance of reporting the results to all relevant stakeholders. SEI technical staff and others have observed incidents where insufficient stakeholder involvement in the creation of process performance baselines and models has seriously jeopardized their productive use, ${ }^{22}$ and there is empirical evidence that the existence of such support can increase the likelihood of the success of measurement programs in general [Goldenson 1999, Goldenson 2000, Gopal 2002].

As shown in Figure 51, there is a moderately strong positive relationship between our composite measure of stakeholder involvement and the respondents' reports of the effects of using their process performance models. However, the apparent effects of better alignment of the models with stakeholder input are seen much more clearly with other interim y factors, as shown in Figure 52 through Figure 54. While stakeholder participation appears to be crucial in deciding what to do and why, its effect is mediated through other activities that are more closely related temporally to the desired outcomes.

22 Participants in the SEl's ongoing workshop series on measurement and analysis in high maturity organizations often emphasize that domain knowledge is even more important than expertise in measurement and analytic methods [Stoddard 2008]. 


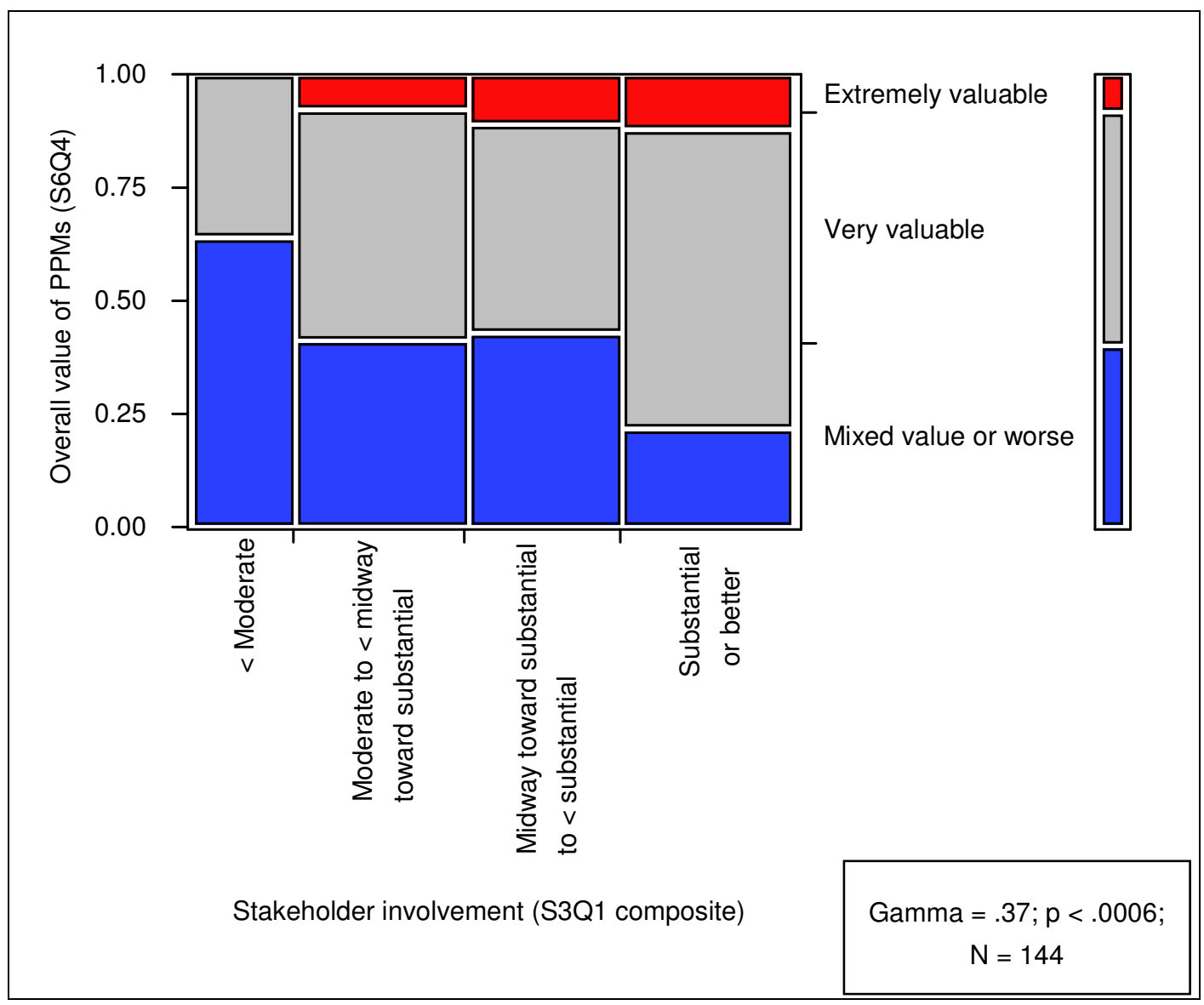

Figure 51: Relationship between stakeholder involvement and overall value attributed to process performance models

As seen in Figure 52, there is a moderately strong relationship between stakeholder involvement and the use of process performance model predictions in the organizations' status and milestone reviews. Perhaps more importantly, a very strong relationship can been seen in Figure 53 between stakeholder involvement and the emphasis on the healthy ingredients that the organizations put in their process performance models. The relationship shown in Figure 54 is even stronger when the healthy-ingredientbased purposes for which the models are used is the interim y factor. 


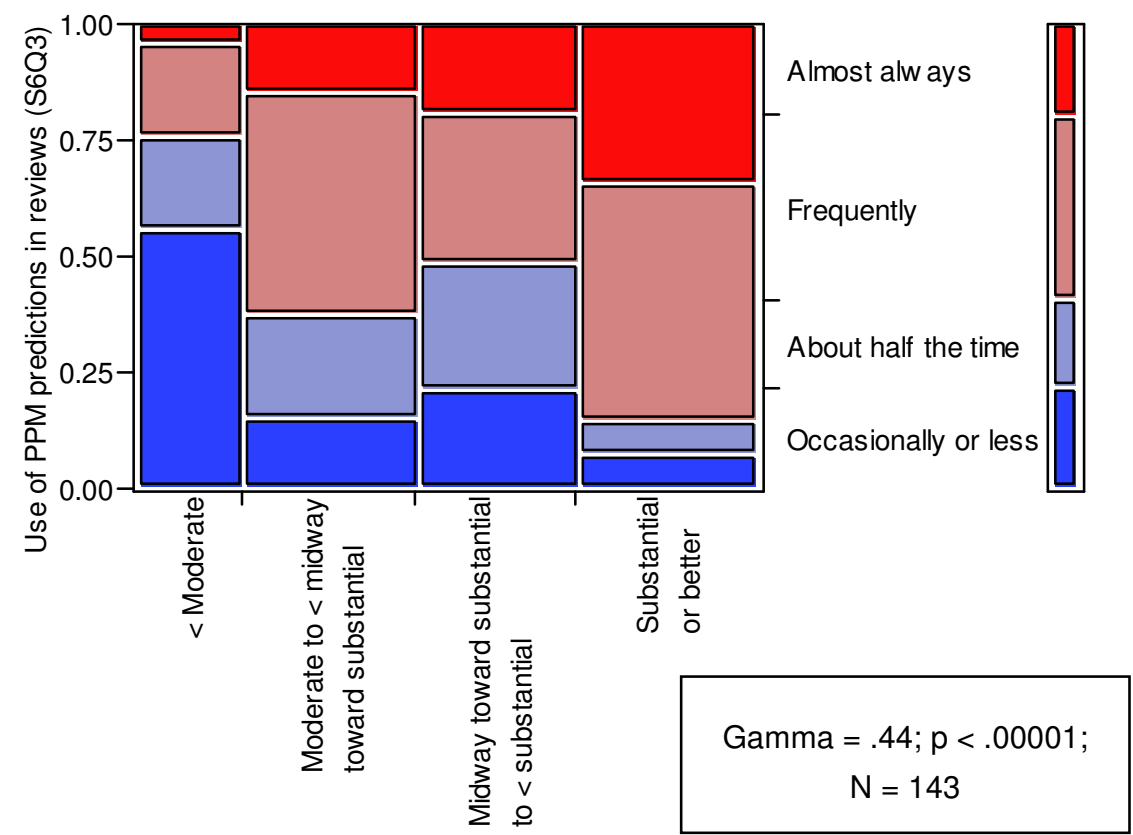

Stakeholder involvement (S3Q1 composite)

Figure 52: Relationship between stakeholder involvement and use of process performance model predictions in status and milestone reviews

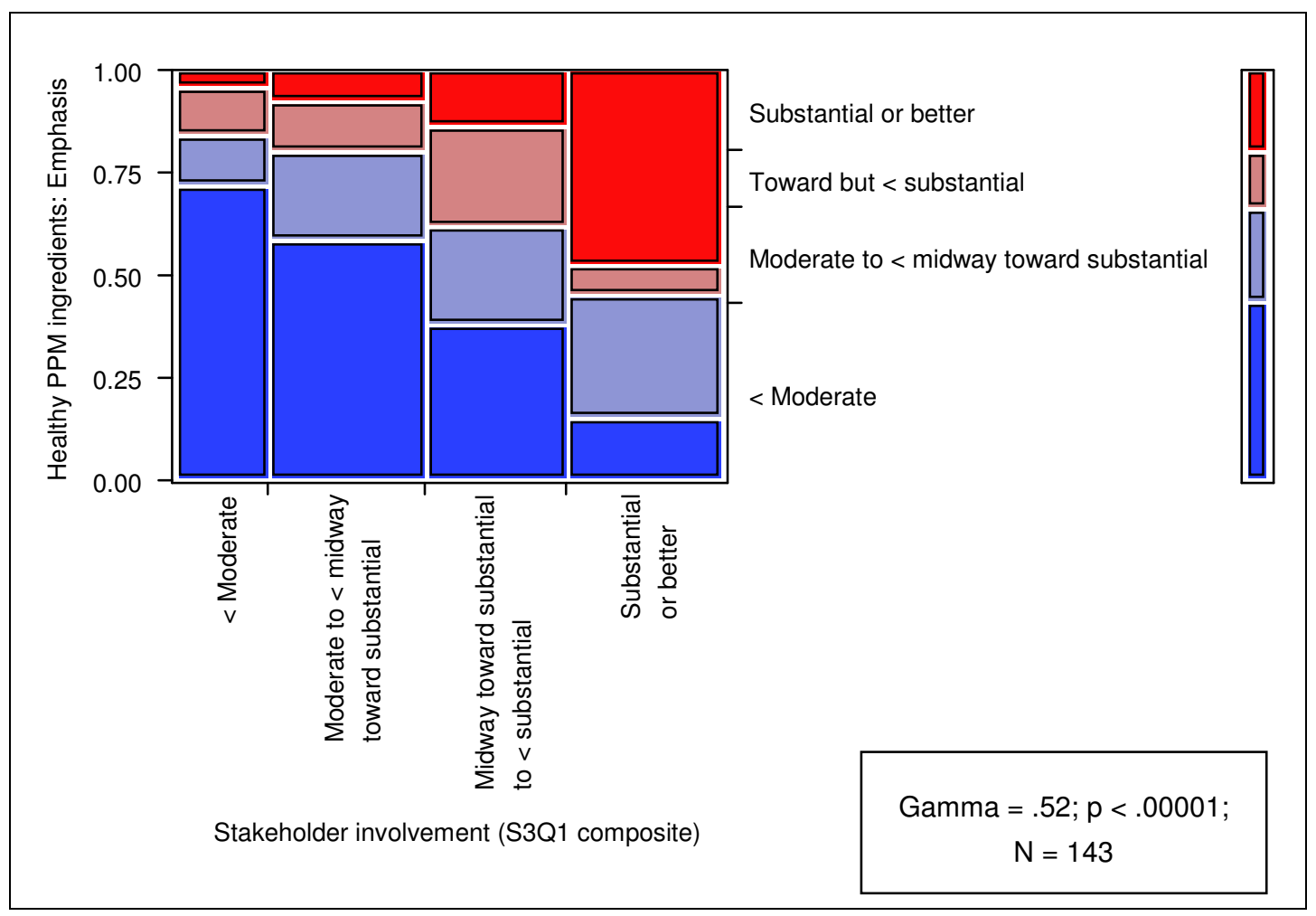

Figure 53: Relationship between stakeholder involvement and emphasis on healthy process performance model ingredients 


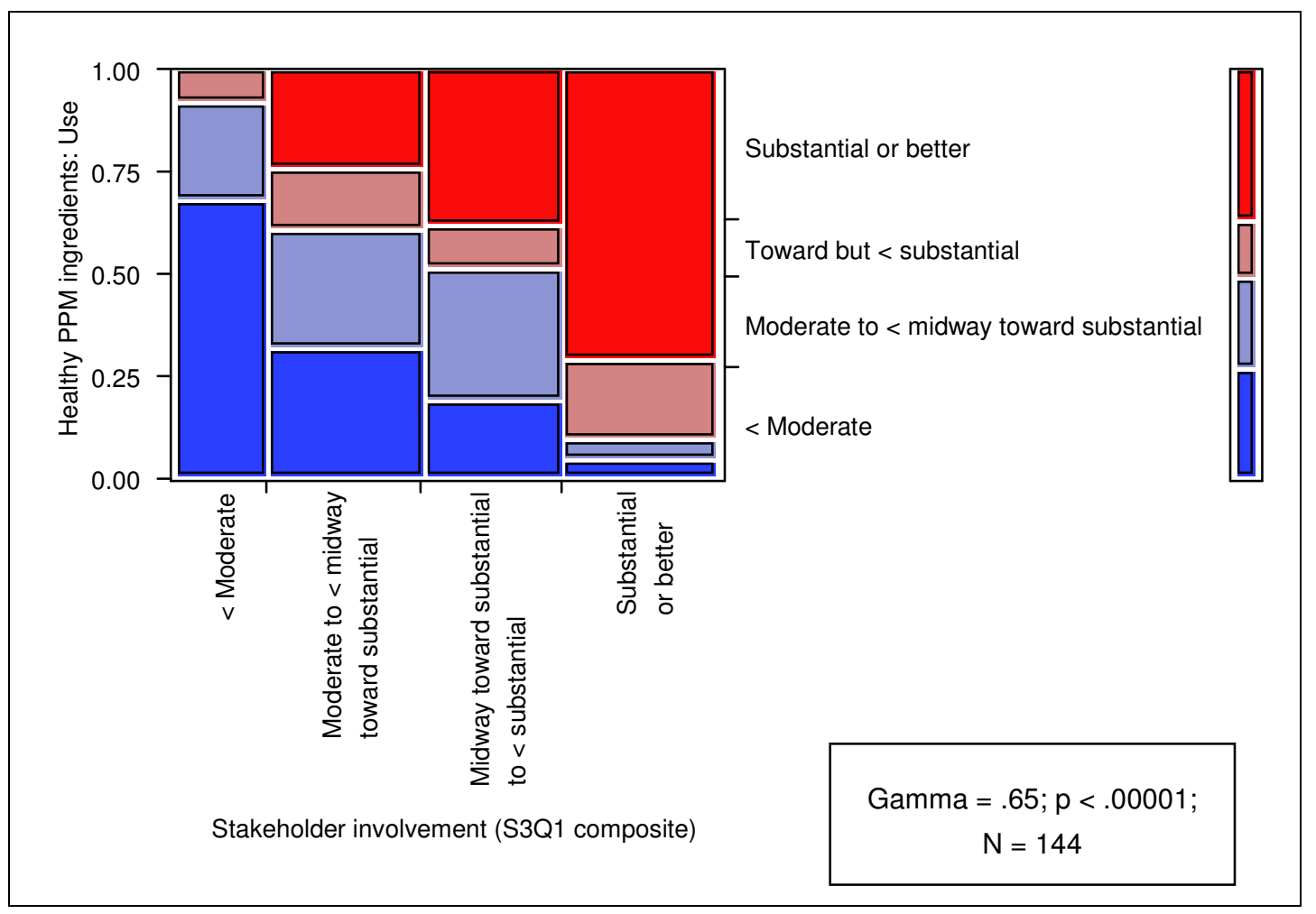

Figure 54: Relationship between stakeholder involvement and use of healthy process performance model ingredients

\subsection{Measurement-Related Training}

We built two composite measures based on the survey respondents' answers to the two-question series described in Figure 12 and Figure 13 in Section 4.2. Recall that those questions refer only to the venues in which the training occurs and its duration. We have no direct measures of the content or quality of that training. We also do not know how many courses are required over what period of time. Hence there may be a good deal of statistical noise in these composite variables. ${ }^{23}$ However, the results do suggest that there may be considerable payoff in providing more and better training and coaching for management. The situation with respect to training for modelers is less clear cut, but it too suggests areas where training can add value.

The management-training composite is based on the responses to the following: "What best characterizes the measurement-related training that your organization requires for its employees?" It sums across the answers for executive and senior managers, middle managers, and project managers.

The modeler-training composite is based on the responses to the following: "What kind of specialized training, if any, does your organization require for its employees who have responsibilities for process performance modeling?" It sums across the answers for process performance model builders and maintainers (e.g., Six Sigma black belts or other measurement specialists), coaches and mentors who assist the model builders and maintainers (e.g., Six Sigma master black belts), and those who collect and manage the baseline data (e.g., Six Sigma green belts, other project engineers, or EPG members).

23 The training-related questions in this survey were chosen largely to provide simple baselines for tracking change over time. We may focus on training in more detail in a subsequent survey. 
Both composite measures are weighted summed indices. The component items were weighted based largely on the duration of the training. Briefings were not included in the composite count for management, as of course there were instances where the respondents said that no training was required. Onthe-job, online/self-paced, and tutorials received one point. One- to two-day courses received two points. One- to four-week and college courses received three points. The weights were the same for the modeler training, except college training received 4 points.

The relationship between our measure of management training and the overall value attributed by the survey respondents to the outcomes of their organizations' process performance modeling is shown in Figure 55. The relationship is moderately strong. So too is the relationship in Figure 56 where the question about the use of process performance model predictions in reviews is used as the interim y variable. There also are moderately strong relationships in Figure 58 and Figure 59, where the questions about the managers' level of understanding of process performance model results and stakeholder involvement composite measure are used respectively as the interim y variables. ${ }^{24}$

There are more discordant patterns in these relationships than in some of the others already seen in the other mosaics, which is why the gamma values are proportionally lower. That is not surprising given the limitations of the management training measure. Notice though that there are some notable differences when one compares those organizations that require more formal training courses with those that do not. That is especially apparent when the use of process performance model predictions in reviews and stakeholder involvement were used as the interim y variables. Both of those relationships may be more directly susceptible to management control than the other two.

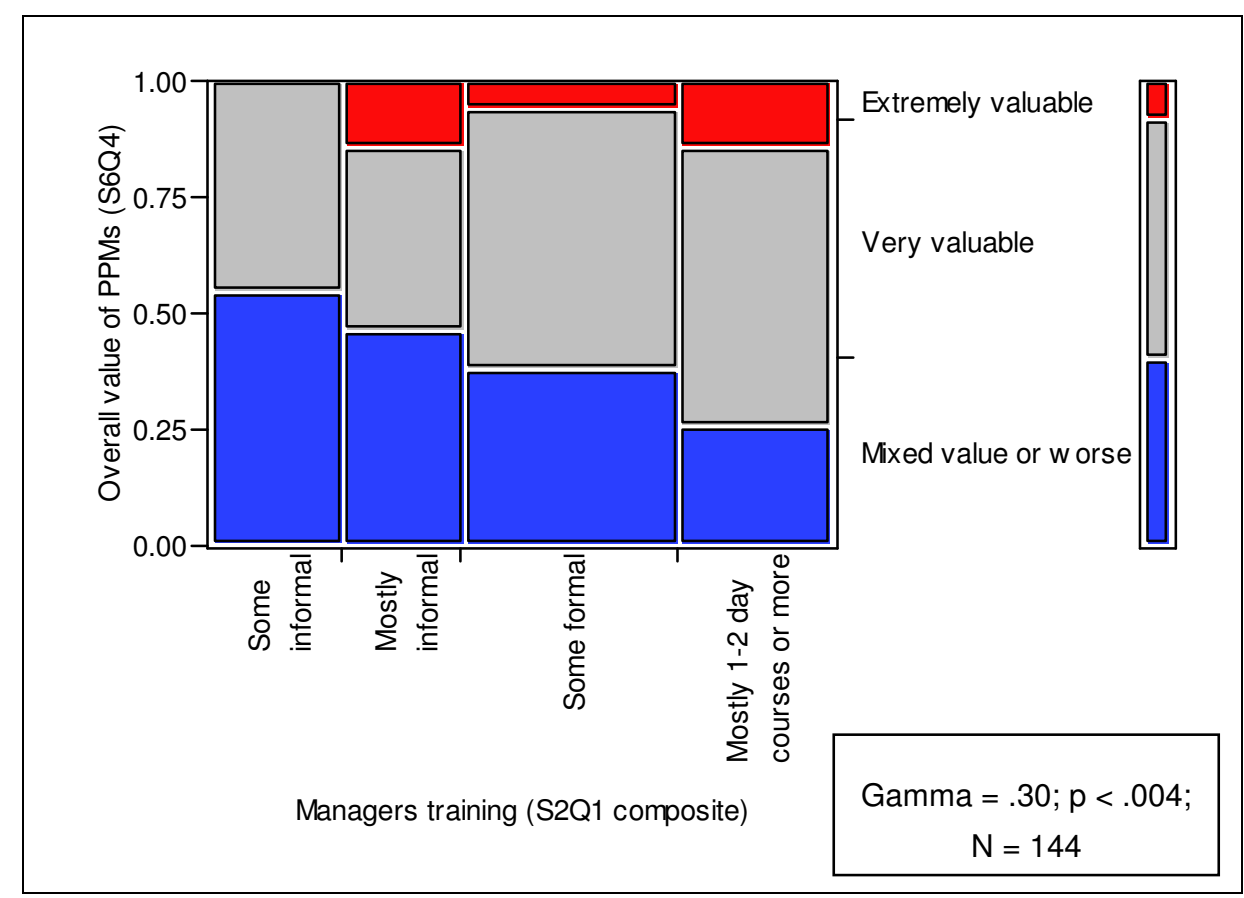

Figure 55: Relationship between management training and overall value attributed to process performance models

24 There is no statistically significant relationship between management training and the composite measure of management support that is summarized in Figure 49. That is not surprising since the latter can be affected by many things other than training per se. 


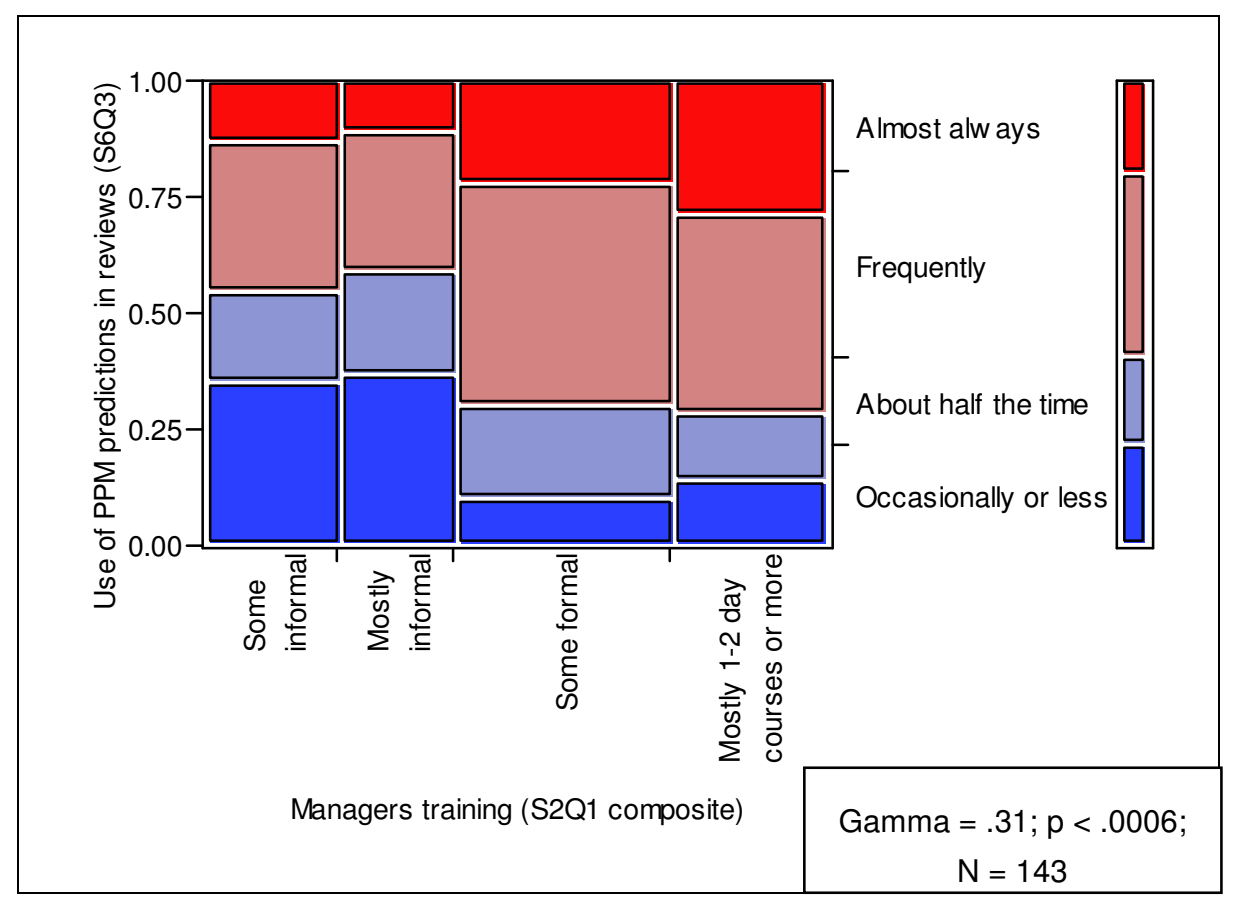

Figure 56: Relationship between management training and use of process performance model predictions in reviews

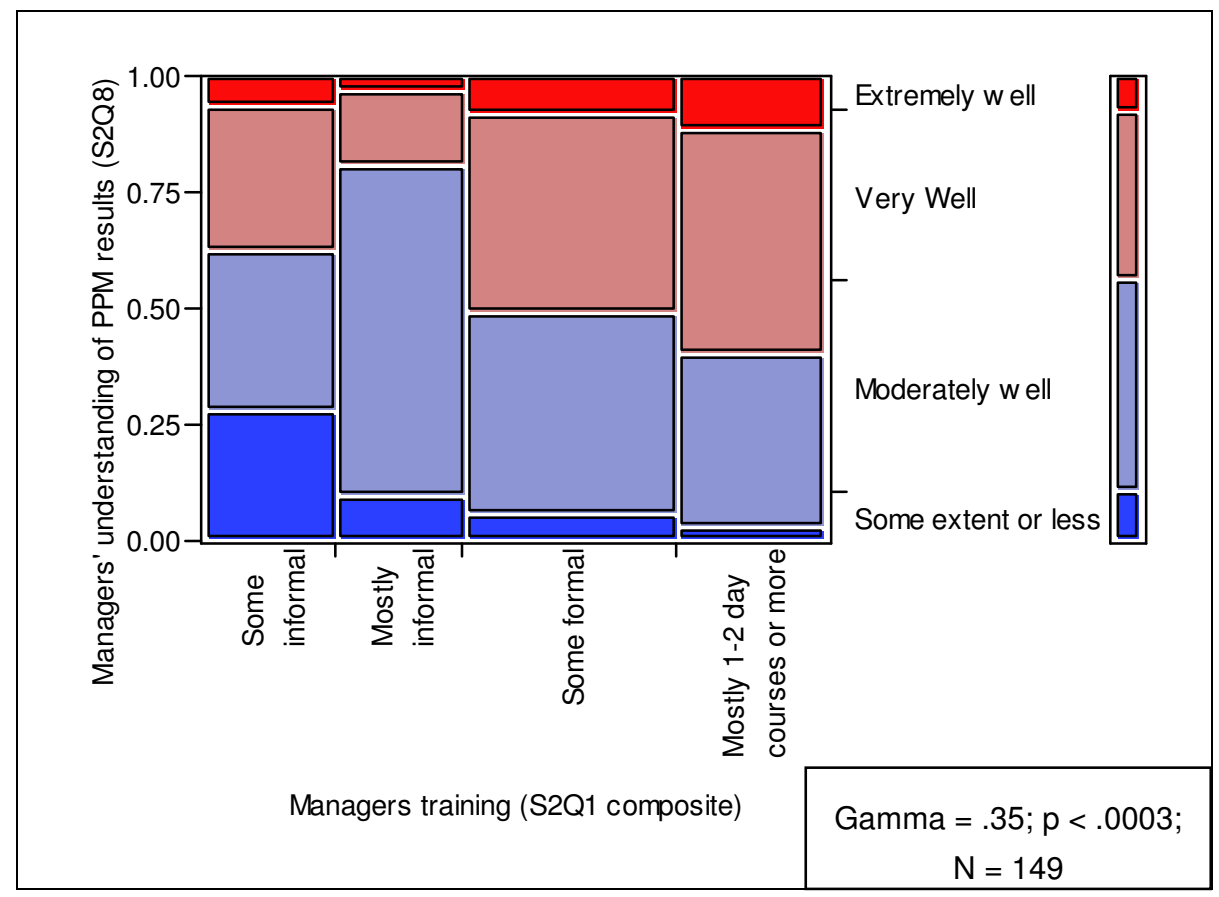

Figure 57: Relationship between management training and level of understanding of process performance model results attributed to managers 


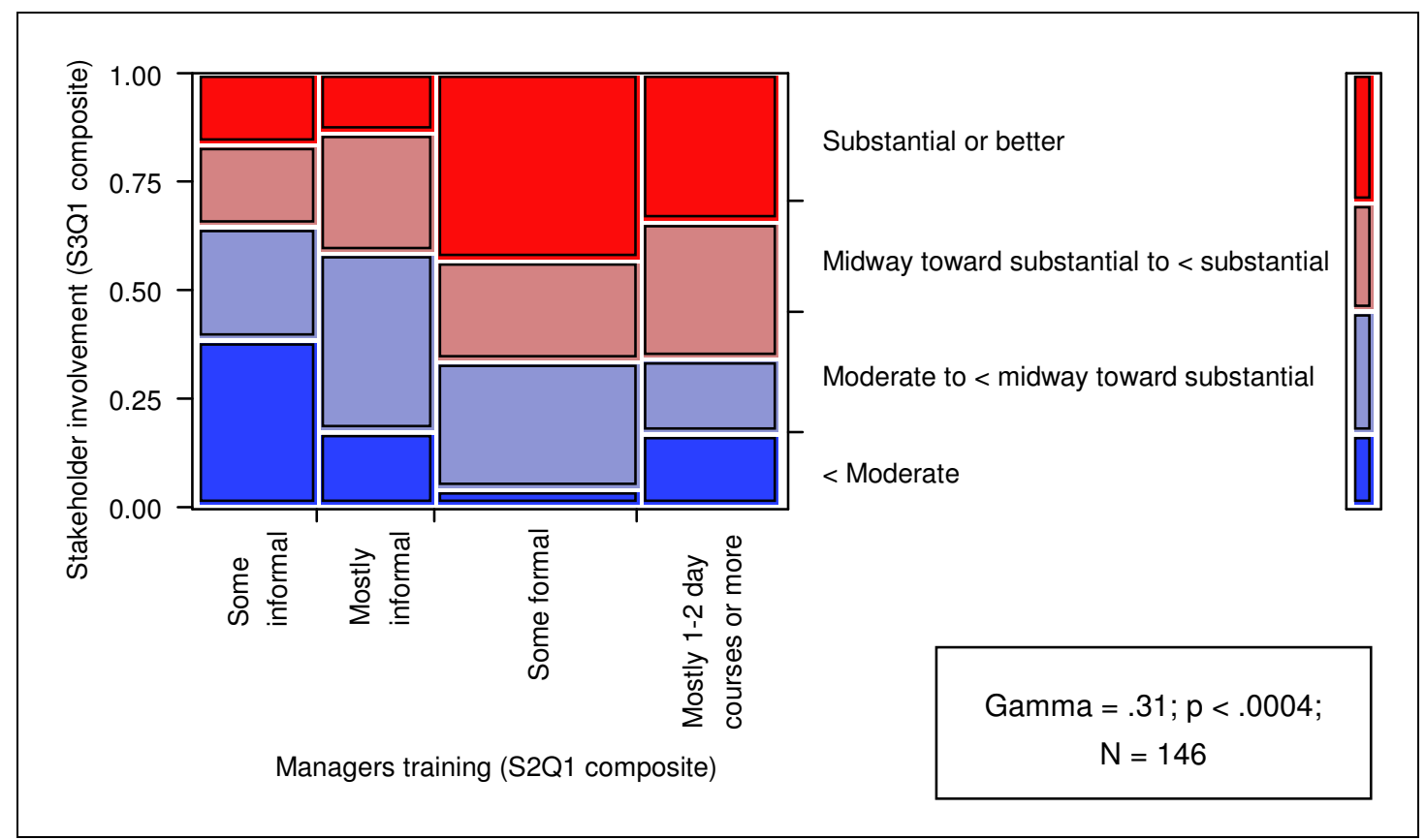

Figure 58: Relationship between management training and stakeholder involvement in responding organizations

Perhaps more interestingly, the relationship strengthens when the interim y variable is the extent to which the organizations emphasize the healthy ingredients of process performance modeling in their own modeling efforts. A moderately strong to strong relationship can be seen in Figure 59. The same is so in Figure 60 where use of diverse statistical methods is the interim y variable. These too may be more under management control. ${ }^{25}$ exhibit moderately strong relationships when they are considered as the interim y variable for management training. These include the use of automated support (gamma $=.35$ ), the use of optimization techniques (gamma $=.33$ ), and the healthy-ingredient-based purposes for which the models are used (gamma $=.27$ ). Of course, effects on training itself may be reciprocal over time. Improvements to an organization's training and coaching activities may be more likely when using the models has been perceived as valuable. 


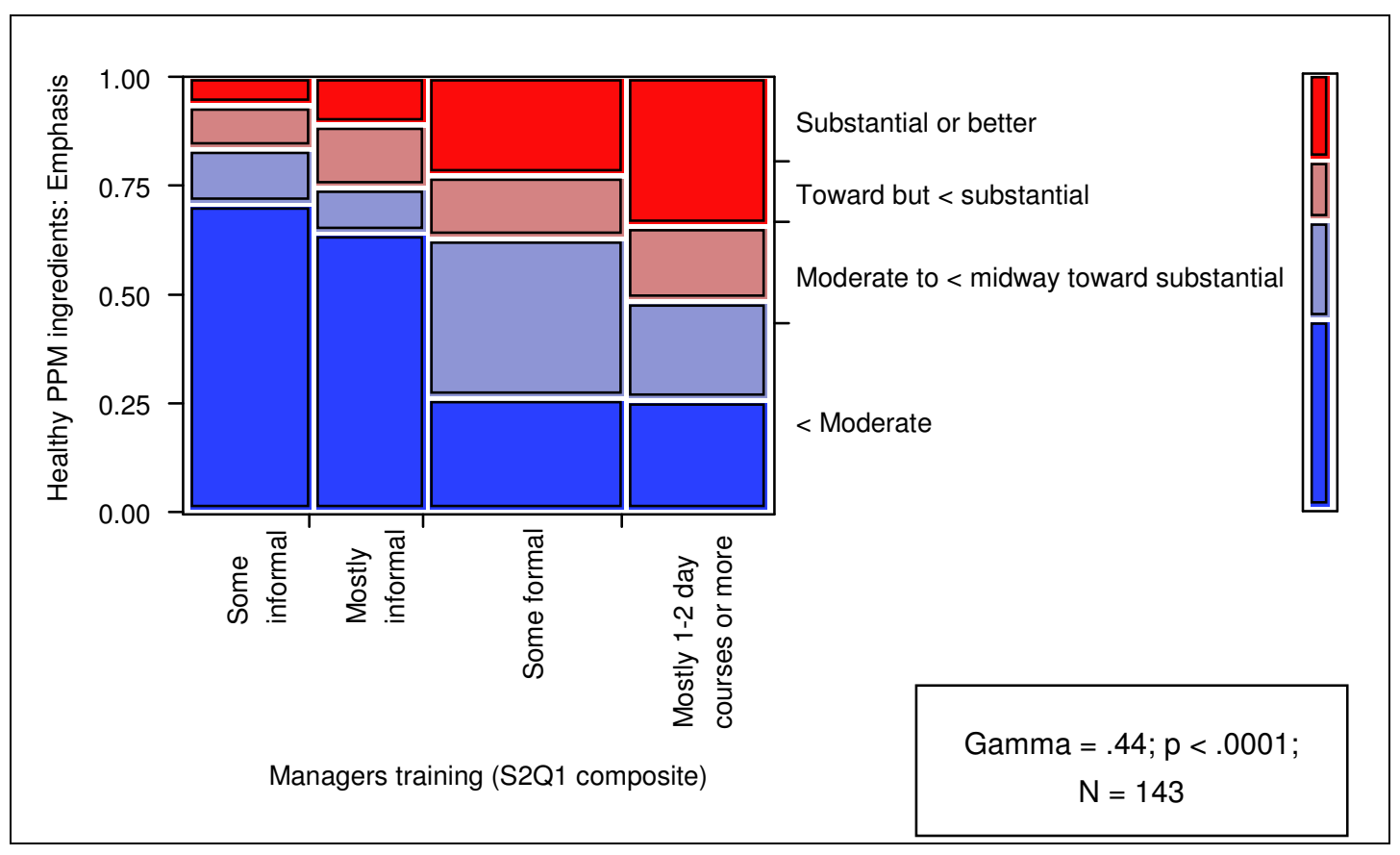

Figure 59: Relationship between management training and emphasis on healthy process performance model ingredients

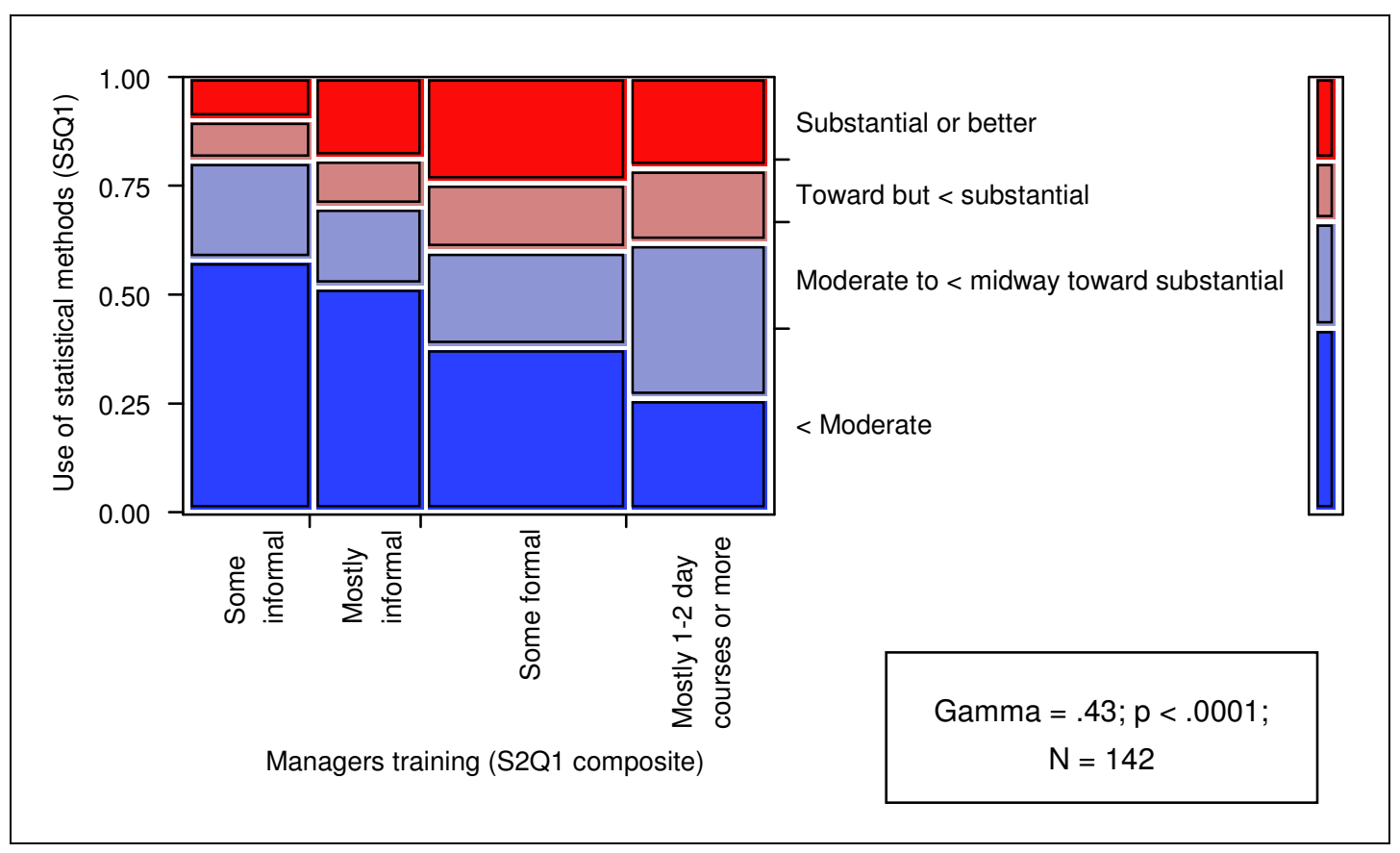

Figure 60: Relationship between management training and use of diverse statistical methods

Modeler training appears to have much less direct effect. Its effects probably are mediated by too many other, more important determinants of overall value. Moreover, the survey respondents, most of whom fill management roles in their organizations, may not have a particularly good sense of the quality of the training the modelers receive. As can be seen in Figure 61, there is a moderate relationship with the overall value the respondents attribute to their organizations' process performance models (gamma = .29); however, the relationships between the management training measure and the other interim y- 
variables are almost all much stronger. There are weak relationships with modeler training when the use of automated support for measurement ( $g a m m a=.27$ ), the use of exemplary modeling approaches $($ gamma $=.24)$, and the use of optimization techniques (gamma $=.21)$ are used as interim y factors. Those may be more clearly a function of modeler knowledge; however, no other measure we examined is associated in a statistically significant way with modeler training.

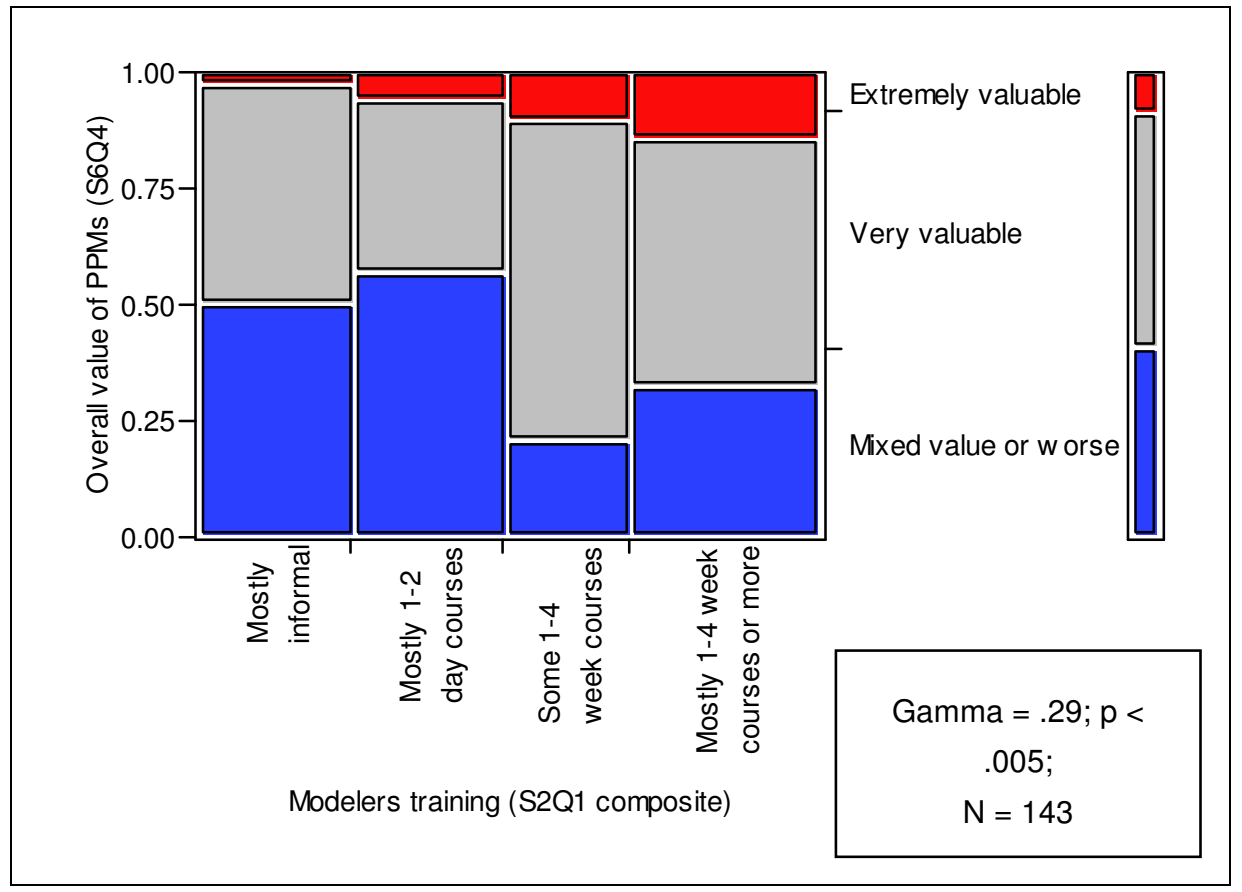

Figure 61: Relationship between modeler training and overall effect attributed to process performance modeling

\subsection{Technical Challenge}

As described in Section 5.2, the technical challenges sometimes faced by projects and product teams can have a direct effect on their chances of completing their work on time, on budget, and with the scope of the deliverables as specified contractually. Different degrees of technical challenge can warrant different degrees of process capability [Elm 2008, Ferguson 2007]. Unlike the systems engineering effectiveness survey just cited, the results in Figure 62 show no such direct relationship. Indeed there is essentially no association between our measure of project technical challenge and the value of the outcomes attributed to process performance modeling by the survey respondents.

The contrast may be due in part to differences in the measures used in the two studies. The one reported here is a composite of the respondents' answers to the question series that is summarized in Figure 34. Although some of those questions relate more directly to organizational context, most focus heavily on the difficulty inherent in certain product characteristics. The measure used in the other survey contains a mix focusing on constraints posed by organizational structure and interdependencies.

Perhaps more likely, the contrast in results may also be due to differences in the two survey samples. The systems engineering survey was not limited to high maturity organizations. ${ }^{26}$ The present results

26 The systems engineering survey was based on large defense projects. Almost 60 percent of them had not been appraised for implementing processes consistent with CMMI. About 70 percent of the rest had not achieved level four or five. Almost all of those lower maturity projects were appraised at maturity level three. 
may simply show that high maturity organizations are better able to handle harder projects. Moreover, most of the responding organizations report that their projects typically face relatively little technical challenge in their work. As shown in the category names on the figure's $\mathrm{x}$ axis, a very large proportion of them reported that the statements on which the composite measure is based typically described their projects to less than a moderate extent.

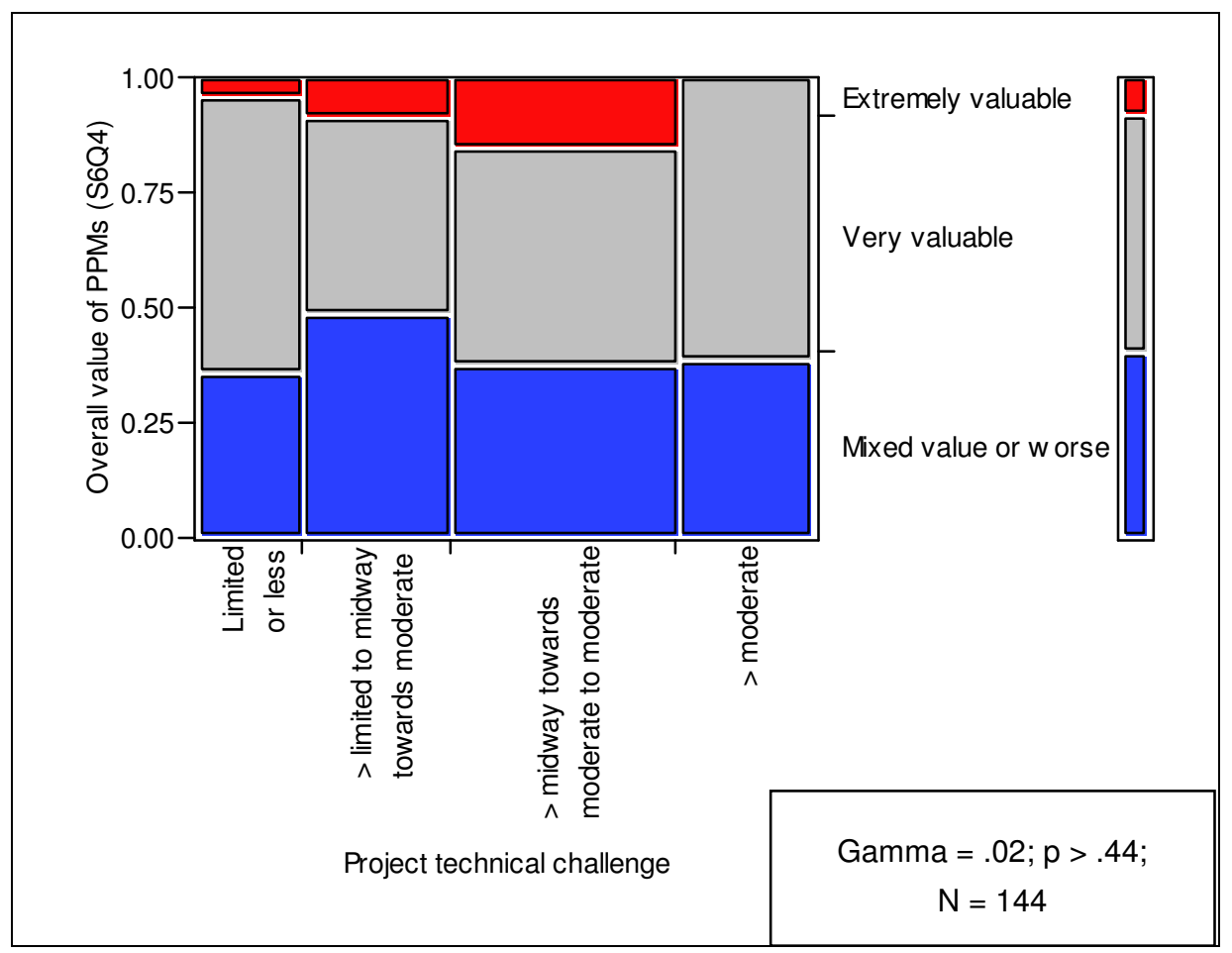

Figure 62: Relationship between project technical challenge and overall organizational effect attributed to process performance modeling

Yet differences in project technical challenge do seem to matter for the high maturity organizations described in this report. There is essentially no difference in the relationship between the technical challenge composite measure and the value of the effects the respondents attribute to process performance modeling, as shown in Figure 62. However the relationships of other measures with reported organizational effects do in fact differ consistently as a function of the extent of technical challenge typically faced by the organizations' projects.

The relationship between reported organizational effects and the use of process performance model predictions in status and milestone reviews is summarized separately in Figure 63 for organizations with projects that face relatively little technical challenge. ${ }^{27}$ The same relationship is summarized in Figure 64 for organizations with projects that face relatively more technical challenge. The relationship for organizations facing lower technical challenge is exceptionally high for survey data such as these. The relationship in Figure 64 for those facing relatively more technical challenge also is very strong, although it is somewhat lower than the overall relationship regardless of technical challenge that is described in Section 4.3.

27 The four categories of project technical challenge shown in Figure 62 are dichotomized here because of the small numbers of cases and resultant fewer degrees of freedom for statistical analysis. 
More importantly though, the organizations with more difficult projects are noticeably more likely to report more valuable effects due to their modeling efforts than are those with projects that face fewer technical challenges. And that is true for those organizations that use process performance model results the least for decision making in their status and milestone reviews as well as for those who use their results the most.

Expectations of what constitutes valuable effects may be lower for those who use the model results the least; however, the fact that they find more value in them under more difficult circumstances is particularly telling, as shown in Figure 64. Recall that all of the organizations surveyed here do at least some process performance modeling. Organizations that have not yet begun to develop such capabilities might also achieve better outcomes by doing so, and that may be true especially for those that face greater technical challenges.

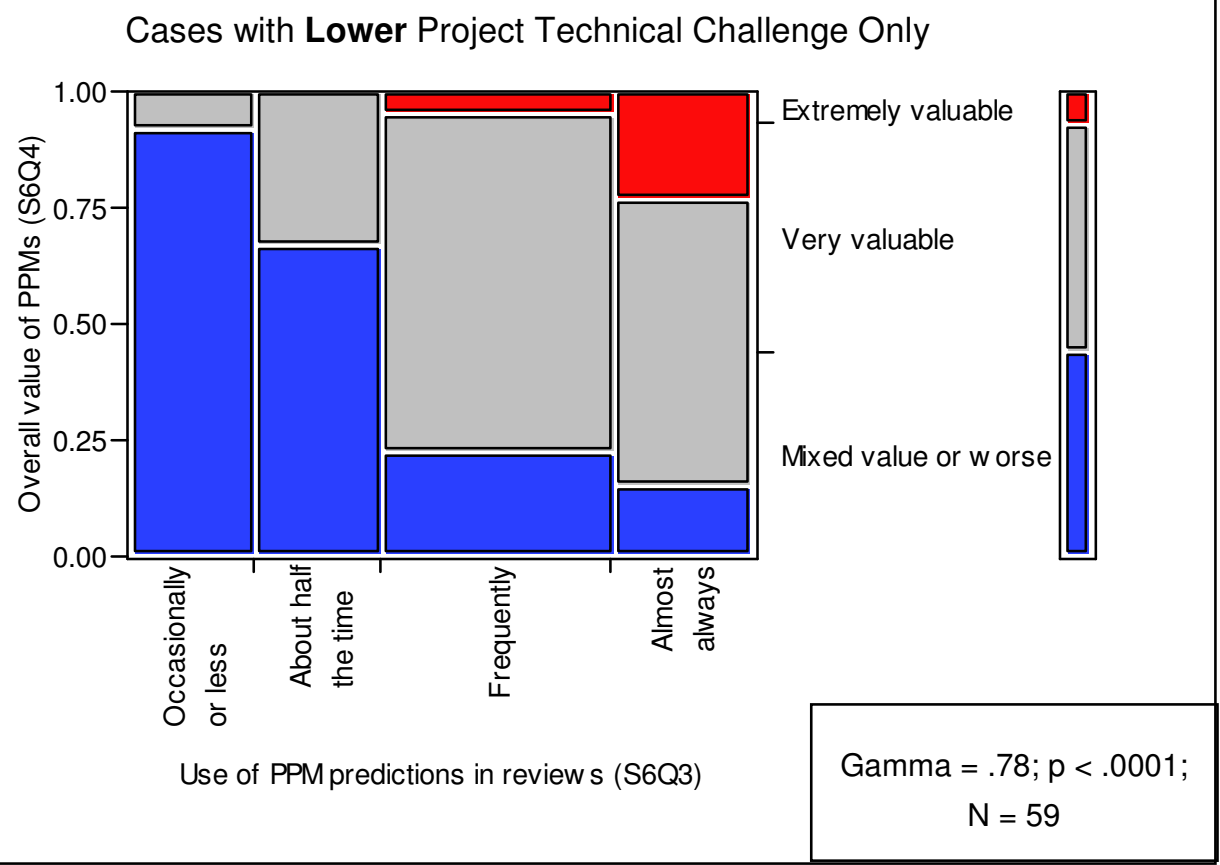

Figure 63: Relationship between use of process performance model predictions in reviews and overall effect attributed to process performance modeling, with lower project technical challenge 


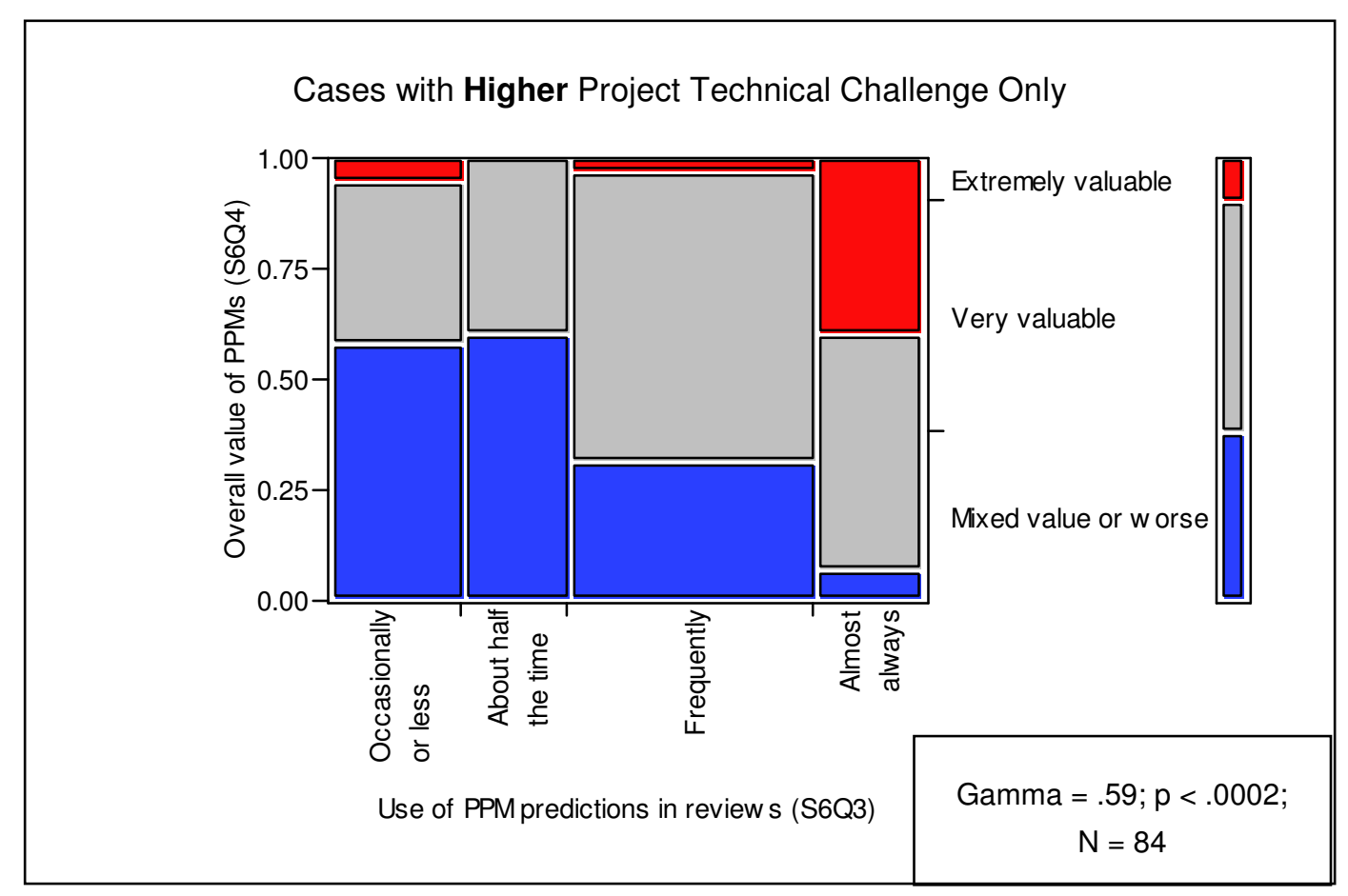

Figure 64: Relationship between use of process performance model predictions in reviews and overall effect attributed to process performance modeling, with higher project technical challenge

Somewhat similar results can be seen in Figure 65 and Figure 66 with respect to the emphasis the organizations put on the healthy ingredients of process performance models. The strength of association with the value attributed to the effects of the modeling is similar here regardless of how much technical challenge the organizations face. Again, the respondents attribute more valuable effects from the modeling when the amount of technical challenge is greater, and that is so for those who place the least emphasis on the healthy ingredients as well as those who place the most emphasis on them. Notice also from the differing widths of the columns in these two figures that fewer organizations emphasize the healthy ingredients when project technical challenge is higher. This too suggests that there may be substantial opportunity for improvement in the future as a result of wider and more effective use of process performance modeling. 


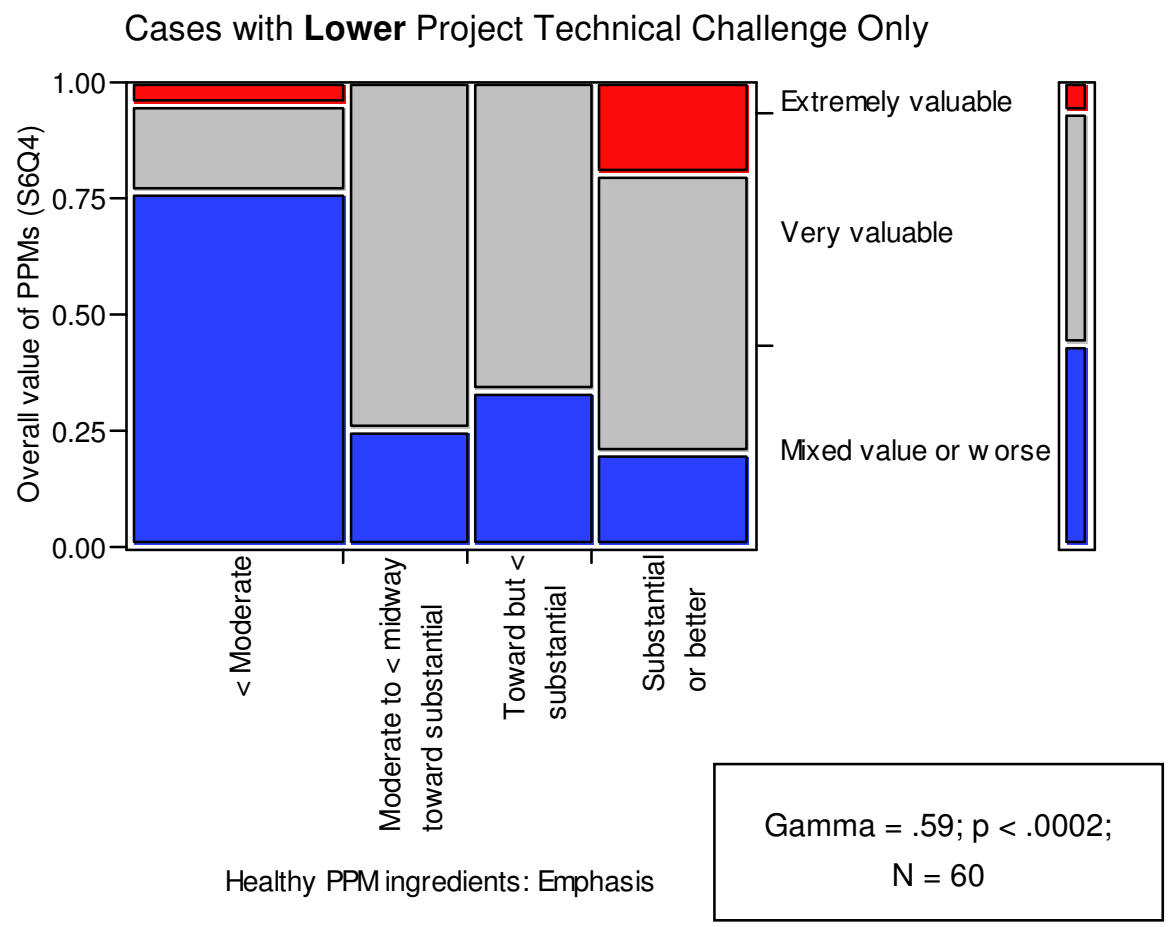

Figure 65: Relationship between emphasis on healthy process performance model ingredients and overall effect attributed to process performance modeling, with lower project technical challenge

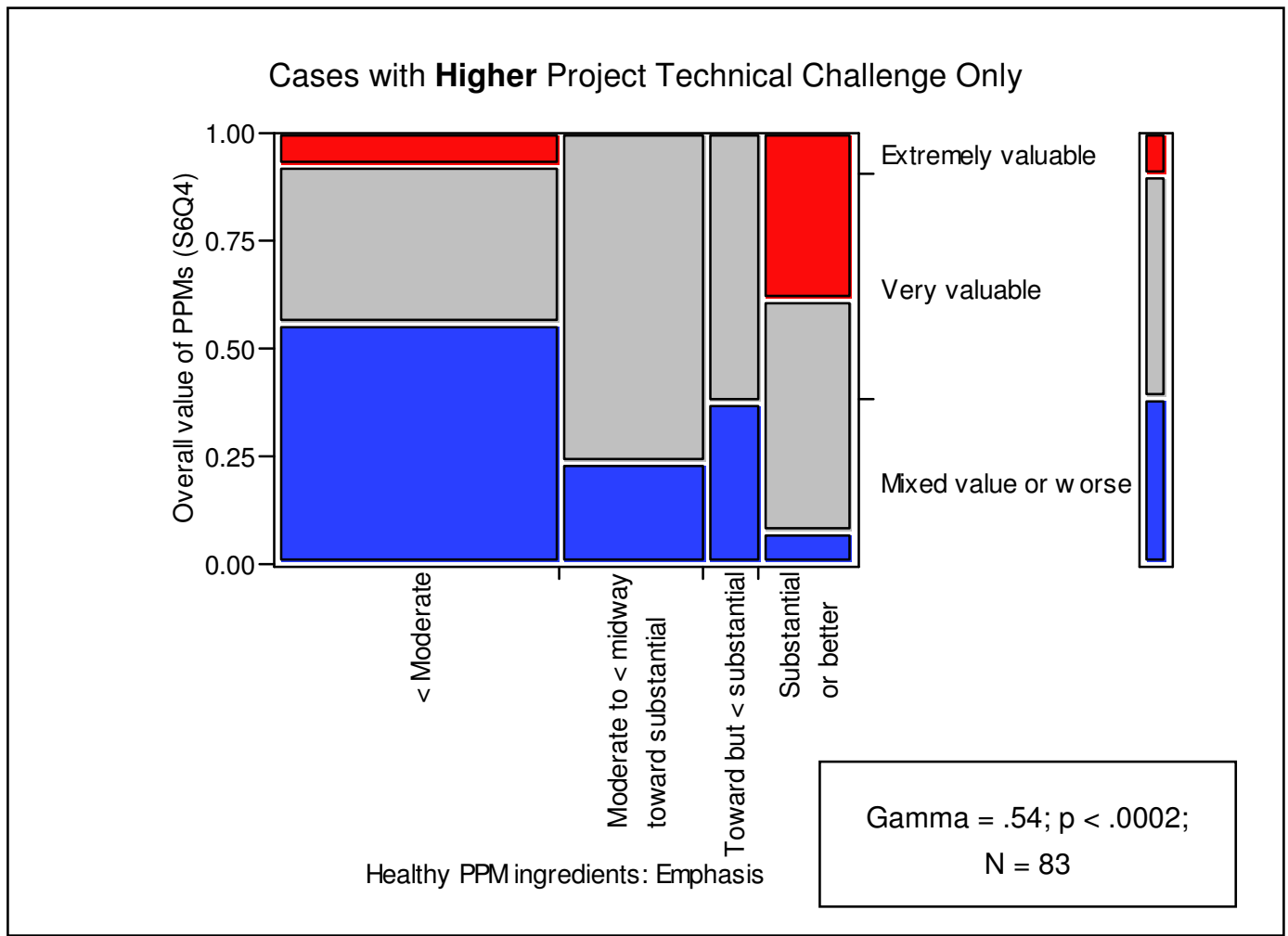

Figure 66: Relationship between emphasis on healthy process performance model ingredients and overall effect attributed to process performance modeling, with higher project technical challenge 
The number of cases on which both of these comparisons rely, controlling for differences in project technical challenge, is small. However, there is a consistent, similar pattern for all of the pertinent process performance modeling, analytic capability, and management support measures that we examined. Organizations with relatively more difficult projects almost always reported more value from their modeling than did those with less difficult projects, and that is especially true for those on the lowest end of the $\mathrm{x}$-variable distributions. The distributions compared include the following:

- use of process performance model predictions in reviews

- emphasis on healthy process performance model ingredients

- $\quad$ use of healthy process performance model ingredients

- $\quad$ exemplary modeling approaches

- diversity of process performance models: product quality and project performance

- $\quad$ use of diverse statistical methods

- $\quad$ use of optimization techniques

- $\quad$ use of automated support for measurement and analysis activities

- availability of qualified process performance modeling personnel

- management support (composite measure)

In all ten comparisons, the responding organizations on the lowest end of the respective $\mathrm{x}$ variable distributions were more likely to report extremely or very valuable effects of their process performance modeling when their reported project technical challenge was higher. Nine of the ten on the highest end of the respective $\mathrm{x}$ variable distributions were more likely to report extremely valuable effects of their process performance modeling when their reported project technical challenge was similarly high. The probability of either proportion occurring simply by chance is quite low, even for such a small number of instances. Based on a simple sign test, $\mathrm{p}<.001$ for those on the lowest end of the $\mathrm{x}$ variable distributions; $\mathrm{p}<.02$ for those on the highest end. ${ }^{28}$

\subsection{In Summary: A Multivariable Model}

It is particularly difficult to tease out interpretations of cause and effect when several variables are interrelated. Such is the case in this study. We are also hampered by the relatively small number of responding organizations. We are able to make what appear to be reasonable conjectures about the indirect effects of stakeholder involvement, measurement-related training, and project technical challenge in Sections 6.4, 6.5, and 6.6; however the limited numbers of cases and interrelated joint distributions prevent further explorations about those conjectures with the currently available data.

However, we have done further exploratory data analyses to describe the combined impact of the various $x$ values that are described earlier in the report. To what extent then does the reported organizational value of process performance modeling change as a function of variation in response to combinations of the individual questions and composite measures? The interrelationships are quite complex, often with mediating effects, so it is difficult to describe the overall relationship simply.

28 The sign test is a simple inferential statistic based on the binomial theorem. A clear description may be found in the classic reference by Siegel and Castellan [Siegel 1998]. A convenient sign test calculator from the Institute of Phonetic Sciences, Amsterdam is available at http://www.fon.hum.uva.nl/Service/Statistics/Sign_Test.html. 
We began by examining the $\mathrm{x}$ factors that are most strongly associated with the reported outcomes of process performance modeling. Knowing that those factors are often quite strongly related with each other, we focused on several combinations of $\mathrm{x}$ factors while looking for as simple a parsimonious model as possible. After using several statistical methods to narrow the search, we used multiple logistic regression for non-categorized measures to settle on a model with four $\mathrm{x}$ factors. As in the rest of this report, the single question about overall value attributed to process performance modeling is used as the $y$ factor. ${ }^{29}$

The $\mathrm{x}$ factors in the best model we found include the following:

- $\quad$ use of process performance model predictions in status and milestone reviews

- diversity of process performance models: product quality and project performance

- a composite measure of management support and exemplary modeling approaches that facilitate process performance modeling ${ }^{30}$

- emphasis on healthy process performance model ingredients

Recall that the strongest bivariate relationship described in this report using overall outcome as the y variable is the one with use of process performance model predictions in status and milestone reviews as the single $\mathrm{x}$ variable $(\mathrm{gamma}=.67)$. The strength of the combined relationship achieved with the multivariable model increases modestly to a gamma value of .71 .

29 Clear treatments of logistic regression methods can be found in several books [Menard 2002, Hosmer 2000, Kleinbaum 2002].

30 Combining component items of both management support and exemplary modeling approaches into a single composite measure works better for modeling purposes since it gets at both conceptual spaces in a single measure. The combined measure is based only on items that are phrased positively as facilitators rather than barriers. 


\section{Performance Outcomes of Measurement and Analysis Across Maturity Levels}

As part an ongoing series of surveys about the state of measurement and analysis practice, the SEI also conducted a companion survey in 2008 of organizations from across the full spectrum of CMMI-based maturity. This section contains selected results from that survey. They highlight the potential payoff of measurement and analysis in lower maturity organizations.

The general population survey had a response rate of 25 percent. Similar to the 2007 survey in the series [Goldenson 2008b], there is evidence that measurement and analysis capabilities and performance outcomes typically improve considerably as the survey respondents' organizations move up in maturity level. All of the respondents in the results shown here were screened to ensure that they use measurement and analysis, either regularly (62\%) or at least occasionally (20\%).

The focus in this report is on three process variables: CMMI maturity level, the use of product and quality measurement results, and the use of project and organizational measurement results. Similar to the high maturity survey, a single question on the overall value of measurement and analysis is used as the $y$ factor in this report. ${ }^{31}$ All three process variables vary predictably with the overall value of measurement and analysis that the survey respondents attribute to their organizations.

There is a moderately strong to strong relationship between CMMI maturity and the respondents' answers about how valuable measurement and analysis has been to their organizations, as seen in Figure 67. CMMI-based maturity is measured by a single question: "To the best of your knowledge, what is the maturity level of your organization?" The results follow a common stair-step pattern. Over twentyfive percent of the organizations that have achieved maturity level four or five status report that the results have been extremely valuable for their organizations, and three-quarters say that the results have been very valuable or extremely valuable. Decreasing value occurs for organizations that have not yet achieved high maturity status, and the pattern is quite the opposite at maturity level one. ${ }^{32}$

31 As with the high maturity survey, we also examined a weighted, summed composite measure based on responses about value added by measurement and analysis to project performance, product quality, and tactical and strategic decisions. The results are similar using either measure as the y factor. Also similar to the high maturity survey, the single question asks "In general, how valuable has measurement and analysis been to your organization?"

32 A relatively small number of the survey respondents did not know their organizations' maturity levels. They are grouped with those at level one because their answers to the other survey questions are essentially the same as those at maturity level one. Note also that the questionnaire gave the respondents an opportunity to say they were "close to" the next level, so that they would be less likely to err by overstating their true status. "Close to" replies were grouped with the next lower levels since maturity level is a discrete concept. 


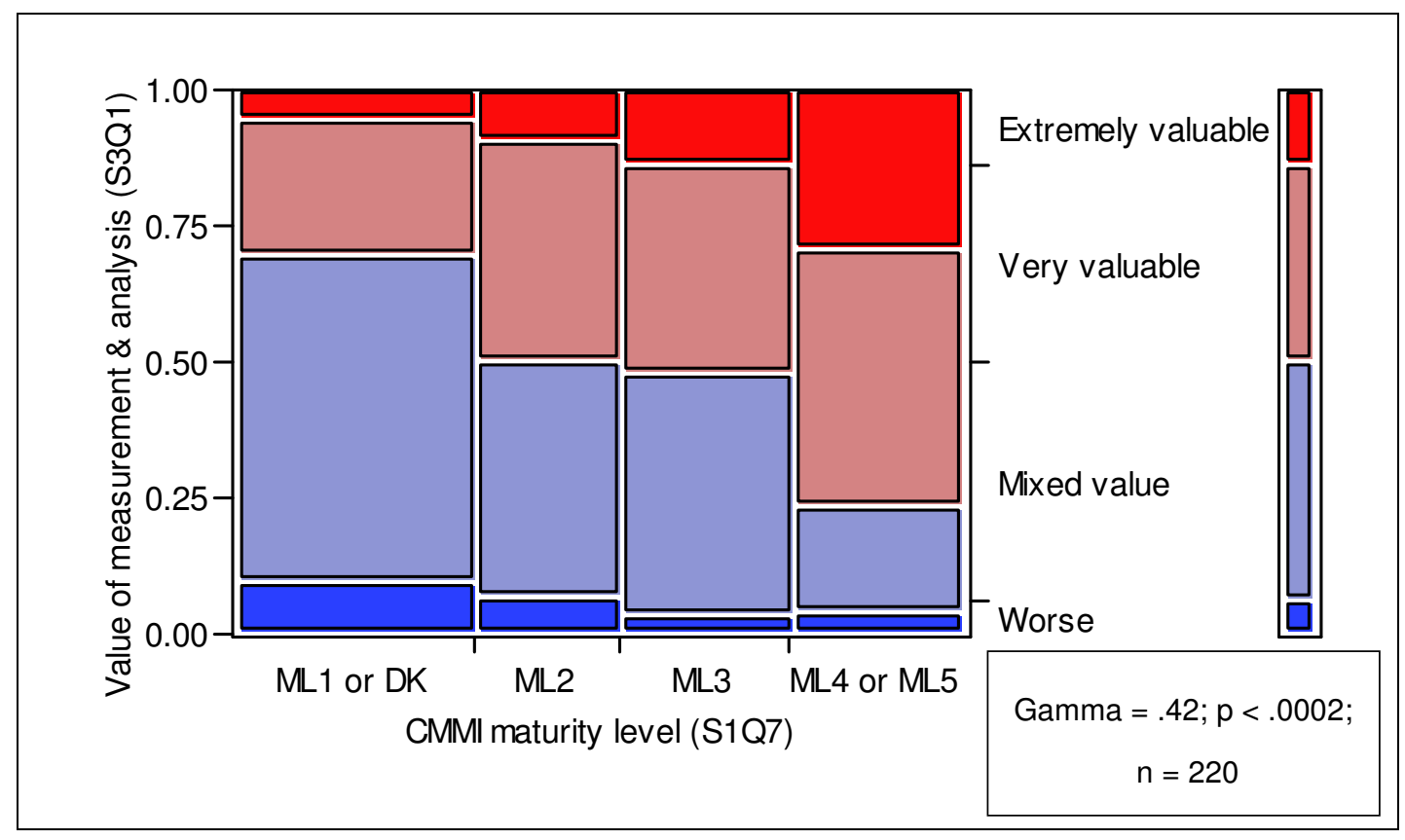

Figure 67: Relationship between maturity level and overall value attributed to measurement and analysis

Interestingly enough, the two other process variables are more closely associated with the respondents' reports about the value of their measurement related activities to their respective organizations than is maturity level alone. That is not surprising, since organizations at all maturity levels do vary in the specifics of what they measure and how they use the results.

Use of product and quality measurement results is measured by a weighted, summed index based on the survey respondents' answers about how often a series of several kinds of product and quality measurement results are reported in their organizations. The categories include the following:

- $\quad$ product requirements or architectures (e.g., completion of customer and technical requirements, or features delivered as planned)

- effort applied to tasks (e.g., productivity, rework, and cost of quality or poor quality)

- $\quad$ defect density (e.g., numbers of defects identified pre and post release)

- $\quad$ defect phase containment (i.e., early detection and removal)

- $\quad$ quality attributes (e.g., maintainability, interoperability, portability, usability, reliability, complexity, criticality, reusability, or durability)

- $\quad$ customer satisfaction (e.g., satisfaction with staff responsiveness or fitness for use of the delivered product)

The results in Figure 68 show a strong degree of association between frequency of use of product and quality measurement results reported by the respondents and the overall value attributed to measurement and analysis value in their respective organizations. The stair-step pattern is considerably more distinct when this more direct measure is used as the $\mathrm{x}$ factor than was true for maturity level alone. The organizations that report the most use of such measurement results are even more likely to report that their measurement and analysis activities have been very valuable or extremely valuable than was true for high maturity status alone, yet almost 90 percent of those where product and quality measures 
typically are used less than occasionally report that their measurement and analysis activities have been of mixed value or worse.

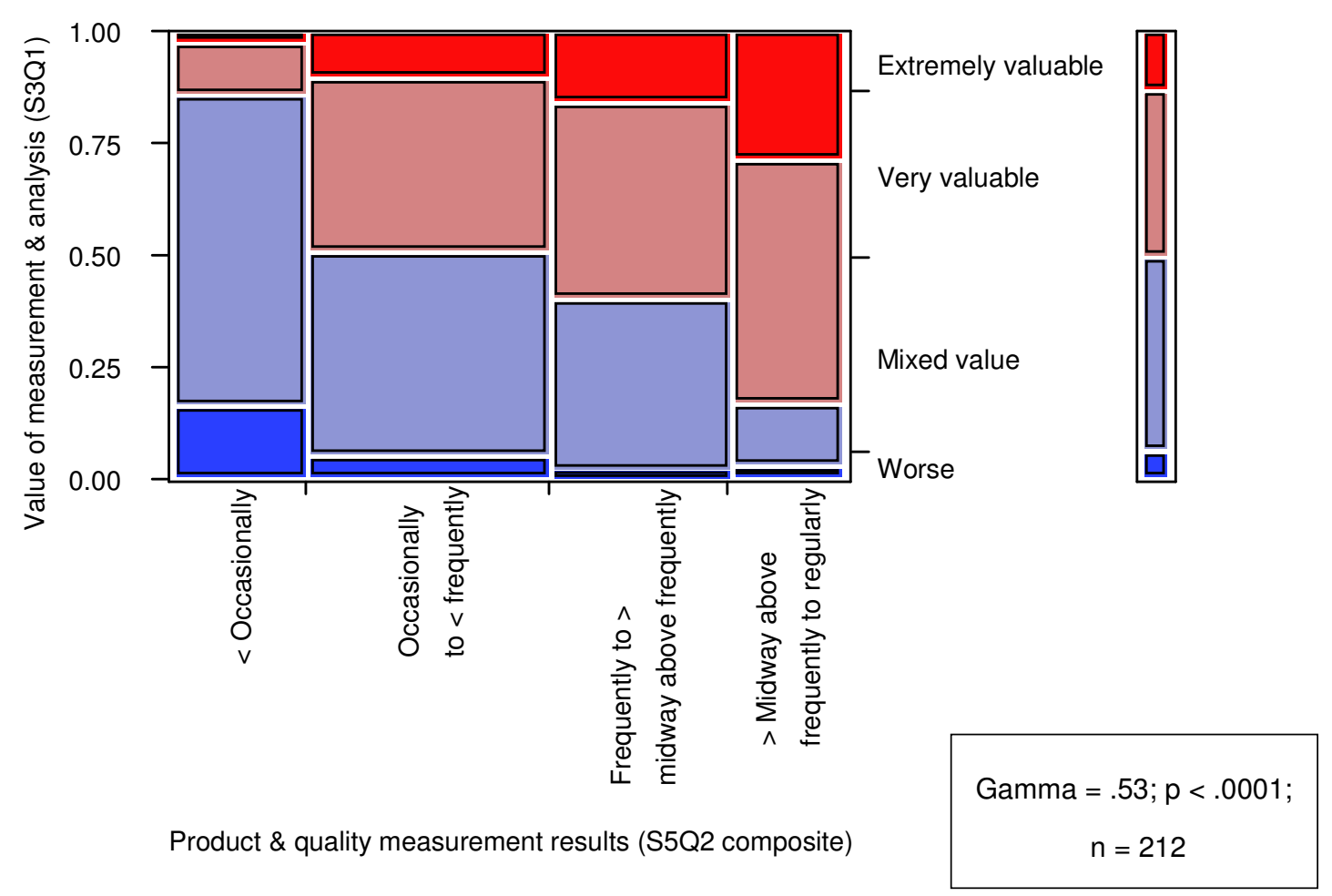

Figure 68: Relationship between use of product and quality measurement results and overall value attributed to measurement and analysis

The differences with respect to value attributed to measurement and analysis are even starker for frequency of use of project and organizational measurement results. That may be because lower maturity organizations often begin the measurement and analysis activities with these kinds of measures.

Use of project and organizational measurement results also is measured by a weighted summed index. It too is based on the respondents' answers about how often a series of several categories of measures were reported in their organizations. The following categories are included in the composite measure:

- $\quad$ staff adherence to development work processes

- cost performance or other measures of budget predictability

- $\quad$ schedule performance, milestone satisfaction, or other measures of schedule predictability

- $\quad$ accuracy of estimates (e.g., effort, cost, or schedule)

- product cycle time, time to market, or delivery rate

- $\quad$ business growth and profitability (e.g., market share, revenue generated, profits, or return on investment)

The relationship summarized in Figure 69 is a very strong one. The stair-step differences are even more pronounced here. While fewer organizations used project and organizational performance measurement results less than occasionally than was true for product and quality, almost none of those organizations 
claim that the overall value of their measurement and analysis activities has provided more than mixed value.

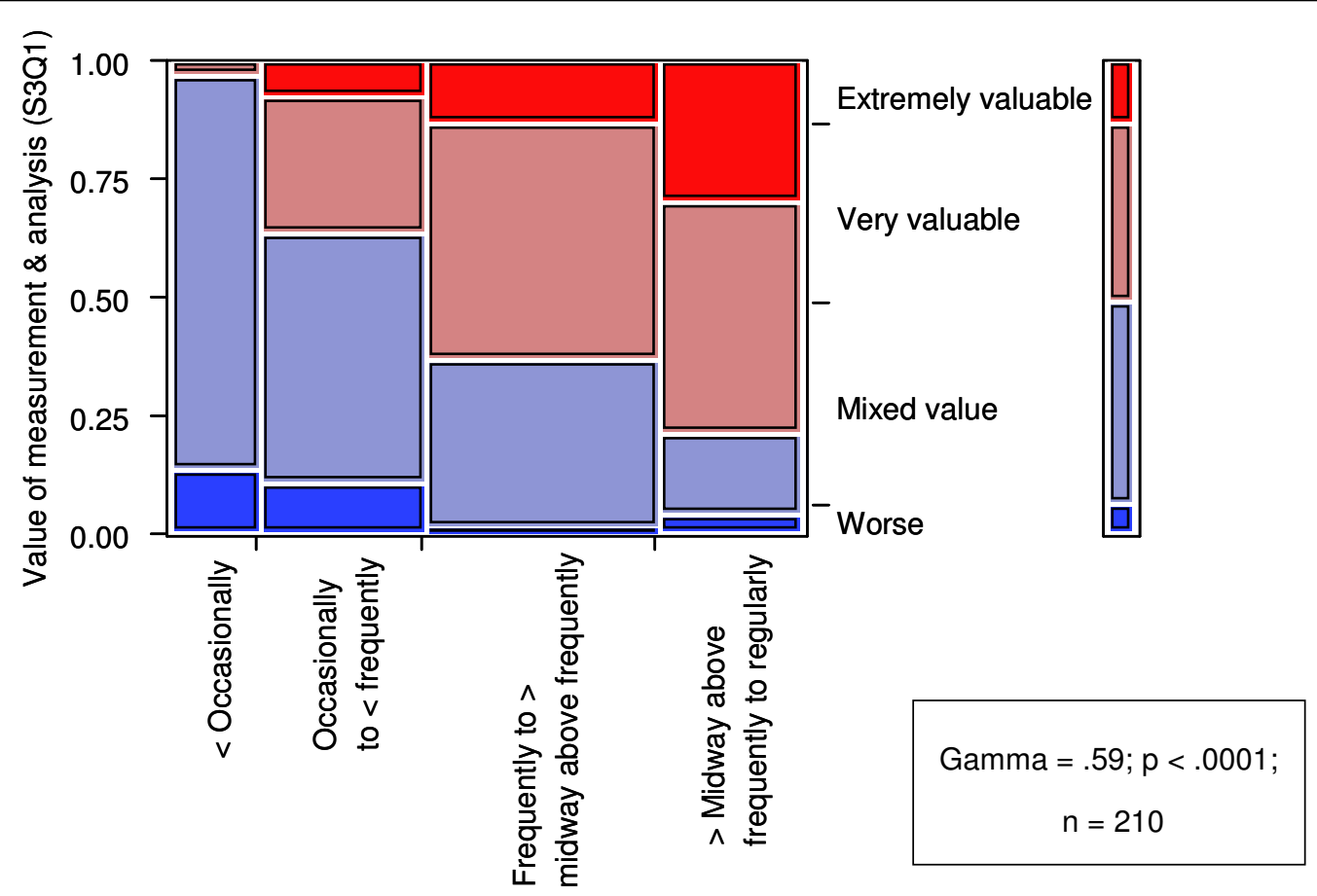

Project \& organizational measurement results (S5Q1 composite)

Figure 69: Relationship between use of project and organizational measurement results and overall value attributed to measurement and analysis

As was shown in Figure 67, other things being equal, higher maturity level organizations clearly are more likely to find value in using measurement and analysis than those at lower maturity levels. However, maturity level itself corresponds with the performance effects largely through increased use of specific measurement results. Some of the relationships between maturity level and overall value persist, but are attenuated (weaker) when examined separately by frequency of use of measurement results. ${ }^{33}$ The use of measurement results continues to be associated with overall value when compared separately by different maturity levels. Those relationships are especially strong in the high maturity organizations, but the use of measurement and analyses shows value even in maturity level one organizations.

The relationships for frequency of use of project and organizational performance measurement results are shown in Figure 70 and Figure 71. Figure 70 shows that the frequency of use of the results is associated with the range of value attributed to measurement and analysis in maturity level four and five organizations. The same comparison is made for the maturity level one organizations in Figure $71 .^{34}$

33 In the interest of space, those differences are not shown here.

34 The comparisons at maturity levels two and three are somewhat less interesting, but the relationships persist there as well. They are not reported here in the interests of space. Relatively similar maturity level differences exist for frequency of use of product and quality measurement results, especially at maturity level one. However, they too are 
As expected, the differences in Figure 70 are quite pronounced at maturity levels four and five, and the relationship is a very strong one. Notice that almost none of the higher maturity organizations use these kinds of measurement results less than frequently. However more frequent reporting of measurement results appears to add additional value, even among these high maturity organizations.

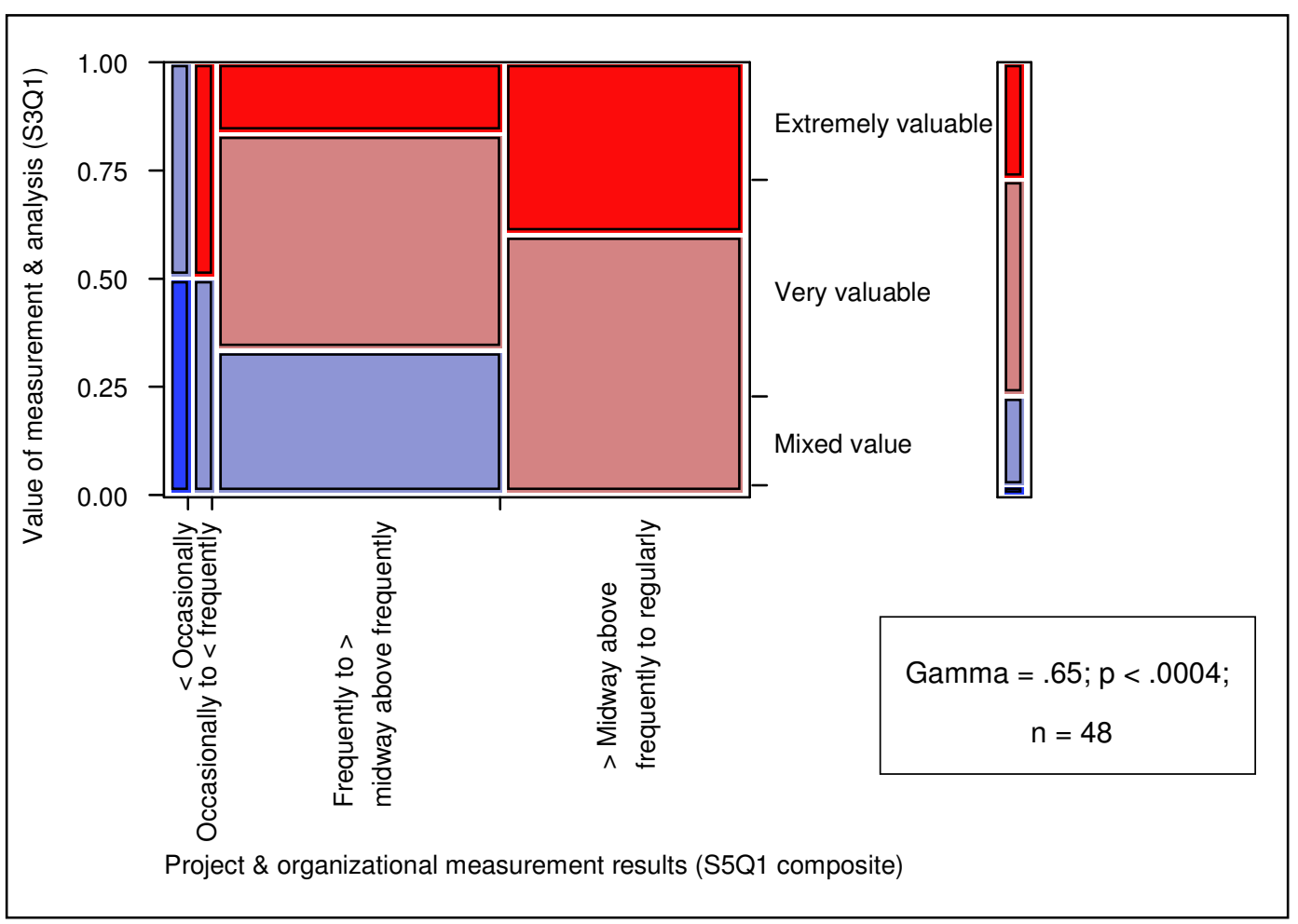

Figure 70: ML 5 only - Relationship between use of project /organizational measurement results and overall value attributed to measurement and analysis 
More frequent use and reporting of measurement results also can add value for lower maturity organizations, even for those at level one. Not surprisingly, fewer maturity level one organizations typically produce and report measurement results on a frequent basis; however the overall relationship remains quite strong. More importantly, there is evidence here that measurement-related activities can begin to add noticeable value early-on, when organizations first begin their process improvement journeys.

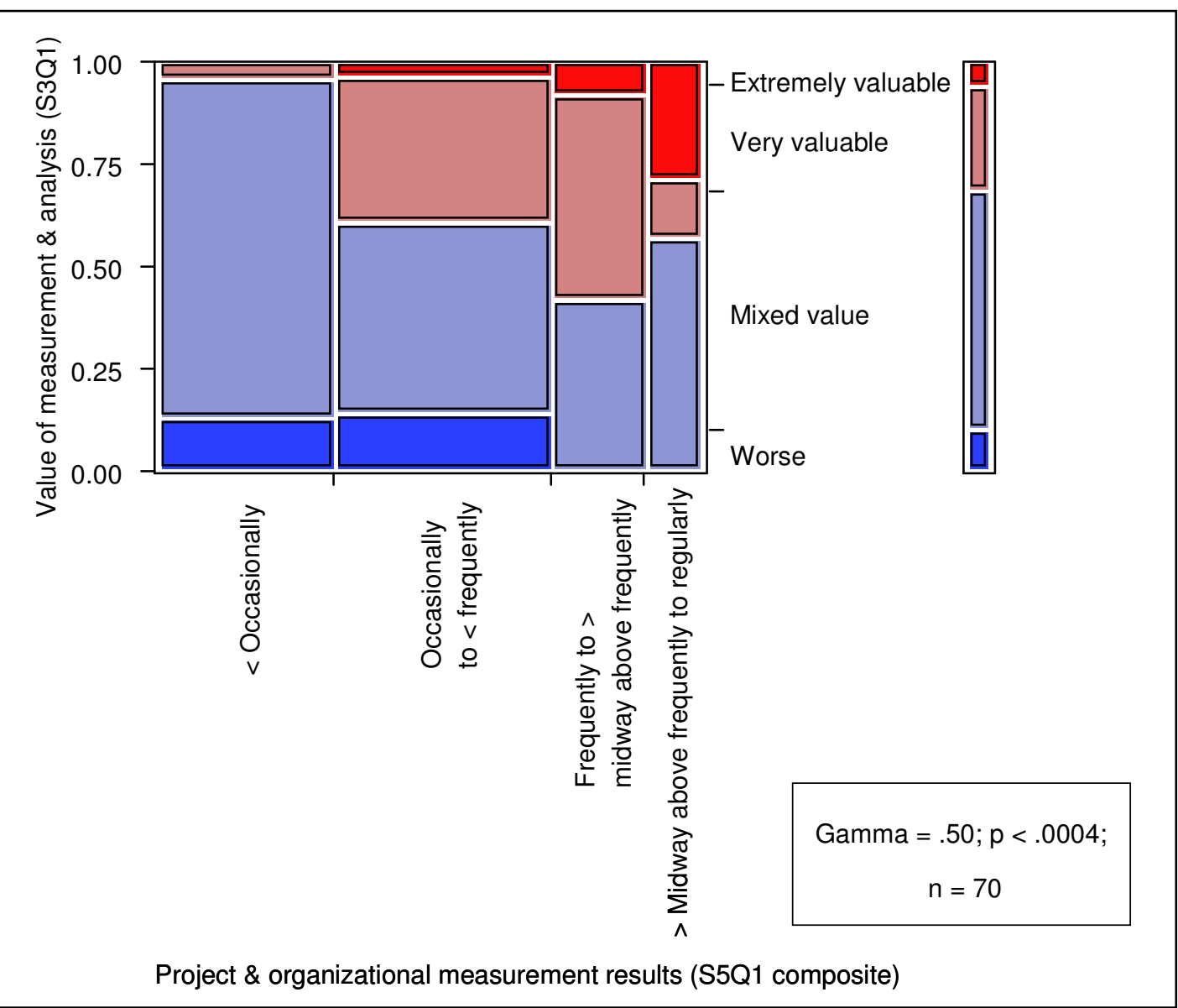

Figure 71: ML1/DK only - Relationship between use of project /organizational measurement results and overall value attributed to measurement and analysis 


\section{Summary and Conclusions}

All of the high maturity organizations in the survey sample reported having received at least some business value as a result of their process performance modeling activities (see Section 3). They most often said that their models were very valuable and that they "have obtained much useful information from them" (52\%); eight percent say that they were extremely valuable, and that they "couldn't do [their] work properly without them." Others did say that their models have provided mixed value, but that they "have obtained useful information on occasion" (38\%), and a very few reported little or no value (2\%). None report being worse off as a result of their process performance modeling efforts. More importantly, differences in the outcomes of the modeling reported vary consistently as a function of how well what have been called the "healthy ingredients" of process performance modeling are understood in these organizations and the uses to which the results have been put (see Section 6.2). They also differ predictably as a function of the extent to which a varied mix of several statistical and analytic methods is used in the modeling (see Section 6.2). Similarly, as is so typical for process improvement in general, the overall value reported varies by how much management support exists for process performance modeling in these organizations (see Section 6.3).

While much of the relationship appears to be mediated by the consequences of other, interim activities, the reported value of the modeling also varies by the extent to which all relevant stakeholders are involved in deciding what to model and the reasons why the modeling should be done (see Section 6.4). The same is true for the extent of training related to measurement and process performance modeling that is required by these organizations (see Section 6.5). The business value of their process performance modeling efforts is not affected directly by differences in the amount of technical challenge faced by projects in the responding organizations; however, significantly more value appears to be added under more difficult circumstances. That is true in spite of the fact that fewer resources tend to be allocated to process performance modeling under such circumstances (see Section 6.6).

As seen throughout this report, many of the statistical relationships just mentioned are quite strong for survey data of this kind. Altogether, we are able to predict over 70 percent of the ranked differences in outcome that the respondents reported about the business value of their process performance modeling activities (see Section 6.7). Other evidence about the value of measurement and analysis in lower maturity organizations is discussed briefly in Section 7.

It is our hope that this first survey on measurement and analysis in high maturity organizations has provided better insight than was previously available into the value that organizations can and have achieved as outcomes of the deployment of their process performance baselines and models. The empirical results presented here may provide a more compelling case to help organizations understand what it takes to be truly successful using process performance models and how to better ensure that the deployment of such models succeeds. Most if not all of the $\mathrm{x}$ factors that we have analyzed and that seem to drive successful use of process performance modeling are controllable by management and technical actions. The results may better arm managers and deployment champions to drive business and product excellence in their own organizations and throughout the CMMI-based process improvement community. 
70 | CMU/SEI-2008-TR-024 


\section{Appendix A: Questionnaire for the Survey of High Maturity Organizations}

This appendix contains a listing of all of the survey questions that have forced-choice, closed-ended answers. It is annotated with the number of responses for each answer and the percentage of the total answers that each answer represents, except for the multiple response questions which present only the counts. Response counts are not provided for questions where the answers vary widely and a concise summary would be misleading. We have also included data tags with each question for cross reference (e.g., S1Q2). The free-form textual answers to selected open-ended questions are in Appendix C. Facsimiles of the invitations and reminder letters sent to the survey respondents follow the question and answer listing in this appendix. ${ }^{35}$

35 We also sent very similar personalized reminders to those who had begun but not yet completed their questionnaires. They are not reproduced here in the interests of space. 
Software Engineering Institute

Carnegie Mellon

The State of Measurement \& Analysis 2008: Survey of Applications in Support of High Maturity Practice

1. Which of the following best describes the role you play in your organization? (S1Q2)

\begin{tabular}{|l|r|r|}
\hline Category & Count & \multicolumn{1}{|c|}{$\%$} \\
\hline 1 = Executive or senior manager & 92 & 59 \\
\hline 2 = Middle manager (e.g., program or product line) & 23 & 15 \\
\hline 3 = Project manager & 15 & 10 \\
\hline $4=$ Project engineer or other technical staff $>$ & 5 & 03 \\
\hline $5=$ Process or quality engineer & 1 & 01 \\
\hline 6 = Measurement specialist & 2 & 01 \\
\hline $7=$ Other Total & 18 & 12 \\
\hline \multicolumn{2}{r}{} & \\
\hline
\end{tabular}

2. How is your organization best described?

\begin{tabular}{|l|r|r|}
\hline Category & Count & $\%$ \\
\hline $\begin{array}{l}\text { 1 = Commercial off the shelf (e.g., shrink-wrap or custom } \\
\text { installation of enterprise solutions such as SAP or Oracle) }\end{array}$ & 7 & 5 \\
\hline $\begin{array}{l}2 \text { = Contracted new development, (e.g., for use in par- } \\
\text { ticular product lines or other novel point solutions=S1Q3) }\end{array}$ & & 51 \\
\hline 3 = In-house or proprietary development or maintenance & 25 & 33 \\
\hline 4 = Defense contractor & 31 & 16 \\
\hline 5 = Other government contractor & 7 & 5 \\
\hline 6 = Department of Defense or military organization & 3 & 2 \\
\hline 7 = Other government agency & 1 & 1 \\
\hline 8 = Other & 30 & 19 \\
\hline
\end{tabular}

3. What is the primary focus of your organization's work?

\begin{tabular}{|c|c|c|}
\hline Category & Count & $\%$ \\
\hline $1=$ Product or system development & 97 & 63 \\
\hline $2=$ Maintenance or sustainment & 19 & 12 \\
\hline $3=$ Acquisition & 22 & 14 \\
\hline $4=$ Service provision & 16 & 10 \\
\hline Total & 154 & \\
\hline
\end{tabular}


4. What kinds of engineering are major parts of your organization's work? (Please select as many as apply) [154 respondents]

\begin{tabular}{|l|r|}
\hline Category & Count \\
\hline 1 = Software engineering & 97 \\
\hline 2 = Systems engineering & 75 \\
\hline 3 = Hardware engineering & 31 \\
\hline 4 = Design engineering & 54 \\
\hline 5 = Test engineering & 75 \\
\hline 6 = Other & 5 \\
\hline
\end{tabular}

5. How would you best describe your involvement with measurement and analysis?

\begin{tabular}{|l|r|r|}
\hline Category & Count & \multicolumn{1}{|c|}{$\%$} \\
\hline $1=$ I am a provider of measurement-based information & 6 & 4 \\
\hline 2 = I am a user (consumer) of measurement-based information & 49 & 31 \\
\hline $\begin{array}{l}3=\text { I am both a provider and user (consumer) of measurement- } \\
\text { based information }\end{array}$ & 96 & 62 \\
\hline $4=$ Other & 5 & 3 \\
\hline & 156 & \\
\hline
\end{tabular}

6. In what country is your organization primarily located?

\begin{tabular}{|l|r|r|}
\hline Category & Count & \multicolumn{1}{|c|}{$\%$} \\
\hline 1 = United States & 41 & 26 \\
\hline 2 = Canada & 4 & 3 \\
\hline 3 = China & 23 & 15 \\
\hline 4 = France & 0 & 0 \\
\hline 5 = Germany & 0 & 0 \\
\hline 6 = India & 46 & 30 \\
\hline 7 = Japan & 6 & 4 \\
\hline 8 = Netherlands & 1 & 1 \\
\hline 9 = United Kingdom & 2 & 1 \\
\hline 10 = All Others Total & 32 & 21 \\
\hline \multicolumn{2}{|c|}{155} & \\
\hline
\end{tabular}


7. Approximately how many full-time employees in your organization work predominantly in software, hardware or systems engineering (e.g., development, maintenance, acquisition or provision of related services)?

\begin{tabular}{|l|r|r|}
\hline \multicolumn{1}{|c|}{ Category } & Count & \multicolumn{1}{c|}{$\%$} \\
\hline $1=25$ or fewer & 0 & 0 \\
\hline $2=26-50$ & 2 & 1 \\
\hline $3=51-75$ & 3 & 2 \\
\hline $4=76-100$ & 3 & 2 \\
\hline $5=101-200$ & 22 & 14 \\
\hline $6=201-300$ & 23 & 15 \\
\hline $7=301-500$ & 17 & 11 \\
\hline $8=501-1000$ & 30 & 19 \\
\hline $9=1001-2000$ & 18 & 12 \\
\hline $10=$ More than 2000 & 38 & 24 \\
\hline Total & 156 & \\
\hline
\end{tabular}

8. To the best of your knowledge, what is the current maturity level of your organization? (Please select one.)

\begin{tabular}{|c|c|c|}
\hline Category & Count & $\%$ \\
\hline $1=$ CMMI Maturity Level 3 or lower & 6 & 4 \\
\hline $2=$ Close To Maturity Level 4 & 6 & 4 \\
\hline $3=$ CMMI Maturity Level 4 & 25 & 16 \\
\hline $4=$ CMMI Maturity Level 5 & 118 & 76 \\
\hline $5=$ Don't know & 1 & 1 \\
\hline Total & 156 & \\
\hline
\end{tabular}




\section{Measurement Related Training \& Staffing}

1. What best characterizes the measurement related training that your organization requires for its employees? (Please select one for each)

Executive and senior managers

\begin{tabular}{|l|r|r|}
\hline Category & Count & \multicolumn{1}{|c|}{$\%$} \\
\hline 1 = None & 6 & 4 \\
\hline $2=$ On the job & 19 & 13 \\
\hline $3=$ Online/self paced & 9 & 6 \\
\hline $4=$ Briefings & 75 & 50 \\
\hline $5=$ Tutorials & 7 & 5 \\
\hline $6=1-2$ day courses & 22 & 15 \\
\hline $7=1-4$ week courses & 7 & 5 \\
\hline $8=$ College courses & 1 & 1 \\
\hline $9=$ Don't know & 3 & 2 \\
\hline $10=$ Does not apply & 0 & 0 \\
\hline \multicolumn{1}{|c|}{ Total } & 149 & \\
\hline
\end{tabular}

Middle managers (e.g., program or product line)

\begin{tabular}{|l|r|r|}
\hline Category & Count & \multicolumn{1}{|c|}{$\%$} \\
\hline $1=$ None & 1 & 1 \\
\hline $2=$ On the job & 16 & 11 \\
\hline $3=$ Online/self paced & 10 & 7 \\
\hline $4=$ Briefings & 22 & 15 \\
\hline $5=$ Tutorials & 18 & 12 \\
\hline $6=1-2$ day courses & 69 & 46 \\
\hline $7=1-4$ week courses & 13 & 9 \\
\hline $8=$ College courses & 0 & 0 \\
\hline $9=$ Don't know & 0 & 0 \\
\hline $10=$ Does not apply & 0 & 0 \\
\hline & 149 & \\
\hline
\end{tabular}

Project managers

\begin{tabular}{|c|c|c|}
\hline Category & Count & $\%$ \\
\hline $1=$ None & 0 & 0 \\
\hline $2=$ On the job & 9 & 6 \\
\hline $3=$ Online $/$ self paced & 12 & 8 \\
\hline $4=$ Briefings & 9 & 6 \\
\hline $5=$ Tutorials & 15 & 10 \\
\hline $6=1-2$ day courses & 76 & 51 \\
\hline $7=1-4$ week courses & 28 & 19 \\
\hline $8=$ College courses & 0 & 0 \\
\hline $9=$ Don't know & 0 & 0 \\
\hline $10=$ Does not apply & 0 & 0 \\
\hline Total & 149 & \\
\hline
\end{tabular}


Project engineers and other technical staff

\begin{tabular}{|c|c|c|}
\hline Category & Count & $\%$ \\
\hline $1=$ None & 0 & 0 \\
\hline $2=$ On the job & 22 & 15 \\
\hline $3=$ Online $/$ self paced & 11 & 7 \\
\hline $4=$ Briefings & 12 & 8 \\
\hline $5=$ Tutorials & 25 & 17 \\
\hline $6=1-2$ day courses & 57 & 38 \\
\hline $7=1-4$ week courses & 19 & 13 \\
\hline $8=$ College courses & 2 & 1 \\
\hline $9=$ Don't know & 0 & 0 \\
\hline $10=$ Does not apply & 1 & 1 \\
\hline Total & 149 & \\
\hline
\end{tabular}


Process or quality engineers

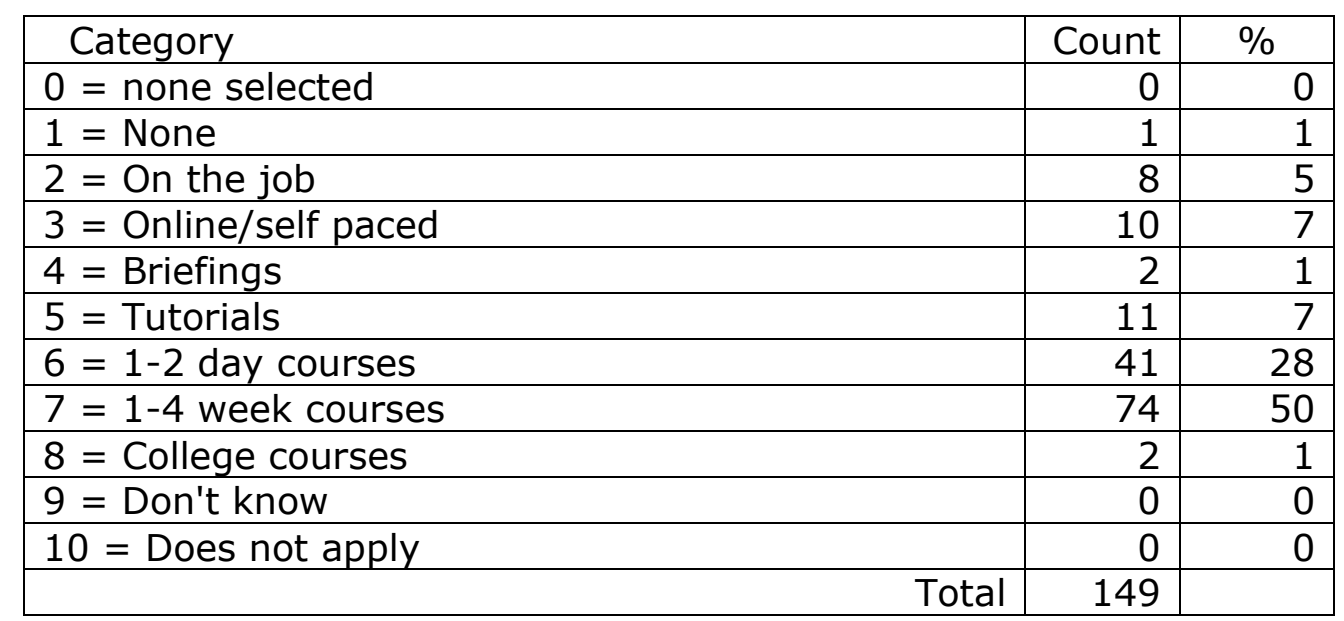

2. What kind of specialized training, if any, does your organization require for its employees who have responsibilities for process performance modeling? (Please select one for each)

Process performance model builders \& maintainers (e.g., Six Sigma black belts or other measurement specialists)

\begin{tabular}{|c|c|c|}
\hline Category & Count & $\%$ \\
\hline $1=$ None & 1 & 1 \\
\hline $2=$ On the job & 7 & 5 \\
\hline $\begin{array}{l}3=\text { Online/self } \\
\text { paced }\end{array}$ & 4 & 3 \\
\hline $4=$ Briefings & 2 & 1 \\
\hline $5=$ Tutorials & 5 & 3 \\
\hline $6=1-2$ day courses & 33 & 22 \\
\hline $\begin{array}{l}7=1-4 \text { week } \\
\text { courses }\end{array}$ & 79 & 53 \\
\hline $8=$ College courses & 13 & 9 \\
\hline $9=$ Don't know & 2 & 1 \\
\hline $10=$ Does not apply & 3 & 2 \\
\hline Total & 149 & \\
\hline
\end{tabular}


Coaches \& mentors who assist the model builders and maintainers (e.g., Six Sigma master black belts)

\begin{tabular}{|l|r|r|}
\hline \multicolumn{1}{|c|}{ Category } & Count & \multicolumn{1}{c|}{$\%$} \\
\hline $1=$ None & 3 & 2 \\
\hline $2=$ On the job & 8 & 5 \\
\hline $3=$ Online/self paced & 7 & 5 \\
\hline $4=$ Briefings & 3 & 2 \\
\hline $5=$ Tutorials & 7 & 5 \\
\hline $6=1-2$ day courses & 40 & 27 \\
\hline $7=1-4$ week courses & 57 & 38 \\
\hline $8=$ College courses & 11 & 7 \\
\hline $9=$ Don't know & 3 & 2 \\
\hline $10=$ Does not apply & 10 & 7 \\
\hline Total & 149 & \\
\hline
\end{tabular}

Those who collect and manage the baseline data (e.g., Six Sigma green belts, other project engineers or EPG members)

\begin{tabular}{|c|c|c|}
\hline Category & Count & $\%$ \\
\hline $1=$ None & 0 & 0 \\
\hline $2=$ On the job & 14 & 9 \\
\hline $3=$ Online/self paced & 9 & 6 \\
\hline $4=$ Briefings & 5 & 3 \\
\hline $5=$ Tutorials & 12 & 8 \\
\hline $6=1-2$ day courses & 49 & 33 \\
\hline $7=1-4$ week courses & 57 & 38 \\
\hline $8=$ College courses & 2 & 1 \\
\hline $9=$ Don't know & 0 & 0 \\
\hline $10=$ Does not apply & 0 & 0 \\
\hline Total & 149 & \\
\hline
\end{tabular}

Users of the models

\begin{tabular}{|c|c|c|}
\hline Category & Count & $\%$ \\
\hline $1=$ None & 1 & 1 \\
\hline $2=$ On the job & 30 & 20 \\
\hline $3=$ Online/self paced & 8 & 5 \\
\hline $4=$ Briefings & 21 & 14 \\
\hline $5=$ Tutorials & 27 & 18 \\
\hline $6=1-2$ day courses & 50 & 34 \\
\hline $7=1-4$ week courses & 10 & 7 \\
\hline $8=$ College courses & 0 & 0 \\
\hline $9=$ Don't know & 0 & 0 \\
\hline $10=$ Does not apply & 1 & 1 \\
\hline Total & 148 & \\
\hline
\end{tabular}


3. In what ways does your organization ensure that its process performance model builders and maintainers are properly trained? [156 respondents]

\begin{tabular}{|l|r|}
\hline Category & Count \\
\hline Training developed and delivered internally within the organization & 131 \\
\hline Purchase of training materials that are developed elsewhere but deliv- & \\
ered internally & 45 \\
\hline Contracts with external training services & 94 \\
\hline Conferences and symposiums & 86 \\
\hline We hire the right people in the first place & 51 \\
\hline Other (Please describe briefly) & 11 \\
\hline
\end{tabular}

4. What, if any, other types of measurement related training or mentoring does your organization provide? (Please describe briefly)

5. Approximately how many people in your organization work with process performance baselines and models - as part of their explicitly assigned work efforts? (Please specify a number for each ... or type $D K$ if you don't know)

\begin{tabular}{|l|}
\hline $\begin{array}{l}\text { Those who collect and manage the baseline data (e.g., Six Sigma } \\
\text { green belts, other project engineers or EPG members) }\end{array}$ \\
\hline Those who build and maintain the models (e.g., Six Sigma black \\
belts or other measurement specialists) \\
\hline Those who mentor or coach the model builders and maintainers \\
(e.g., Six Sigma master black belts) \\
\hline Those who use the model results to inform their decision making \\
\hline
\end{tabular}

6. Approximately how many people build or maintain the models and baselines as their primary work assignments? (Please specify a number for each ... or type DK if you don't know)

\begin{tabular}{|l|}
\hline The builders and maintainers \\
\hline Their mentors or coaches \\
\hline
\end{tabular}

7. How well do the people who create your organization's process performance models and baselines understand the intent of CMMI? (Please select one for each)

The CMMI definition of a process performance model

\begin{tabular}{|l|r|r|}
\hline Category & Count & \multicolumn{1}{|c|}{$\%$} \\
\hline 1 = Extremely well & 46 & 31 \\
\hline 2 = Very well & 77 & 52 \\
\hline 3 = Moderately well & 20 & 14 \\
\hline 4 = To some extent & 3 & 2 \\
\hline 5 = Hardly at all & 0 & 0 \\
\hline 6 = Don't know & 2 & 1 \\
\hline Total & 148 & \\
\hline
\end{tabular}


The CMMI definition of a process performance baseline

\begin{tabular}{|c|c|c|}
\hline Category & Count & $\%$ \\
\hline $1=$ Extremely well & 56 & 38 \\
\hline $2=$ Very well & 72 & 49 \\
\hline $3=$ Moderately well & 17 & 11 \\
\hline $4=$ To some extent & 1 & 1 \\
\hline $5=$ Hardly at all & 0 & 0 \\
\hline $6=$ Don't know & 2 & 1 \\
\hline Total & 148 & \\
\hline
\end{tabular}

The circumstances when process performance baselines are useful

\begin{tabular}{|c|c|c|}
\hline Category & Count & $\%$ \\
\hline 1 = Extremely well & 39 & 26 \\
\hline $2=$ Very well & 74 & 50 \\
\hline $3=$ Moderately well & 32 & 22 \\
\hline $4=$ To some extent & 2 & 1 \\
\hline $5=$ Hardly at all & 0 & 0 \\
\hline 6 = Don't know & 1 & 1 \\
\hline Total & 148 & \\
\hline
\end{tabular}

The circumstances when process performance models are useful

\begin{tabular}{|c|c|c|}
\hline Category & Count & $\%$ \\
\hline $1=$ Extremely well & 31 & 21 \\
\hline $2=$ Very well & 70 & 47 \\
\hline $3=$ Moderately well & 40 & 27 \\
\hline $4=$ To some extent & 6 & 4 \\
\hline $5=$ Hardly at all & 0 & 0 \\
\hline $6=$ Don't know & 1 & 1 \\
\hline Total & 148 & \\
\hline
\end{tabular}

8. How well do the managers in your organization who use process performance model results understand the results that they use? (Please select one.)

\begin{tabular}{|l|r|r|}
\hline Category & Count & \multicolumn{1}{c|}{$\%$} \\
\hline 1 Extremely well & 11 & 7 \\
\hline 2 Very well & 54 & 36 \\
\hline 3 Moderately well & 68 & 46 \\
\hline 4 To some extent & 15 & 10 \\
\hline 5 Hardly at all & 1 & 1 \\
\hline 6 Don't know & 0 & 0 \\
\hline \multicolumn{1}{|r|}{ Total } & 149 & \\
\hline
\end{tabular}


9. How often are qualified, well-prepared people available to work on process performance modeling in your organization when you need them (i.e., people with sufficient measurement related knowledge, competence, and statistical sophistication)? (Please select one.)

\begin{tabular}{|c|c|c|}
\hline Category & Count & $\%$ \\
\hline $1=$ Almost always (Greater than or equal to $80 \%$ ) & 53 & 36 \\
\hline $2=$ Frequently (Greater than or equal to $60 \%$ & 48 & 32 \\
\hline $3=$ About half of the time (Greater than $40 \%$ but less than $60 \%$ ) & 26 & 17 \\
\hline $4=$ Occasionally (Less than or equal to $40 \%$ ) & 19 & 13 \\
\hline $5=$ Rarely if ever (Less than or equal to $20 \%$ ) & 3 & 2 \\
\hline Total & 149 & \\
\hline
\end{tabular}

10. Does your organization provide promotion or financial incentives for its employees that are tied to the deployment and adoption of measurement and analysis (e.g., via six sigma belt programs)? (Please select as many as apply) [156 respondents]

\begin{tabular}{|l|r|}
\hline Category & Count \\
\hline No & 72 \\
\hline Yes ... for executive and senior managers & 38 \\
\hline$\ldots$ for middle managers (e.g., program or product line) & 48 \\
\hline$\ldots$ for project managers & 55 \\
\hline$\ldots$ for project engineers and other technical staff & 50 \\
\hline$\ldots$ for others (Please describe briefly) & 21 \\
\hline Don't know & 4 \\
\hline
\end{tabular}




\section{Alignment, Coordination \& Infrastructure}

1. How would you characterize the involvement of various potential stakeholders in setting goals and deciding on plans of action for measurement and analysis in your organization? (Please select one for each)

Customers

\begin{tabular}{|c|c|c|}
\hline Category & Count & $\%$ \\
\hline $1=$ Extensive & 12 & 8 \\
\hline $2=$ Substantial & 19 & 13 \\
\hline $3=$ Moderate & 48 & 33 \\
\hline $4=$ Limited & 37 & 25 \\
\hline $5=$ Little if any & 14 & 10 \\
\hline $6=$ Don't know & 3 & 2 \\
\hline $7=$ Does not apply & 13 & 9 \\
\hline Total & 146 & \\
\hline
\end{tabular}


Executive and senior managers

\begin{tabular}{|c|c|c|}
\hline Category & Count & $\%$ \\
\hline $1=$ Extensive & 48 & 33 \\
\hline $2=$ Substantial & 52 & 36 \\
\hline $3=$ Moderate & 37 & 26 \\
\hline $4=$ Limited & 6 & 4 \\
\hline $5=$ Little if any & 1 & 1 \\
\hline $6=$ Don't know & 0 & 0 \\
\hline 7 = Does not apply & 0 & 0 \\
\hline Total & 144 & \\
\hline
\end{tabular}

Middle managers (e.g., program or product line)

\begin{tabular}{|c|c|c|}
\hline Category & Count & $\%$ \\
\hline $1=$ Extensive & 40 & 28 \\
\hline $2=$ Substantial & 61 & 42 \\
\hline $3=$ Moderate & 37 & 26 \\
\hline $4=$ Limited & 5 & 3 \\
\hline $5=$ Little if any & 2 & 1 \\
\hline $6=$ Don't know & 0 & 0 \\
\hline 7 = Does not apply & 0 & 0 \\
\hline Total & 144 & \\
\hline
\end{tabular}

Project managers

\begin{tabular}{|c|c|c|}
\hline Category & Count & $\%$ \\
\hline $1=$ Extensive & 45 & 31 \\
\hline $2=$ Substantial & 58 & 40 \\
\hline $3=$ Moderate & 30 & 21 \\
\hline $4=$ Limited & 9 & 6 \\
\hline $5=$ Little if any & 2 & 1 \\
\hline $6=$ Don't know & 0 & 0 \\
\hline $7=$ Does not apply & 1 & 1 \\
\hline Total & 145 & \\
\hline
\end{tabular}

Project engineers and other technical staff

\begin{tabular}{|l|r|r|}
\hline \multicolumn{1}{|c|}{ Category } & Count & \multicolumn{1}{c|}{$\%$} \\
\hline $1=$ Extensive & 5 & 3 \\
\hline 2 = Substantial & 31 & 21 \\
\hline $3=$ Moderate & 53 & 37 \\
\hline $4=$ Limited & 44 & 30 \\
\hline $5=$ Little if any & 7 & 5 \\
\hline $6=$ Don't know & 0 & 0 \\
\hline $7=$ Does not apply & 5 & 3 \\
\hline Total & 145 & \\
\hline
\end{tabular}


Process and quality engineers

\begin{tabular}{|c|c|c|}
\hline Category & Count & $\%$ \\
\hline $1=$ Extensive & 63 & 43 \\
\hline $2=$ Substantial & 55 & 38 \\
\hline $3=$ Moderate & 19 & 13 \\
\hline $4=$ Limited & 6 & 4 \\
\hline $5=$ Little if any & 1 & 1 \\
\hline 6 = Don't know & 0 & 0 \\
\hline 7 = Does not apply & 1 & 1 \\
\hline Total & 145 & \\
\hline
\end{tabular}

Measurement specialists

\begin{tabular}{|l|r|r|}
\hline \multicolumn{1}{|c|}{ Category } & Count & $\%$ \\
\hline 1 = Extensive & 68 & 47 \\
\hline 2 = Substantial & 44 & 30 \\
\hline 3 = Moderate & 19 & 13 \\
\hline $4=$ Limited & 7 & 5 \\
\hline $5=$ Little if any & 2 & 1 \\
\hline 6 = Don't know & 0 & 0 \\
\hline 7 = Does not apply & 5 & 3 \\
\hline Total & 145 & \\
\hline
\end{tabular}

Others (Please describe briefly) name=S3Q1_9_txt

\begin{tabular}{|c|c|c|}
\hline Category & Count & $\%$ \\
\hline 1 = Extensive & 6 & 25 \\
\hline $2=$ Substantial & 1 & 4 \\
\hline $3=$ Moderate & 1 & 4 \\
\hline $4=$ Limited & 0 & 0 \\
\hline $5=$ Little if any & 0 & 0 \\
\hline 6 = Don't know & 2 & 8 \\
\hline $7=$ Does not apply & 14 & 58 \\
\hline Total & 24 & \\
\hline
\end{tabular}

2. Which of the following best describes how work on measurement and analysis is staffed in your organization? (Please select one.)

\begin{tabular}{|c|c|c|}
\hline Category & Count & $\%$ \\
\hline $\begin{array}{l}1=\text { An organization-wide, division or similar corporate support group } \\
\text { (e.g., an engineering process, quality assurance or measurement group) }\end{array}$ & 109 & 76 \\
\hline $\begin{array}{l}2=\text { Separate groups or individuals in different projects or other organ- } \\
\text { izational units (e.g., project, product team or similar work groups }\end{array}$ & 22 & 15 \\
\hline $\begin{array}{l}3=A \text { few key people (or one person) in the organization who are mea- } \\
\text { surement experts }\end{array}$ & 8 & 6 \\
\hline 4 = Other (Please describe briefly) & 5 & 3 \\
\hline Total & 144 & \\
\hline
\end{tabular}


3. How much automated support is available for measurement related activities in your organization? (Please select one for each.)

Data collection (e.g., on-line forms with "tickler" reminders, time stamped activity logs, static or dynamic analyses of call graphs or run-time behavior)

\begin{tabular}{|c|c|c|}
\hline Category & Count & $\%$ \\
\hline $1=$ Extensive & 41 & 28 \\
\hline $2=$ Substantial & 45 & 31 \\
\hline $3=$ Moderate & 30 & 21 \\
\hline $4=$ Limited & 21 & 14 \\
\hline $5=$ Little if any & 6 & 4 \\
\hline $6=$ Don't know & 0 & 0 \\
\hline $7=$ Does not apply & 2 & 1 \\
\hline Total & 145 & \\
\hline
\end{tabular}

Commercial work flow automation that supports data collection

\begin{tabular}{|c|c|c|}
\hline Category & Count & $\%$ \\
\hline $1=$ Extensive & 22 & 15 \\
\hline 2 = Substantial & 27 & 19 \\
\hline $3=$ Moderate & 31 & 21 \\
\hline $4=$ Limited & 25 & 17 \\
\hline 5 = Little if any & 20 & 14 \\
\hline $6=$ Don't know & 0 & 0 \\
\hline $7=$ Does not apply & 20 & 14 \\
\hline Total & 145 & \\
\hline
\end{tabular}

Data management (e.g., relational or distributed database packages, open database connectivity, tools for data integrity, verification, or validation)

\begin{tabular}{|c|c|c|}
\hline Category & Count & $\%$ \\
\hline $1=$ Extensive & 37 & 26 \\
\hline $2=$ Substantial & 45 & 31 \\
\hline $3=$ Moderate & 37 & 26 \\
\hline $4=$ Limited & 14 & 10 \\
\hline $5=$ Little if any & 9 & 6 \\
\hline $6=$ Don't know & 0 & 0 \\
\hline $7=$ Does not apply & 3 & 2 \\
\hline Total & 145 & \\
\hline
\end{tabular}


Spreadsheet add-ons for basic statistical analysis

\begin{tabular}{|c|c|c|}
\hline Category & Count & $\%$ \\
\hline $1=$ Extensive & 47 & 33 \\
\hline $2=$ Substantial & 48 & 34 \\
\hline $3=$ Moderate & 24 & 17 \\
\hline $4=$ Limited & 19 & 13 \\
\hline $5=$ Little if any & 3 & 2 \\
\hline $6=$ Don't know & 2 & 1 \\
\hline $7=$ Does not apply & 0 & 0 \\
\hline Total & 143 & \\
\hline
\end{tabular}

Commercial statistical packages that support more advanced analyses

\begin{tabular}{|c|c|c|}
\hline Category & Count & $\%$ \\
\hline $1=$ Extensive & 23 & 16 \\
\hline $2=$ Substantial & 30 & 21 \\
\hline $3=$ Moderate & 28 & 19 \\
\hline $4=$ Limited & 23 & 16 \\
\hline $5=$ Little if any & 19 & 13 \\
\hline $6=$ Don't know & 2 & 1 \\
\hline 7 = Does not apply & 19 & 13 \\
\hline Total & 144 & \\
\hline
\end{tabular}

Customized spreadsheets for routine analyses (e.g., for defect phase containment)

\begin{tabular}{|c|c|c|}
\hline Category & Count & $\%$ \\
\hline $1=$ Extensive & 43 & 30 \\
\hline $2=$ Substantial & 54 & 38 \\
\hline $3=$ Moderate & 28 & 19 \\
\hline $4=$ Limited & 10 & 7 \\
\hline $5=$ Little if any & 5 & 3 \\
\hline $6=$ Don't know & 1 & 1 \\
\hline 7 = Does not apply & 3 & 2 \\
\hline Total & 144 & \\
\hline
\end{tabular}


Commercial software for report preparation (e.g., graphing packages or other presentation quality results)

\begin{tabular}{|c|c|c|}
\hline Category & Count & $\%$ \\
\hline $1=$ Extensive & 17 & 12 \\
\hline $2=$ Substantial & 27 & 19 \\
\hline $3=$ Moderate & 32 & 22 \\
\hline $4=$ Limited & 28 & 19 \\
\hline $5=$ Little if any & 18 & 12 \\
\hline $6=$ Don't know & 2 & 1 \\
\hline 7 = Does not apply & 21 & 14 \\
\hline Total & 145 & \\
\hline
\end{tabular}

Other (Please describe briefly)

\begin{tabular}{|c|c|c|}
\hline Category & Count & $\%$ \\
\hline $1=$ Extensive & 8 & 27 \\
\hline 2 = Substantial & 4 & 13 \\
\hline $3=$ Moderate & 2 & 7 \\
\hline $4=$ Limited & 0 & $\underline{0}$ \\
\hline $5=$ Little if any & 0 & 0 \\
\hline 6 = Don't know & 2 & 7 \\
\hline $7=$ Does not apply & 14 & 47 \\
\hline Total & 30 & \\
\hline
\end{tabular}

4. How often does your organization do the following with the data it collects? (Please check one for each)

Check for out of range or other illegal values in the recorded data

\begin{tabular}{|l|r|r|}
\hline \multicolumn{1}{|c|}{ Category } & Count & \multicolumn{1}{c|}{$\%$} \\
\hline 1 = Almost always & 86 & 60 \\
\hline 2 = Frequently & 45 & 31 \\
\hline $3=$ About half the time & 7 & 5 \\
\hline $4=$ Occasionally & 6 & 4 \\
\hline $5=$ Rarely if ever & 0 & 0 \\
\hline 6 = Don't know & 0 & 0 \\
\hline \multicolumn{1}{r|}{ Total } & 144 & \\
\hline
\end{tabular}

Evaluate the number and distribution of missing data

\begin{tabular}{|l|r|r|}
\hline Category & Count & \multicolumn{1}{|c|}{$\%$} \\
\hline 1 = Almost always & 57 & 40 \\
\hline 2 = Frequently & 59 & 41 \\
\hline $3=$ About half the time & 7 & 5 \\
\hline $4=$ Occasionally & 14 & 10 \\
\hline $5=$ Rarely if ever & 5 & 4 \\
\hline 6 = Don't know & 1 & 1 \\
\hline \multicolumn{1}{|r|}{ Total } & 143 & \\
\hline
\end{tabular}


Ensure that missing data are not inadvertently treated as zero values

\begin{tabular}{|l|r|r|}
\hline Category & Count & \multicolumn{1}{c|}{$\%$} \\
\hline 1 = Almost always & 78 & 54 \\
\hline 2 = Frequently & 40 & 28 \\
\hline 3 = About half the time & 9 & 6 \\
\hline 4 = Occasionally & 6 & 4 \\
\hline 5 = Rarely if ever & 7 & 5 \\
\hline 6 = Don't know & 4 & 3 \\
\hline \multicolumn{1}{|r|}{ Total } & 144 & \\
\hline
\end{tabular}

Check for precision and accuracy of the data

\begin{tabular}{|c|c|c|}
\hline Category & Count & $\%$ \\
\hline $1=$ Almost always & 62 & 43 \\
\hline $2=$ Frequently & 53 & 37 \\
\hline $3=$ About half the time & 13 & 9 \\
\hline $4=$ Occasionally & 15 & 10 \\
\hline $5=$ Rarely if ever & 0 & 0 \\
\hline $6=$ Don't know & 0 & 0 \\
\hline Tota & 143 & \\
\hline
\end{tabular}

Estimate measurement error statistically

\begin{tabular}{|l|r|c|}
\hline \multicolumn{1}{|c|}{ Category } & Count & $\%$ \\
\hline 1 = Almost always & 20 & 14 \\
\hline 2 = Frequently & 38 & 27 \\
\hline $3=$ About half the time & 14 & 10 \\
\hline 4 = Occasionally & 40 & 28 \\
\hline $5=$ Rarely if ever & 27 & 19 \\
\hline 6 = Don't know & 4 & 3 \\
\hline \multicolumn{1}{r|}{ Total } & 143 & \\
\hline
\end{tabular}

Check for inconsistent interpretations of measurement definitions

\begin{tabular}{|c|c|c|}
\hline Category & Count & $\%$ \\
\hline $1=$ Almost always & 41 & 29 \\
\hline $2=$ Frequently & 67 & 47 \\
\hline $3=$ About half the time & 12 & 8 \\
\hline $4=$ Occasionally & 19 & 13 \\
\hline $5=$ Rarely if ever & 2 & 1 \\
\hline $6=$ Don't know & 2 & 1 \\
\hline Total & 143 & \\
\hline
\end{tabular}


Check for consistency/reliability of measurement results and procedures across time and reporting units

\begin{tabular}{|l|r|r|}
\hline Category & Count & $\%$ \\
\hline 1 = Almost always & 38 & 27 \\
\hline 2 = Frequently & 75 & 52 \\
\hline 3 = About half the time & 8 & 6 \\
\hline 4 = Occasionally & 16 & 11 \\
\hline 5 = Rarely if ever & 4 & 3 \\
\hline 6 = Don't know & 2 & 1 \\
\hline \multicolumn{1}{|r|}{ Total } & 143 & \\
\hline
\end{tabular}

Check for consistency of classification decisions based on the same information, (otherwise known as inter-coder reliability)

\begin{tabular}{|l|r|r|}
\hline Category & Count & $\%$ \\
\hline 1 = Almost always & 23 & 16 \\
\hline 2 = Frequently & 54 & 38 \\
\hline 3 = About half the time & 11 & 8 \\
\hline $4=$ Occasionally & 27 & 19 \\
\hline 5 = Rarely if ever & 15 & 11 \\
\hline 6 = Don't know & 12 & 8 \\
\hline \multicolumn{1}{|r|}{ Total } & 142 & \\
\hline
\end{tabular}

Analyze \& address the reasons for unusual patterns in the data distributions, e.g., outliers, skewness, or other aspects of non normal distributions

\begin{tabular}{|l|r|r|}
\hline \multicolumn{1}{|c|}{ Category } & Count & \multicolumn{1}{c|}{$\%$} \\
\hline 1 = Almost always & 61 & 43 \\
\hline 2 = Frequently & 55 & 39 \\
\hline $3=$ About half the time & 10 & 7 \\
\hline $4=$ Occasionally & 13 & 9 \\
\hline $5=$ Rarely if ever & 2 & 1 \\
\hline 6 = Don't know Total & 1 & 1 \\
\hline \multicolumn{2}{|r|}{142} & \\
\hline
\end{tabular}

Analyze \& address the reasons for unusual or unanticipated relationships between two or more measures

\begin{tabular}{|c|c|c|}
\hline Category & Count & $\%$ \\
\hline $1=$ Almost always & 44 & 31 \\
\hline $2=$ Frequently & 50 & 35 \\
\hline $3=$ About half the time & 15 & 11 \\
\hline $4=$ Occasionally & 25 & 18 \\
\hline $5=$ Rarely if ever & 6 & 4 \\
\hline 6 = Don't know & 2 & 1 \\
\hline Total & 142 & \\
\hline
\end{tabular}


Automate data quality/integrity checks for ease of collecting consistent data

\begin{tabular}{|l|r|r|}
\hline Category & Count & $\%$ \\
\hline 1 = Almost always & 29 & 21 \\
\hline 2 = Frequently & 48 & 34 \\
\hline 3 = About half the time & 14 & 10 \\
\hline 4 = Occasionally & 28 & 20 \\
\hline 5 = Rarely if ever & 19 & 13 \\
\hline 6 = Don't know Total & 3 & 2 \\
\hline \multicolumn{2}{|r|}{ Total } & 141 \\
\hline
\end{tabular}

Other (Please describe briefly)

\begin{tabular}{|l|r|r|}
\hline \multicolumn{1}{|c|}{ Category } & Count & $\%$ \\
\hline 1 = Almost always & 5 & 23 \\
\hline 2 = Frequently & 3 & 14 \\
\hline $3=$ About half the time & 0 & 0 \\
\hline $4=$ Occasionally & 0 & 0 \\
\hline 5 = Rarely if ever & 1 & 5 \\
\hline 6 = Don't know & 13 & 59 \\
\hline \multicolumn{1}{|r|}{ Total } & 22 & \\
\hline
\end{tabular}




\section{Use of Process Performance Models \& Baselines}

1. For what operational purposes are models and baselines routinely used in your project and organizational product development, maintenance or acquisition activities? (Please select as many as apply ... or be sure to check 'None of the above' if appropriate.) [156 respondents]

\begin{tabular}{|l|r|}
\hline Category & Count \\
\hline $\begin{array}{l}\text { Defining the organization's standard processes (e.g., implementing the } \\
\text { entire process asset library in a simulation model) }\end{array}$ & 80 \\
\hline $\begin{array}{l}\text { Composing projects' defined processes (e.g., modeling trade-offs in } \\
\text { cost, schedule and quality to select among alternative subprocesses or } \\
\text { compositions for a given project) }\end{array}$ & \\
\hline Risk management & 100 \\
\hline Project planning & 82 \\
\hline Project monitoring and corrective actions & 128 \\
\hline Identifying opportunities for process or technology improvement & 131 \\
\hline Evaluating process or technology improvements & 114 \\
\hline Other (Please describe briefly) & 103 \\
\hline None of the above & 7 \\
\hline Don't know & 0 \\
\hline
\end{tabular}

2. Where else in the organization are process performance models and baselines used? (Please select as many as apply ... or be sure to check 'None of the above' if appropriate.) [152 respondents]

\begin{tabular}{|l|r|}
\hline Category & Count \\
\hline Corporate planning and strategy & 51 \\
\hline Portfolio planning & 22 \\
\hline $\begin{array}{l}\text { Responses to requests for proposals or tender offers (e.g., cost and } \\
\text { achievability modeling) }\end{array}$ & 75 \\
\hline Marketing & 26 \\
\hline Technology R\&D & 39 \\
\hline Business operations & 63 \\
\hline Supply chain management & 10 \\
\hline Human resources management & 36 \\
\hline Other (Please describe briefly) & 5 \\
\hline None of the above & 20 \\
\hline Don't know & 11 \\
\hline
\end{tabular}


3. Which of the following product quality and project performance outcomes are routinely predicted with process performance models in your organization? (Please select as many as apply ... or be sure to check 'None of the above' if appropriate.) [156 respondents]

\begin{tabular}{|l|r|}
\hline Category & Count \\
\hline Delivered defects & 127 \\
\hline Type or severity of defects & 68 \\
\hline $\begin{array}{l}\text { Product quality attributes (e.g., mean time to failure, design complex- } \\
\text { ity, maintainability, interoperability, portability, usability, reliability, } \\
\text { complexity, reusability or durability) }\end{array}$ & \\
\hline Quality of services provided (e.g., IT ticket resolution time) & 58 \\
\hline Cost and schedule duration & 66 \\
\hline Work product size & 119 \\
\hline Accuracy of estimates (e.g., cost, schedule, product size or effort) & 53 \\
\hline ROI of process improvement or related financial performance & 98 \\
\hline Customer satisfaction & 35 \\
\hline Other (Please describe briefly) & 58 \\
\hline None of the above & 3 \\
\hline Don't know & 1 \\
\hline
\end{tabular}

4. Which of the following (often interim) process performance outcomes are routinely predicted with process performance models in your organization? (Please select as many as apply ... or be sure to check 'None of the above' if appropriate) [156 respondents]

\begin{tabular}{|l|r|}
\hline Category & Count \\
\hline Escaped defects (e.g., as predicted by defect phase containment models) & 98 \\
\hline Cost of quality and poor quality (e.g., rework) & 69 \\
\hline $\begin{array}{l}\text { Estimates at completion (i.e., performed periodically throughout the pro- } \\
\text { ject) }\end{array}$ & 108 \\
\hline Requirements volatility or growth & 41 \\
\hline Effectiveness or efficiency of inspection or test coverage & 83 \\
\hline Practitioner adherence to defined processes & 38 \\
\hline Other (Please describe briefly) & 5 \\
\hline None of the above & 4 \\
\hline Don't know & 1 \\
\hline
\end{tabular}

5. Which of the following processes and activities are routinely modeled in your organization? (Please select as many as apply ... or be sure to check 'None of the above' if appropriate)[156 respondents]

\begin{tabular}{|l|r|}
\hline Category & Count \\
\hline Project planning and estimation & 121 \\
\hline Requirements engineering & 79 \\
\hline Product architecture & 35 \\
\hline Software design and coding & 101 \\
\hline Process documentation & 48 \\
\hline Quality control processes & 108 \\
\hline
\end{tabular}




\begin{tabular}{|l|r|}
\hline Systems engineering processes & 47 \\
\hline Hardware engineering processes & 18 \\
\hline Acquisition or supplier processes & 9 \\
\hline Other (Please describe briefly) & 2 \\
\hline None of the above & 1 \\
\hline Don't know & 0 \\
\hline
\end{tabular}

6. How much emphasis does your organization place upon the following in its process performance modeling? (Please select one for each.)

Accounting for uncertainty and variability in predictive factors and predicted outcomes

\begin{tabular}{|c|c|c|}
\hline Category & Count & $\%$ \\
\hline $1=$ Extensive & 25 & 18 \\
\hline $2=$ Substantial & 44 & 31 \\
\hline $3=$ Moderate & 36 & 25 \\
\hline $4=$ Limited & 20 & 14 \\
\hline $5=$ Little if any & 10 & 7 \\
\hline 6 = Don't know & 3 & 2 \\
\hline $7=$ Does not apply & 4 & 3 \\
\hline Total & 142 & \\
\hline
\end{tabular}

Factors that are under management or technical control

\begin{tabular}{|c|c|c|}
\hline Category & Count & $\%$ \\
\hline $1=$ Extensive & 26 & 19 \\
\hline 2 = Substantial & 60 & 43 \\
\hline $3=$ Moderate & 34 & 24 \\
\hline $4=$ Limited & 11 & 8 \\
\hline $5=$ Little if any & 4 & 3 \\
\hline 6 = Don't know & 3 & 2 \\
\hline $7=$ Does not apply & 2 & 1 \\
\hline Total & 140 & \\
\hline
\end{tabular}

Other product, contractual or organizational characteristics, resources or constraints

\begin{tabular}{|c|c|c|}
\hline Category & Count & $\%$ \\
\hline $1=$ Extensive & 13 & 9 \\
\hline $2=$ Substantial & 36 & 25 \\
\hline $3=$ Moderate & 39 & 27 \\
\hline $4=$ Limited & 21 & 15 \\
\hline 5 = Little if any & 20 & 14 \\
\hline $6=$ Don't know & 4 & 3 \\
\hline 7 = Does not apply & 9 & 6 \\
\hline Total & 142 & \\
\hline
\end{tabular}


Segmenting or otherwise accounting for uncontrollable factors

\begin{tabular}{|c|c|c|}
\hline Category & Count & $\%$ \\
\hline $1=$ Extensive & 10 & 7 \\
\hline $2=$ Substantial & 25 & 18 \\
\hline $3=$ Moderate & 35 & 25 \\
\hline $4=$ Limited & 32 & 23 \\
\hline $5=$ Little if any & 20 & 14 \\
\hline 6 = Don't know & 8 & 6 \\
\hline 7 = Does not apply & 12 & 8 \\
\hline Total & 142 & \\
\hline
\end{tabular}

Factors that are tied to detailed subprocesses

\begin{tabular}{|c|c|c|}
\hline Category & Count & $\%$ \\
\hline $1=$ Extensive & 22 & 15 \\
\hline $2=$ Substantial & 52 & 36 \\
\hline $3=$ Moderate & 39 & 27 \\
\hline $4=$ Limited & 13 & 9 \\
\hline $5=$ Little if any & 11 & 8 \\
\hline $6=$ Don't know & 3 & 2 \\
\hline $7=$ Does not apply & 3 & 2 \\
\hline Total & 143 & \\
\hline
\end{tabular}

Factors that are tied to larger, more broadly defined organizational processes

\begin{tabular}{|c|c|c|}
\hline Category & Count & $\%$ \\
\hline $1=$ Extensive & 17 & 12 \\
\hline $2=$ Substantial & 45 & 32 \\
\hline $3=$ Moderate & 46 & 32 \\
\hline $4=$ Limited & 17 & 12 \\
\hline $5=$ Little if any & 10 & 7 \\
\hline $6=$ Don't know & 5 & 4 \\
\hline $7=$ Does not apply & 2 & 1 \\
\hline Total & 142 & \\
\hline
\end{tabular}

Other (Please describe briefly)

\begin{tabular}{|c|c|c|}
\hline Category & Count & $\%$ \\
\hline $1=$ Extensive & 0 & 0 \\
\hline $2=$ Substantial & 0 & 0 \\
\hline $3=$ Moderate & 4 & 17 \\
\hline $4=$ Limited & 0 & 0 \\
\hline $5=$ Little if any & 0 & 0 \\
\hline 6 = Don't know & 4 & 17 \\
\hline $7=$ Does not apply & 15 & 65 \\
\hline Total & 23 & \\
\hline
\end{tabular}

7. To what degree are your organization's process performance models used for the following purposes? (Please select one for each.) 
Predict final project outcomes

\begin{tabular}{|c|c|c|}
\hline Category & Count & $\%$ \\
\hline $1=$ Extensive & 45 & 32 \\
\hline $2=$ Substantial & 52 & 37 \\
\hline $3=$ Moderate & 33 & 23 \\
\hline $4=$ Limited & 11 & 8 \\
\hline $5=$ Little if any & 0 & 0 \\
\hline 6 = Don't know & 0 & 0 \\
\hline 7 = Does not apply & 0 & 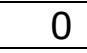 \\
\hline Total & 141 & \\
\hline
\end{tabular}

Predict interim outcomes during project execution (e.g., connecting "upstream" with "downstream" activities)

\begin{tabular}{|c|c|c|}
\hline Category & Count & $\%$ \\
\hline $1=$ Extensive & 39 & 27 \\
\hline $2=$ Substantial & 47 & 33 \\
\hline $3=$ Moderate & 35 & 25 \\
\hline $4=$ Limited & 16 & 11 \\
\hline $5=$ Little if any & 2 & 1 \\
\hline 6 = Don't know & 1 & 1 \\
\hline 7 = Does not apply & 2 & 1 \\
\hline Total & 142 & \\
\hline
\end{tabular}

Model the variation of factors and understand the predicted range or variation of the predicted outcomes

\begin{tabular}{|c|c|c|}
\hline Category & Count & $\%$ \\
\hline $1=$ Extensive & 24 & 17 \\
\hline $2=$ Substantial & 43 & 30 \\
\hline $3=$ Moderate & 36 & 25 \\
\hline $4=$ Limited & 27 & 19 \\
\hline 5 = Little if any & 12 & 8 \\
\hline 6 = Don't know & 1 & 1 \\
\hline $7=$ Does not apply & 1 & 1 \\
\hline Total & 144 & \\
\hline
\end{tabular}

Enable "what-if" analysis for project planning, dynamic re-planning and problem resolution during project execution

\begin{tabular}{|c|c|c|}
\hline Category & Count & $\%$ \\
\hline $1=$ Extensive & 23 & 16 \\
\hline $2=$ Substantial & 42 & 30 \\
\hline $3=$ Moderate & 37 & 26 \\
\hline $4=$ Limited & 27 & 19 \\
\hline $5=$ Little if any & 10 & 7 \\
\hline $6=$ Don't know & 0 & 0 \\
\hline 7 = Does not apply & 3 & 2 \\
\hline Total & 142 & \\
\hline
\end{tabular}


Enable projects to achieve mid-course corrections to ensure project success

\begin{tabular}{|c|c|c|}
\hline Category & Count & $\%$ \\
\hline $1=$ Extensive & 34 & 24 \\
\hline $2=$ Substantial & 50 & 35 \\
\hline $3=$ Moderate & 38 & 27 \\
\hline $4=$ Limited & 18 & 13 \\
\hline 5 = Little if any & 3 & 2 \\
\hline $6=$ Don't know & 0 & $\underline{0}$ \\
\hline 7 = Does not apply & 0 & 0 \\
\hline Total & 143 & \\
\hline
\end{tabular}

Other (Please describe briefly)

\begin{tabular}{|c|c|c|}
\hline Category & Count & $\%$ \\
\hline $1=$ Extensive & 1 & 5 \\
\hline $2=$ Substantial & 0 & 0 \\
\hline $3=$ Moderate & 2 & 11 \\
\hline $4=$ Limited & 0 & 0 \\
\hline $5=$ Little if any & 0 & 0 \\
\hline $6=$ Don't know & 5 & 26 \\
\hline $7=$ Does not apply & 11 & 55 \\
\hline Total & 19 & \\
\hline
\end{tabular}




\section{Other Analytic Methods \& Techniques}

1. To what extent are the following statistical methods used in your organization's process performance modeling? (Please select one for each.)

Regression analysis predicting continuous outcomes (e.g., bivariate or multivariate linear regression or non-linear regression)

\begin{tabular}{|c|c|c|}
\hline Category & Count & $\%$ \\
\hline $1=$ Extensive & 29 & 21 \\
\hline 2 = Substantial & 27 & 19 \\
\hline $3=$ Moderate & 37 & 26 \\
\hline $4=$ Limited & 27 & 19 \\
\hline $5=$ Little if any & 10 & 7 \\
\hline 6 = Don't know & 4 & 3 \\
\hline 7 = Does not apply & 7 & 5 \\
\hline Total & 141 & \\
\hline
\end{tabular}

Regression analysis predicting categorical outcomes (e.g., logistic regression or loglinear models)

\begin{tabular}{|c|c|c|}
\hline Category & Count & $\%$ \\
\hline $1=$ Extensive & 16 & 11 \\
\hline 2 = Substantial & 9 & 6 \\
\hline $3=$ Moderate & 27 & 19 \\
\hline $4=$ Limited & 34 & 24 \\
\hline 5 = Little if any & 21 & 15 \\
\hline $6=$ Don't know & 13 & 9 \\
\hline 7 = Does not apply & 20 & 14 \\
\hline Total & 140 & \\
\hline
\end{tabular}

Analysis of variance (e.g., ANOVA, ANCOVA or MANOVA)

\begin{tabular}{|c|c|c|}
\hline Category & Count & $\%$ \\
\hline $1=$ Extensive & 16 & 12 \\
\hline $2=$ Substantial & 26 & 19 \\
\hline $3=$ Moderate & 28 & 20 \\
\hline $4=$ Limited & 27 & 19 \\
\hline $5=$ Little if any & 23 & 17 \\
\hline $6=$ Don't know & 11 & 8 \\
\hline $7=$ Does not apply & 8 & 6 \\
\hline Total & 139 & \\
\hline
\end{tabular}


Attribute SPC charts (e.g., c, $u, p$, or $n p$ )

\begin{tabular}{|c|c|c|}
\hline Category & Count & $\%$ \\
\hline 1 = Extensive & 27 & 19 \\
\hline $2=$ Substantial & 29 & 20 \\
\hline $3=$ Moderate & 25 & 17 \\
\hline $4=$ Limited & 26 & 18 \\
\hline $5=$ Little if any & 15 & 10 \\
\hline $6=$ Don't know & 10 & 7 \\
\hline $7=$ Does not apply & 11 & 8 \\
\hline Total & 143 & \\
\hline
\end{tabular}

Individual point SPC charts (e.g., ImR or XmR)

\begin{tabular}{|c|c|c|}
\hline Category & Count & $\%$ \\
\hline 1 = Extensive & 43 & 30 \\
\hline $2=$ Substantial & 45 & 32 \\
\hline $3=$ Moderate & 27 & 19 \\
\hline $4=$ Limited & 14 & 10 \\
\hline $5=$ Little if any & 3 & 2 \\
\hline 6 = Don't know & 6 & 4 \\
\hline 7 = Does not apply & 4 & 3 \\
\hline Total & 142 & \\
\hline
\end{tabular}

Continuous SPC charts (e.g., XbarR or XbarS)

\begin{tabular}{|c|c|c|}
\hline Category & Count & $\%$ \\
\hline $1=$ Extensive & 31 & 22 \\
\hline 2 = Substantial & 30 & 21 \\
\hline $3=$ Moderate & 26 & 18 \\
\hline 4 = Limited & 21 & 15 \\
\hline $5=$ Little if any & 15 & 11 \\
\hline $6=$ Don't know & 7 & 5 \\
\hline 7 = Does not apply & 12 & 8 \\
\hline Total & 142 & \\
\hline
\end{tabular}


Design of experiments

\begin{tabular}{|c|c|c|}
\hline Category & Count & $\%$ \\
\hline $1=$ Extensive & 4 & 3 \\
\hline $2=$ Substantial & 7 & 5 \\
\hline $3=$ Moderate & 20 & 14 \\
\hline $4=$ Limited & 35 & 25 \\
\hline $5=$ Little if any & 36 & 26 \\
\hline 6 = Don't know & 10 & 7 \\
\hline 7 = Does not apply & 27 & 19 \\
\hline Total & 139 & \\
\hline
\end{tabular}

Other (Please describe briefly)

\begin{tabular}{|c|c|c|}
\hline Category & Count & $\%$ \\
\hline $1=$ Extensive & 5 & 17 \\
\hline $2=$ Substantial & 1 & 3 \\
\hline $3=$ Moderate & 1 & 3 \\
\hline $4=$ Limited & 1 & 3 \\
\hline $5=$ Little if any & 0 & 0 \\
\hline 6 = Don't know & 4 & 13 \\
\hline 7 = Does not apply & 18 & 60 \\
\hline Total & 30 & \\
\hline
\end{tabular}

2. Which of the following visual display techniques are used to communicate the results of your organization's analyses of process performance baselines? (Please select as many as apply ... or be sure to check 'None of the above' if appropriate) [156 respondents]

\begin{tabular}{|l|r|}
\hline Category & Count \\
\hline Box plots & 80 \\
\hline Histograms & 124 \\
\hline Scatter plots or multivariate charting & 114 \\
\hline Pareto charts, pie charts or bar charts & 129 \\
\hline Mosaic charts for categorical data & 12 \\
\hline Other (Please describe briefly) & 11 \\
\hline None of the above & 0 \\
\hline Don't know & 0 \\
\hline
\end{tabular}


3. Which of the following other optimization approaches are used in your organization's process performance modeling? (Please select as many as apply ... or be sure to check 'None of the above' if appropriate.) [156 respondents]

\begin{tabular}{|l|r|}
\hline Category & Count \\
\hline Monte Carlo simulation & 59 \\
\hline Discrete event simulation for process modeling & 38 \\
\hline Markov or Petri-net models & 6 \\
\hline Probabilistic modeling & 46 \\
\hline Neural networks & 4 \\
\hline Optimization & 39 \\
\hline Other (Please describe briefly) & 5 \\
\hline None of the above & 36 \\
\hline Don't know & 7 \\
\hline
\end{tabular}

4. Which of these decision techniques are used in your organization? (Please select as many as apply ... or be sure to check 'None of the above' if appropriate.) [156 respondents]

\begin{tabular}{|l|r|}
\hline Category & Count \\
\hline Analytic Hierarchy Process (AHP) & 15 \\
\hline Real options & 24 \\
\hline Conjoint analysis & 16 \\
\hline Wide band Delphi & 65 \\
\hline Weighted multi criteria methods (e.g., QFD or \\
Pugh) & 86 \\
\hline Decision trees & 86 \\
\hline Other (Please describe briefly) & 17 \\
\hline None of the above & 4 \\
\hline Don't know & 12 \\
\hline
\end{tabular}




\section{Challenges \& Value Added}

1. Following is a series of statements about the kinds of technical challenges that projects sometimes face. How well do they describe your organization? (Please select one for each.)

Initial project requirements are not well defined

\begin{tabular}{|l|r|r|}
\hline Category & Count & \multicolumn{1}{c|}{$\%$} \\
\hline 1 = Almost entirely & 5 & 3 \\
\hline 2 = To a large extent & 30 & 21 \\
\hline 3 = To a moderate extent & 50 & 35 \\
\hline 4 = To a limited extent & 43 & 30 \\
\hline $5=$ Hardly at all & 14 & 10 \\
\hline 6 = Don't know & 0 & 0 \\
\hline 7 = Not applicable Total & 2 & 144 \\
\hline \multicolumn{2}{|c|}{} \\
\hline \multicolumn{2}{|c|}{} \\
\hline
\end{tabular}

Requirements change significantly throughout the life of the projects

\begin{tabular}{|l|r|r|}
\hline Category & Count & $\%$ \\
\hline $1=$ Almost entirely & 5 & 3 \\
\hline 2 = To a large extent & 32 & 22 \\
\hline $3=$ To a moderate extent & 70 & 49 \\
\hline $4=$ To a limited extent & 34 & 24 \\
\hline $5=$ Hardly at all & 3 & 2 \\
\hline $6=$ Don't know & 0 & 0 \\
\hline $7=$ Not applicable Total & 0 & 0 \\
\hline \multicolumn{2}{|r|}{144} & \\
\hline
\end{tabular}

There is little or no precedent for the kind of work we are doing

\begin{tabular}{|c|c|c|}
\hline Category & Count & $\%$ \\
\hline $1=$ Almost entirely & 2 & 1 \\
\hline $2=$ To a large extent & 4 & 3 \\
\hline $3=$ To a moderate extent & 30 & 21 \\
\hline $4=$ To a limited extent & 65 & 45 \\
\hline $5=$ Hardly at all & 38 & 26 \\
\hline 6 = Don't know & 0 & 0 \\
\hline $7=$ Not applicable & 0 & 0 \\
\hline Total & 144 & \\
\hline
\end{tabular}

Significant constraints are placed on product quality attributes (e.g., reliability, scalability, security, supportability, etc.)

\begin{tabular}{|l|r|r|}
\hline Category & Count & \multicolumn{1}{c|}{$\%$} \\
\hline $1=$ Almost entirely & 10 & 7 \\
\hline 2 = To a large extent & 38 & 27 \\
\hline
\end{tabular}




\begin{tabular}{|c|c|c|}
\hline $3=$ To a moderate extent & 35 & 24 \\
\hline $4=$ To a limited extent & 42 & 29 \\
\hline $5=$ Hardly at all & 14 & 10 \\
\hline $6=$ Don't know & 1 & 1 \\
\hline $7=$ Not applicable & 3 & 2 \\
\hline Total & 143 & \\
\hline
\end{tabular}

The size of the development effort is large

\begin{tabular}{|l|r|r|}
\hline Category & Count & \multicolumn{1}{c|}{$\%$} \\
\hline 1 = Almost entirely & 8 & 6 \\
\hline 2 = To a large extent & 40 & 28 \\
\hline 3 = To a moderate extent & 58 & 40 \\
\hline $4=$ To a limited extent & 27 & 19 \\
\hline $5=$ Hardly at all & 8 & 6 \\
\hline 6 = Don't know & 2 & 1 \\
\hline 7 = Not applicable Total & 1 & 1 \\
\hline \multicolumn{2}{|r|}{144} & \\
\hline
\end{tabular}

The technology needed for the projects is not mature

\begin{tabular}{|l|r|r|}
\hline Category & Count & \multicolumn{1}{c|}{$\%$} \\
\hline 1 = Almost entirely & 0 & 0 \\
\hline 2 = To a large extent & 13 & 9 \\
\hline 3 = To a moderate extent & 27 & 19 \\
\hline 4 = To a limited extent & 65 & 45 \\
\hline $5=$ Hardly at all & 37 & 26 \\
\hline 6 = Don't know & 0 & 0 \\
\hline 7 = Not applicable Total & 2 & 144 \\
\hline \multicolumn{2}{|c|}{} \\
\hline
\end{tabular}

There are extensive needs for interoperability with other systems

\begin{tabular}{|l|r|r|}
\hline Category & Count & \multicolumn{1}{c|}{$\%$} \\
\hline 1 = Almost entirely & 14 & 10 \\
\hline 2 = To a large extent & 40 & 28 \\
\hline 3 = To a moderate extent & 48 & 33 \\
\hline $4=$ To a limited extent & 33 & 23 \\
\hline $5=$ Hardly at all & 6 & 4 \\
\hline 6 = Don't know & 2 & 1 \\
\hline 7 = Not applicable Total & 144 & 1 \\
\hline \multicolumn{2}{|c|}{} \\
\hline
\end{tabular}

Insufficient resources (e.g., people, funding) are available to support the projects

\begin{tabular}{|l|r|r|}
\hline Category & Count & \multicolumn{1}{c|}{$\%$} \\
\hline 1 = Almost entirely & 4 & 3 \\
\hline 2 = To a large extent & 14 & 10 \\
\hline 3 = To a moderate extent & 30 & 21 \\
\hline
\end{tabular}




\begin{tabular}{|c|c|c|}
\hline $4=$ To a limited extent & 62 & 43 \\
\hline $5=$ Hardly at all & 33 & 23 \\
\hline $6=$ Don't know & 0 & 0 \\
\hline $7=$ Not applicable & 1 & 1 \\
\hline Total & 144 & \\
\hline
\end{tabular}

Insufficient skills and subject matter expertise are available to support the projects

\begin{tabular}{|l|r|r|}
\hline Category & Count & \multicolumn{1}{c|}{$\%$} \\
\hline 1 = Almost entirely & 0 & 0 \\
\hline 2 = To a large extent & 9 & 6 \\
\hline 3 = To a moderate extent & 22 & 15 \\
\hline $4=$ To a limited extent & 67 & 47 \\
\hline $5=$ Hardly at all & 45 & 31 \\
\hline 6 = Don't know & 1 & 1 \\
\hline $7=$ Not applicable Total & 0 & 0 \\
\hline \multicolumn{2}{|r|}{144} & \\
\hline
\end{tabular}

Other (Please describe briefly)

\begin{tabular}{|l|r|r|}
\hline Category & Count & \multicolumn{1}{c|}{$\%$} \\
\hline $1=$ Almost entirely & 1 & 5 \\
\hline 2 = To a large extent & 0 & 0 \\
\hline $3=$ To a moderate extent & 1 & 5 \\
\hline $4=$ To a limited extent & 0 & 0 \\
\hline $5=$ Hardly at all & 0 & 0 \\
\hline 6 = Don't know & 2 & 10 \\
\hline $7=$ Not applicable Total & 17 & 81 \\
\hline \multicolumn{2}{|r|}{21} & \\
\hline
\end{tabular}

2. Following are a few statements about the possible effects of using process performance modeling. To what extent do they describe what your organization has experienced? (Please select one for each.)

Better project performance (e.g., more accurate estimation, reduced cost, shorter cycle time or higher productivity)

\begin{tabular}{|c|c|c|}
\hline Category & Count & $\%$ \\
\hline $1=$ Almost always & 33 & 23 \\
\hline 2 = Frequently & 69 & 48 \\
\hline $3=$ About half the time & 19 & 13 \\
\hline $4=$ Occasionally & 19 & 13 \\
\hline $5=$ Rarely if ever & 2 & 1 \\
\hline $6=$ Worse, not better & 0 & 0 \\
\hline $7=$ Don't know & 1 & 1 \\
\hline $8=$ Not applicable & 0 & 0 \\
\hline Total & 143 & \\
\hline
\end{tabular}


Better product quality (e.g., fewer defects or improved customer satisfaction)

\begin{tabular}{|c|c|c|}
\hline Category & Count & $\%$ \\
\hline $1=$ Almost always & 34 & 24 \\
\hline $2=$ Frequently & 69 & 48 \\
\hline $3=$ About half the time & 16 & 11 \\
\hline 4 = Occasionally & 19 & 13 \\
\hline $5=$ Rarely if ever & 4 & 3 \\
\hline $6=$ Worse, not better & 0 & 0 \\
\hline $7=$ Don't know & 2 & 1 \\
\hline $8=$ Not applicable & 0 & 0 \\
\hline Total & 144 & \\
\hline
\end{tabular}

Fewer project failures

\begin{tabular}{|c|c|c|}
\hline Category & Count & $\%$ \\
\hline $1=$ Almost always & 32 & 22 \\
\hline $2=$ Frequently & 61 & 43 \\
\hline $3=$ About half the time & 16 & 11 \\
\hline $4=$ Occasionally & 20 & 14 \\
\hline $5=$ Rarely if ever & 8 & 6 \\
\hline $6=$ Worse, not better & 0 & 0 \\
\hline $7=$ Don't know & 2 & 1 \\
\hline $8=$ Not applicable & 4 & 3 \\
\hline Total & 143 & \\
\hline
\end{tabular}

Better tactical decisions about the adoption or improvement of work processes and technologies)

\begin{tabular}{|c|c|c|}
\hline Category & Count & $\%$ \\
\hline $1=$ Almost always & 16 & 11 \\
\hline $2=$ Frequently & 65 & 45 \\
\hline $3=$ About half the time & 11 & 8 \\
\hline 4 = Occasionally & 32 & 22 \\
\hline $5=$ Rarely if ever & 13 & 9 \\
\hline $6=$ Worse, not better & 0 & 0 \\
\hline $7=$ Don't know & 3 & 2 \\
\hline $8=$ Not applicable & 3 & 2 \\
\hline Total & 143 & \\
\hline
\end{tabular}


Better strategic decision making (e.g., about business growth or profitability)

\begin{tabular}{|c|c|c|}
\hline Category & Count & $\%$ \\
\hline $1=$ Almost always & 10 & 7 \\
\hline $2=$ Frequently & 49 & 34 \\
\hline $3=$ About half the time & 17 & 12 \\
\hline $4=$ Occasionally & 34 & 24 \\
\hline $5=$ Rarely if ever & 18 & 13 \\
\hline $6=$ Worse, not better & 0 & 0 \\
\hline $7=$ Don't know & 8 & 6 \\
\hline $8=$ Not applicable & 7 & 5 \\
\hline Total & 143 & \\
\hline
\end{tabular}

Other (Please describe briefly)

\begin{tabular}{|c|c|c|}
\hline Category & Count & $\%$ \\
\hline $1=$ Almost always & 2 & 9 \\
\hline $2=$ Frequently & 1 & 5 \\
\hline $3=$ About half the time & 0 & 0 \\
\hline 4 = Occasionally & 0 & 0 \\
\hline $5=$ Rarely if ever & 0 & 0 \\
\hline $6=$ Worse, not better & 0 & 0 \\
\hline 7 = Don't know & 5 & 23 \\
\hline $8=$ Not applicable & 14 & 64 \\
\hline Total & 22 & \\
\hline
\end{tabular}

3. How often are process performance model predictions used to inform decision making in your organization's status and milestone reviews? (Please select one.)

\begin{tabular}{|l|r|r|}
\hline Category & Count & $\%$ \\
\hline 1 Almost always & 28 & 20 \\
\hline 2 Frequently & 57 & 40 \\
\hline 3 About half the time & 27 & 19 \\
\hline 4 Occasionally & 23 & 16 \\
\hline 5 Rarely if ever & 7 & 5 \\
\hline 6 Don't know Total & 143 & 1 \\
\hline \multicolumn{2}{|r|}{} \\
\hline
\end{tabular}


4. Overall, how useful have process performance models been for your organization? (Please select one.)

\begin{tabular}{|l|r|r|}
\hline Category & Count & $\%$ \\
\hline $\begin{array}{l}1=\text { Extremely valuable -- we couldn't do our work properly } \\
\text { without them }\end{array}$ & 12 & 8 \\
\hline $\begin{array}{l}2=\text { Very valuable -- we have obtained much useful information } \\
\text { from them }\end{array}$ & 74 & 51 \\
\hline $\begin{array}{l}\text { = Mixed value -- we have obtained useful information on oc- } \\
\text { casion }\end{array}$ & 55 & 38 \\
\hline $4=$ Little or no value & 3 & 2 \\
\hline $5=$ It's been harmful, not helpful & 0 & 0 \\
\hline $6=$ Don't know & 0 & 0 \\
\hline & 144 & \\
\hline
\end{tabular}




\section{Barriers \& Facilitators of Effective Measurement \& Analysis}

1. Which, if any, of the following have been major obstacles during your organization's journey to high maturity? (Please select as many as apply ... or be sure to check 'None of the above' if appropriate.) [156 respondents]

\begin{tabular}{|l|r|}
\hline Category & Count \\
\hline $\begin{array}{l}\text { We focused only on final project outcomes rather than interim out- } \\
\text { comes }\end{array}$ & 36 \\
\hline $\begin{array}{l}\text { We didn't collect data frequently enough to help projects make mid- } \\
\text { course corrections }\end{array}$ & 48 \\
\hline $\begin{array}{l}\text { We failed to collect enough contextual information for proper seg- } \\
\text { mentation and stratification }\end{array}$ & 44 \\
\hline $\begin{array}{l}\text { We failed to achieve enough consistency in our measures to aggre- } \\
\text { gate and disaggregate them properly across the organization }\end{array}$ & \\
\hline $\begin{array}{l}\text { We failed to sufficiently align and prioritize our measurement and } \\
\text { analysis practices with our business and technical goals and objec- } \\
\text { tives }\end{array}$ & 26 \\
\hline $\begin{array}{l}\text { We've encountered resistance to collecting new or additional data } \\
\text { after achieving maturity level 3 }\end{array}$ & 42 \\
\hline $\begin{array}{l}\text { Our management thought that process performance modeling would } \\
\text { be an expensive overhead function rather than an essential part of } \\
\text { project work }\end{array}$ & 23 \\
\hline $\begin{array}{l}\text { We spent too much time creating reports for management review } \\
\text { instead of doing thorough analysis }\end{array}$ & 33 \\
\hline $\begin{array}{l}\text { We emphasized statistics more than domain knowledge and ended } \\
\text { up with ineffective models }\end{array}$ & 15 \\
\hline $\begin{array}{l}\text { We didn't provide sufficient mentoring and coaching for the indi- } \\
\text { viduals responsible for developing the models }\end{array}$ & 31 \\
\hline $\begin{array}{l}\text { Our process performance modelers don't have sufficient access to } \\
\text { people with statistical expertise }\end{array}$ & 35 \\
\hline Other (Please describe briefly) & \\
\hline None of the above & \\
\hline Don't know & \\
\hline
\end{tabular}


2. Following is a series of statements that are made in some organizations about the use of process performance modeling. How well do they describe your organization? (Please select one for each.)

We have trouble doing process performance modeling because it takes too long to accumulate enough historical data

\begin{tabular}{|c|c|c|}
\hline Category & Count & $\%$ \\
\hline $1=$ Almost entirely & 5 & 3 \\
\hline $2=$ To a large extent & 31 & 21 \\
\hline $3=$ To a moderate extent & 34 & 23 \\
\hline $4=$ To a limited extent & 36 & 25 \\
\hline $5=$ Hardly at all & 30 & 21 \\
\hline $6=$ Don't know & 0 & 0 \\
\hline $7=$ Not applicable & 9 & 6 \\
\hline Total & 145 & \\
\hline
\end{tabular}

Doing process performance modeling has become an accepted way of doing business here

\begin{tabular}{|c|c|c|}
\hline Category & Count & $\%$ \\
\hline $1=$ Almost entirely & 14 & 10 \\
\hline 2 = To a large extent & 37 & 26 \\
\hline $3=$ To a moderate extent & 51 & 35 \\
\hline $4=$ To a limited extent & 32 & 22 \\
\hline $5=$ Hardly at all & 8 & 6 \\
\hline 6 = Don't know & 1 & 1 \\
\hline $7=$ Not applicable & 2 & 1 \\
\hline Total & 145 & \\
\hline
\end{tabular}

We make our decisions about the models we build without sufficient participation by management or other important stakeholders

\begin{tabular}{|l|r|r|}
\hline \multicolumn{1}{|c|}{ Category } & Count & $\%$ \\
\hline $0=$ none selected & 2 & 1 \\
\hline $1=$ Almost entirely & 12 & 8 \\
\hline $2=$ To a large extent & 18 & 12 \\
\hline $3=$ To a moderate extent & 51 & 35 \\
\hline $4=$ To a limited extent & 55 & 38 \\
\hline $5=$ Hardly at all & 1 & 1 \\
\hline $6=$ Don't know & 6 & 4 \\
\hline $7=$ Not applicable & 145 & \\
\hline \multicolumn{1}{|r|}{ Total } & 2 & 1 \\
\hline
\end{tabular}


We have trouble convincing management about value of doing process performance modeling

\begin{tabular}{|l|r|r|}
\hline \multicolumn{1}{|c|}{ Category } & Count & \multicolumn{1}{c|}{$\%$} \\
\hline 1 = Almost entirely & 2 & 1 \\
\hline 2 = To a large extent & 7 & 5 \\
\hline 3 = To a moderate extent & 22 & 15 \\
\hline 4 = To a limited extent & 39 & 27 \\
\hline 5 = Hardly at all & 70 & 48 \\
\hline 6 = Don't know & 4 & 3 \\
\hline 7 = Not applicable & 5 & 3 \\
\hline \multicolumn{1}{|r|}{ Total } & 145 & \\
\hline
\end{tabular}

The messenger has been shot for delivering bad news based on process performance model predictions

\begin{tabular}{|l|r|r|}
\hline \multicolumn{1}{|c|}{ Category } & Count & \multicolumn{1}{c|}{$\%$} \\
\hline 1 = Almost entirely & 4 & 3 \\
\hline 2 = To a large extent & 4 & 3 \\
\hline 3 = To a moderate extent & 12 & 8 \\
\hline 4 = To a limited extent & 17 & 12 \\
\hline 5 = Hardly at all & 84 & 58 \\
\hline 6 = Don't know & 1 & 1 \\
\hline 7 = Not applicable & 27 & 19 \\
\hline \multicolumn{1}{|r|}{ Total } & 145 & \\
\hline
\end{tabular}

We thought we knew what was driving process performance, but process performance modeling has taught us otherwise

\begin{tabular}{|l|r|r|}
\hline Category & Count & \multicolumn{1}{c|}{$\%$} \\
\hline $0=$ none selected & 1 & 1 \\
\hline 1 = Almost entirely & 13 & 9 \\
\hline 2 = To a large extent & 37 & 26 \\
\hline $3=$ To a moderate extent & 48 & 33 \\
\hline $4=$ To a limited extent & 24 & 17 \\
\hline $5=$ Hardly at all & 10 & 7 \\
\hline 6 = Don't know & 11 & 8 \\
\hline $7=$ Not applicable & 144 & \\
\hline \multicolumn{1}{|r|}{ Total } & 1 & 1 \\
\hline
\end{tabular}

Our managers want to know when things are off-track

\begin{tabular}{|c|c|c|}
\hline Category & Count & $\%$ \\
\hline $1=$ Almost entirely & 52 & 36 \\
\hline 2 = To a large extent & 50 & 35 \\
\hline $3=$ To a moderate extent & 24 & 17 \\
\hline $4=$ To a limited extent & 9 & 6 \\
\hline $5=$ Hardly at all & 3 & 2 \\
\hline $6=$ Don't know & 2 & 1 \\
\hline $7=$ Not applicable & 4 & 3 \\
\hline Total & 144 & \\
\hline
\end{tabular}


Our managers are less willing to fund new work when the outcome is uncertain

\begin{tabular}{|l|r|r|}
\hline \multicolumn{1}{|c|}{ Category } & Count & \multicolumn{1}{c|}{$\%$} \\
\hline 1 = Almost entirely & 4 & 3 \\
\hline 2 = To a large extent & 33 & 23 \\
\hline $3=$ To a moderate extent & 33 & 23 \\
\hline $4=$ To a limited extent & 33 & 23 \\
\hline $5=$ Hardly at all & 28 & 19 \\
\hline 6 = Don't know & 4 & 3 \\
\hline 7 = Not applicable & 9 & 6 \\
\hline \multicolumn{1}{|r|}{ Total } & 144 & \\
\hline
\end{tabular}

We use data mining when similar but not identical electronic records exist

\begin{tabular}{|l|r|r|}
\hline \multicolumn{1}{|c|}{ Category } & Count & \multicolumn{1}{c|}{$\%$} \\
\hline 1 = Almost entirely & 4 & 3 \\
\hline 2 = To a large extent & 10 & 7 \\
\hline 3 = To a moderate extent & 31 & 21 \\
\hline 4 = To a limited extent & 40 & 28 \\
\hline 5 = Hardly at all & 25 & 17 \\
\hline 6 = Don't know & 18 & 12 \\
\hline 7 = Not applicable & 17 & 12 \\
\hline \multicolumn{1}{|r|}{ Total } & 145 & \\
\hline
\end{tabular}

We do real time sampling of current processes when historical data are not available

\begin{tabular}{|l|r|r|}
\hline Category & Count & \multicolumn{1}{c|}{$\%$} \\
\hline 1 = Almost entirely & 5 & 3 \\
\hline 2 = To a large extent & 23 & 16 \\
\hline 3 = To a moderate extent & 36 & 25 \\
\hline 4 = To a limited extent & 43 & 30 \\
\hline = Hardly at all & 21 & 14 \\
\hline 6 = Don't know & 3 & 2 \\
\hline 7 = Not applicable & 14 & 10 \\
\hline \multicolumn{1}{|r|}{ Total } & 145 & \\
\hline
\end{tabular}

We create our baselines from paper records for previously unmeasured attributes

\begin{tabular}{|c|c|c|}
\hline Category & Count & $\%$ \\
\hline $1=$ Almost entirely & 2 & 1 \\
\hline 2 = To a large extent & 1 & 1 \\
\hline $3=$ To a moderate extent & 18 & 13 \\
\hline $4=$ To a limited extent & 34 & 24 \\
\hline $5=$ Hardly at all & 55 & 38 \\
\hline $6=$ Don't know & 10 & 7 \\
\hline $7=$ Not applicable & 24 & 17 \\
\hline Total & 144 & \\
\hline
\end{tabular}

3. What have been the greatest barriers faced by your organization during its journey to high maturity? What have you done to overcome them? (Please describe fully) 


\section{Facsimile of Survey Announcement}

Measurement and Analysis in CMMI High Maturity Organizations

To the attention of: <Invitee>

From: Mike Phillips, CMMI Program Manager, Software Engineering Institute

Date: May 6, 2008

There has been a great deal of discussion recently about high maturity processes and project performance. Clarification is needed along with good examples of what has worked well and what has not. Measurement and analysis activities are key ingredients.

As part of the SEI's ongoing research and development effort, we are conducting a survey on the use of measurement and analysis in high maturity organizations. Because of your organization's leadership in this area, you will receive an invitation soon [d1] inviting participation in the survey. As always, any information that could identify you or your organization will be held in strict confidence by the SEI for research purposes only.

Participants in the survey will receive an early copy of the results. We hope that the analysis will allow you to make useful comparisons with similar organizations and provide practical guidance for continuing improvement in your own organization. (For a similar example you may visit http://www.sei.cmu.edu/publications/documents/07.reports/07sr014.html.)

Many of the questions center on process performance modeling. You may wish to assign completion of the questionnaire to someone who is more familiar with the day-to-day details of the organization's measurement related activities. (Pertinent CMMI excerpts are at https://seir.sei.cmu.edu/feedback/background.htm.)

I would appreciate knowing if you are unable or unwilling to complete the questionnaire at this time. We need to hear from everyone, and insights on disappointments may be as valuable for improving our performance as those from organizations who have found our current approaches useful. Simply reply to this message; I will receive it in my personal email account.

Thank you in advance. 


\section{Facsimile of Survey Invitation}

Measurement and Analysis in CMMI High Maturity Organizations

To the attention of: <Invitee>

Date: May 6, 2008

As you hopefully have seen earlier today in an email from Mike Phillips, the CMMI Program Manager, the SEI is conducting a survey on the use of measurement and analysis in high maturity organizations. A relatively limited number of organizations have experience in this area, so we would greatly appreciate having yours participate. We need to hear from everyone for the results to be accurate and useful.

Please answer from the perspective of your organizational unit that most recently had a CMMIbased high maturity appraisal. As Mike mentioned, much of the questionnaire centers on process performance modeling. Please feel free to consult with or delegate completion of the questionnaire to someone who may be more familiar with the day-to-day details of the organization's measurement related activities.

You will find your personalized form on the World Wide Web at https://seir.sei.cmu.edu/feedback/HighMaturity2008.asp?ID=<random>.

Please be sure to complete it at your earliest convenience-right now if you can make the time. You or your designee may return to that URL and continue completing the questionnaire at any time. You also may save your work at any time. Answering all of the questions should take about 20 to 30 minutes.

Please complete the questionnaire as candidly and completely as you possibly can. As always, any information that could identify you or your organization will be held in strict confidence by the SEI under promise of non disclosure. The results will be reported in summary aggregate form without attribution. Individual replies will be seen only by selected members of the analysis team, for data management purposes only. You may rest assured that your individual replies will not be used or known for appraisal audit purposes.

Please feel free to contact us at sei-analysis@ sei.cmu.edu if you have any questions or concerns about this work, or have any trouble completing your form over the web. We'll get back to you right away.

Thank you in advance.

Bob Stoddard and Dennis Goldenson

for the Measurement and Analysis Team

Software Engineering Institute

Carnegie Mellon University 


\section{Facsimile of First Reminder}

Reminder - Measurement and Analysis in High Maturity Organizations

To the attention of: <Invitee>

Date: May 21, 2008

About two weeks ago, we asked you to complete a questionnaire on the use of measurement and analysis in high maturity organizations. As you know, yours is one of a still small number of organizations with experience in this area, so your participation is extremely important. We need to hear from everyone to ensure that the survey results are accurate and useful.

Please do complete and submit your questionnaire by June 4. As a reminder, you may find it at https://seir.sei.cmu.edu/feedback/HighMaturity2008.asp?ID=<random>.

Recall that much of the questionnaire centers on process performance modeling. So please feel free to consult with or delegate completion of the questionnaire to someone who may be more familiar with the day-to-day details of the organization's measurement related activities.

Answering all of the questions should take about 20 to 30 minutes. As always, your candid answers and anything that could identify you or your organization will be held in strict confidence by the SEI. An early summary of the results will be sent to those who have completed their questionnaires. We hope that it will prove to be useful for you.

Please feel free to contact us at sei-analysis@ sei.cmu.edu if you have any questions or concerns about this work, or have any trouble completing your form over the web. We'll do our best to resolve any questions or concerns that you may have.

Once again, thank you for your contribution and cooperation in this effort.

Bob Stoddard and Dennis Goldenson for the Measurement and Analysis Team

Software Engineering Institute

Carnegie Mellon University 


\section{Facsimile of Second Reminder}

Second Reminder - Measurement and Analysis in High Maturity Organizations

To the attention of: <Invitee>

Date: June 6, 2008

As you know, the Software Engineering Institute has been conducting a survey on the use of measurement and analysis in high maturity organizations. Naturally we hope that the results will help you better judge your own progress relative to the successes and challenges reported by others.

We have been encouraged by the number of responses we have received so far; however we have not yet received a reply from you.

Please do make about 20 to 30 minutes time to complete your questionnaire as soon as you possibly can, by June 18 if at all possible. Remember that you may return to complete it over more than one session if that's easier for you.

Once again, your personalized form is on the World Wide Web at https://seir.sei.cmu.edu/feedback/HighMaturity2008.asp?ID=<random $>$.

Thank you for your contribution and cooperation with this effort. We hope that the results will prove to be valuable to you.

Most sincerely,

Bob Stoddard and Dennis Goldenson for the Measurement and Analysis Team

Software Engineering Institute

Carnegie Mellon University

sei-analysis@sei.cmu.edu 


\section{Facsimile of Final Reminder}

Final Reminder - Measurement and Analysis in High Maturity Organizations

To the attention of: <Invitee>

Date: June 19, 2008

We are writing to you about the Software Engineering Institute's survey on the use and performance outcomes of measurement and analysis in high maturity organizations. We have not yet received your completed questionnaire.

The survey is the most comprehensive of it's kind yet done, and we expect it to be of considerable value to organizations that wish to continue improving their measurement practices. Of course, your answers are needed to make the survey an accurate representation of the state of the practice in high maturity organizations.

Please do make time to complete your questionnaire as soon as you possibly can, by the end of this month at latest. We will let contributors know as soon as the results are ready.

Once again, your personalized form is on the World Wide Web at https://seir.sei.cmu.edu/feedback/HighMaturity2008.asp?ID=<random>.

Remember that you may return to complete it over more than one session if that's easier for you. Of course, your answers will be held in strict confidence.

Thank you again in advance for your contribution and cooperation with this effort. We hope that the results will prove to be valuable to you.

Most sincerely,

Bob Stoddard and Dennis Goldenson

for the Measurement and Analysis Team

Software Engineering Institute

Carnegie Mellon University

sei-analysis@sei.cmu.edu 


\section{Appendix B: Questionnaire for the General Population Survey}

This appendix contains a listing of all of the survey questions that have forced-choice, closedended answers. It is annotated with the number of responses for each answer and the percentage of the total answers that each answer represents. Facsimiles of the invitations and reminder letters sent to the survey respondents follow the question and answer listing in this Appendix. ${ }^{36}$

36 We also sent very similar personalized reminders to those who had begun but not yet completed their questionnaires. They are not reproduced here in the interests of space. 


\section{The State of Measurement \& Analysis Practice: 2008 Survey}

1. Do you work for or support a software or systems engineering organization as we have defined it here? (Please select one.)

\begin{tabular}{|l|r|r|}
\hline & Count & \multicolumn{1}{|c|}{$\%$} \\
\hline Yes - Currently & 267 & 79 \\
\hline No - But I have within the past two years & 16 & 5 \\
\hline No - I do not & 52 & 15 \\
\hline Total & 283 & \\
\hline
\end{tabular}

2. Which of the following best describes the role you play in your organization? (Please select one.)

\begin{tabular}{|c|c|c|}
\hline Category & Count & $\%$ \\
\hline Executive or senior manager & 43 & 15 \\
\hline Middle manager (e.g., program or product line) & 33 & 12 \\
\hline Project manager & 41 & 15 \\
\hline Project engineer or other technical staff & 30 & 11 \\
\hline Process or quality engineer & 90 & 32 \\
\hline Measurement specialist & 8 & 3 \\
\hline Other (Please describe briefly) & 36 & 13 \\
\hline Total & 281 & \\
\hline
\end{tabular}

3. How is your organization best described? (Please select one.)

\begin{tabular}{|c|c|c|}
\hline Category & Count & $\%$ \\
\hline Commercial off the shelf & 21 & 7 \\
\hline Contracted new development & 62 & 22 \\
\hline In-house or proprietary development or maintenance & 78 & 28 \\
\hline Defense contractor & 46 & 16 \\
\hline Other government contractor & 12 & 4 \\
\hline Department of Defense or military organization & 9 & 3 \\
\hline Other government agency & 11 & 4 \\
\hline Other (Please describe briefly) & 42 & 15 \\
\hline Total & 281 & \\
\hline
\end{tabular}


4. In what country is your organization primarily located? (Please select one.)

\begin{tabular}{|l|r|r|}
\hline & Count & \% \\
\hline United States & 131 & 46 \\
\hline Canada & 2 & 1 \\
\hline China & 7 & 2 \\
\hline France & 6 & 2 \\
\hline Germany & 5 & 2 \\
\hline India & 32 & 11 \\
\hline Japan & 9 & 3 \\
\hline Netherlands & 2 & 1 \\
\hline United Kingdom & 8 & 3 \\
\hline All Others & 80 & 28 \\
\hline \multicolumn{1}{|r|}{ Total } & 282 & \\
\hline
\end{tabular}

5. Approximately how many full-time employees work in your organization? (Please select one.)

\begin{tabular}{|c|c|c|}
\hline Category & Count & $\%$ \\
\hline 25 or fewer & 40 & 14 \\
\hline $26-50$ & 19 & 7 \\
\hline $51-75$ & 12 & 4 \\
\hline $76-100$ & 16 & 6 \\
\hline $101-200$ & 26 & 9 \\
\hline $201-300$ & 19 & 7 \\
\hline $301-500$ & 24 & 9 \\
\hline $501-1000$ & 29 & 10 \\
\hline $1001-2000$ & 17 & 6 \\
\hline More than 2000 & 75 & 27 \\
\hline Total & 277 & \\
\hline
\end{tabular}

6. To the best of your knowledge, what is the maturity level of your organization? (Please select one.)

\begin{tabular}{|c|c|c|}
\hline Category & Count & $\%$ \\
\hline CMMI Maturity Level 1 (Initial) & 47 & 17 \\
\hline Close To Maturity Level 2 & 43 & 15 \\
\hline CMMI Maturity Level 2 (Managed) & 17 & 6 \\
\hline Close To Maturity Level 3 & 34 & 12 \\
\hline CMMI Maturity Level 3 (Defined) & 61 & 21 \\
\hline CMMI Maturity Level 4 (Quantitatively Managed) & 9 & 3 \\
\hline CMMI Maturity Level 5 (Optimizing) & 46 & 16 \\
\hline Don't know & 27 & 10 \\
\hline Total & 284 & \\
\hline
\end{tabular}


7. How would you best describe your involvement with measurement? (Please select one.)

\begin{tabular}{|c|c|c|}
\hline Category & Count & $\%$ \\
\hline I am a provider of measurement-based information & 43 & 15 \\
\hline I am a user (consumer) of measurement-based information & 42 & 15 \\
\hline $\begin{array}{l}\text { * I am both a provider and user (consumer) of measurement-based in- } \\
\text { formation }\end{array}$ & 157 & 56 \\
\hline * Other (Please describe briefly) & 40 & 14 \\
\hline Total & 282 & \\
\hline
\end{tabular}

$$
\text { * - proceed to Section VI }
$$

8. How frequently is measurement and analysis used in your organization? (Please select one.)

\begin{tabular}{|l|r|r|}
\hline \multicolumn{1}{|c|}{ Category } & Count & \multicolumn{1}{c|}{$\%$} \\
\hline Routinely & 176 & 62 \\
\hline Occasionally & 56 & 20 \\
\hline * Rarely if ever & 37 & 13 \\
\hline * Don't know & 15 & 5 \\
\hline Total & 284 & \\
\hline
\end{tabular}

* - proceed to Section VI 


\section{Resources and Infrastructure}

1. Which of the following best describes how measurement related work is staffed in your organization? (Please select one.)

\begin{tabular}{|l|r|r|}
\hline \multicolumn{1}{|c|}{ Category } & Count & \% \\
\hline $\begin{array}{l}\text { An organization-wide, division or similar corporate support group (e.g., } \\
\text { an engineering process, quality assurance or measurement group) }\end{array}$ & 90 & 38 \\
\hline $\begin{array}{l}\text { Separate groups or individuals in different projects or other organizational } \\
\text { units (e.g., project, product team or similar work groups) }\end{array}$ & 68 & 29 \\
\hline $\begin{array}{l}\text { A few key people (or one person) in the organization who are measure- } \\
\text { ment experts }\end{array}$ & 54 & 23 \\
\hline Other (Please describe briefly) & 24 & 10 \\
\hline \multicolumn{2}{|c|}{ Total } & 236 \\
\hline
\end{tabular}

2. How often are qualified, well-prepared people available to work on measurement and analysis in your organization when you need them, i.e., people with sufficient measurement related knowledge, competence or statistical sophistication? (Please select one.)

\begin{tabular}{|l|r|r|}
\hline Category & Count & \multicolumn{1}{c|}{ \% } \\
\hline Almost always (Greater than or equal to 80\%) & 53 & 23 \\
\hline Frequently (Greater than or equal to 60\%) & 50 & 21 \\
\hline About half of the time (Greater than 40\% but less than 60\%) & 36 & 15 \\
\hline Occasionally (Less than or equal to 40\%) & 50 & 21 \\
\hline Rarely if ever (Less than or equal to 20\%) & 44 & 19 \\
\hline & 233 & \\
\hline
\end{tabular}


3. To what extent, if any, has the lack of automated support made measurement related activities difficult for your organization? (Please select one.)

\begin{tabular}{|l|r|r|}
\hline \multicolumn{1}{|c|}{ Category } & Count & \multicolumn{1}{c|}{ \% } \\
\hline Extensive difficulty & 17 & 7 \\
\hline Substantial & 71 & 30 \\
\hline Moderate & 73 & 31 \\
\hline Limited & 37 & 16 \\
\hline Little if Any difficulty & 22 & 9 \\
\hline Don't know Total & 14 & 6 \\
\hline \multicolumn{2}{|r|}{ Tota } & \\
\hline
\end{tabular}

4. How would you best characterize the measurement related training that is available in your organization? (Please select one.)

\begin{tabular}{|c|c|c|}
\hline Category & Count & $\%$ \\
\hline Excellent & 14 & 6 \\
\hline Good & 53 & 23 \\
\hline Adequate & 50 & 21 \\
\hline Fair & 60 & 26 \\
\hline Poor & 57 & 24 \\
\hline Total & 234 & \\
\hline
\end{tabular}




\section{Value Added}

1. In general, how valuable has measurement and analysis been to your organization? (Please select one.)

\begin{tabular}{|l|r|r|}
\hline \multicolumn{1}{|c|}{ Category } & Count & \multicolumn{1}{c|}{ \% } \\
\hline Extremely valuable -- we couldn't do our work properly without it & 30 & 13 \\
\hline Very valuable -- we have obtained much useful information from it & 80 & 35 \\
\hline Mixed value -- we have obtained useful information on occasion & 96 & 42 \\
\hline Little or no value & 13 & 5 \\
\hline It's been harmful, not helpful & 1 & 0 \\
\hline Don't know & 11 & 5 \\
\hline
\end{tabular}

2. Following are a few statements about the possible effects of measurement and analysis. To what extent do they describe what your organization has experienced? (Please select one for each.)

Better project performance (e.g., more accurate estimation, reduced cost, shorter cycle time, higher productivity)

\begin{tabular}{|l|r|r|}
\hline \multicolumn{1}{|c|}{ Category } & Count & \multicolumn{1}{c|}{ \% } \\
\hline Almost always & 44 & 19 \\
\hline Frequently & 65 & 29 \\
\hline About half the time & 33 & 14 \\
\hline Occasionally & 53 & 23 \\
\hline Rarely if ever & 18 & 8 \\
\hline "Worse, not better" & 2 & 1 \\
\hline Don't know Total & 5 & 2 \\
\hline Not applicable & 8 & 4 \\
\hline \multicolumn{2}{|c|}{} \\
\hline
\end{tabular}

Better product quality (e.g., fewer defects, improved customer satisfaction)

\begin{tabular}{|l|r|r|}
\hline \multicolumn{1}{|c|}{ Category } & Count & \% \\
\hline Almost always & 54 & 24 \\
\hline Frequently & 72 & 32 \\
\hline About half the time & 34 & 15 \\
\hline Occasionally & 30 & 13 \\
\hline Rarely if ever & 18 & 8 \\
\hline "Worse, not better" & 1 & 0 \\
\hline Don't know Total & 8 & 4 \\
\hline Not applicable & 8 & 4 \\
\hline \multicolumn{2}{|c|}{$\quad$} \\
\hline
\end{tabular}


Better tactical decisions about the adoption or improvement of work processes and technologies

\begin{tabular}{|l|r|r|}
\hline \multicolumn{1}{|c|}{ Category } & Count & \% \\
\hline Almost always & 31 & 14 \\
\hline Frequently & 62 & 28 \\
\hline About half the time & 25 & 11 \\
\hline Occasionally & 58 & 26 \\
\hline Rarely if ever & 31 & 14 \\
\hline "Worse, not better" & 1 & 0 \\
\hline Don't know & 9 & 4 \\
\hline Not applicable Total & 7 & 3 \\
\hline \multicolumn{2}{|c|}{224} & \\
\hline
\end{tabular}

Better strategic decision making (e.g., about business growth and profitability)

\begin{tabular}{|c|c|c|}
\hline Category & Count & $\%$ \\
\hline Almost always & 24 & 11 \\
\hline Frequently & 48 & 22 \\
\hline About half the time & 29 & 13 \\
\hline Occasionally & 60 & 27 \\
\hline Rarely if ever & 32 & 14 \\
\hline "Worse, not better" & 2 & 1 \\
\hline Don't know & 14 & 6 \\
\hline Not applicable & 13 & 6 \\
\hline Total & 222 & \\
\hline
\end{tabular}

Other (Please describe briefly)

\begin{tabular}{|c|c|c|}
\hline Category & Count & $\%$ \\
\hline Almost always & 6 & 18 \\
\hline Frequently & 6 & 18 \\
\hline About half the time & 1 & 3 \\
\hline Occasionally & 2 & 6 \\
\hline Rarely if ever & 1 & 3 \\
\hline "Worse, not better" & 6 & 18 \\
\hline Don't know & 11 & 33 \\
\hline Not applicable & 6 & 18 \\
\hline Total & 33 & \\
\hline
\end{tabular}

3. In what specific ways has the use of measurement and analysis been most helpful, or harmful, to your organization? (Please describe briefly) 


\section{Alignment and Coordination of Measurement Activities}

1. Do you agree or disagree with the two following statements? (Please select one for each.)

I generally find the definitions of the measures that are used in my organization to be understandable and consistent.

\begin{tabular}{|c|c|c|}
\hline Category & Count & $\%$ \\
\hline Strongly agree & 40 & 18 \\
\hline Agree & 91 & 40 \\
\hline Somewhat agree & 51 & 22 \\
\hline Not sure & 5 & 2 \\
\hline Somewhat disagree & 18 & 8 \\
\hline Disagree & 12 & 5 \\
\hline Strongly disagree & 4 & 2 \\
\hline Not applicable & 6 & 3 \\
\hline Total & 227 & \\
\hline
\end{tabular}

I usually can understand and interpret the measurement results that I see.

\begin{tabular}{|l|r|r|}
\hline \multicolumn{1}{|c|}{ Category } & Count & \% \\
\hline Strongly agree & 42 & 19 \\
\hline Agree & 113 & 50 \\
\hline Somewhat agree & 38 & 17 \\
\hline Not sure & 6 & 3 \\
\hline Somewhat disagree & 10 & 4 \\
\hline Disagree & 5 & 2 \\
\hline Strongly disagree & 3 & 1 \\
\hline Not applicable Total & 7 & 3 \\
\hline \multicolumn{2}{|c|}{ T24 } & \\
\hline
\end{tabular}

2. To what extent, if any, do concerns about data accuracy and quality make measurement and analysis difficult for your organization? (Please select one.)

\begin{tabular}{|c|c|c|}
\hline Category & Count & $\%$ \\
\hline Extensive difficulty & 7 & 3 \\
\hline Substantial & 71 & 31 \\
\hline Moderate & 89 & 39 \\
\hline Limited & 32 & 14 \\
\hline Little if Any difficulty & 21 & 9 \\
\hline Don't know & 8 & 4 \\
\hline Total & 228 & \\
\hline
\end{tabular}


3. How well do the following statements describe the team with whom you work most closely? (Please select one for each.)

There exist measurable criteria for the products and services to which I contribute.

\begin{tabular}{|l|r|r|}
\hline \multicolumn{1}{|c|}{ Category } & Count & \% \\
\hline Almost always & 62 & 27 \\
\hline Frequently & 79 & 35 \\
\hline About half the time & 23 & 10 \\
\hline Occasionally & 39 & 17 \\
\hline Rarely if ever & 19 & 8 \\
\hline Don't know Total & 4 & 2 \\
\hline \multicolumn{2}{|r|}{ Tot } & \\
\hline
\end{tabular}

I use measurement to understand the quality of the products and/or services that I work on.

\begin{tabular}{|c|c|c|}
\hline Category & Count & $\%$ \\
\hline Almost always & 76 & 33 \\
\hline Frequently & 73 & 32 \\
\hline About half the time & 26 & 11 \\
\hline Occasionally & 28 & 12 \\
\hline Rarely if ever & 23 & 10 \\
\hline Don't know & 3 & 1 \\
\hline Total & 229 & \\
\hline
\end{tabular}

My team follows a documented process for collecting measurement data.

\begin{tabular}{|l|r|r|}
\hline \multicolumn{1}{|c|}{ Category } & Count & \multicolumn{1}{c|}{ \% } \\
\hline Almost always & 97 & 43 \\
\hline Frequently & 50 & 22 \\
\hline About half the time & 28 & 12 \\
\hline Occasionally & 24 & 11 \\
\hline Rarely if ever & 25 & 11 \\
\hline Don't know Total & 4 & 2 \\
\hline \multicolumn{2}{|c|}{228} & \\
\hline
\end{tabular}

My team follows a documented process for reporting measurement data to management.

\begin{tabular}{|l|r|r|}
\hline Category & Count & \% \\
\hline Almost always & 104 & 46 \\
\hline Frequently & 45 & 20 \\
\hline About half the time & 24 & 11 \\
\hline Occasionally & 24 & 11 \\
\hline Rarely if ever & 26 & 11 \\
\hline Don't know Total & 4 & 2 \\
\hline \multicolumn{2}{|c|}{227} & \\
\hline
\end{tabular}


Corrective action is taken when measurement data indicate that a threshold has been exceeded. (By "threshold" we mean a target or boundary that when exceeded is evidence that a risk or problem exists.)

\begin{tabular}{|l|r|r|}
\hline \multicolumn{1}{|c|}{ Category } & Count & \multicolumn{1}{c|}{ \% } \\
\hline Almost always & 73 & 32 \\
\hline Frequently & 69 & 30 \\
\hline About half the time & 26 & 11 \\
\hline Occasionally & 30 & 13 \\
\hline Rarely if ever & 26 & 11 \\
\hline Don't know Total & 4 & 2 \\
\hline & 228 & \\
\hline
\end{tabular}

I understand the purposes for the data I collect or report.

\begin{tabular}{|l|r|r|}
\hline \multicolumn{1}{|c|}{ Category } & Count & \% \\
\hline Almost always & 150 & 66 \\
\hline Frequently & 46 & 20 \\
\hline About half the time & 16 & 7 \\
\hline Occasionally & 10 & 4 \\
\hline Rarely if ever & 4 & 2 \\
\hline Don't know Total & 3 & 1 \\
\hline \multicolumn{2}{|c|}{229} & \\
\hline
\end{tabular}

\section{Measures Used}

1. Approximately how often are the following kinds of project and organizational measurement results reported in your organization? (Please select one for each.)

Staff adherence to development work processes

\begin{tabular}{|c|c|c|}
\hline Category & Count & $\%$ \\
\hline Regularly & 99 & 44 \\
\hline Frequently & 34 & 15 \\
\hline Occasionally & 41 & 18 \\
\hline Rarely if ever & 41 & 18 \\
\hline Don't know & 5 & 2 \\
\hline Not applicable & 4 & 2 \\
\hline Total & 224 & \\
\hline
\end{tabular}


Cost performance or other measures of budget predictability

\begin{tabular}{|c|c|c|}
\hline Category & Count & $\%$ \\
\hline Regularly & 114 & 51 \\
\hline Frequently & 41 & 18 \\
\hline Occasionally & 33 & 15 \\
\hline Rarely if ever & 25 & 11 \\
\hline Don't know & 8 & 4 \\
\hline Not applicable & 3 & 1 \\
\hline Total & 224 & \\
\hline
\end{tabular}

Schedule performance, milestone satisfaction or other measures of schedule predictability

\begin{tabular}{|c|c|c|}
\hline Category & Count & $\%$ \\
\hline Regularly & 124 & 55 \\
\hline Frequently & 53 & 24 \\
\hline Occasionally & 28 & 13 \\
\hline Rarely if ever & 13 & 6 \\
\hline Don't know & 3 & 1 \\
\hline Not applicable & 3 & 1 \\
\hline Total & 224 & \\
\hline
\end{tabular}

Accuracy of estimates, e.g., effort, cost or schedule

\begin{tabular}{|c|c|c|}
\hline Category & Count & $\%$ \\
\hline Regularly & 59 & 26 \\
\hline Frequently & 58 & 26 \\
\hline Occasionally & 57 & 25 \\
\hline Rarely if ever & 40 & 18 \\
\hline Don't know & 7 & 3 \\
\hline Not applicable & 3 & 1 \\
\hline Total & 224 & \\
\hline
\end{tabular}

Product cycle time, time to market, or delivery rate

\begin{tabular}{|c|c|c|}
\hline Category & Count & $\%$ \\
\hline Regularly & 56 & 25 \\
\hline Frequently & 48 & 21 \\
\hline Occasionally & 45 & 20 \\
\hline Rarely if ever & 44 & 21 \\
\hline Don't know & 19 & 8 \\
\hline Not applicable & 12 & 5 \\
\hline Total & 224 & \\
\hline
\end{tabular}


Business growth and profitability (e.g., market share, revenue generated, profits, or return on investment)

\begin{tabular}{|c|c|c|}
\hline Category & Count & $\%$ \\
\hline Regularly & 73 & 33 \\
\hline Frequently & 34 & 15 \\
\hline Occasionally & 34 & 15 \\
\hline Rarely if ever & 39 & 17 \\
\hline Don't know & 29 & 13 \\
\hline Not applicable & 15 & 7 \\
\hline Total & 224 & \\
\hline
\end{tabular}

2. Approximately how often are the following kinds of product and quality measurement results reported in your organization? (Please select one for each.)

Product requirements or architectures (e.g., completion of customer and technical requirements, or features delivered as planned)

\begin{tabular}{|c|c|c|}
\hline Category & Count & $\%$ \\
\hline Regularly & 84 & 38 \\
\hline Frequently & 53 & 24 \\
\hline Occasionally & 45 & 20 \\
\hline Rarely if ever & 30 & 13 \\
\hline Don't know & 8 & 4 \\
\hline Not applicable & 3 & 1 \\
\hline Total & 223 & \\
\hline
\end{tabular}

Effort applied to tasks (e.g., productivity, rework, and cost of quality or poor quality)

\begin{tabular}{|c|c|c|}
\hline Category & Count & $\%$ \\
\hline Regularly & 89 & 40 \\
\hline Frequently & 50 & 22 \\
\hline Occasionally & 39 & 17 \\
\hline Rarely if ever & 38 & 17 \\
\hline Don't know & 5 & 2 \\
\hline Not applicable & 3 & 1 \\
\hline Total & 224 & \\
\hline
\end{tabular}

Defect density (e.g., numbers of defects identified pre and post release)

\begin{tabular}{|l|r|r|}
\hline \multicolumn{1}{|c|}{ Category } & Count & \multicolumn{1}{c|}{ \% } \\
\hline Regularly & 89 & 40 \\
\hline Frequently & 37 & 17 \\
\hline Occasionally & 43 & 19 \\
\hline Rarely if ever & 43 & 19 \\
\hline Don't know & 6 & 3 \\
\hline Not applicable Total & 5 & 3 \\
\hline \multicolumn{2}{|r|}{ Tor } & \\
\hline
\end{tabular}


Defect phase containment (i.e., early detection and removal)

\begin{tabular}{|c|c|c|}
\hline Category & Count & $\%$ \\
\hline Regularly & 53 & 24 \\
\hline Frequently & 42 & 19 \\
\hline Occasionally & 54 & 24 \\
\hline Rarely if ever & 59 & 26 \\
\hline Don't know & 8 & 4 \\
\hline Not applicable & 8 & 4 \\
\hline Total & 224 & \\
\hline
\end{tabular}

Quality attributes (e.g., maintainability, interoperability, portability, usability, reliability, complexity, criticality, reusability, or durability)

\begin{tabular}{|c|c|c|}
\hline Category & Count & $\%$ \\
\hline Regularly & 33 & 15 \\
\hline Frequently & 26 & 12 \\
\hline Occasionally & 66 & 29 \\
\hline Rarely if ever & 71 & 32 \\
\hline Don't know & 15 & 7 \\
\hline Not applicable & 13 & 6 \\
\hline Total & 222 & \\
\hline
\end{tabular}

Customer satisfaction (e.g., satisfaction with staff responsiveness or fitness for use of the delivered product).

\begin{tabular}{|l|r|r|}
\hline Category & Count & \% \\
\hline Regularly & 71 & 32 \\
\hline Frequently & 51 & 23 \\
\hline Occasionally & 58 & 26 \\
\hline Rarely if ever & 30 & 13 \\
\hline Don't know & 8 & 4 \\
\hline Not applicable Total & 5 & 2 \\
\hline \multicolumn{2}{|c|}{223} & \\
\hline
\end{tabular}




\section{Use of Measurement}

Following is a series of statements about the use of measurement and analysis in organizations. How well do they describe your organization? (Please select one for each.)

The effort required for people to submit data is often considered to be onerous or burdensome.

\begin{tabular}{|l|r|r|}
\hline \multicolumn{1}{|c|}{ Category } & Count & \multicolumn{1}{|c|}{$\%$} \\
\hline Almost entirely & 23 & 9 \\
\hline To a large extent & 70 & 28 \\
\hline To a moderate extent & 68 & 27 \\
\hline To a limited extent & 43 & 17 \\
\hline Hardly at all & 29 & 12 \\
\hline Don't know & 13 & 5 \\
\hline Not applicable Total & 251 & 2 \\
\hline \multicolumn{2}{|c}{} \\
\hline
\end{tabular}

Measurement data and analysis results are generally understandable and easily interpretable.

\begin{tabular}{|l|r|r|}
\hline \multicolumn{1}{|c|}{ Category } & Count & \multicolumn{1}{c|}{$\%$} \\
\hline Almost entirely & 33 & 13 \\
\hline To a large extent & 81 & 33 \\
\hline To a moderate extent & 58 & 23 \\
\hline To a limited extent & 46 & 18 \\
\hline Hardly at all & 14 & 6 \\
\hline Don't know & 14 & 6 \\
\hline Not applicable Total & 249 & 1 \\
\hline \multicolumn{2}{|r|}{} \\
\cline { 1 - 3 }
\end{tabular}

The way measurement data are collected and used is often considered to be inappropriate by the people who must provide the necessary information (e.g., irrelevant to their own work, or used to unfairly evaluate performance by individual people or projects).

\begin{tabular}{|l|r|r|}
\hline \multicolumn{1}{|c|}{ Category } & Count & \multicolumn{1}{|c|}{ \% } \\
\hline Almost entirely & 14 & 6 \\
\hline To a large extent & 44 & 18 \\
\hline To a moderate extent & 49 & 20 \\
\hline To a limited extent & 59 & 24 \\
\hline Hardly at all & 54 & 22 \\
\hline Don't know & 22 & 9 \\
\hline Not applicable Total & 7 & 3 \\
\hline \multicolumn{2}{|c}{ Th } & \\
\hline
\end{tabular}

The measurement data that we collect are in fact analyzed on a regular basis. 


\begin{tabular}{|l|r|r|}
\hline \multicolumn{1}{|c|}{ Category } & Count & \multicolumn{1}{c|}{ \% } \\
\hline Almost entirely & 51 & 20 \\
\hline To a large extent & 80 & 32 \\
\hline To a moderate extent & 42 & 17 \\
\hline To a limited extent & 36 & 14 \\
\hline Hardly at all & 24 & 10 \\
\hline Don't know & 11 & 4 \\
\hline Not applicable Total & 7 & 3 \\
\hline \multicolumn{2}{|c}{$\quad 251$} & \\
\hline
\end{tabular}

Measurement and data analysis are an integral part of the way we normally do business.

\begin{tabular}{|l|r|r|}
\hline \multicolumn{1}{|c|}{ Category } & Count & \multicolumn{1}{c|}{ \% } \\
\hline Almost entirely & 40 & 16 \\
\hline To a large extent & 68 & 27 \\
\hline To a moderate extent & 48 & 19 \\
\hline To a limited extent & 42 & 17 \\
\hline Hardly at all & 34 & 14 \\
\hline Don't know & 11 & 4 \\
\hline Not applicable Total & 5 & 2 \\
\hline \multicolumn{2}{|r|}{} \\
\hline
\end{tabular}

The measurements that we collect aren't very relevant to the business and development decisions that we face.

\begin{tabular}{|l|r|r|}
\hline \multicolumn{1}{|c|}{ Category } & Count & \multicolumn{1}{c|}{ \% } \\
\hline Almost entirely & 9 & 4 \\
\hline To a large extent & 34 & 14 \\
\hline To a moderate extent & 41 & 16 \\
\hline To a limited extent & 55 & 22 \\
\hline Hardly at all & 82 & 33 \\
\hline Don't know & 14 & 6 \\
\hline Not applicable Total & 14 & 6 \\
\hline \multicolumn{2}{|c|}{249} & \\
\hline
\end{tabular}

The need for objective evidence about quality and performance is highly valued in our organization.

\begin{tabular}{|c|c|c|}
\hline Category & Count & $\%$ \\
\hline Almost entirely & 57 & 23 \\
\hline To a large extent & 78 & 31 \\
\hline To a moderate extent & 45 & 18 \\
\hline To a limited extent & 31 & 12 \\
\hline Hardly at all & 26 & 10 \\
\hline Don't know & 9 & 4 \\
\hline Not applicable & 3 & 1 \\
\hline Total & 249 & \\
\hline
\end{tabular}


There is resistance to doing measurement around here (e.g., people think of it as unnecessary, extra work, unfair, or an imposition on the way they do their work).

\begin{tabular}{|l|r|r|}
\hline \multicolumn{1}{|c|}{ Category } & Count & \multicolumn{1}{c|}{ \% } \\
\hline Almost entirely & 23 & 9 \\
\hline To a large extent & 50 & 20 \\
\hline To a moderate extent & 56 & 22 \\
\hline To a limited extent & 58 & 23 \\
\hline Hardly at all & 48 & 19 \\
\hline Don't know & 11 & 4 \\
\hline Not applicable Total & 4 & 2 \\
\hline \multicolumn{2}{|r|}{} \\
\hline
\end{tabular}




\section{Facsimile of Survey Invitation}

The State of Software Measurement Practice - 2008

To the attention of: <Invitee>

From: Measurement and Analysis Team

Date: May 7, 2008

The Software Engineering Institute (SEI) is conducting its third annual survey about the state of measurement and analysis practice. The results will be used to provide guidance for future measurement efforts, and they will allow valuable comparisons to be made among organizations similar to your own.

You are part of a carefully chosen sample for the survey. Your participation is necessary for the results to be accurate and useful, even if your organization rarely if ever does measurement. Answering all of the questions typically takes about 15 or 20 minutes at most, less than 5 minutes if your organization does not customarily do measurement. As always, any information that could identify you or your organization will be held in strict confidence by the SEI under promise of non disclosure.

You will find your personalized form on the World Wide Web at https://seir.sei.cmu.edu/feedback/Measurement2008.asp?ID=<random $>$.

Please be sure to complete it at your earliest convenience -- right now if you can make the time. You may save your work at any time, and you may return to complete your form over more than one session if you wish. Everything will be encrypted for secure transfer and storage.

Please feel free to contact us at sei-measurement@ sei.cmu.edu if you have any questions or concerns about this work, or have any trouble completing your form over the web. We'll get back to you right away.

Thank you in advance.

Measurement and Analysis Team

Software Engineering Institute 


\section{Facsimile of First Reminder}

Reminder - The State of Software Measurement Practice - 2008

To the attention of: <Invitee>

Date: May 21, 2006

About two weeks ago, we asked you to complete a questionnaire for the SEI's third annual survey about the state of measurement and analysis practice. We have begun receiving responses; however we have not yet heard from you.

Remember that you are part of a carefully selected sample. We need to hear from you to have accurate and useful results, whether or not your organization is a regular user of software measurement.

Please be sure to complete your questionnaire by June 4 . As a reminder, you will find it on the World Wide Web at https://seir.sei.cmu.edu/feedback/Measurement2008.asp?ID=<random>.

It should take you about 15 or 20 minutes, less than 5 minutes if your organization does not customarily do measurement. As always, your candid answers and anything that could identify you or your organization will be held in strict confidence by the SEI. An early summary of the results will be sent to those who have completed their questionnaires. We hope that it will prove to be useful for you.

Please contact us at sei-measurement@ sei.cmu.edu if you have any questions or concerns about this work, or have any trouble completing your form over the web. We'll get back to you right away.

Once again, thank you in advance.

Most sincerely,

Software Measurement and Analysis Team

Software Engineering Institute

Carnegie Mellon University 


\section{Facsimile of Second Reminder}

Second Reminder - The State of Software Measurement Practice

To the attention of: <Invitee>

Date: June 4, 2006

As you know, the Software Engineering Institute has been conducting its third annual survey about the state of measurement and analysis practice. Naturally we hope that the results will help you better judge your own progress relative to the successes and challenges reported by others.

We have been encouraged by the number of responses we have received so far; however we have not yet received a reply from you.

Please do make about 15 or 20 minutes time to complete your questionnaire as soon as you possibly can, by June 18 if at all possible. Remember that you may return to complete it over more than one session if that's easier for you.

And please be sure to let us know if your organization does not develop software or does not customarily do software measurement. Doing that should take you well less than 5 minutes.

Once again, your personalized form is on the World Wide Web at https://seir.sei.cmu.edu/feedback/Measurement2008.asp?ID=<random>.

Thank you for your contribution and cooperation with this effort. We hope that the results will prove to be valuable to you.

Most sincerely,

Measurement and Analysis Team

Software Engineering Institute

Carnegie Mellon University

sei-measurement@sei.cmu.edu 


\section{Facsimile of Final Reminder}

Final Reminder - The State of Software Measurement Practice

To the attention of: <Invitee>

Date: June 19, 2006

We are writing to you about the Software Engineering Institute's third annual survey about the state of measurement and analysis practice. We have not yet received your completed questionnaire.

We expect the results to be of considerable value to organizations that wish to continue improving their measurement practices and their resulting performance outcomes. Of course, your answers are needed to make the survey an accurate representation of the state of the practice.

Please do make time to complete your questionnaire as soon as you possibly can, by the end of this month at latest. We will let contributors know as soon as the results are ready.

And please be sure to let us know if your organization does not develop software or does not customarily do software measurement. Doing that should take you well less than 5 minutes.

Once again, your personalized form is on the World Wide Web at https://seir.sei.cmu.edu/feedback/Measurement2008.asp?ID=<random>.

Remember that you may return to complete it over more than one session if that's easier for you. Of course, your answers will be held in strict confidence.

Thank you again in advance for your contribution and cooperation with this effort. We hope that the results will prove to be valuable to you.

Most sincerely,

Measurement and Analysis Team

Software Engineering Institute

Carnegie Mellon University

sei-measurement@sei.cmu.edu 


\section{Appendix C: Open-Ended Replies: Qualitative Perspectives on the Quantitative Results}

This appendix contains the free-form textual answers to selected "open-ended" questions from the questionnaire for the survey of high maturity organizations. Some of the answers have been edited to for purposes of nondisclosure. The questions include the following.

- S1Q2: Which of the following best describes the role you play in your organization? "Other" responses (page 137)

- S1Q3: How is your organization best described? - "Other” responses (page 138)

- S1Q4: What is the primary focus of your organization's work? - “Other” responses (page 140)

- S2Q4: What, if any, other types of measurement related training or mentoring does your organization provide (page 140)

- S3Q3: How much automated support is available for measurement related activities in your organization? - “Other" responses (page 146)

- S4Q4: Which of the following (often interim) process performance outcomes are routinely predicted with process performance models in your organization? - "Other" (page 147)

- S6Q1: Following is a series of statements about the kinds of technical challenges that projects sometimes face. How well do they describe your organization? (page 147)

- S7Q1: Which, if any, of the following have been major obstacles during your organization's journey to high maturity? - "Other" responses (page 147)

- S7Q3: What have been the greatest barriers faced by your organization during its journey to high maturity? What have you done to overcome them? (page 148)

- In Conclusion: Is there anything else that you would like to tell us about the use or usefulness of measurement and analysis in your organization? (page 160)

S1Q2: Which of the following best describes the role you play in your organization? "Other" responses

I am leading development processes, especially CMMI activities.

Former executive manager and sponsor in this organization

Software Functional Manager - responsible for software staff, tooling, process, and as a check on line (project) activities

Business Excellence Manager

QA Manager

Engineering Process Group Chairperson

Chief Executive of the organization

Manager of EPG and QA

137 | CMU/SEI-2008-TR-024 
S1Q2: Which of the following best describes the role you play in your organization? "Other" responses

consultant, past VP

Director

CMMI compliance lead, measurements lead, backup to the SEPG lead and backup to the CMMI assessment project lead

Managing director of [company name]

Enterprise measurement IPT lead

SEPG leader

Lead appraiser who performed the last appraisal

Process consultant

SEPG

Manager of division measurement and analysis office and high maturity initiatives

In charge of process management

Software quality engineering manager; organization process group (a.k.a. SEPG) lead

\section{S1Q3: How is your organization best described? - "Other" responses}

Shrink-wrap or custom installation of enterprise solutions and contracted new development

Software development \& maintenance

Development \& maintenance services

Global provider of software solutions and IT services, ranging from specialization in quality custom software development, product development, consulting services to systems integration, and outsourcing

System integrator

Financial institution

Commercial contractor

Design \& engineering consultancy

Product and technology development for aerospace and automation control systems

Custom development applications, device driver applications, COTS with and without customization and application maintenance

An IT company that delivers consulting, systems integration, and outsourcing solutions to customers

Software solutions and services provider for application development and maintenance 
S1Q3: How is your organization best described? - "Other" responses

Government contractor for several government departments

All the above

Software solutions and services provider

Software development and integration, focused on: IT consulting, business intelligence, development and integration, software factory, security, testing factory, and consulting services

Software products and projects related to scientific, engineering, financial, business analytics \& enterprise applications; software product development

Service provision

Application software and service provider for trade customers (development, maintenance, testing, application management services

IT software services organization with capabilities in application development and COTS implementation

Software development company providing solutions to the industry. Also defense subcontractor.

Offshore software service provider

IT services provider

Software factories for external customers

Defense contractor and other government contractor

Software development and maintenance services

A leading global provider of IT services and business solutions for software development, maintenance, enhancement, testing and production support

COTS and contracted new development

* Implementation, Maintenance \& Support of COTS products

* Development, maintenance \& support using [specified commercial] technologies

Item number 1,2 and 3 above

Application management services, including new development/customization and on-going maintenance of self-developed or off-the-shelf packages for both in-house and external clients

Software vendor (insurance enterprise solutions)

A mixture of in-house or proprietary development or maintenance and contracted new development

Provider of IT solutions and services, 1nfrastructure services, engineering and industrial services, asset based solutions, consulting

Product development/implementation and contracted new development and maintenance 
S1Q4: What is the primary focus of your organization's work? - "Other" responses

Systems development \& maintenance

Development \& maintenance services

IT solutions including new application development, maintenance and testing.

Product development, customized solution development. Maintenance services, \& IT related services

Product and system development, maintenance and sustainment

Application development, product implementation, maintenance and sustainment

Application development, maintenance, production support, product engineering, system integration, IT consultancy, package implementation, IT Infrastructure management, product development, testing and validation services

Maintenance and sustainment

All the above

IT consulting, business intelligence, development and integration, software factory, security, testing factory, and consulting services

System development and maintenance

Both product and system development and maintenance

Design, development and maintenance of software

Software development and maintenance services

Software development, maintenance, enhancement, testing, production support and package implementation

Software development, application maintenance and infrastructure management

Product and system development, maintenance and sustainment

both item 1 and 2

In-house, maintenance and sustainment

Development and maintenance for external clients

Engineering, operations and maintenance

IT solutions and services, infrastructure services, engineering and industrial services

S2Q4: What, if any, other types of measurement related training or mentoring does your organization provide?

Role based process training is conducted periodically for the project managers. Metrics council members are provided training on measurements related areas by both internal and external faculty.

Monthly reviews of measurement with executive management 
S2Q4: What, if any, other types of measurement related training or mentoring does your organization provide?

On the job training by experienced people to people who are responsible for measurement

Quality coaches for knowledge transfer to the projects

On the job training from specialists to process practitioners within 6 sigma projects

Specialized library of books available for consultation

Our activity is supported by measurement-related-specialists in another division within our company.

Lean and six sigma training

Training and application of training by measurement champions and mentoring customers on belt and belt-like activities..

Lean Six Sigma and Theory of Constraints training

Statistical Process Control

Training in COTs Tools

Measurement workshops for project managers and quality managers.

Statistics courses in local universities.

Six Sigma black belt programs, Green belt programs and introduction to Measurement techniques to new engineers. Refresher courses to the managers and project engineers

"Manage project by data" is trained for Project managers and QA staff.

Training on use of the [organization's measurement repository] to collect data is provided for all staff

Six Sigma, PBM, EVM,

Statistical methodology

Basic Statistics

Six Sigma Green Belt (self paced - online training)

We hire (temporarily) a specialized consultant to help on the performance model building activities, as needed. These consultants act like mentors or coaches for the model builders and maintainers.

1. Internal facilitation on basic statistics

2. Internally developed Six Sigma Green Belt training.

Statistical Process Control

We provide training on usage of statistical techniques, Six Sigma Yellow Belt / Green Belt / Black Belt training. Additionally role-based training is provided on applicability and usage of metrics for statistically managing the projects.

Open contracts with measurement specialists, specifically statistics specialists.

Training on software measurement program that covers measurement related activities $\&$ artifacts both at organization level as well as project level.

One-on-one mentoring between the organization quality engineer and the project quality engineer.

We provide a wide variety of measurement training. A large majority of employees have either 6- 
S2Q4: What, if any, other types of measurement related training or mentoring does your organization provide?

Sigma Black Belt Expert training or 6-Sigma Green Belt training. In addition, we have a 2-week Program Management course that all PMs must attend which has significant measurement training included. These PMs are tested prior to the course and after the course to ensure the required skills/knowledge are obtained. In addition a variety of internal measurement training is developed by 6-Sigma Black Belts and delivered to employees at all levels. All managers receive the 3 day CMMI training. Several selected process engineers have attended the Understanding High Maturity Practices course offered by the SEI. We also offer all employees a Work Study program which allows them to focus on their items of interest - many work study groups have been focused on measurement and analysis.

Basic concepts of measurement

Function Point counting

Ongoing facilitation to projects

Regular skill upgrades through in-house training sessions.

Measurement specialists work one-on-one with project analysts.

1. SPC techniques

2. Training on measurement tools

Metrics based management as part of engineering process training

Coaching and mentoring by Six Sigma black belts in the organization

We provide to our internal employees involved in metrics activities training from [external training organizations] for helping us in our six sigma projects \& building process performance models.

GQM

SPC work shop and case studies

a) Training on knowledge, usage and practices of metrics at [external training agency]

b) Training on statistical tools

c) Training on [project management Tool] for capturing, usage, practice and reporting of measurement data

d) Training in Function Point and Use Case Point methodology for estimation of efforts, cost etc.

e) Facilitation to project and support function users with respect of measurement related activities

We have hired a senior professor from [university] as a consultant to train our folks on statistical analysis and set direction for our metrics program

Regular training on [organization's quality manual]

LEAN, Process Mapping / Re-engineering, VSM, 6 Sigma

Project risk

Consulting services to mentor the users of the data and internal coaches and mentors, tailored specifically to their project work

- S/W process improvement training on measure and analysis

- Statistical Process Control training

- Inspection and defects training

- SW project quality and measurement mentoring (face to face) 
S2Q4: What, if any, other types of measurement related training or mentoring does your organization provide?

- SW project measurement mentoring [using specified management system]

- Quality audit and mentoring (face to face), etc.

SPC

Regular workshops are conducted, on an ongoing basis for project managers and middle managers to brief them and bring them up date with latest requirements of CMMI

Our organization provides the training of measurement tools

Statistical Process Control, basic statistics, process performance model Course, CMMI level 5 training.

Lean facilitation and training provided both internally and through vendor organizations

Statistical Process Control training (internally)

Quantitative management overview

Regular refresher programs

Every individual technical/non-technical person is trained to collect his/her own data.

CMMI Lead Appraisers and measurements matter experts provide regular briefing sessions to all levels of the organization. In addition each project manager is assigned a quality analyst to assist

Our normal [process] provides continuous training reinforcement via the team meetings.

Specific training about the models developed and to be used in the organization is provided on at least an annual basis to all measurements users (or when models change).

Measurement training for an as-needed basis for various organizational roles.

- Internal 1-day Measurements Analysis class as a basic for all process and metrics staff who collect and manage the baseline data, and build and maintain the model.

- Internal brief sessions about how to use measurements as well as embedding it in some current courses, such as a metrics brief session for project managers, and how to use metrics within peer review moderator course.

- Green Belt Six Sigma by external trainer

Six Sigma Green Belt training

Brown bag sessions

1. Green belt training

2. Lean sigma training

3. High Maturity workshop for Managers

4. Advanced metrics training

5. Statistical process control

Six Sigma MBBs and Lead Black belts mentor the analytics team

We have developed internal training courses that are conducted at regular intervals, for the different roles in the organization. The Six Sigma program is designed to provide middle managers and senior managers a good understanding of measurement and analysis using different statistical techniques.

Case study based metrics training program provided for project managers and leads PMP certification program for project managers 
S2Q4: What, if any, other types of measurement related training or mentoring does your organization provide?

Process Performance Model builders are encouraged to attend SPIN meetings and to do extensive literature search.

We bring in consultants conversant with high-maturity practices to perform customized training and workshops.

Contact with a specialized mentor and conferences as applicable

Process workshops and quizzes

Measurement \& analysis, Metrics, SPC, SQC

SEI consultant

The PPM training session is recorded and available on the [company] intranet for all users to access anytime.

SEPG process consultants attached to every project are available for mentoring throughout the duration of the project.

Green Belt and Black Belt Training, CMMI High Maturity Mentoring and special topics sessions

Estimation training, metrics monitoring and tracking tool training and other software process and tool training

- Customer specific measurement and tools training

- Standard training on data capturing for practitioners and QA

- Metrics management training for project leads and QA people

- Senior management review for metrics analysis

QPM CBT

Kickoffs w/ new programs to set expectations for program measurement responsible individuals (PMRIs). PMRIs are mentored by members of the Enterprise Measurement IPT as part of program rollout.

We have an excellent tuition reimbursement program that supports staff pursuit of graduate education. Many of our staff take advantage of this. Our primary model builder and maintainer received formal education in statistical techniques through this program. Our process improvement program has benefited significantly through this formal education avenue.

SPC

Weekly meetings of the measurement team

We have a measurement and analysis training course on line, we also have instructor-led 6 Sigma training courses

Quality measures, customer satisfaction measures, performance measures

Six Sigma Green Belt and Black Belt training and mentoring; CMMI Level 4 \& 5 training/mentoring (in-house); and SEI High Maturity training

We provide in-house training on Statistical Project Management and Quantitative Process Measurement. Apart from that there is a very strong mentoring that happens from the senior management on specific areas.

Black Belts work with Green Belts. Belts are 'seeded' around the organization so that knowledge 
S2Q4: What, if any, other types of measurement related training or mentoring does your organization provide?

is shared. The Metrics Office also provides internal coaching and mentoring.

Statistical concepts, Six Sigma, Quantitative Management

There are 2 levels of trainings we focus upon

Level 1: e.g., Six Sigma for continuous improvements with respect to measurement and it's actual benefit to the organizations goals and objectives

Level 2: e.g., ISO 20K, IT Service Management to strengthen delivery of ALL our services to the customer

\section{Six Sigma Black Belt Training}

In our organization exists an area that generates the baselines and process performance models, this area is performed by Green Belts and Black Belts and they support the projects with coaching about metrics interpretation and the use of some statistics tools.

Another type of mentoring is provided by the improvement teams (IM). The IMs are groups of professionals that work in some subprocess, they have improvement meetings where they analyze and understand the process performance behavior, with meeting participation by a Black Belt or Green Belt that supports the IM to understand and apply statistics in order to find a root cause for process variation.

Before the SCAMPI our Lead Assessor provides the SCAMPI Team a lot of Maturity Level 4 and 5 materials in order to have a better understanding about metrics, this material had been used like reference in some initiatives and understanding.

A variety of courses e.g., QMS training, performance engineering; six sigma, professional memberships, magazine subscriptions, certifications are sponsored for all associates who wish to study in this area; books and training are also freely available for all those who are interested

Explanation of metrics and measurement related to the organization on a one to one basis by the SQA group members

(a) Working groups in QPM, CAR and M\&A (meeting every 2-3 weeks) mentor and guide launching and optimizing activities in these areas under direction of experts.

(b) Lean Six Sigma training for Green Belts (2 weeks) and Black Belts (4 weeks), provide mentoring and guidance from Master Black Belts. Numerous Six Sigma projects, conducted to measurably improve, are under mentoring of Black Belts and MBB.

Periodic workshops on Saturdays, once per month and OJT

QPM Course

Statistics (General, SPC and variance) courses (few levels) provided by the [organization]

We have internally developed statistical analysis training courses; how to develop the correct measures courses; six-sigma mentors.

In-house training coursed developed for Managing Process Performance, Measurement for Data Collectors and Analysts, Measurement Overview, Measurement Program: Orientation and Measurement Workshops.

Consulting services (e.g., [specified consultancy])

Statistical process control 
S2Q4: What, if any, other types of measurement related training or mentoring does your organization provide?

We encourage and sponsor our middle level managers to go in for professional certifications in the project management realm. The course curriculum / certification requirements cover scheduling and metrics measurement, among others.

S3Q3: How much automated support is available for measurement related activities in your organization? - "Other" responses

Macros developed in-house to collect verification/validation data

Macros developed in-house to download data from OMR into the PPMs

Measurement tool developed in-house to consolidate data from different data sources ([COTS products], Checklists...)

We have a proprietary tool which helps for complete comprehensive project management, which includes data management, quantitative data analysis on a periodic basis etc...

Data collection but not automated ([specific COTS product])

In-house tools

Home-made tool and extensive use of open source software.

In-house developed tools provide data capture, graphing, and report capability, which can be automated, batched, and scheduled. This reduces these time-consuming tasks, and the analysts can focus on the analysis.

[Commercial statistics package] - Organization wide license available for all in the organization

[Organization] has its own web based project management tool for managing project management activities including measurement activities and analysis. This tool generates various reports including reports on measurements.

[Organization] owned - [COTS] statistical tool, [and other COTS tools]

Proprietary, best in class manufacturing and development tool sets

Process simulation model, [named COTS tool

Self-built

Apart from the above, we have developed our internal measurement and analysis systems. These intranet applications are extensively used for data capture, consolidation, analysis and reporting.

We have in-house developed tools to carry out various functions which can generate data and reports; a request management system tracks all the defects from customer requirements through delivery.

[Proprietary time management product] for data on productivity also helps in determining estimated versus actual effort

[Proprietary testing product]

[Proprietary management system product] which is being further developed to meet quality needs A skills database for employee training needs and skills and knowledge repository helps to provide a lot of data for organizational training

[Proprietary version management product]

Project Management Software 
S3Q3: How much automated support is available for measurement related activities in your organization? - "Other" responses

We are also planning to develop software that can cater to the needs of CMMI practices while integrating with already existing software in [proprietary product suite] mentioned above.

A process automation tool is under pilot stage.

S4Q4: Which of the following (often interim) process performance outcomes are routinely predicted with process performance models in your organization? - "Other"

Support service quality \& productivity

NOTE: Performance models may not meet the SEI essential characteristics definition in all cases.

S6Q1: Following is a series of statements about the kinds of technical challenges that projects sometimes face. How well do they describe your organization?

Insufficient schedule

We have a well-defined competency framework program to address skill set gaps in [organization's domain], technology and process.

S7Q1: Which, if any, of the following have been major obstacles during your organization's journey to high maturity? - "Other" responses

In summary the difficulties arise due to:

Variations in governance models for different customers. This results in same type of service having different project priorities and thus different measurement plans.

Projects that do not follow the classical application development cycle (i.e., support, maintenance and enhancement projects).

Projects that deliver a 'bundle' of services such as support and enhancements by using the same resources flexibly

Need to train more people in modeling and using data effectively to predict outcomes

Lesser Instance of repeated data of similar type, on projects due to size of the organization

Lack of enough data for analysis

Customers do not value the activity and do not wish to pay the premium for high quality. Moving beyond CMMI-5 is NOT a desired state for our business any longer and is seen as a negative due to high cost. As a result we have made a systematic decision to STOP advertising our more recent CMMI 5 assessments to cost sensitive customers.

A high percentage of our business is small project maintenance and operations. Little examples exist in the industry to leverage from for this type of project. Statistical Analysis and modeling can be high overhead for smaller projects unless done in a scaled approach. CMMI model does 
S7Q1: Which, if any, of the following have been major obstacles during your organization's journey to high maturity? - "Other" responses

not allow for this scaled approach very well - it is geared more towards the large project with dedicated measurements staff.

- The lack of automated project and service data collection means that we cannot provide realtime metrics to the projects.

- The varied nature of existing and new domains in the software development center creates a need to change some metrics definitions and design new metrics. There is not enough stableprocess historical data for process performance models.

- The limitation of process and metrics engineers' effort and budget make an insufficient metrics training and communication for 1000+ staff (project managers, software development and service engineers).

In a few cases, though process performance measures are consistent within a project, it has been difficult to get the consistency across projects.

We see a business case need to balance the approach as it relates to Level 4 activities \& the practical implementation of modeling \& predictive performance on a broader scale than just those measures that are being statistically managed.

There are no major obstacles. Senior management is highly supportive and the team has a high spirit to go for high maturity.

We failed to demonstrate the leverage measurement and analysis provides for business process improvement.

Because this is mainly a service environment some of the major processes are usually tailored at the account level. This means that it is difficult to aggregate them across the organization.

Resistance to new improvements that brings change still exists, but it is coming to be accepted as a normal culture.

Providing digitization support in a timely manner is a challenge.

S7Q3: What have been the greatest barriers faced by your organization during its journey to high maturity? What have you done to overcome them?

Convincing the project team members that process modeling and adherence to processes will result in better quality and cost control.

Application of high maturity models meant for large projects to small projects of $<50$ engineering-months of effort.

We don't have enough methodology to control our products' quality.

Therefore we are collecting various techniques and trying it.

To convince managers that quantitative management will improve their management activities, and will improve the project performance.

It takes a long time to convince managers; we first convinced the senior management, then continuous training to managers with good examples from other organizations.

The greatest barrier has been the knowledge needed to get the "gestalt" understanding of the model; once the problem was understood, the solution was clear. In order to overcome this barrier, extensive time was spent by a few key people to acquire the knowledge by getting consulta- 
S7Q3: What have been the greatest barriers faced by your organization during its journey to high maturity? What have you done to overcome them?

tion from experts, training, reading books and papers, and experimenting the acquired knowledge in real projects.

People buy-in and involvement. We overcame them by effective communication, training, change management and setting up rewards \& recognition measures.

In an old, long service organization that takes pride in the diversity of its work, we had difficulty shifting from long period to short period measurements because it just wasn't done that way. We developed a model with a modest number of standard work package types with reusable measurement patterns. This reduced training load, improved the consistency and amount of relevant data.

The combination of Six Sigma with CMM/CMMI Level 3, 4, \& 5 has been very helpful. It broadens the corporate expectation of objectivity and useful measurement as well as provides a useful toolkit.

The fundamental nature of life is to balance the need to change (improve) with the need for stability (control). We and many others have had problems to the effect that the organization would rather control than improve. Many managers and others are not worried if an organization is "in control" but not improving. Given an impetus from ISO or CMMI, and maybe with an inclination to let "perfect" kill "better," and a preference for control over real improvement, without care, the CMMI presents opportunities to straight-jacket organizations in perfectly executed but relatively meaningless minutia. It is important to let noise (diversity) into the system, to think about alternatives, to keep the end goals, but let the approaches wander. Support the objective thinkers in your organization. If you don't have enough staff who are "naturals" at this, people who hate the description, "out of the box thinkers," consider training some staff in Altschuler's TRIZ.

Sufficient data points for creation of performance baselines and models and then convincing the managers to use the baselines. This was overcome by ensuring management commitment and conducting awareness session on the topic.

Changing from a culture of "deliver on deadline regardless of completion state" to "deliver only when quality standards are met."

We have difficulties in change management in the continuous growth of the organization size. Dealing with these, we built an in-house management suite to transfer information all over the organization.

Barriers - Lack of confidence that the cost of moving to higher maturity levels is worth the benefit. Still have skepticism in parts of the organization.

Actions - Showing the benefit in data from various parts of the organization has helped to mitigate the skepticism

Resource constraints

Barrier: The insufficient understanding on PPM model.

Overcome Method: Our LA of CMMI level 5 appraisal provided consultation on this area.

We took pains most to understand statistics. We take external seminars on statistical understanding, and are spreading the concept in our company.

We misinterpreted some high level practices and defined some subprocesses that were not implemented as required by CMMI. It was not caught in one of the performed assessments (SCAMPI A!!). As a consequence, we used the model in an improper way during almost a year. After the issue was detected (unfortunately during another SCAMPI A evaluation) we hired a specialized 
S7Q3: What have been the greatest barriers faced by your organization during its journey to high maturity? What have you done to overcome them?

consultant to help us to re-interpret the practices and to redesign these subprocesses. After the appropriate internal communication and (re)training, we consider that the mistake has been corrected.

The difficulties have arisen due to:

1) Variations in governance models for different customers. This results in the same type of service having different project priorities and thus different measurement plans.

2) Projects that do not follow the classical application development cycle i.e. support, maintenance and enhancement projects)

3) Projects that deliver a "bundle" of services such as support and enhancements by using the same resources flexibly

To overcome some of these issues, we have

1) Created service specific metrics definitions

2) Decentralized the metrics office from the corporate level to individual business units for better understanding, mentoring and facilitation at the project level. The corporate metrics office still exists for preparing PPMs and PCBs, the team is headed by a person with college degree in statistics.

3) Initiated a series of project trainings on basic statistics

The greatest barrier is the variety of existing and new domains in the organization, and their growth. We have been trying to collect and display metrics for each set for each domain.

-Number of data points is insufficient to build Process Performance Models

-Data accuracy is not there

-Statistical domain expertise is not there

-Data collection mechanism is weak

Ensuring awareness and consistent usage of high maturity practices across the organization, considering the rapid growth and large number of new recruitments was the biggest challenge. This risk was overcome by developing e-learning materials for implementing high maturity practices, training coverage, continuous process facilitation, communications, focused audits on high maturity practices, conducting quiz and other promotional events to spread awareness of high maturity practices.

The biggest barrier has been organizational culture. We used to think doing software was art, not an industry. We have evolved, from an art production to an industry production, managing our software development center based on models such as CMMI and ISO 9001:2000.

Development of Process Performance Models is not that easy.

To convince middle management to spend extra time on project management issues, including measurements and modeling.

Change in behavior

It was hard to identify stable processes because it was hard to find out the real driving parameter that we now call [named parameter]. Once it was identified, we found that many processes are dependent on this driving parameter.

Understanding what a process performance model is and how/when it can/should be used.

Changing the culture from a "Seat of the Pants" cowboy driven environment to one that utilizes 
S7Q3: What have been the greatest barriers faced by your organization during its journey to high maturity? What have you done to overcome them?

measurement data to make or support decisions. Primarily it was overcome by showing historical measurement data where the measurement program had identified issues prior to their otherwise becoming visible to management. Also we had true executive management buy-in. We established our program and successfully demonstrated level 5 capabilities, but now we must continue to expand, refine and strengthen the capability. Executive buy-in is a major factor and lack of it is the quickest way to fail

The institutionalization of the processes to support the activities of high-maturity, associated with the culture of the organization. To remove this block we used examples and results of improvement in some projects with the use of those practices.

People feel insecure applying new knowledge they do not fully understand or control. A lot of training is required.

Lack of previous expertise in the subject. We have collected all the reference books in the market and hired external training and support from the European Software Institute.

Having project's identify process improvements. We have increased our partnering relationships with the projects and have provided updates to our process documentation for recommended improvements that should be flowed up to the integrated process group for evaluation and piloting if the improvement is deemed to support lean process execution or shows the improved process to be more cost effective.

The two greatest barriers faced by the organization were:

1. Conceptualization of process performance models suited to a project's context and

2. Training the practitioners on usage and sustenance of the high maturity practices.

The first barrier posed challenges since projects in the organization were disparate in nature and one model would not have suited all the projects. This meant rolling out generic process performance models at an organization level, and these were tailored to suit a project's needs. There were many brainstorming sessions held among the [modeling team] members and the delivery team in the model formulation. The delivery team provided inputs in terms of possible alternatives for process composition and the [modeling team] members helped in modeling. Through constant interaction, project specific models were rolled out, and the same were reviewed by senior management in the monthly review meetings.

The second barrier posed challenges in terms of getting the intent of high maturity practices to the practitioners. "Statistical thinking" was needed for the journey, and multiple programs were launched to achieve the same. Along with the project managers, "process champions" were identified in all projects. Waves of High Maturity workshops were conducted in the organization to get the practitioners to think statistically. There were many quizzes, and awareness mailers were sent out periodically. Projects were rewarded for exceptional implementation of high maturity practices. Applications of basic and advanced statistical techniques in software project management were discussed with practitioners periodically. Also knowledge sharing by projects on high maturity practices was conducted regularly.

Thinking in terms of statistical performance is a paradigm shift from "planned versus actual" thinking. The following have helped: enhancing tools to automate analysis; providing support to projects for analysis; conducting quarterly reviews for projects to share their activities and improvements.

In order to maintain a high level of process maturity, an organization needs professional process 
S7Q3: What have been the greatest barriers faced by your organization during its journey to high maturity? What have you done to overcome them?

engineers and measurement specialists who can provide technical service support for practical work. Employees with professional technical skills are hard to keep, which is the biggest problem our organization encountered. To maintain the stability of our process engineers group, we have to provide competitive salary, better welfare, and space for their self-development.

The growth of the organization and training them to meet high maturity expectations. Rigorous Six Sigma DFSS and engineering process training (using Six sigma tools). Many waves of Black Belt training and increasing awareness of DFSS Methodologies and tools. Rigorous Green Belt training and mandatory GB certification for everyone in the organization. Organization-wide [named statistical package] tool availability.

Initial resistance from the project managers during implementation of sub processes metrics. However, commitment from senior management, continuous coaching \& mentoring to the project team and convincing them about the advantages of these metrics helped in overcoming the initial resistance.

1. There was some schedule delay in selected projects due to the effort spent on various training programs. We communicated all our clients about the CMMI initiatives. Most of them supported us by accepting the schedule slippage.

2. Interpretation of the CMMI requirements was not clear, particularly with respect to usage of high maturity tools like ANOVA, Chi Square, Monte Carlo simulation, etc. We recently have understood these requirements and started implementing them (as of now more than $50 \%$ of the projects are practicing these requirements). We started our re-assessment plan by the middle of last year (2007) and are planning to complete it by the beginning of 2009 with all these high maturity practices in place across the organization.

1) We get very few turn-key development projects (less than 10\%) from clients as compared to maintenance projects, which results in non-usage of 'development project' related processes (software specifications, Technical Solution etc) and metrics (effort variance, schedule variance etc). To overcome this problem, we are applying these processes and metrics to in-house developed (internal) projects and products.

Challenges:

1. Enabling across the organization the usage of process performance models and their benefits.

2. Creating a data culture across the organization.

How it is addressed:

1. Role-wise enabling sessions, certification programs, and e-Learning courses

2. We have created a very strong data culture across the organization through a Balanced Score card approach. The business goals in the score card include process related goals like quality, productivity, reuse percentage, customer satisfaction levels etc. These performance goals are reviewed with board members at regular frequency for mid-course corrections. In most cases these benefits are showcased to our customers and have won various accolades.

There were no barriers in the true sense. Focused training and awareness helped in the implementation of the performance models.

Understanding the expectations of Process Performance Models from SEI Guidelines and then developing the best suited ones for our business model was the most difficult part.

Our process and process performance model didn't apply to the fast extended business. 
S7Q3: What have been the greatest barriers faced by your organization during its journey to high maturity? What have you done to overcome them?

So we subdivided our process and established a new process and process performance model for the extended business.

The overhead of CMMI L5 is high, which causes higher cost in the projects. We cannot solve this problem.

The project managers did not want to use models where the effects cannot be actually "felt" (especially through measurement).

Education centered on the purpose and the effect on the organization's people. Explanation of the new mind set was repeated in quality audits every month.

Historical data was saved in a distributed database which made it difficult to analyze.

We first collected these data into a centralized database with uniform data specifications. After

that, we performed further data analysis and established process performance models.

Providing an effective Process Performance Model for the organization that is useful and makes sense to implement.

We failed to sufficiently align and prioritize our measurement and analysis practices with our business and technical goals and objectives.

Frequent changes driven by SEI and interpretation challenges with CMMI version 1.2 have been a major barrier to achieving high maturity.

To overcome these we are monitoring closely the changes being driven by SEI and working closely with external consultants to adopt to the new requirements, apart from undergoing self learning and in-house training.

The greatest barriers are how to verify the validity of data, and we have enhanced training and checking data.

The time to market pressure for project development, the deadlines for implementation of high maturity levels: Process tailoring according to the specific characteristics was used to overcome these challenges. The value of a process culture was emphasized by demonstrating the results of the projects, statistically managed understanding, specialized trained on statistical concepts (process engineering), theoretical training instead of practical, and executive involvement.

The greatest barriers have been acquiring enough expertise to support the growing demands for predictive models. We recognize the need to understand our capability so that as we chart the course in to new market areas we have a better idea of what is needed to be successful in that area. We continue to grow the expertise internally but constantly seek additional training/mentoring aids to augment our internal resources (people, training, tools...).

People support across all business units: Identification of the right people, education, training, focus on aspect of usefulness, motivation, awards. Putting projects on hold for various reasons, metrics. Measurement data was not sufficient. Selection of alternate projects was time-

consuming. People leaving the organization created backups for everything and was costly, so we worked on retention, people policies, etc.

Demonstrating the value of improvements based on quantitative data.

We did not have data to make a process performance model. Therefore we began with the collection of the correct data.

The business models employed by our organization require positive ROI within 12-24 months of 
S7Q3: What have been the greatest barriers faced by your organization during its journey to high maturity? What have you done to overcome them?

an investment. This is often not possible with higher orders of CMMI maturity which greatly in-

hibits investment. Furthermore our customers rarely value the additional quality and predictability sufficiently to pay a premium during the time when the organization is experiencing the cultural shift.

Alignment of the entire organization in process improvement initiative (CMMI), including facilitation, the training program, project audits, project reviews, senior management review.

Adapting the CMMI model to our small project and maintenance environment. To overcome this we made our SPC a standard process that is repeatable rather than using a lot of different SPC techniques to look at data in multiple different ways. This may diminish some potential benefits from SPC but it also allows us to perform SPC within the budgets and time constraints for small projects and maintenance projects.

Selecting sub-processes

Use historical data for statistical analysis

Creating process performance models and deploying them extensively.

Identifying process measures that naturally lend themselves to predicting meaningful, actionable outcomes for project managers. Also, developing process performance baselines and models that can be useful to all projects - operational factors like client requirements, SLAs, etc... may introduce performance requirements that differ from our typical organization performance. We have conducted user focus groups and data analysis projects to understand modeling needs and to standardize operational definitions. We've also stratified process performance baselines where applicable, and enabled project teams to establish their own baseline limits.

Finding resources to work with PPMs and PPBs

To get the practitioners to believe in the benefit of using predictive models.

Overcame this, to some extent, by demonstrating this with sample data.

Customized tools have been developed to reduce manual work on data analysis. Practitioners were not convinced about the quality and suitability of the tools initially. We had to convince the team through early pilot results of the tools.

Cultural barriers.

I think the greatest barrier that our organization faced is changing the mind set of staff members towards a quality system and particularly metrics analysis. We found once the software engineer / project leader / project manager sees the value in CMMI best practices the implementation becomes smooth.

It has been a learning journey all the way. Our systems and processes have evolved with that learning. Change is for the good, but it takes time to accept. Over a period of time we have been able to institutionalize the changes. And the journey continues as we focus on continued improvement.

Sub process implementation when the development life cycle is short (e.g., the project comprises a number of reports which individually take 5 - 20 days of effort). When the overall cycle time or development effort is small, implementing the sub-process management became challenging. By the time measurement results are available, development is complete without much scope for control at the sub-process level. The alternative in this case is to treat each of these developments as a sub-process of the over all project. 
S7Q3: What have been the greatest barriers faced by your organization during its journey to high maturity? What have you done to overcome them?

Identification and implementation of prediction models: Selection of the right variables for a prediction model is not an easy task when an organization is embarking on CMMI L4 implementation or a CMM to CMMI transition. Performance modeling is one area where not many external training programs or consulting expertise are easily available. In most cases model builders have to rely on literature search and data available on the web for designing a model that would work in their own organizational environment. Historical data availability (and accuracy of it if available) is the next major challenge. Many times this leads to a situation where models are built using whatever data is available. This is one area where the organization needs to be prepared to do trial and error until you get it right. The only solution is to constantly watch for opportunities to fine tune the model based on the implementation results.

Ensuring data accuracy and usage: Many times it will be difficult get the right data because of the wrong usage of the data (e.g., usage of data for performance evaluation) in the past. The key challenge is to restrict usage of the data only for process improvement and not for performance management. Once people lose faith in the data, it is very difficult to ensure appropriate usage of it in decision making and for improvement actions. A solution to overcome this problem is decoupling performance objectives from the metrics program. Data inaccuracy may result from wrong interpretation of guidelines, lack of adherence to standards and / or lack of awareness of quantitative management. Entire project teams need to be trained on the defect classification guidelines, time entry guidelines, metrics interpretation and statistical techniques. Measurement errors can be reduced to a great extent by automating data collection. Another important means to ensure metrics usage is to focus on few metrics that are important to the users' day to day activities rather than collect lot of data. Quality time needs to be spent on analysis and corrective measures. The results from such actions should be shared among potential users to improve acceptance of quantitative management among them.

Effect of corporate systems and processes on a subsidiary's high maturity journey. Many times, the global processes and tools prescribed at the corporate level may meet the CMMI related measurement requirements or support high maturity practices. Corporate reporting requirements mandate the usage of such tools and processes across the divisions / subsidiaries. In such cases, subsidiaries end up having redundant systems that might add extra effort and negate the benefits that would have derived from high maturity practices.

- Collecting measures with needed frequency. (action: direct involvement of quality team members with the project teams

- Building the models based on the available data (action: dividing the measures into smaller units based on components or iteration or both to have sufficient data to create models)

- Depending on the output that comes from the prediction models in monitoring and controlling the project (action: extensive involvement of the quality team with the PM for decision support based on prediction model outcomes)

- Convincing practitioners to use available historical data in their planning for the project (action: extensive assistance of the quality team to the PM during estimation and reviewing the estimation output accordingly)

1. Lack of consensus on common and unified qualified system was a barrier when we started. This was overcome by establishing a SEPG group and having them actively engage with the individual groups in a democratic approach. We eventually developed one of the best processes around. 
S7Q3: What have been the greatest barriers faced by your organization during its journey to high maturity? What have you done to overcome them?

2. Measurement was daunting with so many metrics to be collected and so little automation, when we started. We overcame this by developing an online metrics capture and tracking tool. The tool is so much part of our work life today.

3. Getting the engineer level people to understand and appreciate the need for a performance model was a big challenge; they would see the process as 'avoidable' and an obstacle on their way. We overcame this by constantly having our senior people establish and demonstrate the benefits. This enthused all others into a participative approach, making quality the nature of our work.

1) Unavailability of people with necessary expertise. 2) Interpretation of L4 \& L5 practices, especially 'critical sub-process'.

1) Obtained buy-in from top management to make people available. 2) Consulted industry experts \& HMLAs.

Determining what, if any, ROI high maturity has yielded. There is never enough time to do things that add value to our product in a smart way.

[Organization name] was assessed at CMM level 5 in 1999 and later at CMMI level 5 (ver 1.1) in 2005. To that extent, [organization name] has been an organization practicing high maturity for many years. The addition to the existing practices was the introduction of the process performance model - the challenge faced was the limited statistical knowledge of the practitioners. Extensive trainings and mentoring were conducted for projects across locations at various levels.

Convincing technical project leaders that the overhead associated with the data collection and reporting is justified by the benefit. It's still a work in progress.

Effective application of control charts for development projects having too few iterations: We were not having sufficient data points to plot control charts. We used data from similar projects to arrive at in initial baseline. We also reduced data capturing cycle time.

1. In a few cases we have had problems stabilizing process performance data. We have applied a variety of techniques to overcome this. Segmenting the data is one of the techniques adopted. It has yielded satisfactory results in a few or all the segments. As a standard practice, we also do CAR analysis on outliers to understand the abnormality and eliminate the causes for abnormal behavior. This has also resulted in greater stability of data.

2. One of the most important quality related measure for us is the defects leaking to the customer. Getting defect data from the customer has been a little difficult, given that most of our customers are abroad and we have our own onshore organizations that at times support the user acceptance phase. To ensure quicker turn-around time, sometimes our onshore organizations or the clients themselves fix the defects detected during user acceptance testing without our knowledge. Again, during integration testing, what we develop needs to be finally integrated with existing systems or systems developed by other vendors. During this phase, quite often the customer fixes the errors detected and does not inform us. To overcome this, we provide collaborative tools like [named vendor] in which everybody including the customer enters defects data and such data is available to us for our analysis and modeling.

Collecting accurate data

Project team \& managers are not familiar with all types of advance statistical techniques used for QPM. To overcome this issue the following actions have been implemented.

1. The Metrics \& EPG team had conducted various levels of training, induction session, tutorials 
S7Q3: What have been the greatest barriers faced by your organization during its journey to high maturity? What have you done to overcome them?

and guidelines to enhance the knowledge on SPC \& PPM.

2. Macro-based spreadsheets were designed to enable the PL/PM to implement advanced SPC techniques and PPMs with optimal effort.

Different expectations between industry and SEI due to changing emphasis of what constitutes high maturity (apparent stronger emphasis on PPMs.): To better understand these expectations and identify value added opportunities for implementation, we are engaging other high maturity organizations to leverage their experiences as well as collaboration areas with the SEI.

Determining which measures will give us the best insight into our processes. Over time, we have been willing to eliminate measures which have been determined not to add value and introduce new ones with potential to have higher benefit.

Coordination and common process among the sites in our business unit. We have a common process team and a common measurement team.

Sometimes when staff changes, process performance models may not be well used to predict project process performance since software process performance is significantly influenced by employees.

No additional resources are added in the organization solely for the purpose of CMMI.

All work related to CMMI is integrated as one's job duty. CMMI becomes the core value of the organization.

The greatest barrier has been the projects' inability to see clearly the benefits of high maturity.

We try to overcome this barrier through training and persistent attempts to convince people of the benefits of high maturity.

Onsite teams have a reduced level of quality and process maturity and have a reduced interest in investing in bringing onsite teams up to same level as offshore.

Use of corporation baselines \& models for standard processes that are too generic or high-level to provide insight into standard process implementation.

The greatest barrier faced was to make people understand the spirit of the process areas, rather than blindly following them. We have been able to overcome this partially, and there are remarkable improvements in the areas where the essence and spirit is understood. It will require further patience and perseverance to imbibe and institutionalize it such that it becomes part of life.

Changes in management $\&$ differences in styles. Overcoming the fear culture that was in place due to previous management has been a slow process - building trust takes time, personality, pragmatism, and great communication. Introducing culture changes quickly without impacting on morale or the client is always a challenge. It helps to analyze impact and value of changes before approval, making sure that measures and 'extra' work focus on business objectives and deliver visible value.

One of the major barriers we faced early in our quality journey was changing mindsets of individuals as we moved towards implementing organization project management practices based on statistical thinking. This was overcome largely due to continued commitment and support from senior management towards process improvement initiatives. We also under took some formal organization change management programs.

Another area where we faced challenges was adequate training for project managers and staff on quantitative methods and statistical techniques. We overcame this by increasing budget allocation 
S7Q3: What have been the greatest barriers faced by your organization during its journey to high maturity? What have you done to overcome them?

for various training efforts.

1) The availability of historic and reliable data was a challenge when organizations were in operation for only few years at the time of our CMMI implementation journey. That was especially true with limited but large projects (insurance software implementations) when embarking on a journey for a high maturity level. We tried sampling, using industry benchmarks for known areas, and also waited to implement M\&A and HML practices until we could accumulate statistically significant data.

2) The perception of people that too much measurement and analysis, data collection etc consumes a lot of time: We challenged this perception by sharing the benefits that these same processes have provided to the projects, the organization and also how they have helped in improving the quality of work life. Now people see processes as something that will help them rather then a burden for the sake of company.

3) When we were undergoing an implementation of CMMI high maturity, staff had enthusiasm and drive towards achieving the maturity level. However, to keep them equally motivated after achievement was a big challenge. We have overcome this through

- Extensive checkpoints/gates and audits at every process

- Mistake proofing all the key areas and ensuring refresher training at periodic intervals

- Communicating the achievements through processes

- Adoption of a carrot and stick approach for process compliance \& non-compliance respectively - Continuous alignment of processes (and improving them) to meet organization objectives

Journey was difficult due to unavailability of relevant info regarding the "application of CMMI in the embedded product development environment."

In the beginning the lack of standardization for data collection. To correct this we defined standards as well as criteria of good capture.

Lack of culture to collect some data, for example functional points, fails. To correct this we generated a strategy to reinforce the knowledge and the culture to collect data as well as the inclusion of standards and the modification of the tools that facilitate their registry.

The idea that quantitative analysis represents more work, because it implies more reports. To decrease this we developed some automatic tools that give the projects the information on time and in the form that is required for quantitative analyses.

In the beginning we intended to quantitatively manage a lot of indicators and all process in all the technologies and services. Since then, we have identified and prioritized the indicators and sub process that would be quantitatively managed considered the impact in our vision and mission.

In the beginning our data point size was a project. We changed it and now we use a small unit that we call a work package and sub process.

The improvements to common causes were defined by a group outside the operation teams, and it was very difficult to deploy those improvements. We now have created improvement teams with personnel from the operation for common causes analysis and the optimization of process performance.

Tailoring processes commensurate to business risk, customer process maturity diversity, responding with new/ refined processes for new business models in a timely manner, deploying processes systematically and quickly to a growing globally diverse workforce: All of these are systematically addressed through an improvement program executed collaboratively with stakeholders. 
S7Q3: What have been the greatest barriers faced by your organization during its journey to high maturity? What have you done to overcome them?

Assimilation of data and varied nature of service contracts: We did introduce EPM to streamline project operational data.

The largest barrier is the culture shift, people accepting the processes as the integral part of their practice. We work on overcoming it by:

- developing processes that enhance the best practice of the organization

- involving practitioners in defining processes

- having dedicated resources in SEPG and QMG (full time assignment)

- maintaining constant presence in projects (consulting on process tailoring and implementation, preparing data for analysis, helping with the analysis and decision making)

- communicating frequently -newsletters, lunch \& learn sessions, formal training sessions (internal training), presentations

- having strong support from management team

How to build performance models fit to the organization

Level 3 measurements and analysis as the end state of M\&A has been a potential limiting barrier. We move past this by emphasizing that we need to achieve predictable performance and capability ranges for critical processes that meet specified goals and objectives. This will enable us to be able (eventually) to assess which of these processes are influencing program performance (e.g., positively) and by how much, and determine if the voice of the business/customers expectations are being met or we need to refocus on other processes that will be measurably more influential for a program's performance.

Use of statistical techniques and interpretation of statistical data was an area of concern for us as the practitioners (project groups) were not uniformly conversant with the same. This affected the appropriateness and quality of corrective actions at the project level.

Several training sessions by external experts helped us substantially to get over this problem and substantially improve effective use of the data and metrics.

The greatest barriers have been resistance to doing extra work. Work to show the teams/managers that it is not extra work; it's what they are already doing. They just need to use the data and improve.

It's difficult to pick up critical factors while we do process performance modeling. Developers' technical experience always become the critical factor.

The senior staff will not put enough emphasis on it, and they care about only short-term things. And because of this, project managers will also focus on fixing current work and current status only.

1. To understand the requirements of the CMMI model and the "deep reasons" why those requirements were selected. This was overcome by using extensive consulting help and training (inhouse and contracted).

2. Historical data availability. Since the organization is characterized by a small number of large projects - it was very difficult to find consistent and complete information across years (before the CMMI implementation effort started). A great deal of labor was invested in locating and validating the consistency of "private" databases (and we were pretty lucky to find historical data...)

3. Implementation of QPM across all projects. It required (and is still requiring) high level management attention for doing the QPM practices in a routine manner. 
S7Q3: What have been the greatest barriers faced by your organization during its journey to high maturity? What have you done to overcome them?

There are some factors that are not under statistical management but do influence the outputs of our modules, e.g., the customers' processes. People skills, experience, etc. also need to be treated as PPM factors, but that still is in progress. We try to discuss those things with customers, and have reached some agreement.

Programs do not always see an immediate ROI for collecting and analyzing measures. Besides making measurement collection a requirement, the quality organization participates in the collection and analysis of metrics. This service has proved beneficial.

Convincing practitioners about the usefulness of Process Performance Models and getting their support in measuring the necessary parameters was a challenge. This happened in spite of management commitment. During daily project management activities, use of Process Performance Models are not taken as a priority at times or put to correct use.

Gaining sufficient resources throughout the organization to support an advanced measurement program, including generation and use of process performance models to drive process and technology change. Also, understanding / interpreting the CMMI.

1. A perception that Maturity Models can be adopted only by big players existed among the members of the delivery organization. This perception had to be removed through education and sharing of case studies from small and medium players who have adopted maturity models successfully.

2. Again, a perception that the high cost of adopting a maturity model overweighs the benefits derived from it. Highlighting the importance of the intangible benefits of predictable quality has helped us combat this perception.

3. Lack of clear knowledge of the benefits of process modeling leading to lack of involvement at the grassroots level. Constant education and discussion in the quality council meetings has helped us reinforce knowledge and its importance to the target audience.

4. Resistance to change!

In Conclusion: Is there anything else that you would like to tell us about the use or usefulness of measurement and analysis in your organization?

Measurement program has helped us to realize the improvements quantitatively and also identify new areas for improvement.

Measurement and Analysis are central to our organization's ability to understand the current state and predict the future state of projects. It is inherent in how we design our systems.

We would like to refer to effective cases in other organizations to improve our process.

You can only manage what you can measure, and understanding variation is the key to managing chaos.

The measurement and analysis processes have been defined and implemented in the organization. But there is a continuous drive required for ensuring that the organization baseline and models are used. At the time of usage and seeking concessions every project appears to be an exception.

Metrics and measurements have become our organization DNA and helped us to achieve greater success. 
In Conclusion: Is there anything else that you would like to tell us about the use or usefulness of measurement and analysis in your organization?

For customer-oriented purposes, our measurement and analysis needs customizing to adapt with each customer requirement. Thus, a number of sub-systems of measurement and analysis need to be set up and maintained.

Given some new guidance from the SEI we now have a better understanding of how to develop and implement new models and expect our usage to improve over the next year.

We have come a long way. There are still pockets of resistance but overall measurement and analysis is becoming institutionalized.

Complexities in the project governance models complicate the use of the traditional approach of measurement and analysis, especially when projects have different customer objectives, different services executed within the same project and also requirements changing from the customer side. Getting customer satisfaction becomes the primary objective and inputs for that go beyond pure process performance and include certain intangibles such as attitude, proactiveness, resource skills and stability, etc.

We have institutionalized a metrics-based management culture in the organization. Executive management is always informed about process effectiveness. The data task level collected is rolled up to get useful insights at the project, account, business vertical and organization levels. Decisions on improving organization process performance are taken based on measurement and analysis which are reported in the form of management reports and dashboards.

Measurement analysis activities have helped us align measurements activities with the business goals, and provide a quantitative understanding of both the process and the product that is built. Analysis also identifies areas of improvements and situations that need corrective action to ensure achievement of objectives.

1. The most useful things about [organization's measurement and analysis process] is the control charts that help us manage our projects better.

2. It also is a major process that helps us better estimate and manage the projects.

The introduction of measurement and analysis practices and models has been a great experience for us.

Very important also for customer and staff satisfaction, as well as the company's overall success.

Because of the High Maturity journey, the organization has been able to instill "statistical thinking" in its DNA. Decisions in projects are based on past performance and analysis of the performance modeling. Processes are composed using models and critical subprocesses are controlled using control charts. Effectiveness of causal analyses is evaluated statistically thereby eliminating ambiguity. Improvement Initiatives are evaluated, piloted and deployed. Benefits realized are validated statistically.

To summarize, [organization] encourages data based decision making.

As mentioned above, [named quality measurement] has been the mantra in the organization for many years. This is tracked every month at the various levels of management reviews and decisions are taken based on the analysis of the data that helps us to improve our process performance. 
In Conclusion: Is there anything else that you would like to tell us about the use or usefulness of measurement and analysis in your organization?

Useful in

1. Managing projects more proactively by taking mid-term corrective actions

2. Providing mechanism to foresee problems at an early stage of the [specified life cycle]

3. Identifying granular \& controllable sub process parameters, effective

in managing projects better

Measurement and Analysis in particular, and the implementation of various Quality Processes have resulted in the reduction of costs through the hiring of a very young work force that delivers the same level of quality that can be expected from a more mature, more expensive work force. Essentially we have moved from software development as an individual capability to software development as a group capability wherein different members of a team focus on individual aspects of a major software application and collaborate with each other to provide knowledge as needed by other members of the team. Our effort estimation variance has decreased from over $25 \%$ in December 2003 to just over 3.4\% by March 2008.

All our efforts in quality processes are based on providing "Delight" to our customers. We do our customer satisfaction surveys through [named vendor]. As per [named vendor] the customer satisfaction benchmark is 7.5 on a scale of 10 whereas we have consistently achieved $10 \%$ higher ratings than this industry average.

1) Automation of data capturing, data analysis and reporting: Our project management tool provides online efforts and schedule variance at phase, ticket, feature (module) and project levels.

2) [Named tool] has a significant feature of publishing and releasing data through dashboards at both the organization and project level. This helps in finding the process health online

3) [Named tool] provides many features such as (a) resource productivity and utilization, (b) defects related reports, (c) measurements and variance related reports, (d) other reports such as timesheet status, project status, resource status etc.

4) [Named tool] also helps in capturing data on non-traditional areas such as responsiveness of systems and our networking group (problem tickets in systems and hardware), human resource related issues, general admin (logistics related problems).

Though measurement and analysis does not directly demand the usage of sophisticated tools such as [named statistical package], we need tools of this sort to enable better and easy use of the data and better interpretation of the data sets that are available to us. Measurement and analysis is helping the organization take informed decision about its projects which in turn helps the organization make strategic decisions based on its quantitative management reports.

Please teach me useful measurements item for the development of software.

Extremely useful but unfortunately interpretation guidelines not provided earlier on for users.

We would like to share some experiences of other organizations' measurement and analysis.

It takes time to achieve high maturity; there is little information about modeling and baselines, according to the budget of median companies. It is necessary dedicate specialized personnel to create the models and baselines. And it is necessary to provide direct access to SEI specialists to support these concepts. Benchmarks of similar industries are not available for statistically managed data for developing better process performance baselines (PPB) and models (PPM). 
In Conclusion: Is there anything else that you would like to tell us about the use or usefulness of measurement and analysis in your organization?

Senior management recognizes the importance of understanding our performance capabilities through measurement and analysis. They continue to challenge the organization toward developing an end to end approach to measurement and analysis in each phase of product development. Our primary focus has been in Engineering but the push/trend to understand the performance at inception/proposal through project closeout is ever increasing.

Measurements and analysis is any time and every time useful to my organization.

Use of an appropriate tool for data collection is key to MA success, as is communication of the outcome of resulting SPC to the wider organization so practitioners are aware the data is being used in the interests of continuing improvement.

Helped us define and analyze the important metrics to collect

We are using Six Sigma projects for improving our processes. Six Sigma requires a measurement system, analysis and high quality data. We have found that the metrics data available in our database is of great value for these projects.

Measurements are the key to evaluate how the organization is performing. The metrics defined at the organization level are aligned to our business goals and customer satisfaction. The same concept flows down to the project level. The emphasis on quantitative management has resulted in our project managers looking ahead and taking course corrections earlier, rather than being reactive.

Once we established the measurement systems, we could benchmark ourselves with the best in the industry. This was like reality-check and correction. This helped us improve our project success ratios substantially.

Measurement and Analysis also gives a feeling of pride to our associates. They know that the way we do our software engineering is quite different from what they have experienced earlier.

Better insight \& quantitative monitoring of project progress, ability to measure product \& process quality, adoption of a data-driven decision making approach

We do M\&A very well.

The process performance model gives the projects a clear view of the current and future product and process quality. It thus enables them to take corrective actions guided by the what-if analysis.

It's widely used to predict schedule and effort variance based on the project health sheet. The leading indicators help some projects in re-planning and critical decision making. This is now being propagated across the organization. 
In Conclusion: Is there anything else that you would like to tell us about the use or usefulness of measurement and analysis in your organization?

General observation:

1. Performance models on size, effort, defect and schedule have maximum acceptance

2. Measures need to relate to organizational goals

3. Project manager/leaders education on measurement $\&$ analysis is key to success.

Success:

1. We have done pioneering work in the measurement of size and defining productivity benchmarks in package products like [named proprietary products]. It has improved our estimation and planning processes substantially.

2. We have also done original work in collecting, analyzing, segmenting, modeling and benchmarking productivity data in the form of ticket resolution effort and time in the areas of application and infrastructure management. Deployment of high maturity principles here has been highly beneficial to us

3. By combining Six Sigma and Lean techniques combined with high maturity principles, we have experienced improvements in productivity, cycle time and quality in the range of $10-25 \%$ at the organization level and between 10-65\% at individual project levels.

We feel we have a strong, goal-based measurement infrastructure that supports a robust business and program rhythm of review to provide insights into performance, early corrective actions, and performance improvement opportunities. Tools are in place to automate data collection, program and organizational reporting and analysis. Strong top down management support exists for the measurement and analysis program.

As a fairly recent high level maturity appraised organization, our ability to benefit from our measurement and analysis program is improving as our database grows and as we experience where we get the most bang for the buck. We also have plans to increase the sophistication of our tools over the coming year.

Our model builders, maintainers, mentors and coaches are all part of our technical project staff. Although measurement and analysis is not their primary assignment, they do have a percentage of their time dedicated to their roles in our measurement program.

We are increasing the effort around our quality systems and measures.

Application of M\&A and other CMMI practices has definitely helped us in achieving our set objectives to a great extent. Today, we can confidently say with supporting data that we have been able to improve in many areas. We stand on a better platform altogether from when we started a few years back.

One of the recommendations that I would like to make to SEI is to include in the standard "overview of CMMI" training sessions to not only mention "what an organizations should do" to implement high maturity levels but also "how to do" it with details on commonly used tools, handson and case studies for the participants. Participants for such training usually end up just knowing the standard with very little clue on the tools, their implementation and most importantly what kinds of value they can derive from high maturity practices particularly that are related to process capabilities including PPMs. The training does convey the value but it is mostly theoretical.

It is only when a hired consultant educates the participants/staff of the organization on their CMMI HML journey that they will get the deeper insight into HML practices. I have personally experienced as an ATM during the assessment of maturity level 5 that sometimes an interpretation of the hired consultant, of a particular practice and the documents that can support it, is different from the interpretation of the assessors / Lead appraisers which in turn is negative for the 
In Conclusion: Is there anything else that you would like to tell us about the use or usefulness of measurement and analysis in your organization?

organization. If SEI can have a database on common misinterpretations it will help organizations in implementation HML practices.

The major benefits that we identify are:

Having a better understanding about the quality of the product allows better management decisions with highly satisfied customers.

Process Improvement implementations are managed by quantitatively based decisions and aligned to the organization vision and mission.

Measuring the cost of finding and fixing defects.

We now can make project to project comparisons in order to understand their variation.

Common processes/measures allow better use of historical data.

Calibrating cost estimation models has led to better estimation.

Align measurement and analysis tightly with overall business objectives and as a part of overall business excellence. The measurement and statistical analysis should be simple and easy to understand.

Adopting this model has forced us to customize the modeling to our needs and set benchmarks and try to outperform the same.

It would be useful to have webinars organized to share industry challenges and various user feedback on overcoming them across different process areas. There is not much data available on software service industry (non products) models.

Though the initial impression was of added effort towards data collection and interpretation at the project group levels, proper training, mentoring and performance improvement have changed the mind-set of almost everyone, and the activity has now been well-accepted as an integral part of the work.

1. Regarding selection of subprocesses base on their capabilities. We are using standard processes/subprocesses where tailoring is basically done only upon contractual requirements. We didn't come to a situation where we need to choose a subprocess (out of set of alternative subprocesses) based on each subprocess capability.

2. It is hard to complete a CAR process change within the project where a problem was detected, since the detection, process change, piloting the new process with statistical data (not to mention deployment in other projects) cycle is in many cases longer than the time frame of the project where the process problem was detected.

To conclude, we gain a lot from high maturity implementation. Although it is difficult to calculate an ROI, we have seen improvements on all performance indicators at the organization level!

Measurement and Analysis should be used in the context wherein it aids the organization to achieve its business objectives. In many occasions, organizations could be using a hammer to kill a fly by deploying an overweight M\&A system complying with QPM and OPP requirements of CMMI. Add to this, the GP 2.8 requirements! Judicious usage of M\&A practices and meaningful application of CMMI PAs are the keys to success in getting the management and practitioners' buy in. That should be the focus in the appraisals too!

The use of measurement and analysis has enabled us and our clients to "feel" the quality as opposed to evaluating quality only from a set of numbers. As the only [named domain] company to have gone for maturity level 4 , we are happy that we have gotten there first. Now that we have 
In Conclusion: Is there anything else that you would like to tell us about the use or usefulness of measurement and analysis in your organization?

reached a state of consolidation, we are inspired to get to the next level soon.

Nothing, thank you. $\{12$ other respondents gave similar answers. $\}$

[Company name] is a growing organization; certainly most of these practices are very useful for us. SEI can bring out guidelines for the implementation of CMMI in small projects (specific to high maturity practices).

[Named organization provided a two page summary of its business history and scope, along with a description of its measurement program and process performance modeling work.]

We have consistently grown at the rate $25 \%$ to $30 \%$ per year and still we could achieve the following among other things for our customers:

1. Repeat business of close to $95 \%$ with higher engagement level ratings.

2. We have seen productivity improvement of $7 \%$ to $10 \%$ per year with world class quality. Close to $80 \%$ of projects deliver zero defects

3. Consistent delivery on time. $97 \%$ of projects deliver on or before agreed timelines in application development and maintenance projects

We have well-integrated measurement tools ([named COTS and proprietary tools]) for effort, size, schedule and defect tracking which help in collecting the metrics at the point of action. The tools also have mechanisms to ensure integrity and completeness of data. We have dedicated people on the metrics team who are responsible for aggregating and analyzing the project level data and building Process Performance Baselines at the organization level. The PPBs are usually revised every quarter. This data is used to

1. Benchmark our performance with the best in class companies and identify improvement opportunities

2. Provide historical data to quantitatively predict the performance of the projects

3. Monitor the performance at the organization and project level to take proactive steps

We have also created our own Process performance models for schedule optimization based on historical data that are used to predict schedule and performance. Our [named] health dashboard uses leading indicators to predict future performance. Our automated milestone reports help monitor the performance in projects/accounts/units quantitatively.

The measurement program is very unique because it sets the direction for many organization level improvement initiatives, score cards for senior management, etc. The data is translated to measurable and manageable goals at all levels up to project manager. The scorecard performance is measured every quarter. A portion of salary is linked to meeting the scorecard goals.

This survey appears to be aimed at creating products and services to help organizations move beyond CMMI level 3. No such services are currently being sought by this organization. 
In Conclusion: Is there anything else that you would like to tell us about the use or usefulness of measurement and analysis in your organization?

I would like to see SPC become more useful to smaller organizations wishing to obtain benefits from these process areas. Too many of the requirements for higher maturity level process areas seem to be stuck in the academic world rather than creating good real world practices that can scale level 4/5 process areas for smaller organizations. QPM, OPP, CAR and OID should be able to be done in repeatable processes that work for 1-3 person teams (rather than just 10-100 person teams). Our organization had successfully implemented several streamlined level $4 / 5$ processes, but then a few years later the SEI determined that they would turn up the gain on higher maturity levels and put them out of reach (from a business perspective) of smaller organization. I think the SEI should rethink how level $4 / 5$ process areas must be met so as to enable smaller organizations to participate in these valuable process areas. 
168 | CMU/SEI-2008-TR-024 


\section{References}

URLs are valid as of the publication date of this document.

\section{[Coleman 1964]}

Coleman, James S., Models of Change and Response Uncertainty. Englewood Cliffs, N.J.: Prentice-Hall, 1964.

\section{[EIm 2008]}

Elm, Joseph P.; Goldenson, Dennis R.; El Emam, Khaled; Donatelli, Nicole; Neisa, Angelica; \& NDIA SE Effectiveness Committee. A Survey of Systems Engineering Effectiveness - Initial Results (with detailed survey response data) (CMU/SEI-2008-SR-034), December 2008. http://www.sei.cmu.edu/pub/documents/08.reports/08sr034.pdf

\section{[Ferguson 2007]}

Ferguson, Robert W. "Systems Engineering Complexity \& Project Management," Presentation at CMMI Technology Conference \& User Group, Denver, CO, November 12-15, 2007.

\section{[Freeman 1965]}

Freeman, Linton C. Elementary Applied Statistics for Students in Behavioral Science. John Wiley \& Sons , 1965.

\section{[Gibson 2006]}

Gibson, Diane L.; Goldenson, Dennis R.; Kost, Keith. Performance Results of CMMI-Based

Process Improvement (CMU/SEI-2006-TR-004). Pittsburgh, PA: Software Engineering Institute, Carnegie Mellon University, 2006.

http://www.sei.cmu.edu/pub/documents/06.reports/pdf/06tr004.pdf

\section{[Goldenson 1999]}

Goldenson, Dennis R., Gopal, Anandasivam; \& Mukhopadhyay, Tridas. "Determinants of Success in Software Measurement Programs: Initial Results," in Proceedings of the $5^{\text {th }}$ IEEE International Software Metrics Symposium, 1999.

\section{[Goldenson 2000]}

Goldenson, Dennis R., "What Does it Take to Succeed in (the Software Measurement) Business?" Software Quality, ASQ Software Division, December 2000.

\section{[Goldenson 2003a]}

Goldenson, Dennis R.; Jarzombek, Joe; \& Rout, Terry. "Measurement and Analysis in Capability Maturity Model Integration Models and Software Process Improvement." Crosstalk (June 2003). 


\section{[Goldenson 2003b]}

Goldenson, D. \& Gibson, D. Demonstrating the Impact and Benefits of CMMI: An Update and Preliminary Results (CMU/SEI-2003-SR-009). Pittsburgh, PA: Software Engineering Institute, Carnegie Mellon University, 2003.

http://www.sei.cmu.edu/publications/documents/03.reports/03sr009.html

\section{[Goldenson 2007a]}

Goldenson, Dennis, ed. Software Tech News 10, 1, March 2007. Special Issue on Performance Outcomes from Process Improvement.

\section{[Goldenson 2007b]}

Goldenson, Dennis. "Understanding CMMI Measurement Capabilities Performance \& Outcomes: Results From the 2007 SEI State of Measurement Practices Survey." Presentation at CMMI Technology Conference \& User Group, Denver, CO, November 12-15, 2007.

\section{[Goldenson 2008a]}

Goldenson, Dennis. "Understanding CMMI Measurement Capabilities \& Impact on Performance: Results from the 2007 SEI State of the Measurement Practice Survey." Presentation at SEPG NA 2008 Conference, Tampa, FL, March 17-20, 2008.

\section{[Goldenson 2008b]}

Goldenson, Dennis. "The State of Software Measurement Practice: Results from the SEI Annual Survey Series." Presentation at SEPG Europe 2008 Conference, Munich, Germany, June 10-13, 2008.

\section{[Gopal 2002]}

Gopal, A.; Krishnan, M.; Mukhopadhyay, T.; \& Goldenson, D. "Measurement Programs in Software Development: Determinants of Success," IEEE Transactions on Software Engineering, 2002.

\section{[Guilford 1954]}

Guilford, J.P. Psychometric Methods, 2nd edition, McGraw-Hill Inc., December 1954.

\section{[Hill 2006]}

Hill, Thomas \& Lewicki, Pawel. Statistics: Methods and Applications: a Comprehensive Reference for Science, Industry, and Data Mining. StatSoft, Inc., 2006.

\section{[Hosmer 2000]}

Hosmer, David \& Lemeshow, Stanley. Applied Logistic Regression, 2nd ed. NY: Wiley \& Sons, 2000.

\section{[Kasunic 2006]}

Kasunic, Mark. The State of Software Measurement Practice: Results of 2006 Survey (CMU/SEI2006-TR-009). Software Engineering Institute, Carnegie Mellon University, 2006. http://www.sei.cmu.edu/pub/documents/06.reports/pdf/06tr009.pdf 


\section{[Kasunic 2008]}

Kasunic, Mark; McCurley, James; \& Zubrow, David. Can You Trust Your Data? Establishing the Need for a Measurement and Analysis Infrastructure Diagnostic (CMU/SEI-2008-TN-028). Software Engineering Institute, Carnegie Mellon University, 2008. http://www.sei.cmu.edu/pub/documents/08.reports/08tn028.pdf.

\section{[Kleinbaum 2002]}

Kleinbaum, David G. \& Klein, Mitchel. Logistic Regression: A Self-Learning Text, 2nd ed. NY: Springer-Verlag, 2002.

\section{[Menard 2002]}

Menard, Scott. Applied Logistic Regression Analysis, 2nd Edition. Thousand Oaks, CA: Sage Publications, 2002.

\section{[Paulk 1993]}

Paulk M., Curtis B., Chrissis M., Weber C. Capability Maturity Model for Software (Version 1.1) (CMU/SEI-93-TR-024). Software Engineering Institute, Carnegie Mellon University, 1993. http://www.sei.cmu.edu/pub/documents/93.reports/pdf/tr24.93.pdf

\section{[Park 1996]}

Park, Robert E.; Goethert Wolfhart B.; \& Florac, William A. Goal-Driven Software Measurement-A Guidebook (CMU/SEI-96-HB-002). Software Engineering Institute, Carnegie Mellon University, 2006. http://www.sei.cmu.edu/pub/documents/96.reports/pdf/hb002.96.pdf.

\section{[SEI 2002]}

CMMI Product Team. Capability Maturity Model Integration (CMMI) for Systems Engineering/Software Engineering/Integrated Product and Process Development/Supplier Sourcing, Version 1.1, Staged Representation (CMMI-SE/SW/IPPD/SS, V1.1, Staged) (CMU/SEI-2002-TR012). Software Engineering Institute, Carnegie Mellon University, 2002. http://www.sei.cmu.edu/pub/documents/02.reports/pdf/02tr012.pdf

\section{[SEI 2008a]}

CMMI Appraisal Program. “CMMI ${ }^{\circledR}$ SCAMPI ${ }^{\text {SM }}$ Class A Appraisal Results 2007 Year-End Update." September 2008.

http://www.sei.cmu.edu/appraisal-program/profile/pdf/CMMI/2008SepCMMI.pdf

\section{[SEI 2008b]}

SEI Process Maturity Profile. http://www.sei.cmu.edu/appraisal-program/profile/profile.html.

\section{[Siegel 1998]}

Siegel, Sidney \& Castellan, N. John Jr. Nonparametric Statistics for the Behavioral Sciences. McGraw-Hill, 1998. 


\section{[Stoddard 2008]}

Stoddard II, Robert W.; Goldenson, Dennis R.; Zubrow, Dave; \& Harper, Erin. CMMI High Maturity Measurement and Analysis Workshop Report: March 2008 (CMU/SEI-2008-TN-027). Software Engineering Institute, Carnegie Mellon University, 2008.

http://www.sei.cmu.edu/pub/documents/08.reports/08tn027.pdf

\section{[van Solingen 1999]}

van Solingen, Rini \& Berghout, Egon. The Goal/Question/Metric Method: A Practical Guide for Quality Improvement of Software Development. Chicago: McGraw-Hill Publishers, 1999.

\section{[Young 2008a]}

Young, Rusty \& Stoddard, Robert. "A Practitioner View of CMMI Process Performance Models." Presented at SEPG NA, March 17-20, 2008.

http://www.sei.cmu.edu/sema/presentations/practitioner-view.pdf.

\section{[Young 2008b]}

Young, Rusty; Stoddard, Robert; \& Konrad, Mike. 'If You're Living the 'High Life,' You're Living the Informative Material." Presented at SEPG NA, March 17-20, 2008.

http://www.sei.cmu.edu/sema/presentations/highlife.pdf. 


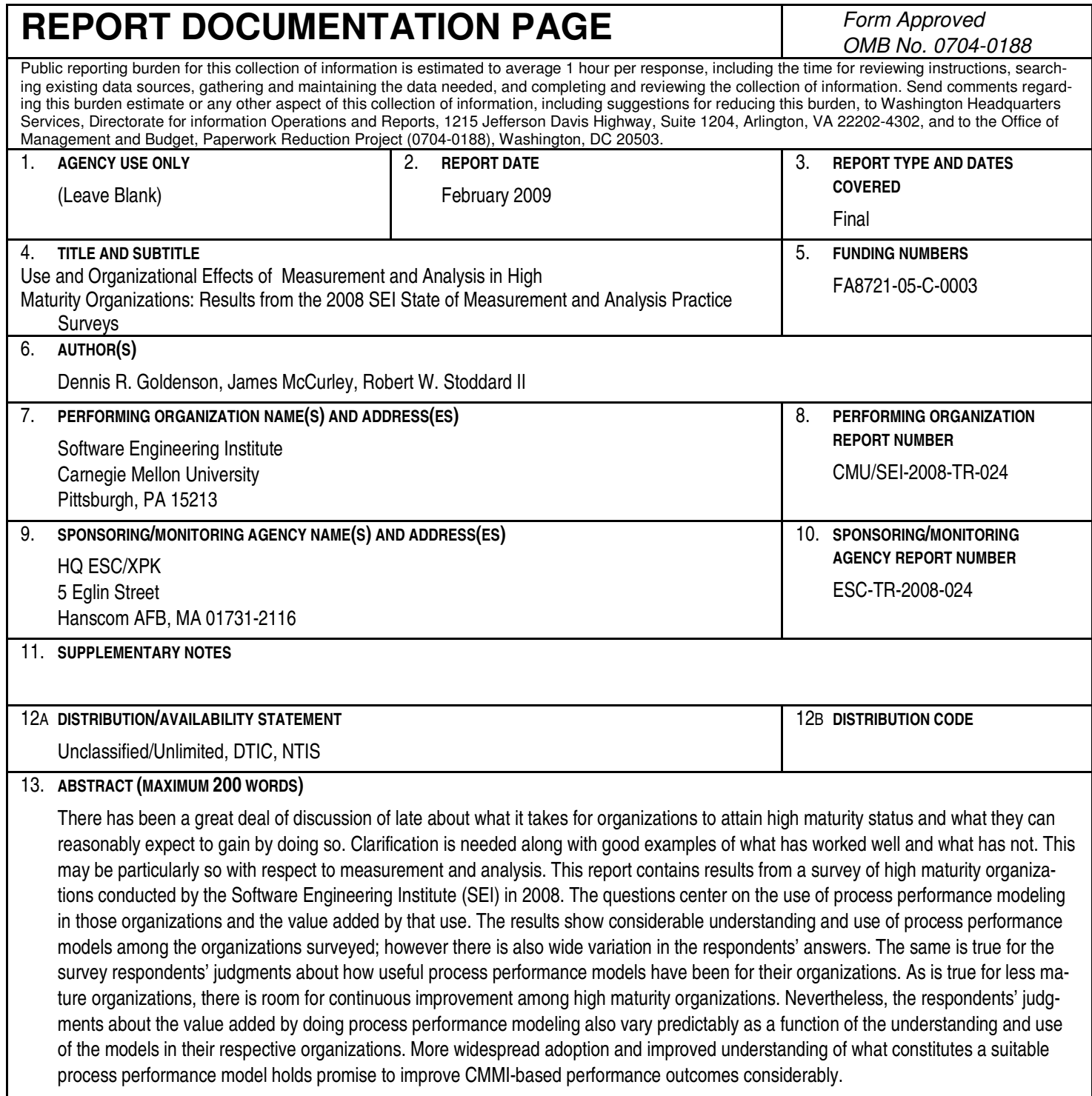

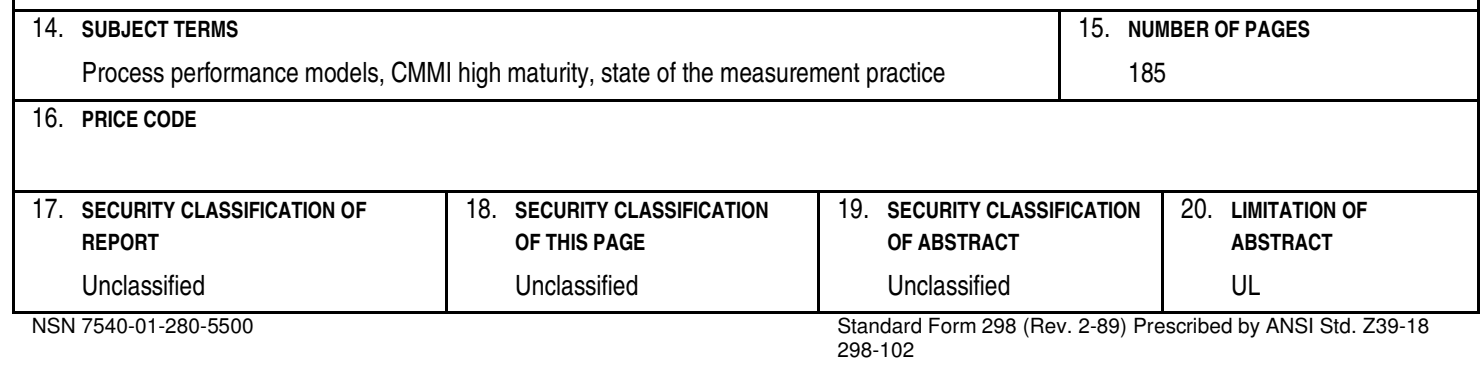

